\title{
ANAIS DA 80? SEMANA BRASILEIRA DE ENFERMAGEM - MACAPÁ/AP E III ENCONTRO AMAPAENSE DE PRODUÇÃO CIENTÍFICA DE ENFERMAGEM
}

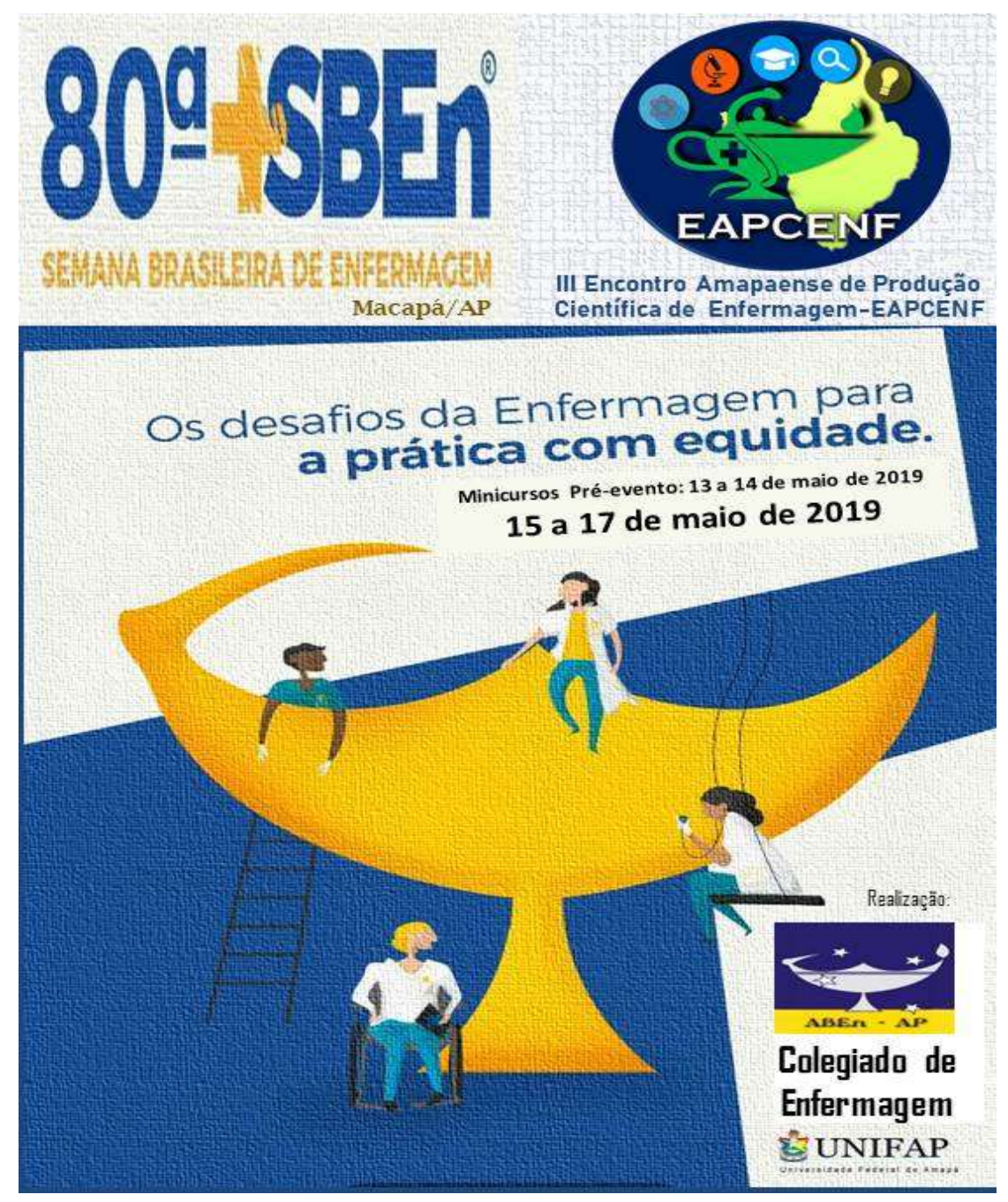

APOIO:

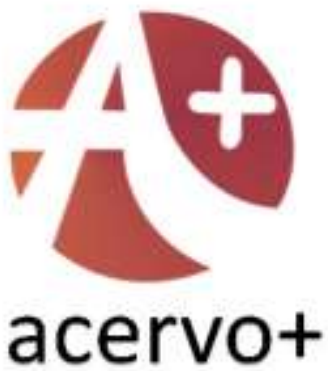
Eventos

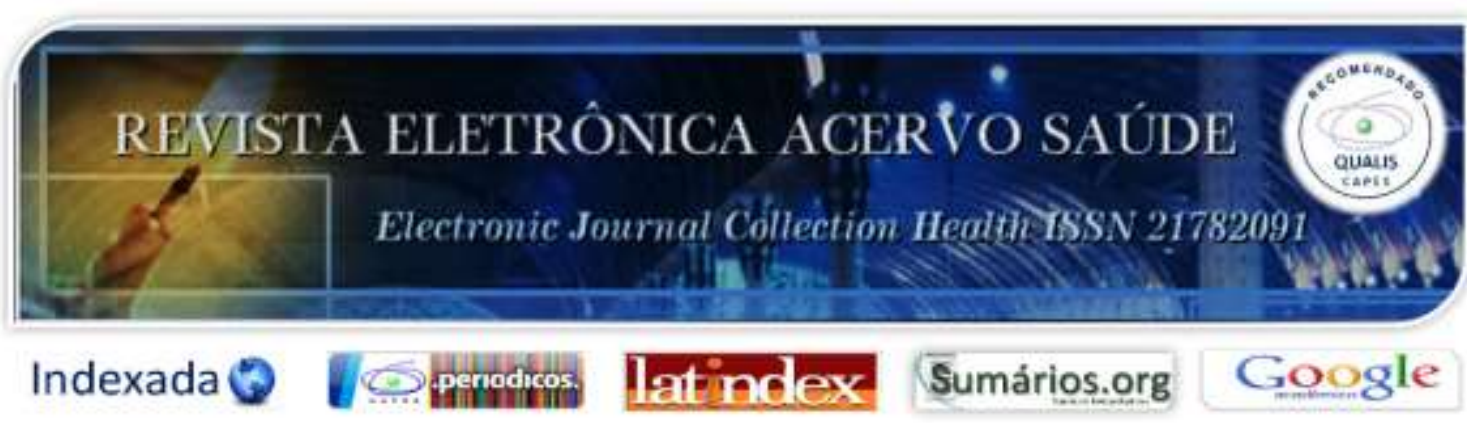




\section{Presidente}

Camila Rodrigues Barbosa Nemer

Vice-presidente

Nely Dayse Santos da Mata

Coordenador eixo temático I: Equidade como pré-requisito de promoção da saúde

Erika Tatiane de Almeida Fernandes Rodrigues

Coordenador eixo temático II: Pesquisa em saúde como caminho para equidade

Marina Nolli Bittencourt

Coordenador eixo temático III: O princípio da equidade baseado nas necessidades de saúde da população e na estruturação da política de atenção básica no contexto amazônico

Nely Dayse Santos da Mata

Coordenador eixo temático IV: Ética e bioética no princípio da equidade

Marlucilena Pinheiro da Silva

Diagramação e Editoração

Camila Rodrigues Barbosa Nemer

Stayllon Crystian Picanço Gomes

Comissão Científica

Ana Rita Pinheiro Barcessat

Anneli Mercedes Celis de Cárdenas

Camila Rodrigues Barbosa Nemer

Clodoaldo Tentes Cortes

Clovis Luciano Giacomet

Dirley Cardoso Moreira

Erika Tatiane de Almeida Fernandes Rodrigues

Fabio Rodrigues Trindade

Francineide Pereira Pena

Gardênia Menezes de Araújo

Inara Mariela da Silva Cavalcante

José Luís da Cunha Pena José Luis Picanço

Klingerry da Silva Penafort

Luzilena de Sousa Prudêncio

Maria Izabel Tentes Côrtes

Maria Virginia Filgueiras Mello

Marina Nolli Bittencourt

Marlucilena Pinheiro da Silva

Nely Dayse Santos da Mata

Rosemary Ferreira de Andrade

Rubens Alex de Oliveira Menezes 


\section{COMISSÃO DO EVENTO}

Secretaria e documentação

Clóvis Luciano Giacomet

Diego Quaresma Ferreira

Gardênia Menezes de Araújo

Luiza Picanço Nunes

Maira Beatrine de Rocha Uchôa

Maria Virginia Filgueiras de Assis Mello

Marina Nolli Bittencourt

Rubens Alex de Oliveira Menezes

\section{Alunos}

Anderson Rodrigues Ribeiro

Darci Francisco dos Santos Júnior

Eloisa Melo da Silva

Luana Jandira Weber Silva

Stayllon Crystian Picanço Gomes

\section{Finanças e monitoria}

Camila Rodrigues Barbosa Nemer José Luís da Cunha Pena

\section{Alunos}

Alana Corrêa Santos

Caroline Lima de Freitas

Rosinete Almeida dos Santos

\section{Infraestrutura}

Dirley Cardoso Moreira

Francineide Pereira Pena

José Luiz Picanço da Silva

Luzilena de Sousa Prudêncio

Marlucilena Pinheiro da Silva
Rosilda Alves da Silva Isla Chamilco

Tatiana do Socorro dos Santos Calandrini

Vanessa da Silva Oliveira

\section{Alunos}

Ana Lívia Sales Vaz

Ana Vitória dos Santos Menezes

Amanda Karine de Moraes Cardoso

Kevin Henrique Oliveira da Costa

Neylane Araújo Cordeiro

Max Amaral Balieiro

Viviane de Souza Bezerra

\section{Divulgação e atividades sócio- culturais}

Rosana Oliveira do Nascimento

Edmundo Souza Moura Filho

João Farias da Trindade

Silvana Rodrigues da Silva

Rosa Natália Muniz Carneiro Mota

\author{
Alunos \\ Bruno Raphael Da Silva Feitosa \\ Erick Souza Neri \\ Izabele Grazielle da Silva Pojo \\ João Douglas Quaresma de Oliveira \\ Luiza Soares Pinheiro \\ Mariana Matias de Sousa \\ Rafael Nascimento da Silva \\ Silly Emanuela do Socorro das Merces \\ Marques
}




\section{SUMÁRIO}

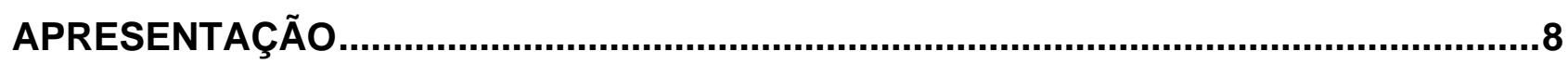

EIXO I: EQUIDADE COMO PRÉ-REQUISITO DE PROMOÇÃO DA SAÚDE..................10

PERFIL SOCIODEMOGRÁFICO E CLÍNICO DE IDOSOS COM DIABETES MELLITUS

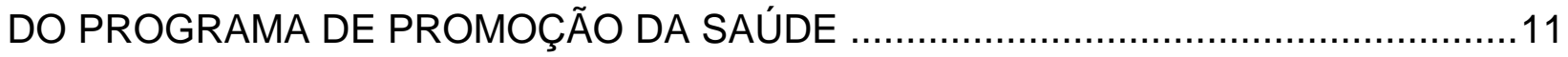

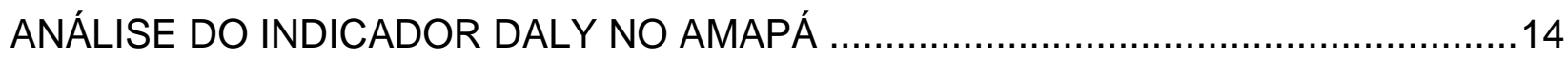

A PEGA ERRADA E AS ORIENTAÇÕES DE ENFERMAGEM NO PUERPÉRIO:

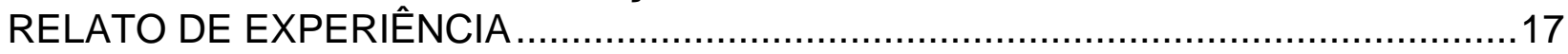

EQUIDADE, EDUCAÇÃO E ATENÇÃO À SAÚDE DE ADOLESCENTES GRÁVIDAS

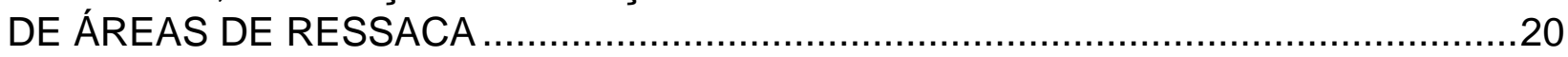

MODELO DE PROTOCOLO PARA INDUÇÃO DE FERIDAS CUTÂNEAS IN VIVO:

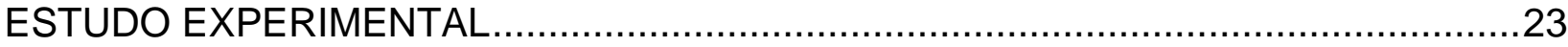

INDUÇÃO DO TRABALHO DE PARTO: REFLEXÃO PARA A PRÁXIS.......................26

CONTRIBUIÇÕES DE UM PROJETO DE EXTENSÃO PARA O EMPODERAMENTO

DE GESTANTES ADOLESCENTES.

AVALIAÇÃO DO DESEMPENHO DO SISTEMA DE SAÚDE: DETERMINANTES DA

SAÚDE NO AMAPÁ.

PROMOÇÃO DA SAÚDE PARA O PÉ DIABÉTICO: CUIDADO CLÍNICO-SENSÍVEL

ORIENTADO PELO PRINCÍPIO DA EQUIDADE

A IMPORTÂNCIA DO ACOMPANHANTE NO CUIDADO PRÉ-NATAL DE

ADOLESCENTES PRIMIGESTAS: RELATO DE EXPERIÊNCIA

EXERCÍCIO FÍSICO E DIABETES MELLITUS: RELATO DE EXPERIÊNCIA DE

RESIDENTES DE EDUCAÇÃO FÍSICA.

RELATO DE EXPERIÊNCIA SOBRE A INSERÇÃO DO PRÉ-NATAL DO PARCEIRO

NA UNIDADE DE SAÚDE.

PRÁTICAS CUIDATIVAS À GESTANTE NA FRONTEIRA OIAPOQUE-

TUMUCUMAQUE: UM RELATO DE EXPERIÊNCIA

TRABALHANDO EDUCAÇÃO EM SAÚDE NO CONTEXTO DA ATENÇÃO PRIMÁRIA

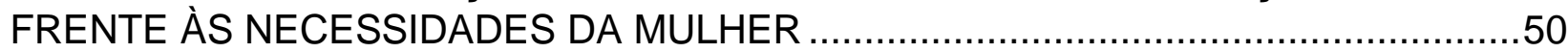

EIXO II: PESQUISA EM SAÚDE COMO CAMINHO PARA EQUIDADE. .53

CONSTRUÇÃO DE PROTOCOLO DE PESQUISA PARA AVALIAÇÃO DE

ACADÊMICOS DE ANATOMIA: RELATO DE EXPERIÊNCIA

SÍFILIS EM GESTANTES ADOLESCENTES: REALIDADE NO ESTADO DO AMAPÁ 57 AS PARCERIAS PÚBLICO-PRIVADAS ENQUANTO ESTRATÉGIAS DE AMPLIAÇÃO DO ACESSO À SAÚDE .60

PERCEPÇÕES DE FAMILIARES NO CUIDADO A UMA CRIANÇA COM MUCOPOLISSACARIDOSE TIPO II 
SINTOMATOLOGIA E PARÂMETROS HEMATOLÓGICOS E BIOQUÍMICOS FRENTE À TERAPIA ILIB - RELATO DE CASO CLÍNICO

FATORES ASSOCIADOS E AVALIAÇÃO DA COGNIÇÃO DE UM GRUPO DE IDOSOS INSTITUCIONALIZADOS.

PROTOCOLO CLÍNICO COM TÉCNICAS FOTOATIVADAS PARA UTILIZAÇÃO EM

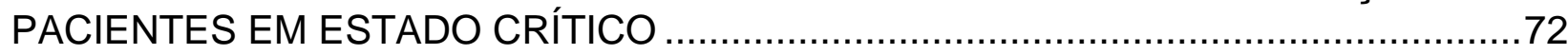

ENFERMAGEM FRENTE ÀS CONDIÇÕES DE SAÚDE DOS MOTORISTAS DA UNIVERSIDADE FEDERAL DO AMAPÁ.

SOFRIMENTO MENTAL DE DISCENTES DE PÓS-GRADUAÇÃO STRICTO SENSU78 HIV NA GESTAÇÃO: ESTUDO EPIDEMIOLÓGICO EM UMA MATERNIDADE DO AMAPÁ. .80

DOENÇAS CRÔNICAS NÃO TRANSMISSÍVEIS EM UMA POPULAÇÃO RIBEIRINHA DE MACAPÁ, AMAPÁ. .83

CONSTRUÇÃO DE UM PROTOCOLO DE PESQUISA EM MODELO EXPERIMENTAL ANIMAL COM TERAPIA FOTODINÂMICA. .86

POTENCIAL BIOMARCADOR NA PREDIÇÃO DO DESENVOLVIMENTO DE DCNT EM PACIENTES CONTAMINADOS POR MERCÚRIO 89

EXAME DOS PÉS NO DIABETES MELLITUS REFLETIDO ATRAVÉS DA PESQUISA COMO CAMINHO PARA EQUIDADE

PERFIL NUTRICIONAL MATERNO DE UM GRUPO DE APOIO A ADOLESCENTES PRIMIGESTAS. .95

PROCESSO SAÚDE-DOENÇA SOB A ÓTICA DE ADOLESCENTES GRÁVIDAS MORADORAS DE ÁREA DE RESSACA

PROTOCOLO DE ENSAIO CLÍNICO RANDOMIZADO COM TECNOLOGIA REAC NO ESTUDO DE BIOMARCADORES DE ESTRESSE.

REPARO DE LESÕES CUTÂNEAS INDUZIDAS FRENTE A DUAS TÉCNICAS:

ESTUDO CLÍNICO E HISTOPATOLÓGICO.

PREDIÇÃO DA CLASSE DE GORDURA VISCERAL UTILIZANDO MACHINE

LEARNING EM PESSOAS COM DIABETES MELLITUS

DEFICIÊNCIA E FAMÍLIA: RELATO DE EXPERIÊNCIA.

PERFIL SOCIODEMOGRÁFICO E OS ASPECTOS CLÍNICOS DOS PROFISSIONAIS OURIVES NO MUNICÍPIO DE OIAPOQUE...

IMPACTO BIOQUÍMICO DA TERAPIA ILIB EM SITUAÇÕES CLÍNICAS DISTINTAS117 ANEMIA ASSOCIADA AO ESTADO NUTRICIONAL E PARASITOSES INTESTINAIS EM UMA COMUNIDADE RIBEIRINHA DE MACAPÁ, AMAPÁ

USO DE ÁLCOOL E OUTRAS DROGAS EM DISCENTES DE PÓS-GRADUAÇÃO STRICTO SENSU

CONTRIBUIÇÕES DA PESQUISA E EXTENSÃO NO PROCESSO DE FORMAÇÃO DO ACADÊMICO DE ENFERMAGEM. 
EIXO III: O PRINCÍPIO DA EQUIDADE BASEADO NAS NECESSIDADES DE SAÚDE DA POPULAÇÃO E NA ESTRUTURAÇÃO DA POLÍTICA DE ATENÇÃO BÁSICA NO CONTEXTO AMAZÔNICO

DIAGNÓSTICO SITUACIONAL DE PUERICULTURA EM UM MUNICÍPIO DA AMAZÔNIA: RELATO DE EXPERIÊNCIA …......................................................130

COBERTURA VACINAL DE HPV NO ESTADO DO AMAPÁ 133

PERFIL DOS IDOSOS RESIDENTES EM UMA INSTITUIÇÃO DE LONGA PERMANÊNCIA DO ESTADO DO AMAPÁ.... 136

ALGUNS PASSOS A MENOS PARA UM PRÉ-NATAL DE QUALIDADE EM MACAPÁ

EDUCAÇÃO POPULAR EM SAÚDE COMO PRÁTICA DA EQUIDADE EM UM GRUPO DE GESTANTES ADOLESCENTES.

GESTANTES RIBEIRINHAS: DESAFIOS E BARREIRAS NO PRÉ-NATAL 144 PROPOSTA DE ENSAIO CLÍNICO RANDOMIZADO PARA TRATAMENTO FOTOQUÍMICO DE DEISCÊNCIAS CIRÚRGICAS PÓS-CESARIANA.

PUERICULTURA E PUERPÉRIO NA REGIÃO AMAZÔNICA: ATENÇÃO À VULNERABILIDADE PROGRAMÁTICA DAS POPULAÇÕES RIBEIRINHAS 150 PROPOSTA DE INTERVENÇÃO PARA O ENFRENTAMENTO DA DOENÇA DIARREICA AGUDA: UM RELATO DE EXPERIÊNCIA

EQUIDADE DE ACESSO: VISITA DOMICILIAR ÀS FAMÍLIAS RESIDENTES EM ÁREA DE RESSACA 156 SAÚDE SEXUAL E REPRODUTIVA DE MULHERES EM ÁREAS DE GARIMPAGEM

A PRÁXIS FREIRIANA COMO FERRAMENTA À PROMOÇÃO DA SAÚDE MATERNOINFANTIL 162

BAIXA ADESÃO DO EXAME CITOPATOLÓGICO NAS COMUNIDADES RIBEIRINHAS: RELATO DE EXPERIÊNCIA.

RELATO DE EXPERIÊNCIA SOBRE O $1^{\circ}$ SIMPÓSIO INTERDISCIPLINAR DA SAÚDE - "ABRAÇANDO A DIVERSIDADE" 168 ORGANIZAÇÃO DO PROCESSO DE TRABALHO DA ESF: ATENDIMENTO À DEMANDA ESPONTÂNEA - UBS NOVO HORIZONTE

PAPEL DA ENFERMAGEM NO CONTEXTO AMAZÔNICO: VALORIZANDO A DIVERSIDADE CULTURAL ATRELADA AO CONHECIMENTO CIENTÍFICO 174 PLANEJAMENTO ESTRATÉGICO SITUACIONAL: UM RECURSO PARA A SAÚDE SEXUAL E REPRODUTIVA DE COMUNIDADE QUILOMBOLA...

A IMPORTÂNCIA DA VISITA DOMICILIAR A IDOSOS HIPERTENSOS MORADORES DE ÁREAS DE RESSACA 180

EIXO IV: ÉTICA E BIOÉTICA NO PRINCÍPIO DA EQUIDADE 183

EQUIDADE E ELO EMOCIONAL NA AUTONOMIA DE INDIVÍDUOS PORTADORES DE PARKINSON E ALZHEIMER 
DOENÇA DE ALZHEIMER, PERDA DE IDENTIDADE E CONFLITOS NAS ATRIBUIÇÕES DO FAMILIAR CUIDADOR 190 VIOLAÇÃO DA EQUIDADE: UM OBSTÁCULO PARA A PROMOÇÃO DA SAÚDE EM COMUNIDADE QUILOMBOLA

FUNDAMENTOS ÉTICOS NO ATENDIMENTO A GRÁVIDAS ADOLESCENTES:

RELATO DE UM GRUPO DE APOIO 196

PRINCÍPIO DA BENEFICÊNCIA: PERCEPÇÃO E INTERVENÇÃO NA RELAÇÃO DO CUIDADOR E SEU FAMILIAR 


\section{APRESENTAÇÃO}

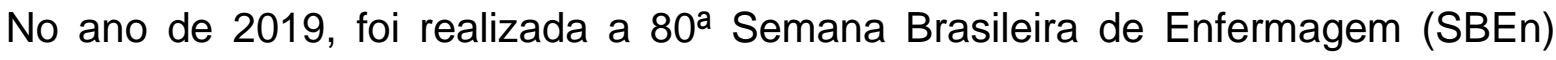
promovida pela Associação Brasileira de Enfermagem Nacional (ABEn), suas Seções, Regionais e Núcleos, com tema central "Os desafios da Enfermagem para uma prática com equidade".

Diante disto, a ABEn Seção Amapá e o Curso de Bacharelado em Enfermagem da Universidade Federal do Amapá Campus Marco Zero promoveram neste mesmo ano, a $80^{\underline{a}}$ Semana Brasileira de Enfermagem (SBEn) - Macapá-AP e III Encontro Amapaense de Produção Científica de Enfermagem-EAPCENF ocorrido na cidade de Macapá-Amapá, no período de 15 a 17 de maio de 2019. Com minicursos pré-evento nos dias 13 e 14 de maio de 2019.

A programação científica do evento atentos à conjuntura da saúde foi orientada pelo tema central "Os desafios da Enfermagem para uma prática com equidade". Que se desdobrou também para o desenvolvimento do III Encontro Amapaense de Produção Científica de Enfermagem-EAPCENF.

$\mathrm{Na}$ concepção metodológica da participação ativa e do compartilhamento do conhecimento foram definidos quatro eixos temáticos: Eixo temático I: Equidade como prérequisito de promoção da saúde; Eixo temático II: Pesquisa em saúde como caminho para equidade; Eixo temático III: O princípio da equidade baseado nas necessidades de saúde da população e na estruturação da política de atenção básica no contexto amazônico; e Eixo temático IV: Ética e bioética no princípio da equidade.

O Encontro Amapaense de Produção Científica da Enfermagem- EAPCENF está em sua terceira edição, tendo sido promovido em suas duas edições anteriores pelo Curso de Bacharelado e Licenciatura em Enfermagem, direcionado a acadêmicos, docentes e pesquisadores da área de enfermagem, profissionais integrantes da área de saúde e de outras áreas, em um contexto multi e transdisciplinar.

O evento geral teve submissão de resumos de simples e expandidos, com apresentação oral (e-pôster) e oral para trabalhos que concorreram à menção honrosa. Ao todo, foram inscritos 143 participantes.

Contou com um número de 50 resumos simples, todos apresentados como apresentação oral (e-pôster) cujos resumos foram publicados no Caderno de Resumos do 3ํE Encontro Amapaense de Produção Científica de Enfermagem ISSN 2359-0416 V.3, 2019 - disponibilizados em CD-ROM. E com 63 resumos expandidos, que serão apresentados nestes anais. 
A enfermagem do Amapá sente-se honrada em contribuir com a discussão nacional, disseminando experiências relacionadas à prática de enfermagem e saúde com equidade, nos âmbitos da assistência, do ensino, da investigação, da gestão e em outros cenários de atuação da enfermagem.

A comissão organizadora 


\section{EIXO I: EQUIDADE COMO PRÉ-REQUISITO DE PROMOÇÃO DA SAÚDE}




\title{
PERFIL SOCIODEMOGRÁFICO E CLÍNICO DE IDOSOS COM DIABETES MELLITUS DO PROGRAMA DE PROMOÇÃO DA SAÚDE
}

\author{
${ }^{1}$ Adriane Stefanny Rocha Ribeiro; ${ }^{2}$ Francineide Pereira da Silva Pena; ${ }^{3}$ José Luís da \\ Cunha Pena; ${ }^{4}$ Walter de Souza Tavares; ${ }^{5}$ Vanessa da Silva Oliveira.
}

\begin{abstract}
${ }^{1}$ Enfermeira. Residente em enfermagem na Atenção à Saúde do Adulto e Idoso; Unifap. Voluntária no Programa de Promoção da Saúde para Pessoas com Diabetes Mellitus. E-mail: stefannyribeiror@gmail.com;

${ }^{2}$ Enfermeira. Doutora em Ciências; Universidade de São Paulo - USP. Professora efetiva Colegiado do Curso de Bacharelado em Enfermagem;

${ }^{3}$ Enfermeiro. Doutor em Ciências; USP. Professor efetivo Colegiado do Curso de Bacharelado em Enfermagem;

${ }^{4}$ Enfermeiro. Doutorando em Inovação Farmacêutica; Unifap. Professor efetivo Colegiado do Curso de Bacharelado em Enfermagem;

${ }^{5}$ Enfermeira. Mestranda em Ciências da Saúde; Unifap. Professora efetiva Colegiado do Curso de Bacharelado em Enfermagem.
\end{abstract}

\section{RESUMO}

Introdução: Os processos de transição demográfica e epidemiológica no Brasil são claramente heterogêneos e estão associados, em grande parte, às desiguais condições sociais observadas no país. A população idosa constitui um grupo bastante diferenciado entre si e em relação aos demais grupos etários, tanto do ponto de vista das condições sociais quanto dos seus aspectos demográficos, epidemiológicos e condições de saúde com sua fisiologia e declínio inerentes ao processo de envelhecimento. Considerando ainda as diferenças de gênero e raça, nesse processo, deve-se buscar a equidade e resolubilidade do cuidado a ser ofertado aos idosos, por constituírem uma parcela da sociedade $^{1-2}$ que necessita de uma atenção constante e continuada. O Diabetes Mellitus Tipo 2 (DM2) é uma Doenças Crônicas Não transmissíveis (DCNTs) e o envelhecimento consiste em um dos fatores potencializadores para adoecer de DM. Em 2017, a Federação Internacional de Diabetes (IDF) estimou que o número de pessoas entre 65 e 99 anos que vivem com diabetes é de 122,8 milhões, com $18,8 \%$ de prevalência. Se as tendências continuarem, número de pessoas com mais de 65 anos vivendo com diabetes será de 253,4 milhões em 20453. Objetivo: Investigar o perfil sociodemográfico e clínico de idosos diabéticos em segmento no programa de idosos atendidos em um grupo de promoção da saúde. Método: Estudo descritivo de abordagem quantitativa, com 21 idosos diabéticos em segmento no Programa de Promoção da Saúde para Pessoas com Diabetes Mellitus (PPSPDM) da cidade Macapá-AP, vinculado à Unidade Básica de Saúde (UBS) na Universidade Federal do Amapá - Unifap, realizado no período de abril a novembro de 2018, tendo sido aprovado pelo comitê de ética em pesquisa, sob o parecer consubstanciado de número 2.853.437 e CAEE 95595718.4.0000.0003. Foram convidados a participar da pesquisa idosos de 60-80 anos, com DM2, que aceitaram participar e assinaram o Termo de Consentimento Livre e esclarecido (TCLE). Posteriormente foi aplicado um questionário sociodemográfico cujas variáveis foram: sexo, idade, raça, estado civil, escolaridade, situação trabalhista e renda. E os clínicos: Tempo de DM, média glicêmica, média de 
hemoglobina glicada (HbA1), média de Índice de massa corporal (IMC), média de cintura abdominal (CA), média de gordura visceral (GV). A análise estatística de dados foi realizada com o programa Statistical Package for the Social Sciences (SPSS), versão 22 para Windows. Resultados: Perfil sociodemográfico - a média de idade foi de 67,6 anos $( \pm 5,6)$, caracterizando uma população idosa jovem. A maioria foi do sexo feminino $(85,7 \%)$, constatando que a mulher busca mais os serviços de saúde que os homens; predomínio da raça parda $(71,4 \%)$, confirmando a taxa significativa de pessoas de etnia parda no Estado do Amapá. Mais da metade era casada (38,1\%) ou vivia em união estável $(19,0 \%)$, sendo que o apoio familiar recebido influência de forma significativa na adesão ao tratamento do DM 2. Trata-se de um grupo com baixa escolaridade (66,7\%), inferior ao Ensino Médio, o que se soma aos fatores que interferem de maneira negativa na adesão e continuidade do tratamento farmacológico e não farmacológico, além da compreensão do mecanismo do adoecimento por diabetes. Houve predomínio entre os idosos daqueles que trabalham como autônomo e recebem benefício da Previdência Social (42,9\%) e têm renda de mil a 2 mil reais $(57,1 \%)$. A renda em qualquer cenário exerce papel relevante, considerando que, em sua maioria, a renda do idoso constitui complementação da renda familiar ou até mesmo a principal renda da família, os gastos com alimentação, lazer e consumo se mostram restritos quando se obtém uma renda reduzida, esses também constituem um fator que interfere no estio de vida do idoso com DM 2. Perfil Clínico: tempo de diabetes foi $<5$ anos $(33,3 \%)$ e $>10$ anos $(28,6 \%)$, considerando que o tempo de DM implica as comorbidade e complicações. A média glicêmica foi de 151,8 $( \pm 72,7)$, caracterizando assim um valor glicêmico não satisfatório em relação ao recomendado pelos documentos e diretrizes que tratam de DM. Porém a média da HbA1 7,2 $( \pm 1,5)$ teve um valor aceitavél para a população idosa com DM, considerando que a idade, mais o diabetes mellitus contribuem substancialmente para o aumento dos níveis de hemoglobina glicada. A média de IMC 28,2 $( \pm 6,0)$, que implica uma média aceitavel conforme os parâmetros de IMC para pessoas idosas, considerando que a perda de apetite e tônus muscular são característicos da pessoa idosa, influenciando os valores do IMC. A média da GV $10,6( \pm 3,6)$ é um indicador importante para risco de doença cardiovascular, tendo como principais a resistência à insulina e as dislipidemias. Considerações finais: $O$ perfil dos idosos em seguimento corrobora com a realidade nacional, que constitui demanda da população com diabetes, em que a maioria deles é do sexo feminino em período de menopausa, casados ou em união estável, escolaridade e renda baixas, o que evidencia um perfil sociodemográfico de uma população que necessita de atenção diferenciada em que a prática da assistência à saúde integral seja garantida. Os dados ora analisados e apresentados enfatizam a importância de conhecer o perfil sociodemográfico e clínico da população em questão, considerando que a estimativa da população brasileira de idosos e com DM2 crescerá de forma alarmante. Isso evidencia a importância de estudos que envolvam a temática em questão, pois favorecem a organização e o planejamento dos serviços de saúde para o seguimento de idosos com DM. Implicações para a enfermagem: $O$ conhecimento do perfil sociodemográfico e clínico contribui para o enfermeiro delinear metas e negociar estratégias para efetivar promoção da saúde, fomentar adesão ao tratamento de DM2 e seguimento, além de trabalhar as singularidades dos idosos, facilitando e garantindo o acesso aos serviços oferecidos pela rede de atenção à saúde. Esse perfil sociodemográfico e clínico implica relevância biossociocultural para atuação da enfermagem na Estratégia 
Saúde da Família (ESF), pois contribuirá para cobertura assistencial integrada das áreas, sustentada no perfil sociodemográfico e clínico de cada idoso.

Descritores: Enfermagem; Diabetes Mellitus tipo 2; Idoso.

\section{Referências}

1. Miranda GMD, Mendes ACG, Silva ALA. O envelhecimento populacional brasileiro: desafios e consequências sociais atuais e futuras. Rev Bras Geriatr Gerontol. 2016;19(3):507-19.

2. Brasil. Diretrizes para o cuidado das pessoas idosas no SUS: proposta de modelo de atenção integral. Ministério da Saúde. 2014. Disponível em:

http://bvsms.saude.gov.br/bvs/publicacoes/diretrizes_cuidado_pessoa_idosa_sus.pdf.

3. Internacional Diabetes Federation-IDF. Atlas de la Diabetes de la FID. 8ed. [Internet]. 2017 Ago [cited 2018 Dec. 17]. Disponível em: https://www.idf.org/elibrary/epidemiologyresearch/diabetes-atlas.html. 


\section{ANÁLISE DO INDICADOR DALY NO AMAPÁ}

${ }^{1}$ Ana Cláudia Paiva Cardoso; ${ }^{2}$ Bruno Raphael da Silva Feitosa; ${ }^{3}$ Mariana Matias de Sousa; ${ }^{4}$ Érika Tatiane de Almeida Fernandes Rodrigues; ${ }^{5}$ Rubens Alex de Oliveira Menezes; ${ }^{6}$ Camila Rodrigues Barbosa Nemer.

\footnotetext{
${ }_{1}^{1}$ Acadêmica de Enfermagem da Universidade Federal do Amapá - Unifap, Macapá, Amapá, Brasil. E-mail: anacloudiaa@gmail.com;

${ }^{2}$ Acadêmico do Curso de Bacharelado em Enfermagem da Unifap;

${ }^{3}$ Acadêmica do Curso de Bacharelado em Enfermagem da Unifap;

4 Enfermeira. Doutora em Ciências. Professora do Colegiado do Curso de Bacharelado em Enfermagem da Unifap;

${ }^{5}$ Enfermeiro. Doutor em Doenças Infecciosas e Parasitárias da Universidade Federal do Pará UFPA. Professor do Colegiado do Curso de Bacharelado em Enfermagem da Unifap;

${ }^{6}$ Enfermeira. Mestre em Enfermagem. Doutoranda em Saúde Pública pela Escola Nacional de Saúde Pública Ensp/Fundação Oswaldo Cruz - Fiocruz. Professora do Colegiado do Curso de Bacharelado em Enfermagem da Unifap.
}

\section{RESUMO}

Introdução: A transição epidemiológica no Brasil não tem ocorrido nos moldes da maioria dos países desenvolvidos. No Brasil, doenças crônico-degenerativas e doenças transmissíveis coexistem e desempenham um papel importante nos problemas de saúde. Conceituam-se como transição epidemiológica as transformações ocorridas ao longo do tempo nos padrões de morte, morbidade e invalidez que caracterizam uma população específica, sendo que estas geralmente ocorrem em conjunto com outras transformações demográficas, sociais e econômicas. Há uma superposição entre as etapas nas quais predominam as doenças transmissíveis e crônico-degenerativas; a reintrodução de doenças (dengue e cólera) ou o recrudescimento de outras (malária, hanseníase e leishmanioses) indicam uma natureza não unidirecional denominada contratransição; o processo não se resolve de maneira clara, criando uma situação em que a morbimortalidade persiste elevada para ambos os padrões, o que caracteriza uma transição prolongada; e um processo chamado de polarização epidemiológica em que as situações epidemiológicas de diferentes regiões em um mesmo país se tornam contrastantes. ${ }^{1}$ Objetivo: Descrever o padrão epidemiológico no Amapá utilizando como indicador o Disability Adjusted Life of Years (DALY - anos de vida perdidos ajustados por incapacidade). Método: O DALY mede ao mesmo tempo o impacto da mortalidade e dos problemas de saúde que afetam a qualidade de vida dos indivíduos, medindo os anos de vida perdidos por morte prematura (YLL - Years of Life Lost - anos de vida perdidos por morte prematura) ou incapacidade (YLD - Years Lived with Disability - anos de vida vividos com incapacidade) em relação a uma esperança de vida ideal (utilização do padrão do Japão, país com maior esperança de vida ao nascer do mundo, 80 anos para homens e 82,5 anos para mulheres). ${ }^{1}$ Como fonte de dados utilizou-se a base de dados Carga Global de Doenças (Global Burden of Disease - GBD 2017) do Instituto de Métricas e Avaliação de Saúde (Institute for Health Metrics and Evaluation - IHME). Este é um centro de pesquisa global de saúde independente da Universidade de Washington. A abordagem da Carga Global de Doenças procura medir a incapacidade e a morte de uma multiplicidade de 
causas em todo o mundo. Ela cresceu nos últimos anos em um consórcio internacional entre pesquisadores, e suas estimativas estão sendo atualizadas anualmente. O GBD estuda a transição epidemiológica. No Brasil, o GBD conta com parcerias com o Ministério da Saúde e a Fiocruz na realização de cálculos epidemiológicos em regiões subnacionais. O design flexível do GBD permite atualizações regulares, à medida que novos dados e estudos epidemiológicos são disponibilizados. As ferramentas podem ser usadas nos níveis global, nacional e local para entender as tendências de saúde ao longo do tempo, assim como os dados do produto interno bruto são usados para monitorar a atividade econômica de um país. ${ }^{2}$ Resultados: Os agravos são agrupados em três grandes grupos: Grupo 1 Doenças transmissíveis, maternas, neonatais e nutricionais; Grupo 2 - Doenças não transmissíveis; Grupo 3 - Causas externas. Nas informações referentes à distribuição proporcional do DALY em ambos os sexos, todas as idades, segundo grupos de causa no Amapá, observam-se, que dentro do Grupo 1, destacam-se transtorno do período neonatal, apresentando concentração de 8,08\% e infecções das vias áreas inferiores com 3,05\%. No Grupo 2, dor lombar baixa e cefaleia apresentam-se em destaque, para ambas as situações - Amapá apresenta concentração de 4,62\% e 3,88\% respectivamente. No Grupo 3 destacam-se violência interpessoal e acidente de trânsito, para ambas as situações, o Amapá apresenta concentração de 10,03\% e 3,95\% respectivamente. Nas informações referentes à distribuição proporcional do DALY em ambos os sexos, faixa etária menor que 5 anos de idade, segundo grupos de causa no Amapá, destacam-se transtornos do período neonatal (Grupo 1) e anomalias congênitas (Grupo 2) com 48,65\% e 15,52\% respectivamente. Nas informações referentes à distribuição proporcional do DALY em ambos os sexos, faixa etária entre 5 e 14 anos de idade, segundo grupos de causa no Amapá, destacam-se cefaleias (Grupo 2) e afogamento (Grupo 3) com 6,79\% e 5,59\% respectivamente. Nas informações referentes à distribuição proporcional do DALY em ambos os sexos, faixa etária entre 15 e 49 anos de idade, segundo grupos de causa no Amapá, destacam-se violência interpessoal (Grupo 3) e dor lombar (Grupo 1) com 18,03\% e 6,01\% respectivamente. Nas informações referentes à distribuição proporcional do DALY em ambos os sexos, faixa etária entre 50 e 69 anos de idade, segundo grupos de causa no Amapá, destacam-se doença isquêmica do coração (Grupo 2) e doença cerebrovascular (Grupo 2) com 8,64\% e 7,01\% respectivamente. Nas informações referentes à distribuição proporcional do DALY em ambos os sexos, faixa etária 70 ou mais idade, segundo grupos de causa no Amapá, destacam-se doença cerebrovascular (Grupo 2) e doença isquêmica do coração (Grupo 2) com 10,22\% e 10,05\% respectivamente. Contribui com um percentual expressivo de DALY no Amapá, entre os homens em todas as idades, a violência interpessoal $(15,93 \%)$ e, entre as mulheres em todas as idades, transtornos do período neonatal $(9,06 \%)$. Considerações finais: Analisando o ranking das principais causas de anos de vida perdidos por morte prematura ou por incapacidade (DALY) para o Amapá, observa-se uma diminuição dos percentuais de doenças transmissíveis, porém com a persistência de tuberculose e HIV. A análise do DALY em ambos os sexos, todas as idades, destaca a violência e autolesão em 2017. As doenças não transmissíveis representam mais de $50 \%$ do DALY geral no Amapá. Há uma superposição entre as etapas, mostrando um contexto de extrema complexidade e desigualdade social. A superposição de problemas de saúde ao longo dos anos garante a manutenção de uma carga de magnitude semelhante, de morbidade e mortalidade na população, e reduzir essa carga se configura como um 
desafio para a definição de políticas de saúde. Implicações para a enfermagem: $O$ uso do indicador DALY pode ajudar na identificação de prioridades em função do perfil epidemiológico, embasando a tomada de decisões de prioridades de investigação em saúde com a finalidade de superar as iniquidades (ou desigualdades) encontradas.

Descritores: Transição epidemiológica; Iniquidade Social; Carga Global da Doença.

\section{Referências}

1. Schramm JMA, Oliveira AF de, Leite IC, Valente JG, Gadelha AMJ, Portela MC et al . Transição epidemiológica e o estudo de carga de doença no Brasil. Ciênc. saúde coletiva [Internet]. 2004 Dec [cited 2019 Apr 29]; 9(4): 897-908. Available from: http://www.scielo.br/scielo.php?script=sci_arttext\&pid=S1413-

$81232004000400011 \& \operatorname{lng}=$ en.

2. Institute for Health Metrics and Evaluation [homepage na internet]. GBD COMPARE [acesso em 20 abr 2019]. Disponível em: https://vizhub.healthdata.org/gbd-compare/. 


\title{
A PEGA ERRADA E AS ORIENTAÇÕES DE ENFERMAGEM NO PUERPÉRIO: RELATO DE EXPERIÊNCIA
}

\author{
${ }^{1}$ Ana Karolina Oliveira Moura; $;{ }^{2}$ Luíny de Souza Lobato; ${ }^{3}$ Kaila Correa Santos; ${ }^{4}$ Marluci \\ de Souza Ledo Santos; ${ }^{5}$ Vanessa da Silva Oliveira; ${ }^{6}$ Rosa Natália Muniz Carneiro Mota. \\ ${ }_{1}^{1}$ Acadêmica do Curso de Bacharelado em Enfermagem; Universidade Federal do Amapá - Unifap. \\ E-mail: anak.moura.5@gmail.com; \\ ${ }^{2}$ Acadêmico do Curso de Bacharelado em Enfermagem; Unifap; \\ ${ }^{3}$ Acadêmico do Curso de Bacharelado em Enfermagem; Unifap; \\ ${ }^{4}$ Acadêmico do Curso de Bacharelado em Enfermagem; Unifap; \\ ${ }^{5}$ Enfermeira. Especialista em Enfermagem; Unifap. Professora Efetiva Colegiado do Curso de \\ Bacharelado em Enfermagem; \\ ${ }^{6}$ Enfermeira. Especialista em Estratégia Saúde da Família; Unifap. Professora Substituta do \\ Colegiado do Curso de Bacharelado em Enfermagem.
}

\section{RESUMO}

Introdução: A prática do aleitamento materno oferta inúmeros benefícios tanto para a puérpera quanto para o bebê. De acordo com o Ministério da Saúde, o leite materno fornece ao bebê anticorpos, evita infecções respiratórias e diarreicas, reduz a chance de obesidade e o risco de alergias, provê todos os nutrientes necessários para os primeiros meses de vida. Enquanto, para a mãe, auxilia na involução uterina. É utilizado como método de contracepção, possui fator de proteção contra o câncer de mama, e, ainda, ajuda na promoção do binômio mãe-filho e não possui alto custo. Em meio a tantos benefícios, recomenda-se $o$ aleitamento até os 2 anos ou mais, sendo que, nos primeiros seis meses de vida, deve ser exclusivo. Do contrário, há riscos a que a criança fica exposta a partir do momento em que o desmame é realizado antes do período previsto, como a não absorção eficaz de nutrientes, menor ingestão de anticorpos e imunoglobulinas, aumentando a morbimortalidade infantil. Assim, não basta ao profissional de saúde ter conhecimentos básicos e habilidades em aleitamento materno, ele precisa ter também competência para se comunicar com eficiência, o que se consegue mais facilmente usando a técnica do aconselhamento em amamentação. Para que o manejo dessa prática possua eficiência, é de extrema importância que os profissionais que atendem na atenção primária estejam sensibilizados e capacitados para preparar a mulher, seja durante a consulta de enfermagem, seja durante as rodas de conversas para o período da gestação e do puerpério. Objetivo: $O$ presente estudo tem como objetivo evidenciar a importância da consulta de puerpério no manejo do aleitamento materno, através da experiência vivenciada como acadêmicos durante a prática em saúde pública. Método: Trata-se de um relato de experiência, com abordagem descritiva, realizado no período de abril de 2019, por acadêmicos a partir da vivência no Estágio Supervisionado I, em uma Unidade Básica de Saúde em Macapá-AP, durante uma consulta de enfermagem. Resultados: Ao receber a puérpera com o seu parceiro, a fim de realizar a primeira consulta do recém-nascido ( $R N)$, nos primeiros 11 dias de vida, as acadêmicas de enfermagem, juntamente com a preceptora, tiveram a oportunidade de realizar uma abordagem de forma holística compreendendo-os num todo, o que possibilitou orientar sobre diferentes temáticas acerca 
das suas principais dúvidas. A puérpera queixou-se do fato de que a bebê não estava realizando a pega adequada para a amamentação e com isso a mãe utilizava como estratégia a ordenha do leite materno para ofertar em mamadeira, e esse meio escolhido foi de grande sucesso. $O$ fato de a RN não realizar a pega para mamada foi motivo de preocupação para a equipe; ao exame físico, o reflexo de busca e de sucção estava preservado, porém a RN havia se habituado ao uso da mamadeira. Nisso, foi observado que a família tinha carência de orientações com relação ao cuidado e armazenamento do leite materno. De modo que imediatamente foram passadas as informações necessárias sobre cuidados com as mamas e o leite materno, como: a exposição das mamas ao sol por alguns minutos a fim de prevenir o surgimento de fissuras, demonstração da posição correta do bebê para que ela faça uma boa pega. Desse modo, no momento da consulta, foi necessário ensinar à mãe como é a correta posição para realizar o aleitamento, deixandoa segura em relação a como deveria fazer quando chegasse a sua residência, pois esse momento é um dos momentos de formação de vínculo no binômio mãe-filho. Outro fator questionado pela mãe foi sobre a frequência das mamadas, sendo de livre demanda, ou seja, sem restrição quanto ao quantitativo de vezes e nem tempo de permanência nas mamadas, além de cuidados com a higiene perineal e, principalmente, como realizar 0 manejo do leite materno, uma vez que ele pode ser congelado por até 15 dias após a coleta, tendo que conter o registro da data da coleta, o que possibilita o uso correto com o passar dos dias. Explicou-se também sobre o seu manuseio, mesmo tendo sido orientada sobre o armazenamento correto do leite, foi informada sobre a importância de a $\mathrm{RN}$ fazer 0 processo de mamar. Vale ressaltar também que, em relação à dificuldade da $\mathrm{RN}$ em realizar a pega, além das orientações realizadas, a puérpera foi aconselhada a marcar uma consulta com o fonoaudiólogo para identificação de qualquer déficit que envolva a parte de comunicação humana. Considerações finais: Observou-se, assim, a essencialidade de, durante as consultas, repassar todas as informações sobre o processo de aleitamento materno, possíveis dificuldades e como prevenir problemas advindos de uma pega errada e/ou falta de conhecimento da família com relação aos cuidados necessários com o corpo da mãe. Deve-se incentivar sempre a gestante a retornar à unidade básica de saúde para dar prosseguimento ao seu roteiro de consultas pré-natais, assim como no pós-parto, nos primeiros 5 dias de vida do $\mathrm{RN}$, de preferência. Nesse sentido, será possível preparar melhor essa mulher para os cuidados com o seu bebê, a fim e ter o conhecimento do roteiro de consultas, zelar pela saúde e bem-estar do $\mathrm{RN}$, sabendo quais profissionais estarão aptos a realizar esse acompanhamento. Aos profissionais, cabe realizar as devidas orientações em tempo de tranquilizar os pais, assegurar que o bebê esteja bem nutrido na fase inicial da vida para o fortalecimento do sistema imunológico para prevenção de futuras patologias no RN, bem como no desenvolvimento e crescimento do mesmo. Implicações para enfermagem: A enfermagem tem papel fundamental em todos os processos na saúde da mulher e da criança. Contudo, é necessário que os profissionais reconheçam a importância do trabalho desenvolvido nas consultas de enfermagem a partir das orientações prestadas, haja vista que uma gestante bem orientada durante o ciclo da vida tona-se uma mulher com a saúde preservada, uma gestante pré-natal bem acompanhada e uma puérpera preparada a dar seguimento em mais uma fase do seu ciclo de vida.

Descritores: Aleitamento Materno; Período Pós-parto; Enfermagem. 


\section{Referências}

1. Almeida JM, Luz SAB, Ued FV. Apoio ao aleitamento materno pelos profissionais de saúde: revisão integrativa da literatura. Rev. Paul Pediatr. Minas Gerais, 2015. v33(3): 355-362.

2. Ministério da Saúde (BR). Saúde da criança: aleitamento materno e alimentação complementar. Caderno de Atenção Básica no23. Brasília: Ministério da Saúde; 2015.

3. Ministério Da Saúde (BR). Saúde da criança: o que é, cuidados, políticas, vacinação, aleitamento. [acesso em 27 abr 2019]. Disponível em: http://portalms.saude.gov.br/saude-de-a-z/crianca.

4. Silva DD, Schmitt IM, Costa R, Zampiere MFM, Bohn IE, Lima MM. Promoção Do Aleitamento Materno No Pré-natal: Discurso Das Gestantes E Dos Profissionais De Saúde. Rev Min Enferm. Santa Catarina, 2018. 22:e-1103.

5. Silva DP, Soares P, Macedo MV. Aleitamento Materno: Causas E Consequências Do Desmame Precoce. Rev Unimonte Científica. Monte Claros, 2017. v. 19(2). 157-146. 


\title{
EQUIDADE, EDUCAÇÃO E ATENÇÃO À SAÚDE DE ADOLESCENTES GRÁVIDAS DE ÁREAS DE RESSACA
}

\begin{abstract}
${ }^{1}$ Anderson Rodrigues Ribeiro; ${ }^{2}$ Joyce Taynara Sousa de Miranda; ${ }^{3}$ Hiago Rafael Lima da Silva; ${ }^{4}$ Katiciane Rufuno da Silva; ${ }^{5}$ Nely Dayse Santos da Mata.
\end{abstract}

\author{
${ }^{1}$ Acadêmico do Curso de Bacharelado em Enfermagem; Unifap. Email: \\ anderson100costa@gmail.com; \\ ${ }^{2}$ Acadêmico do Curso de Bacharelado em Enfermagem; Unifap; \\ ${ }^{3}$ Acadêmico do Curso de Bacharelado em Enfermagem; Unifap; \\ ${ }^{4}$ Enfermeira. Residente em Saúde Coletiva; Unifap; \\ ${ }^{5}$ Enfermeira. Doutora em Ciências. Professora efetiva do Colegiado do Curso de Bacharelado em \\ Enfermagem, Unifap.
}

\section{RESUMO}

Introdução: A adolescência é uma fase de crescimento e desenvolvimento biológico, psicológico, emocional e social ${ }^{1}$. Quando ocorrem singularidades como a gravidez na adolescência, eventualmente surgem demandas e seus respectivos produtos são consequências sociais e de saúde. Acrescenta-se que há ruptura dos projetos pessoais da adolescente em função da gravidez em si e do nascimento da criança e é comum a estudante afastar-se da escola e de outros ambientes de interações sociais e enfrentar conflitos diante das mudanças simultâneas próprias da adolescência e da gravidez ${ }^{1}$. Refletir sobre a temática da gravidez na adolescência é mais uma vez buscar materializar seus dilemas sociais, bioéticos e políticos, motivando a discussão sobre instrumentos legais e concepções de aspectos éticos envolvidos no tema que não sustem mais discutir esse tema na visão biológica, no trato com o corpo, com a moral, com a sexualidade e a reprodução propriamente dita. A discussão deste tema deve ser direcionada aos reflexos do evento para adolescente/ filho/ família/ sociedade quanto à preservação de direitos, dignidade $e$ justiça como dever do Estado, a fim de garantir qualidade de vida, [...] que é uma noção eminentemente humana, subjetiva e polissêmica que se refere ao bem-estar que o indivíduo e a coletividade encontram na vida familiar, amorosa, social e ambiental ${ }^{2}$. Há fatores que fragilizam ainda mais este processo complexo que é a gravidez na adolescência, como vulnerabilidade social, que nem sempre está atrelada completamente a condições socioeconômicas, mas vinculada à debilidade das relações afetivas com o seu meio e a dificuldade de acesso a bens e serviços públicos, condições estas que the direcionam para os determinantes sociais de Saúde ${ }^{3}$. A gravidez na adolescência tem um sem- fim de fatores considerados causa desse evento, envolvendo aspectos diferentes ordens [...], seja no âmbito social, emocional, por desconhecimento do funcionamento do corpo, por questões culturais, por violência física, entre tantas outras razões que constituem objetos de estudos que sustentam a busca da compreensão ${ }^{2}$. Outros fatores que devem ser considerados são as transformações que sucedem com a adolescência gerando produtos como a maturação sexual, aquisição da capacidade de reprodução e comportamentos individuais e comportamentais que influenciam no número de parceiros e uso de métodos contraceptivos, fatores mal delimitados, das condições de vida. Aspectos macroestruturais e socioculturais são influenciadores da resultante filho na adolescência ${ }^{1,4}$. 
O Sistema Único de Saúde (SUS), através de princípios de universalidade, equidade e integralidade, a serem alcançados por estratégias como descentralização, hierarquização e regionalização com participação social, teve por intuito oferecer adequado acompanhamento à gestante adolescente, prevenindo intercorrências obstétricas, prematuridade e baixo peso ao nascer. Objetivos: Relatar a experiência dos acadêmicos do Curso de Bacharelado em Enfermagem e residente em saúde coletiva sobre as principais atividades de educação em saúde ofertadas no Grupo de Extensão de Apoio a Grávidas Adolescentes. Método: Trata-se de um estudo descritivo com abordagem qualitativa, qualificado como relato de experiência de acadêmicos de Enfermagem e residente em saúde coletiva, observando as adolescentes grávidas que moram em área de ressaca, atendidas pela equipe multidisciplinar do Grupo de Extensão de Apoio a Grávidas Adolescentes (Geaga), que visa trabalhar com grávidas primigestas, sem agravos de saúde, que fazem seu pré-natal em uma UBS de Macapá. As oficinas ocorrem aos sábados, em períodos quinzenais, das $8 \mathrm{~h}$ às $10 \mathrm{~h} 30$, e as atividades são feitas por professores, enfermeiros, educador físico, residentes em saúde coletiva e acadêmicos. As tarefas efetuadas no grupo são: o acolhimento de grávidas, verificação da pressão arterial, peso, altura, índice de massa corporal (IMC), cálculo da idade gestacional e data provável do parto. Adiante é trabalhada a educação em saúde, de acordo com o período gestacional, que visa nortear as grávidas e companheiros/acompanhantes. No grupo, são abordados os seguintes temas: modificações gravídicas tanto físicas quanto fisiológicas, importância de fazer o pré-natal, alimentação saudável e atividade física, saúde bucal, cuidados com higiene íntima para evitar infecções do trato urinário, violência obstétrica, cuidados com recém-nascidos/coto umbilical, aleitamento materno, consulta puerperal e planejamento familiar. Os temas são trabalhados em rodas de conversas, com a linguagem adaptada ao grau de instrução das grávidas, assim possibilitando a explanação de conhecimento científico de modo mais dinâmico. Além das abordagens das temáticas, são realizados exercícios de alongamento, respiração e exercícios obstétricos para fortalecer o assoalho pélvico, assim como são ofertadas práticas integrativas e complementares à saúde da mulher. Resultados: Observou-se que, a partir das atividades desenvolvidas pelo grupo Geaga, as grávidas e companheiros/acompanhantes adquiriram conhecimento científico respectivo ao momento do parto e do recém-nascido, o qual, anteriormente, era limitado em razão de conhecimentos empíricos e pela difusão de conhecimento tácito das pessoas com quem convivem. Com a explanação do conhecimento científico, ouve uma interlocução e, em alguns casos, divergências com o conhecimento empírico, possibilitando, assim, tirar dúvidas, responder sobre curiosidades e desmitificar ideias errôneas acerca do trabalho de parto. As temáticas trabalhadas em consonância com exercícios de alongamento, respiração e obstétricos concederam prontidão para as grávidas serem protagonista do seu parto humanizado, e, quanto ao companheiro/acompanhante, ele vai trabalhar todo 0 conhecimento e informações que adquiriu no grupo para dar suporte à gestante. Considerações finais: $O$ grupo oferece um diferencial na assistência à saúde das adolescentes grávidas de área de ressaca, pois é colocado em prática o princípio da equidade por meio de exercícios, atividades, temáticas e práticas integrativas e complementares, a que antes não tinham acesso por conta das vulnerabilidades sociais. $A$ promoção de saúde advém das temáticas trabalhadas no grupo, que são definidas de acordo com o período gestacional, demandas em saúde e social. Implicações para a 
enfermagem: $O$ enfermeiro tem, entre suas várias funções, a responsabilidade de promoção, manutenção e restauração da saúde do paciente/cliente e o seu instrumento é a educação em saúde. A atuação do enfermeiro no incremento de ações educativas com essas jovens busca superar modelos tradicionais, estimular a expressão dos sujeitos diante das circunstâncias da gravidez precoce com momentos de cuidados e promoção da saúde ${ }^{1}$.

Descritores: Grávidas; Adolescência; Vunerabilidade social.

\section{Referências}

1. Santos RCAN, Silva RM, Queiroz MVO, Jorge HMF, Brilhante AVM. Realidades e perspectivas de mães adolescentes acerca da primeira gravidez. Rev Bras Enferm. 2018;71(1):73-80.

2. Guimarães ALM. Vulnerability in pregnancy in adolescents: differences between the status of the child and the adolescent (eca) and the. Tese - Univ do Estado do Rio Janeiro, Inst Med Soc. 2017;102 f-102 f.

3. Carmo ME do, Guizardi FL. O conceito de vulnerabilidade e seus sentidos para as políticas públicas de saúde e assistência social. Cad Saude Publica. 2018;34(3).

4. Queiroz OS. Os determinantes sociais da gravidez na adolescência em município de médio porte no nordeste do brasil: um estudo prospectivo. Diss - Univ Fed do Ceará Mestr em Saúde Pública Fortaleza, CE 1. 2010;84. 


\section{MODELO DE PROTOCOLO PARA INDUÇÃO DE FERIDAS CUTÂNEAS IN VIVO: ESTUDO EXPERIMENTAL}

${ }^{1}$ Erick Souza Neri; ${ }^{2}$ Charton Frankson Madureira Nascimento Júnior; ${ }^{3}$ Taynara Camille Guilherme Lima; ${ }^{4}$ Italo Soares Eneias; ${ }^{5}$ Lucas dos Santos Nunes; ${ }^{6}$ Ana Rita Pinheiro Barcessat.

\footnotetext{
${ }^{1}$ Acadêmico do Curso de Bacharelado em Enfermagem - Unifap. Grupo de Pesquisa em Biofotônica e Neuromodulação. Bolsista Pibic CNPq. E-mail: erickneri13@gmail.com;

${ }^{2}$ Acadêmico do Curso de Bacharelado em Enfermagem - Unifap. Grupo de Pesquisa em Biofotônica e Neuromodulação;

${ }^{3}$ Enfermeira. Especialista em Saúde Coletiva - Unifap;

${ }^{4}$ Acadêmico do Curso de Bacharelado em Enfermagem - Unifap. Grupo de Pesquisa em Biofotônica e Neuromodulação;

${ }^{5}$ Acadêmico do Curso de Bacharelado em Enfermagem - Unifap. Grupo de Pesquisa em Biofotônica e Neuromodulação. Bolsista PROBIC-VS/Unifap;

${ }^{6}$ Cirurgiã Dentista. Doutora em Estomatologia básica e aplicada: Patologia Bucal. Professora efetiva do colegiado do Curso de Bacharelado em Enfermagem e Programa de Pós-Graduação em Ciências da Saúde - Unifap.
}

\section{RESUMO}

Introdução: As feridas são afecções que afetam o sistema tegumentar, atribuídos a processos traumáticos, químicos, mecânicos ou associadas a outras disfunções sistêmicas. O reparo tecidual é um processo complexo e dinâmico do organismo, visando restabelecer a estrutura e função tissular ${ }^{1}$. Desta forma, estudos com modelos experimentais são necessários na ciência biomédica, a fim de garantir uma fonte biológica comparativa segura para a compreensão de estruturas macro e microscópicas e seus mecanismos fisiológicos, farmacológicos e patológicos, além de efeitos secundários de intervenções cirúrgicas ${ }^{2}$. Assim, este trabalho se propõe sugerir um modelo de protocolo para indução de feridas cutâneas em roedores, auxiliando no desenvolvimento de novos estudos na área, visto a carência de trabalhos semelhantes na literatura. Objetivos: Descrever os procedimentos implementados na construção de um modelo de protocolo experimental para a indução de feridas cutâneas em camundongos Mus Musculos. Método: Trata-se de um estudo descritivo, experimental, realizado a partir de uma amostra de conveniência com 12 camundongos Mus musculus do sexo masculino. Para testar qual método seria mais apropriado, os animais foram divididos em 2 grupos: a) grupo 1 (G1) foi testada a indução por meio de lâmina de Bisturi no 15, analisando medidas lineares e de profundidade por meio de uma sonda milimetrada odontológica e, a seguir, realizado corte a mão livre; b) grupo 2 (G2), foi testada a indução da ferida por meio do instrumento punch cirúrgico, sugerido como um método por ser um instrumental já utilizado em ambientes ambulatoriais e preconizado em outro protocolo ${ }^{3}$. Foram avaliados parâmetros de estética, diferença de volume e possibilidade de gerar mais de uma lesão, e definidos o padrão de localização das feridas, método de medição e o tipo de tricotomia, com base em literaturas disponíveis na área. Resultados: O modelo de indução de lesões cutâneas sugerido deverá considerar metodologicamente os passos a seguir, levando-se em conta as especificidades de cada 
estudo, em especial, no que concerne às exigências da Comissão de Ética no Uso de Animais (CEUA), tais como delineamento estatístico, e os cuidados preconizados pelo Conselho Nacional de Controle de Experimentação Animal (CONCEA) ${ }^{4}$. 1. Aspectos éticos: o projeto de pesquisa foi submetido à apreciação da CEUA da Universidade Federal do Amapá (Unifap), considerando-se os aspectos de finalidade do projeto, experiência prévia, objetivos, justificativa, relevância do estudo, modelo animal, procedência, condições de condicionamento, manejo, método de eutanásia e descarte, sendo posteriormente aprovado sob o protocolo no 005/2015. 2. Descrição do Local de estudo: o estudo foi realizado no Laboratório de Toxicologia do Curso de Ciências Farmacêuticas da Unifap, no período de abril de 2015 até março de 2016. 3. Amostra do estudo: foram utilizados dez camundongos adultos machos da espécie Mus Musculos, família Muridae, raça Swiss, cedidos pelo biotério do laboratório. 4. Acondicionamento dos animais: os animais foram acondicionados em gaiolas individuais, com alimentação e hidratação à vontade, submetidos à controle de ciclos claro e escuro de 12/12 horas, e controle de temperatura e ruídos. 5. Cálculo amostral: a amostra foi definida por conveniência e pela disponibilidade dos animais, e em função do cálculo amostral, foram definidos 6 animais por grupo para a realização do estudo. 6 . Definição de grupos e alocação randômica: após a definição dos grupos experimentais, optou-se por utilizar alocação randomizada do tipo determinística, com base na data de nascimento para alocar os animais nos grupos experimentais. 7 . Técnica anestésica adotada: os animais foram pesados, e em seguida foram anestesiados com Cloridrato de Quetamina (100 mg/kg) e Cloridrato de Xilazina $(10 \mathrm{mg} / \mathrm{kg}$ ), com administração via intraperitoneal, em seringas de insulina de $100 \mathrm{Ul}$ com agulha descartável $(13 \times 4,5)$, avaliando-se o grau de depressão da atividade reflexa, do tônus muscular e do sistema nervoso central para prosseguir com a indução das lesões. 8. Tricotomia: após a sedação, foram demarcadas as áreas de indução por pincel atômico na região dorsal, seguida da testagem de 3 métodos para a remoção do pelo: a) bisturi; b) lâmina de barbear; e c) barbeador elétrico, sendo este último o mais eficaz. Optou-se por não testar o método de epilação manual, por ser um método menos eficaz e mais demorado. 9. Confecção das feridas: uma vez determinada a área tricotomizada, iniciou-se a realização dos testes, sendo o método utilizando a indução pelo instrumento punch cirúrgico, de tamanho médio, é mais eficaz, induzindo feridas com medidas lineares $6 \times 6 \mathrm{~mm}$ em função do seu desenho geométrico em forma de círculo e a profundidade de $3 \mathrm{~mm}$ estabelecida pela espessura da derme na região do dorso do animal, avaliada por sonda milimetrada. 10. Padronização de medidas: para minimizar as variações de volume (altura, largura e profundidade), os métodos adotados para avaliar as medidas foram o paquímetro cirúrgico (avaliou medidas lineares) e a sonda milimetrada (avaliou medidas em profundidade). 11. Eutanásia dos animais: para a eutanásia, foi administrada superdosagem das drogas citadas na técnica descrita no item 7, avaliando-se a profundidade anestésica: redução significativa dos reflexos autonômicos da cauda, córnea e pálpebra do animal, perda de consciência e sinais de depressão cardiorrespiratória. 12. Destinação dos animais: os animais foram acondicionados em sacos plásticos especiais para a coleta e armazenados em freezer $18^{\circ}$, seguidos do transporte e destinação final por empresa terceirizada, nos termos da RDC no $306^{5}$, para destinação de resíduos de serviço de saúde. Considerações finais: Com este estudo, foi possível realizar a caracterização desse protocolo e espera-se auxiliar na padronização do processo de indução de feridas em modelos experimentais para a 
execução de novos estudos na área, tendo em vista a pesquisa de novos tratamentos. Implicações para a Saúde: A prestação de cuidados com portadores de feridas é crescente no âmbito do SUS, sendo de extrema importância pesquisar e propor novas alternativas terapêuticas, que sejam efetivas e de baixo custo, visando a sua aplicação na prática assistencial.

Descritores: Ferimentos e Lesões; Animais de Laboratório; Modelos Animais.

\section{Referências}

1. Carvalho KC, Nicolau RA, Maia ALM, Barja PR, Sá HP, Santo LAE et al. Estudo da resistência cicatricial cutânea de ratos tratados com fototerapia a laser. Conscientiae Saúde [Internet]. 2010 [citado em 17 abr 2019]; 9(2): 179-186. Disponível em: https://www.redalyc.org/articulo.oa?id=92915260003.

2. Ferreira LM, Hochman B, Barbosa MVJ. Modelos experimentais em pesquisa. Acta Cir Bras [Internet]. 2005 [citado em 17 abr 2019]; 20(2): 28-34. Disponível em: http://www.scielo.br/scielo.php?script=sci_arttext\&amp;pid=S0102-

86502005000800008\&amp;Ing=en.

3. Massahud MR Jr, Salomé GM. Protocolo de cirurgia experimental em ferida cirúrgica em ratos [Dissertação]. Pouso Alegre: Universidade do Vale do Sapucaí (UNIVÁS). Mestrado Profissional em Ciências Aplicadas à Saúde [Internet]; 2016 [citado em 17 abr 2019].

Disponível

em: http://www.univas.edu.br/mpcas/egresso/publicacao/2016110741403363295396.pdf.

4. Ministério da Ciência, Tecnologia, Inovações e Comunicações (BR), Conselho Nacional de Controle de Experimentação Animal - CONCEA. Resolução no 33, de 18 de novembro de 2016. Procedimentos - Roedores e lagomorfos mantidos em instalações de instituições de ensino ou pesquisa cientifica. Brasília: Ministério da Ciência, Tecnologia, Inovações e Comunicações, 2016.

5. Ministério da Saúde (BR), Agência Nacional de Vigilância Sanitária - ANVISA. Resolução no 306, de 07 de dezembro de 2004. Regulamento Técnico para o gerenciamento de resíduos de serviços de saúde. Brasília: Ministério da Saúde, 2004. 


\title{
INDUÇÃO DO TRABALHO DE PARTO: REFLEXÃO PARA A PRÁXIS
}

\author{
${ }^{1}$ Francisca Evelen Suelen Silva de Aguiar; ${ }^{1}$ Jéssica Natasha Brandão da Silva Bezerra; \\ ${ }^{2}$ Nely Dayse Santos da Mata.
}

${ }^{1}$ Enfermeira Residente em saúde coletiva com atenção integral à saúde da criança e adolescente; Universidade Federal do Amapá - UNIFAP. E-mail: franciscaaguiar.enf@gmail.com;

${ }^{2}$ Enfermeira. Doutora em Enfermagem; Unifap. Professora efetiva Colegiado do Bacharelado em Enfermagem.

\section{RESUMO}

Introdução: A indução do trabalho de parto se iniciou na década de 50 , com a produção da ocitocina sintética via endovenosa, sendo um dos uterotônicos mais utilizados para indução do trabalho de parto em mulheres com colo pérvio. A indução do parto compreende o estímulo ativo do colo uterino no primeiro período do parto, tendo como propósito amadurecer o colo e estimular contrações antes do trabalho de parto espontâneo ${ }^{(1)}$. Este procedimento é recomendado para mulheres a partir da $22^{\mathrm{a}}$ semana de gestação com 0 intuito de possibilitar o parto vaginal quando o progresso da gravidez significa risco materno-fetal maior do que a sua interrupção. As indicações para induzir o parto podem ser classificadas em eletivas ou terapêuticas. Indicações eletivas são aquelas que se dão por opção do médico e/ou da gestante. Indicações terapêuticas são consequentes do maior risco fetal pelo tempo na cavidade uterina, o que pode ocorrer devido aos anexos fetais, como a rotura prematura das membranas ovulares ou infecção ovular; ao próprio feto; às intercorrências clínicas maternas; e à idade gestacional (2). A técnica indicada para avaliação do colo uterino é o Índice de Bishop, que busca analisar sistematicamente as alterações clínicas do colo e o nível de descida da apresentação fetal em relação à bacia materna. Este método se baseia em escore numérico e avalia qualitativamente características como orientação, amolecimento, esvaecimento, dilatação e altura da apresentação fetal ${ }^{(3)}$. A ocitocina é utilizada de forma rotineira nas maternidades, junto com - misoprostol para a indução do trabalho de parto. Essa droga, quando usada indiscriminadamente, poderá acarretar prejuízos para a mãe e o bebê (4). As pesquisas revelam que ocorre um "efeito cascata" no uso de intervenções no parto, uma vez que uma intervenção acabaria por gerar problemas, que, por sua vez, seriam resolvidos com uma nova intervenção, e assim constantemente ${ }^{(5)}$. Indicações de indução para o parto: gravidez prolongada $(52 \%)$, pré-eclâmpsia/hipertensão $(20 \%)$, retardo de crescimento intrauterino $(10 \%)$ e diminuição dos movimentos fetais $(7 \%)^{(3)}$. Objetivo: Identificar o quantitativo de partos induzidos em uma maternidade pública do município de Macapá-AP. Método: Estudo exploratório, descritivo e documental do tipo transversal, com abordagem quantitativa, de base hospitalar, identificando a indução do trabalho de parto em um hospital de referência da cidade de Macapá. Quanto aos aspectos éticos, a pesquisa foi realizada obedecendo à Resolução n. 466/2012 do Conselho Nacional de Saúde, tendo sido submetida ao Comitê de Ética em Pesquisa da Universidade Federal do Amapá (Unifap) com CAAE: 97459118.3.0000.0003. Após aprovação, foi realizada a coleta de dados por meio de um questionário semiestruturado, que continha perguntas relacionadas ao parto. Ao fim da aplicação, foi explicado às participantes sobre o Termo de Consentimento Livre 
e Esclarecido (TCLE) e, para as participantes menores de 18 anos, o Termo de Assentimento Pós-Informado. Posteriormente foram assinados por elas em duas vias, sendo uma cópia entregue à participante. A população desta pesquisa se compôs de mulheres que tiveram parto normal, admitidas na enfermaria de pós-parto normal. Foram estabelecidos como critérios de inclusão: puérperas de parto normal, nulíparas ou multíparas, mulheres de todas as idades, feto vivo, ausência de complicações intrapartais. Critérios de exclusão: presença de complicações intrapartais, trabalho de parto prematuro e gestação inferior a 37 semanas. Resultados: Obteve-se um resultado de 300 participantes e notaram-se dados preocupantes em relação à evolução do trabalho de parto, visto que foi possível identificar que houve a prática de indução na maioria dos partos, alcançando um total de $58 \%$ ( $n=173)$ de partos com indução, se compararmos aos partos que evoluíram de maneira espontânea, $42 \%(n=127)$. O método mais utilizado para realizar a indução do parto foi expressivamente a Ocitocina, fármaco este que estimula as contrações uterinas, tendo sido utilizada em $47 \%(n=142)$ dos casos. Essa conduta por vezes pode ser prejudicial ao feto. Souza et al. (2010) afirmam que leva ao sofrimento fetal e consequentemente ao óbito, encontra-se frequentemente associada ao número excessivo de contrações uterinas, provocando a síndrome de hiperestimulação uterina, que pode ser provocada com a indução do parto através desses fármacos. Quanto ao profissional que acompanhou o trabalho de parto, o(a) enfermeiro(a) obstetra/obstetriz foi o profissional que mais acompanhou o trabalho de parto, $50 \%(n=150)$ dos casos, seguido pelo médico, com $22 \%(n=66), 19 \%$ ( $n=57)$ sem informação e $9 \%(n=27)$ foram identificados como outros. Considerações finais: Este trabalho é de grande impacto para a sociedade, pois o número de partos induzidos revelado aponta a realidade atual da maternidade pública do Estado. Apesar de tantas atualizações sobre humanização do parto pelo Ministério da Saúde, pelas políticas públicas voltadas para a saúde da mulher e da criança, capacitações realizadas para os profissionais atuantes, nota-se que esse índice não reduz. Fica a reflexão para os profissionais da saúde sobre a conduta realizada diariamente durante 0 trabalho de parto, tantos procedimentos realizados desnecessariamente, beneficiando o profissional, mas impedindo o parto fisiológico e causando óbitos maternos e infantis. Implicações para enfermagem: Para uma assistência mais humanizada durante o trabalho de parto, é preciso respeitar as particularidades da fisiologia de cada parturiente. Isso implica avaliar adequadamente a mulher e realizar intervenções como a indução do parto em casos em que esta seja totalmente indispensável para a sobrevivência maternofetal. O parto é um mecanismo fisiológico e toda mulher deve ser protagonista desse momento. Este trabalho mostra que ainda é mantido de forma exagerada o uso de fármacos para acelerar os partos, atingindo mais da metade dos partos realizados durante o período da pesquisa, o que aponta que os partos estão sendo conduzidos, em sua maioria, da mesma maneira, desconsiderando-se o tempo de dilatação de cada mulher. Tendo em vista que o profissional que mais acompanhou partos foi o enfermeiro, pode-se destacar essa categoria como agente fundamental para promoção de mudanças na humanização do parto e das práticas obstétricas, estimulando a redução de indução medicamentosa no trabalho de partos.

Descritores: Trabalho de parto induzido; Ocitocina; Enfermagem. 


\section{Referências}

1. Lara SRG, Oliveira RF. Utilização do método de Krause e prostaglandinas na indução do trabalho de parto em gestantes com feto viável. Revista Nursing, 2018, 22 (248):2514-2519.

2. Scapin SQ, Gregorio VRP, Collaco VS, Knobel R. Indução de parto em um hospital universitário: métodos e desfechos. Texto Contexto Enferm, 2018; 27(1):e0710016.

3. Gomes K, Sousa AMM, Mamede FV, Mamede MV. Indução do trabalho de parto em primíparas com gestação de baixo risco. Rev. Eletr. Enf. [Internet]. 2010;12(2):360-6.

4. Schincaglia CY, Santos GC, Ribeiro JA, Figueiredo RY, Menezes S, Maia JS, et al. As consequências do uso de ocitócitos durante o parto. São Paulo: Revista Recien. 2017; 7(19):75-82.

5. Nucci Marina, Nakano AR, Teixeira LA. Ocitocina sintética e a aceleração do parto: reflexões sobre a síntese e o início do uso da ocitocina em obstetrícia no Brasil. História, Ciências, Saúde - Manguinhos, Rio de Janeiro, 2018; 25(4):979-998. 


\section{CONTRIBUIÇÕES DE UM PROJETO DE EXTENSÃO PARA O EMPODERAMENTO DE GESTANTES ADOLESCENTES}

${ }^{1}$ Izabele Grazielle Da Silva Pojo; ${ }^{2}$ Viviane de Souza Bezerra; ${ }^{3}$ Victor Hugo Oliveira Brito; ${ }^{4}$ Amanda Almeida da Silva Carvalho; ${ }^{5}$ Katiciane Rufino da Silva; ${ }^{6}$ Nely Dayse Santos da Mata.

\footnotetext{
${ }_{1}^{1}$ Acadêmica do Curso de Bacharelado em enfermagem; Unifap. E-mail: izabele.pojo@gmail.com

${ }^{2}$ Acadêmica do Curso de Bacharelado em enfermagem; Unifap.

${ }^{3}$ Acadêmico do Curso de Bacharelado em enfermagem; Unifap.

${ }^{4}$ Acadêmica do Curso de Bacharelado em enfermagem; Unifap.

${ }^{5}$ Enfermeira. Residente em Saúde Coletiva;

${ }^{6}$ Enfermeira. Doutora em Ciências. Professora efetiva do Colegiado do Curso de Bacharelado em Enfermagem, Unifap.
}

\section{RESUMO}

Introdução: A gravidez na adolescência constitui-se como uma questão polêmica por ligar aspectos relacionados ao exercício da sexualidade e da vida reprodutiva às condições materiais de vida e às múltiplas relações de desigualdades que estão presentes na vida social do país'. É vista como uma questão social que requer atenção dobrada devido à complexidade dos fatores que a envolvem. Além disso, é considerada de alto risco devido suas complicações tanto no âmbito fisiológico quanto social. Frequentemente, os direitos desse público são desconhecidos por elas, violados, e até mesmo não efetivados, colocando-as em situação de vulnerabilidade ${ }^{2}$. De acordo com pesquisas, a maioria das mulheres brasileiras perde sua autonomia no momento do parto, ficando elas sujeitas a intervenções desnecessárias. Além disso, demonstram que variáveis como cor de pele, escolaridade, região demográfica, atendimento proveniente de setor público ou privado podem significar diferença no atendimento e, concomitante a isso, na satisfação das parturientes em relação à experiência de parto ${ }^{3}$. Diante disso, é necessário ampliar a visão acerca do parto para além dos aspectos biológicos da mulher e da criança, focando no reconhecimento dos seus direitos e a promoção do protagonismo feminino no processo de parto ${ }^{4}$. Objetivo: Relatar a experiência de acadêmicos de enfermagem membros do Grupo de Extensão de Apoio a Grávidas Adolescentes (Geaga) quanto à contribuição do grupo para o desenvolvimento do empoderamento das gestantes adolescentes. Método: Tratase de estudo caracterizado como relato de experiência, vivenciado durante o desenvolvimento de oficinas do grupo Geaga. O grupo faz o acompanhamento periódico de grávidas adolescentes, onde são propostas atividades com o objetivo de preparar a gestante para o momento do parto, por meio de exercícios de relaxamento, respiração e fortalecimento dos músculos da pelve, além disso, o grupo desenvolve ações de educação em saúde sobre temas pertinentes ao período gestacional. O processo de participação das grávidas nem sempre é automático, por esse motivo existe a necessidade de ações estratégicas para sua obtenção, como utilização de linguagem acessível, de material didático, de dinâmicas, entre outros ${ }^{2}$. Por esse motivo, os momentos de educação em saúde são desenvolvidos por meio de rodas de conversa, palestras, exposições de material audiovisual, dinâmicas, entre outros, a fim de facilitar o entendimento das grávidas quanto 
aos temas abordados, ampliando seus conhecimentos e sua autonomia. Após o parto, a puérpera retorna ao grupo para relatar a experiência vivenciada durante o processo de parturição, expondo tanto as contribuições que o grupo proporcionou para tal momento, quanto às dificuldades enfrentadas, podendo assim o grupo refletir e aprimorar a assistência oferecida. Resultados: A gestação é um momento ímpar na vida da mulher, caracterizado por grandes mudanças tanto no âmbito físico quanto no emocional e social, sendo a etapa da vida em que a gestante vai se sentir mais vulnerável e dependente. Quando a gestação acontece durante a adolescência, a necessidade de amparo, apoio, segurança e esclarecimento por parte dos profissionais de saúde é maior, por esse motivo o grupo Geaga, a fim de atender a essas necessidades, adotou um modelo de assistência integral com abordagens humanizadas, levando em consideração a especificidade da clientela atendida. Verificando a necessidade de empoderamento feminino, o grupo executou estratégias de discussão sobre temas que contemplem o momento gravídico e do parto. Os momentos de discussão proporcionaram às integrantes a oportunidade de discorrer sobre informações com mais evidências científicas para colaborar no processo de decisão livre e esclarecida durante a gravidez, favorecendo a promoção de sua autonomia. Por meio dos debates se constituiu um ambiente agradável e sem timidez, em que as dúvidas foram sanadas, possibilitando o desenvolvimento de conhecimentos a respeito de direitos sociais, trabalhistas, direitos no pré-natal, direitos no parto, como a escolha da posição para parir, do tipo de parto e do acompanhante, assim como direitos após o parto de permanecer ao lado do seu filho e ser acompanhada no puerpério, sobretudo ser respeitada e tratada de acordo com os princípios da equidade, considerando suas necessidades individuais e peculiaridades. A apropriação desses conhecimentos favoreceu a autonomia das gestantes adolescentes durante o processo de parturição, tornando-as mais empoderadas, o que foi percebido por meio das experiências relatadas. Apesar de a gravidez na adolescência ser um fator de vulnerabilidade, o grupo, por meio de uma ação humanizada, escuta qualificada e estratégias de atuação, possibilitou o protagonismo das gestantes adolescentes durante seus partos através de conhecimentos adquiridos no Geaga, reduzindo assim o impacto dos determinantes sociais de saúde aos quais estão submetidas. Considerações finais: Não obstante ainda existirem muitos casos em que a assistência obstétrica é caracterizada pela institucionalização do modelo biomédico e uso rotineiro de práticas intervencionistas desnecessárias, atualmente vem buscando práticas que incentivem a autonomia da mulher nesse momento singular de sua vida. Rodas de conversa, dinâmicas e palestras, simples atos podem ajudar a gestante a desenvolver conhecimentos que posteriormente irão contribuir para 0 fortalecimento do seu protagonismo e a tomada de decisões durante o momento do parto, garantindo seus direitos a um parto humanizado e atendimento ético. Ressalta-se que a presença do grupo de extensão, além de por meio de suas ações estimular o empoderamento feminino, faz com que essas mulheres se sintam mais seguras, pois se procurou trabalhar de modo humanizado suas necessidades, medos e fragilidades, buscando estratégias para orientar, reabilitar e fornecer subsídios para que as gestantes adolescentes adquiram corresponsabilidade no cuidado a sua saúde. Implicações para a enfermagem: reconhece-se a gravidez na adolescência como um aspecto complexo, que envolve Fatores de âmbitos social e psicológico, como seus medos que crescem exponencialmente, dúvidas, fatores familiares, sociais e culturais. Considera-se fundamental a interação entre 
enfermeiro e gestante, para que o profissional tome conhecimento das carências apresentadas por ela e forneça as orientações necessárias para a aquisição da autonomia. A gestante adolescente necessita de atenção especial, levando em consideração o seu grau de vulnerabilidade, portanto, o papel do enfermeiro é essencial, promovendo equidade durante sua assistência em todo o ciclo de parturição.

Descritores: Gravidez na Adolescência; Empoderamento; Saúde da Mulher.

\section{Referências}

1. Brasil. Ministério da saúde. Secretaria de Atenção à Saúde Departamento de Ações Programáticas e Estratégicas. Brasília, DF: Proteger e cuidar da saúde de adolescentes na atenção básica; 2017.

2. Silva ALS, Nascimento ER, Coelho EAC. Práticas de enfermeiras para promoção da dignificação, participação e autonomia de mulheres no parto normal. Esc Anna Nery Revista de Enfermagem. 2015; 19 (3): 424-431. DOI: 10.5935/1414-8145.20150056.

3. Leal MC, Gama SGN. Nascer no Brasil: Inquérito Nacional sobre Parto e Nascimento. Rio de Janeiro: Editora Fiocruz; 2012.

4. Reis TLR, Padoin SMM, Toebe TRP, Paula CC, Quadros JS. Autonomia feminina no processo de parto e nascimento: revisão integrativa da literatura. Rev Gaúcha Enferm. 2017; 38 (1). doi:http://dx.doi.org/10.1590/1983-1447.2017.01.64677. 


\title{
AVALIAÇÃO DO DESEMPENHO DO SISTEMA DE SAÚDE: DETERMINANTES DA SAÚDE NO AMAPÁ
}

\author{
${ }^{1}$ Jordânia Vieira Silva; ${ }^{2}$ Luzilena de Sousa Prudêncio; ${ }^{3}$ Nely Dayse Santos da Mata; \\ ${ }^{4}$ Rosana Oliveira do Nascimento; ${ }^{5}$ Camila Rodrigues Barbosa Nemer.
}

\begin{abstract}
${ }^{1}$ Acadêmica de Enfermagem da Universidade Federal do Amapá - Unifap, Macapá, Amapá, Brasil. E-mail: jordaniavieiragje@gmail.com;

${ }^{2}$ Enfermeira. Doutora em Saúde Coletiva. Professora do Colegiado do Curso de Bacharelado em Enfermagem da Unifap;

3 Enfermeira. Doutora em Ciências. Professora do Colegiado do Curso de Bacharelado em Enfermagem da Unifap;

${ }^{4}$ Enfermeira. Mestre em Saúde Coletiva. Professora do Colegiado do Curso de Bacharelado em Enfermagem da Unifap;

${ }^{5}$ Enfermeira. Mestre em Enfermagem. Doutoranda em Saúde Pública pela Escola Nacional de Saúde Pública (ENSP)/Fundação Oswaldo Cruz (Fiocruz). Professora do Colegiado do Curso de Bacharelado em Enfermagem da Unifap.
\end{abstract}

\section{RESUMO}

Introdução: Os determinantes de saúde abrangem fatores combinados dos meios físicos e sociais sobre os indivíduos e as comunidades. A saúde de ambos é influenciada por fatores de diferentes ordens: o lugar onde vivem, as condições ambientais, os fatores genéticos, a renda dos indivíduos, o nível educacional e a rede de relações sociais. ${ }^{1} \mathrm{O}$ Relatório Lalonde (1974) é um dos documentos de grande contribuição para a discussão sobre os determinantes da saúde. Pauta-se no entendimento de que as categorias estilo de vida, biologia humana e ambiente estabelecem relações específicas que contribuem para o adoecimento. ${ }^{1}$ Observa-se o avanço no estudo das relações entre a maneira como se organiza e se desenvolve uma determinada sociedade e a situação de saúde de sua população, particularmente marcante no estudo das iniquidades em saúde (desigualdades de saúde entre grupos populacionais, sistemáticas, relevantes, evitáveis, injustas e desnecessárias). Podem-se identificar três gerações de estudos sobre as iniquidades em saúde. A primeira geração se dedicou a descrever as relações entre pobreza e saúde; a segunda, a descrever os gradientes de saúde de acordo com vários critérios de estratificação socioeconômica; e a terceira e atual geração está dedicada principalmente aos estudos dos mecanismos de produção das iniquidades. ${ }^{2}$ Estudos apontam que regiões mais pobres possuem piores indicadores de saúde. As áreas com maiores vulnerabilidades sociais caracterizadas pela baixa renda, pouca presença do Estado e pequena coesão social são responsáveis pela manutenção de epidemias em centros urbanos. Há uma superposição das precariedades, e estas não se concretizam isoladamente, os piores índices se concentram nas mesmas áreas, o que significa que uma mesma população está precarizada no conjunto das condições sociais de existência, ou ainda, que as situações de exclusão são decorrentes da superposição de carências de diferentes naturezas. ${ }^{3}$ Objetivo: Avaliar a dimensão de determinantes da saúde no Estado do Amapá. Método: A análise ocorreu por meio da matriz conceitual do Projeto de Avaliação de Desempenho de Sistemas de Saúde (Proadess). O Proadess tem por objetivo monitorar e avaliar o 
desempenho do Sistema Único de Saúde (SUS), ${ }^{2}$ a fim de estabelecer dados e estatísticas que atuam como facilitadores de estudo para políticas, programas e ações de saúde, instituições que prezam pelo ensino e pesquisa. Vale ressaltar que a análise do Sistema de Saúde é feita dentro de um contexto, ou seja, o Proadess analisa os fatores que possam influenciar, de forma direta ou indireta, a saúde da coletividade, tais como fatores sociais, políticos, econômicos, históricos e a sua conformação atual, seus objetivos e suas prioridades. Dentro desse cenário, devem ser identificados os determinantes associados aos problemas de saúde considerados prioritários, evitáveis e passíveis de intervenção, cuja análise deve ser feita considerando o seu impacto em diferentes grupos sociais. ${ }^{1}$ Os indicadores foram construídos a partir de base de dados dos sistemas nacionais de informação, dos Censos Demográficos e de inquéritos domiciliares. ${ }^{1} \mathrm{~A}$ maioria dos dados são referentes à análise de 2013. Resultados: A população no Estado do Amapá segundo o Censo 2010 era de 669.526 pessoas, com $11 \%$ da população residente em zona rural. ${ }^{4}$ A dimensão determinante da saúde é dividida nas seguintes subdimensões: fatores físicos, químicos e biológicos do ambiente que atuam como determinantes de agravos à saúde; características demográficas e socioeconômicas, contextuais e individuais, relacionadas à produção de agravos à saúde e; atitudes, práticas, crenças, comportamentos e fatores biológicos individuais que condicionam, predispõem ou influenciam a ocorrência de agravos à saúde. Quanto aos fatores ambientais: o percentual da população residente em área rural com abastecimento adequado de água no Amapá é de 30,1\%, já, em área urbana, esse percentual é de $56,9 \% ; 96,1 \%$ da população em área urbana é atendida por serviço regular de coleta de lixo domiciliar, em contraste com apenas $16,6 \%$ da população rural. 0 percentual da população residente em área rural com disposição adequada do esgoto sanitário é de $12,4 \%$ e, em área urbana, é de 36,1\%. Com relação aos fatores socioeconômicos e demográficos: o percentual de analfabetismo entre pessoas de 15 anos ou mais é $6,0 \%$; a densidade demográfica é de 5,1 ; a taxa de desemprego é de $12,4 \%$; a esperança de vida ao nascer é 72,2 anos; o percentual da população ocupada com carteira assinada é de 67,0\%; o Índice de Desenvolvimento Humano é 0,708 (2010); Índice de Gini - grau de desigualdade existente na distribuição de indivíduos segundo a renda domiciliar per capita é de 0,522; a média de anos de escolaridade da população de 25 anos ou mais é de 8,7 anos; o percentual da população residente com renda domiciliar mensal per capita de até meio salário mínimo é de 45,7\% (2010); razão de dependência 57,69; razão entre a renda dos $10 \%$ mais ricos e a dos $40 \%$ mais pobres é de 14,6 ; renda média per capita (em $R \$$ ) é de 974.71; percentual da população de 18 anos ou mais que fuma é de $13,3 \%$ e com excesso de peso é de 54,9\%; percentual da população de 18 anos ou mais fisicamente inativa é de 16,8\% e consumidora de álcool de forma abusiva é de $21,1 \%$. Considerações finais: Evidencia-se a discrepância dos fatores ambientais entre a área urbana e área rural no Estado do Amapá, a área urbana apresenta melhores percentuais. Entretanto, o percentual de disposição adequada do esgoto sanitário é baixo nas duas áreas. O Estado obteve, no ano de 2013, o maior percentual de desemprego do país, a proporção da população considerada em situação de pobreza é elevada e o percentual de pessoas de 18 anos ou mais com obesidade também. As relações entre esses indivíduos com o território influenciam as suas condições de saúde. Implicações para a enfermagem: Tal análise permite também identificar onde e como devem ser feitas as intervenções, com o 
objetivo de redução das iniquidades de saúde, identificando os pontos mais sensíveis onde tais intervenções podem provocar maior impacto.

Descritores: Iniquidade Social; Determinantes Sociais da Saúde; Saúde ambiental.

\section{Referências}

1. Avaliação do Desempenho do Sistema de Saúde [homepage na internet]. Antecedentes. $\begin{array}{llllll}\text { [acesso em } 20 & \text { abr 2019]. }\end{array}$ https://www.proadess. icict.fiocruz.br/index.php?pag=fic\&cod=T01\&tab=1.

2. Albuquerque Ceres, Martins Mônica. Indicadores de desempenho no Sistema Único de Saúde: uma avaliação dos avanços e lacunas. Saúde debate [Internet]. 2017 Mar [cited 2019 Apr 30]; 41(spe):118-137. Available from: http://www.scielo.br/scielo.php?script=sci_arttext\&pid=S0103$11042017000500118 \& \operatorname{lng}=e n$.

3. Barcellos CC. Os indicadores da pobreza e a pobreza dos indicadores: uma abordagem geográfica das desigualdades sociais em saúde. In: Christovam Barcellos, ed. A geografia e o contexto dos problemas de saúde. Rio de Janeiro: Abrasco; 2008, p. 10739.

4. Instituto Brasileiro de Geografia e Estatística (IBGE). Censo Brasileiro de 2010. Rio de Janeiro: IBGE, 2010. 


\title{
PROMOÇÃO DA SAÚDE PARA O PÉ DIABÉTICO: CUIDADO CLÍNICO-SENSÍVEL ORIENTADO PELO PRINCÍPIO DA EQUIDADE
}

\author{
${ }^{1}$ Luan Andrade de Souza; 2 Jéssica Gomes da Silva; ${ }^{3}$ Edicilene Marinho Ferreira; \\ ${ }^{4}$ Vanessa da Silva Oliveira; ${ }^{5}$ Jocastra Sousa Moura; ${ }^{6}$ Francineide Pereira da Silva Pena. \\ ${ }^{1}$ Acadêmico do Curso de Bacharelado em Enfermagem; Fama. E-mail: luan22andrade@gmail.com; \\ 2 Enfermeira. Residente de enfermagem; Unifap; \\ ${ }^{3}$ Acadêmica do Curso de Bacharelado em Enfermagem; Estácio Macapá; \\ ${ }^{4}$ Enfermeira. Mestranda em ciências da saúde; Unifap. Professora efetiva do colegiado do Curso \\ de Bacharelado em Enfermagem; \\ ${ }^{5}$ Enfermeira. Pós-graduanda de enfermagem; Fama; \\ ${ }^{6}$ Enfermeira. Doutora em Ciências da Saúde; Unifap. Professora efetiva colegiado do Curso de \\ Bacharelado em Enfermagem.
}

\section{RESUMO}

Introdução: O princípio da equidade está intimamente relacionado à capacidade dos sistemas de saúde se organizarem de modo a responder adequadamente às necessidades dos cidadãos, tratando-os conforme sua condição de saúde ${ }^{1}$. Assim também deve se dar a assistência proporcionada a pessoas com Diabetes Mellitus, por meio do cuidado igualitário e diferenciado a uma demanda que exige um olhar clínico-sensível para o igual-diferente, isto é, o diagnóstico clínico de DM, entretanto, vivido de forma diferente por apresentar sinais, sintomas, complicações e necessidades de cuidados que diferem de pessoa para pessoa. Se tratando desta singularidade de diferenciação, chama atenção ao controle inadequado das taxas glicêmicas, que pode desencadear complicações agudas e/ou crônicas. Entre as crônicas, com frequência de ocorrência elevada, está o denominado pé diabético, cuja definição é infecção, ulceração e/ou destruição de tecidos moles associadas a alterações neurológicas e graus variados de doença arterial periférica (DAP) nos membros inferiores ${ }^{2}$. Portanto, o profissional de saúde precisa avaliar a pessoa com pé diabético de forma diferenciada, devido tal complicação, que a torna diferente daquelas que apresentam apenas o diabetes mellitus. Comportamentos e atitudes adequadas para 0 autocuidado podem reduzir o risco de feridas, infecções e amputações em pessoas com pé comprometido. Cuidados profissionais prévios contribuem para prevenção de feridas e lesões nos pés, e os exames de rotina dos pés são as estratégias mais potentes para esta prevenção, os quais são realizados por profissional habilitado para identificar as complicações do pé diabético. Um aumento de presença de feridas nos pés e amputações tem sido identificado em pessoas com DM que não adotam essas práticas ${ }^{3}$. Nesse contexto, a realização deste estudo se justifica por apresentar estratégias planejadas e negociadas que visam atender portadores de pé diabético, conforme a sua necessidade, almejando prestar uma assistência qualificada, diferenciada e resolutiva. Objetivo: Descrever o relato de caso de acordo com o seguimento e a realização de curativo de pé diabético na tentativa de cumprir com o princípio da equidade. Método: Trata-se de um estudo de caso, vivenciado durante a realização de curativo de pé diabético, no período de março a abril de 2019, em uma Unidade Básica de Saúde (UBS), no município de Macapá. Resultados: Sexo masculino, 64 anos, com diabetes há aproximadamente 20 anos (SIC), presença de 
ferida na região calcânea do MIE, há aproximadamente dez meses (SIC). Após o acolhimento, percebeu-se que o paciente não tinha o conhecimento adequado quanto à sua patologia, o que está relacionado de forma direta com o processo de reparação e manutenção da saúde, o mesmo não realiza atividade física e não segue um plano alimentar saudável. Em 03.04.2019, realizada a 1a avaliação, com acolhimento e educação em saúde. No momento da educação em saúde, foram explicados e orientados os cuidados com os pés, com a ferida e o autocuidado necessário para a evolução da ferida para cicatrização. Também foram negociadas algumas modalidades de cuidado, sobre: limpeza dos pés, uso do calçado adequado, diminuição da deambulação para melhora da área ferida, alimentação com maior quantidade de legumes, verduras e frutas, menor quantidade de carboidratos e gordura, aumento de ingesta hídrica e controle glicêmico por glicemia capilar pelo menos duas vezes na semana. Importante ressaltar que as modalidades negociadas foram escritas e entregues ao cliente com a recomendação de como deveria ser realizada. Na avaliação da ferida, constataram-se bordas irregulares, com inversão das mesmas, presença de tecido de granulação, sem edema, sem odor, presença de exsudato de cor clara em moderada quantidade, ausência de sinais flogísticos, sensibilidade e dor. Para mensura, foi utilizada a régua própria para medir feridas, as quais foram: maior eixo transverso: $8,5 \mathrm{~cm}$, maior eixo longitudinal: $2,5 \mathrm{~cm}$, extensão total: $21,25 \mathrm{~cm}^{2}$, a profundidade do leito da ferida: $1,3 \mathrm{~cm}$. Após mensuração, foi realizado curativo com limpeza em jato de soro fisiológico 0,9\%, cobertura primária oclusiva, com gaze seca, cobertura secundária atadura. Dia 24.04.2019, 2ª avaliação, na mensuração, apresentava medidas: maior eixo transverso: $7,5 \mathrm{~cm}$, maior eixo longitudinal: $2,0 \mathrm{~cm}$, extensão total: 15 $\mathrm{cm}^{2}$ e a profundidade do leito da ferida: $1 \mathrm{~cm}$. A evolução em duas avaliações demonstra a progressão positiva da regeneração tecidual com a diminuição de área da ferida, de exsudato e a melhora no tecido de granulação, fomentando a potencialidade dos cuidados de enfermagem para pessoa com DM acometida pela complicação pé diabético. Essa melhora se deu devido à assistência qualificada e à referenciação do paciente para a equipe multiprofissional, como a nutrição. A prática de cuidados às pessoas com feridas é uma especialidade na Enfermagem reconhecida pela Sociedade Brasileira de Enfermagem Dermatológica. Nesse sentido, compete aos enfermeiros ampliar e aperfeiçoar os conhecimentos relacionados às especificidades dessa área, a fim de proporcionar assistência com resolubilidade e qualidade ${ }^{4}$. Considerações finais: Cabe à enfermagem o acolhimento, a educação em saúde, o seguimento, a avaliação da ferida no pé diabético, que emerge da demanda populacional atingida pelo DM. A responsabilidade do enfermeiro requer conhecimento específico da área e manejo de ferramentas que subsidiem a potencialidade da assistência de enfermagem à pessoa com pé diabético. Adotar a mensuração da ferida configura ferramenta de suporte para melhor avaliar a evolução do processo de cicatrização da ferida, principalmente de pé diabético, e possibilita obter seguimento fidedigno da evolução positiva ou negativa relacionada à cicatrização. Trata-se de uma estratégia diferenciada, condizente com a necessidade de cada cliente com ferida de pé diabético. Implicações para enfermagem: As estratégias utilizadas no acompanhamento/evolução das feridas são primordiais para que a assistência de enfermagem seja qualificada e humanitária, visando às particularidades dos pacientes, 0 acompanhamento fidedigno em conjunto com as necessidades de saúde de cada indivíduo se torna fundamental para que ocorra um atendimento eficaz. O enfermeiro como 
profissional responsável pela realização e acompanhamento de curativos, precisa, mediante o princípio da equidade, prestar uma assistência diferenciada que venha a suprir as demandas do paciente, assim objetivando resolubilidade.

Descritores: Pé diabético; Cuidados de enfermagem; Diabetes mellitus, Promoção da Saúde.

\section{Referências}

1. Barros FPC, Lopes JS, Mendonça AVM, Sousa MF. Acesso e equidade nos serviços de saúde: uma revisão estruturada. Rev Saúde e Debate. 2016; 40, (110): 264-271. Disponível em: http://www.scielo.br/pdf/sdeb/v40n110/0103-1104-sdeb-40-1100264.pdf Acesso em 29 abr. 2019.

2. Diretrizes da Sociedade Brasileira de Diabetes-SBD (2017-2018). Organização: Oliveira JEP, Junior RMM, Vencio S; A.C. Farmacêutica. São Paulo; 2017.

3. Ramirez-Perdomoa. C., Perdomo-Romero A, Rodríguez-Vélez M Conocimientos y prácticas para la prevención de pie diabético. Rev Gaúcha Enferm. [Internet] 2019, 40:e20180161. Disponível em: http://www.scielo.br/pdf/rgenf/v40/1983-1447-rgenf-40e20180161.pdf. Acesso em 29 abr. 2019.

4. Andrade LL, Carvalho GCP, Valentim FAAA, Siqueira WA, Melo FMAB, Costa MML. Caracterização e tratamento de úlceras do pé diabético em um ambulatório. Rev Fun Care Online. [Internet] 2019 jan/mar; 11(1):124-128. DOI: http://dx.doi.org/10.9789/2175-5361.2019.v11i1.124-128 Acesso em: 29 de abr.2019. 


\title{
A IMPORTÂNCIA DO ACOMPANHANTE NO CUIDADO PRÉ-NATAL DE ADOLESCENTES PRIMIGESTAS: RELATO DE EXPERIÊNCIA
}

\author{
${ }^{1}$ Luana Jandira Weber Silva; ${ }^{2}$ Victor Hugo Oliveira Brito; ${ }^{3}$ Hiago Rafael Lima da Silva; \\ ${ }^{4}$ Nely Dayse Santos da Mata; ${ }^{5}$ Tatiana do Socorro dos Santos Calandrini.
}

\begin{abstract}
${ }^{1}$ Acadêmica do Curso de Bacharelado em Enfermagem; Universidade Federal do Amapá - Unifap; E-mail: weber.luana19@gmail.com;

${ }^{2}$ Acadêmico do Curso de Bacharelado em Enfermagem; Unifap;

${ }^{3}$ Acadêmico do Curso de Bacharelado em Enfermagem; Unifap;

${ }^{4}$ Enfermeira. Doutora em Ciências pela Universidade de São Paulo - USP; Unifap. Professora efetiva Colegiado do Curso de Bacharelado em Enfermagem;

5 Enfermeira. Mestre em Ciências da Saúde pela Universidade Federal do Amapá- Unifap. Professora efetiva Colegiado do Curso de Bacharelado em Enfermagem.
\end{abstract}

\section{RESUMO}

Introdução: A adolescência consiste em um longo período de transição entre a infância e a idade adulta, no qual ocorre uma série de mudanças, que vão desde os aspectos psicológicos aos hormonais, corporais e sexuais, como a descoberta da sexualidade. $O$ início cada vez mais precoce da atividade sexual comumente acompanha-se de uma gravidez. A gestação representa para a mulher, independentemente de sua idade, importantes mudanças em aspectos físicos, psicológico, emocionais e sociais. Para adolescentes, essas transformações assumem proporções mais significativas e impactantes, pois frequentemente, não há planejamento gestacional, as interações familiares tornam-se instáveis, há baixas condições socioeconômicas, além da interferência dos aspectos biopsicossociais característicos da adolescência, como a falta de estrutura emocional pela construção da identidade pessoal, que pode levá-las à autonegligência frente às responsabilidades envolvidas na manutenção de uma gravidez saudável ${ }^{1,2}$. Sendo assim, evidencia-se a necessidade de voltar a atenção a esse público de maneira particular pela equipe de saúde, buscando envolver os diversos aspectos dessa gestante, especialmente o âmbito familiar, incluindo e ressaltando a importância, e o direito, da presença de acompanhante durante todo o ciclo gravídico-puerperal, como a Lei ํㅜ 11.108, de 7 de abril de 2005 prevê ${ }^{3}$. A relevância do acompanhante para a grávida adolescente, sustenta-se a partir de: aspectos legais, devido a sua menoridade; o auxílio na responsabilidade para o seguimento do pré-natal; a assimilação das orientações; formação de vínculo afetivo mãe-criança e acompanhante; além de reforçar os fatores emocionais e psicológicos da adolescente frente à nova fase. Objetivo: Relatar a experiência de acadêmicos do curso de Bacharelado em Enfermagem da Universidade Federal do Amapá (Unifap), integrantes do Grupo de Extensão de Apoio Grávidas Adolescentes (Geaga), a respeito de orientações acerca da importância do acompanhante na assistência ao prénatal e suas implicações no trabalho de parto de adolescentes primigestas. Método: Estudo descritivo, de caráter qualitativo, caracterizado como relato de experiência, a partir de um grupo de extensão, a respeito de atividades educativas relacionadas à participação ativa do acompanhante no cuidado pré-natal e assistência ao trabalho de parto humanizado de adolescentes primigestas. $O$ Geaga foi criado com a finalidade de expandir a assistência 
prestada a adolescentes primigestas que realizam suas consultas em uma Unidade Básica de Saúde (UBS) de Macapá. As oficinas do Geaga ocorrem quinzenalmente, aos sábados, e sua equipe multidisciplinar é composta por acadêmicos do Curso de Bacharelado em Enfermagem, enfermeiros obstetras, educadora física e médicos. Suas atividades são voltadas para a educação para o parto, sendo realizadas através de exercícios respiratórios e exercícios para o fortalecimento da musculatura do assoalho pélvico, a fim de reduzir os riscos de lacerações perineais na fase expulsiva do trabalho de parto. Além disso, são realizadas rodas de conversa, dinâmicas e palestras para promover educação em saúde relacionada a temas específicos do ciclo gravídico-puerperal. Os temas são escolhidos a partir do que é preconizado pelo Ministério da Saúde, e das necessidades expostas pelas grávidas no grupo, referindo-se a modificações gravídicas, importância do cuidado prénatal, lei do acompanhante, entre outros. Resultados: A partir da vivência da equipe do Geaga com as participantes do grupo, evidenciou-se a importância da presença dos acompanhantes durante o pré-natal das adolescentes primigestas, uma vez que são capazes de ajudá-las a processar o momento tão singular no qual estão inseridas e grande parte das informações. O apoio emocional vindo do parceiro, da família ou de outras pessoas com as quais essas adolescentes possuem laços afetivos, de modo geral, é de extrema importância para a manutenção de sua saúde no contexto biopsicossocial. Pode repercutir de forma benéfica em uma evolução gestacional mais tranquila, sem o estresse excessivo e prejudicial ao binômio mãe-filho, sobretudo quando se refere à primeira gestação. Partindo dessa premissa, o vínculo familiar torna-se mais forte e isso reforça a compaixão, a gentileza, a beneficência e o altruísmo que deve haver nas interações sociais, especialmente no contexto familiar. Ademais, o acompanhante acaba tornando-se um aliado da equipe de saúde, no que se refere à observação dos hábitos alimentares, de higiene e de cuidado da grávida durante a gestação. Além disso, acaba por assimilar as orientações transmitidas no decorrer das consultas e oficinas do Geaga, incentivando essas adolescentes nos momentos em que se sintam desanimadas ou indispostas com relação ao seu pré-natal. No processo parturitivo propriamente dito, o acompanhante tem papel essencial durante o mecanismo de parto, incentivando a gestante a pôr em prática os conhecimentos adquiridos ao longo das consultas de pré-natal e oficinais do Geaga, possibilitando, dessa forma, o trabalho de parto mais natural e prazeroso. Considerações finais: $O$ Geaga acompanha adolescentes primigestas, que fazem parte de um público socialmente vulnerável, e disponibiliza a elas um cuidado equitativo, com acompanhamento desde a chegada ao grupo especialmente pensado e elaborado visando atender suas particularidades. Dessa maneira, há necessidade, não apenas de oferecer acolhimento, escuta terapêutica e acompanhamento diferenciados para essas adolescentes, mas também de perceber e explorar as potencialidades existentes em seus contextos biológico, social, psicológico e familiar, de modo que sejam vistas de maneira cada vez mais holística. Diante disso, inclui-se também a participação ativa do acompanhante no pré-natal e nas oficinas do grupo, uma vez que este recebe as orientações, juntamente com a adolescente, em todas as etapas, e se torna, dessa forma, um importante alicerce no auxílio à mulher $\mathrm{e}$ à equipe de saúde durante todo o ciclo gravídico-puerperal. Implicações para a enfermagem: $O$ empoderamento do acompanhante através do conhecimento mostra-se um eficiente método capaz de auxiliar a equipe de saúde na melhora da qualidade do prénatal e trabalho de parto de primigestas adolescentes. À vista disso, ressalta-se a 
importância da educação em saúde de acordo com as peculiaridades de cada público e, sendo a Enfermagem a principal propagadora desses conhecimentos por se fazer presente e atuante constantemente junto à população, sugere-se a expansão da educação em saúde, de forma a ampliar o acesso à informação para que a comunidade possa exercer o verdadeiro protagonismo em saúde.

Descritores: Gravidez na adolescência; Cuidado pré-natal; Parto humanizado.

\section{Referências}

1. Luz NF; Assis TR; Rezende FR. Puérperas adolescentes: percepções relacionadas ao pré-natal e ao parto. ABCSHealth Sciences [Internet]. 2015. DOI: https://doi.org/10.7322/abcshs.v40i2.735.

2. Nunes, JT. Qualidade e equidade da assistência pré-natal e pós-parto entre adolescentes [Dissertação]. Teresina: Universidade Federal do Piauí.2017.

3. Brasil. Lei n: 11.108, de 7 de abril de 2005. Dispõe sobre o direito das parturientes à presença de acompanhante durante o trabalho de parto, parto e pós-parto imediato, no âmbito do Sistema Único de Saúde. Diário Oficial da União, Brasília, 07 de abr. 2005. 


\title{
EXERCÍCIO FÍSICO E DIABETES MELLITUS: RELATO DE EXPERIÊNCIA DE RESIDENTES DE EDUCAÇÃO FÍSICA
}

\author{
${ }^{1}$ Luane Lorrana de Souza Barbosa; ${ }^{1}$ Samily Batista da Silva; ${ }^{1}$ Silvane Silva Corrêa; \\ 2 Francineide Pereira da Silva Pena.
}

${ }^{1}$ Residentes de Educação Física da Residência Multiprofissional em Saúde Coletiva, área de concentração: Saúde do Adulto e do Idoso; Universidade Federal do Amapá (Unifap). E-mail: lorranaluane22@gmail.com;

2 Supervisora e Professora da Residência Multiprofissional em Saúde Coletiva, área de concentração: Saúde do Adulto e do Idoso; Unifap.

\section{RESUMO}

Introdução: Diabetes Mellitus (DM) é uma desordem metabólica de etiologia múltipla decorrente do defeito na secreção e/ou na ação biológica da insulina, ou em ambas, caracterizada pela hiperglicemia crônica ${ }^{1}$. Para o controle da desordem metabólica, a atividade física, o plano alimentar e o lazer compõem as modalidades de tratamento não medicamentoso. A diminuição do sedentarismo e a avaliação nutricional se tornam modalidades singulares tanto na melhora do controle glicêmico quanto na melhora de certas comorbidades, como excesso de peso, dislipidemia, além da redução ou prevenção de algumas doenças como osteoporose e os desvios de postura. Além desses benefícios, a prática regular de exercícios físicos auxilia na manutenção da massa magra e previne e/ou trata a sarcopenia em idosos ${ }^{2}$. Para pessoas com DM, a prática de exercícios físicos se torna indispensável, sendo que, no planejamento, devem-se incluir: os aeróbios e os de intensidade moderada com frequência superior a três vezes por semana, além dos exercícios de resistência e flexibilidade ${ }^{2}$. O olhar sensível do educador físico à necessidade do tipo de exercício a ser praticado pela pessoa com DM, cuja finalidade é o controle metabólico e a promoção da saúde, incluem o conceito de equidade, "como julgamento e intervenção situacional, ou seja, conforme cada caso, pressupõe a inexistência de estrutura, normas ou conhecimentos perfeitos $[\ldots]^{3}$. A busca em atender, com olhar para as diferentes necessidade apresentadas por cada um, remete a equidade "como prática indispensável à cidadania plena, capaz de garantir o gozo de situação de igual bem-estar para todos os cidadãos"3. Objetivo: Relatar a experiência vivenciada por residentes de Educação Física no programa de Promoção da Saúde para Pessoas com Diabetes Mellitus. Método: Trata-se de relato de experiência das vivências das residentes de Educação Física da residência multiprofissional em saúde coletiva na área de concentração de atenção à saúde do adulto e do idoso da Universidade Federal do Amapá durante dois semestres, no referido programa. A atuação profissional é realizada na Associação dos Magistrados do Amapá, localizada no bairro Universidade, no turno da manhã, das $7 \mathrm{~h} 30$ às $11 \mathrm{~h} 30$, às terças, quintas e sextas-feiras. Atualmente o programa atende 85 pessoas com DM. Na dinâmica da atividade, optou-se por um posicionamento intervencionista, de modo a oportunizar um processo de troca de saberes e construção conjunta das ações profissionais com as ações dos participantes, considerando os profissionais envolvidos como propagadores de práticas e conhecimentos. Resultados: Nos três dias de atendimento, realiza-se aferição de pressão arterial e glicemia capilar. Na primeira quinta-feira de cada 
mês residentes de enfermagem realizam a bioimpedância e as residentes de educação física a perimetria e dobras cutâneas para acompanhar 0 desenvolvimento e 0 comprometimento de cada pessoa. Nos três primeiros meses, observou-se que as pessoas não reconheciam a importância da prática regular de exercícios como modalidade de tratamento não medicamentoso, havendo evasão em massa dos mesmos durante a prática da atividade. Dos 85 pacientes atendidos, certa vez, compareceu apenas um para aula de educação física. A partir desse fato, sentiu-se a necessidade de intervenção que resultasse no reconhecimento dos benefícios da prática regular dos exercícios. Durante dois meses, ocorreram diferentes intervenções para ampliar a adesão à prática de exercícios, fundamentadas na orientação da Sociedade Brasileira de Diabetes (SBD). Às terças-feiras, são praticados exercícios aquáticos (hidroginástica e natação). Às quintas-feiras, realizamse exercícios de alongamento e exercícios na cadeira. Às sextas-feiras, treinamento de força, pilates, aula de ritmos e caminhada, com aulas alternadas divididas em dois grupos de acordo com as especificidades de cada participante. No início do ano (2019), o planejamento da Educação em Saúde foi por área de conhecimento, fomentando a importância de cada profissional e sua contribuição para o alcance da meta, que é o controle metabólico do DM. Apesar de a maioria dos participantes frequentarem o programa desde sua implementação, somente com as intervenções conheceram a importância dos exercícios físicos planejados conforme a necessidade e limites de cada um. Isso foi possível porque o educador físico orientou e forneceu conhecimentos de forma clara e objetiva, sobre DM e a prática de exercícios para a manutenção do controle glicêmico. Entretanto, ainda parcela significativa relutante em praticar exercícios e parte destes só comparece às quintas-feiras para passar pelo acolhimento. As justificativas para falta nos outros dias variam, porém, a mais citada é o horário; informando trabalhar somente pela manhã e que dedicam um dia da semana para saber como está a pressão arterial e a glicemia, alegando também que, se as aulas de educação física fossem à tarde, participariam. Outra questão pertinente diz respeito a importância do uso de vestimentas e calçados adequados para a prática de exercício, de que os participantes não tinham conhecimento, principalmente 0 calçado visto que a pessoa com DM apresenta especificidades para o pé, que requerem atenção, pois, caso ocorram lesões e não sejam tratadas, estas podem causar amputação do membro ${ }^{4}$. Considerações finais: Constatou-se que, após as intervenções por meio de roda de conversas sobre a importância do exercício físico, a adesão ao exercício foi ampliada, com vestes e calçados apropriados. Houve melhora significativa nos indicadores de saúde como: média glicêmica entre 99 a 150mg/dL, pressão arterial entre: 120/90 e 140/90mmHg, diminuição das queixas de dor nos membros inferiores, lombalgia, melhora do sono, ganho de massa muscular, diminuição do peso, prega cutânea tendendo à normalidade. A experiência estimulou a busca de conhecimento sobre DM, adequar os exercícios para cada necessidade apresentada pelos participantes, isso reforçou a importância do educador físico na equipe multiprofissional, visto que cada profissional exerce seu papel, mas o foco em conjunto solidifica a importância das ações pautadas na coletividade, objetivando promover qualidade de vida. Implicações para a saúde: A experiência vivenciada por meio de ações como essas contribui como elemento de reflexão e atenção à saúde, não só dos pacientes, mas também implica de forma positiva a atuação do profissional no atendimento dessas pessoas e, por conseguinte, na melhoria do cuidado prestado e promoção da qualidade de vida em pessoas com DM. 
Descritores: Educação Física; Exercício Físico; Diabetes Mellitus.

\section{Referências}

1. Ferreira LT; Saviolli IH; Valenti VE; Abreu LC. Diabetes melito: hiperglicemia crônica e suas complicações. Arquivos Brasileiros de Ciências da Saúde. Disponível em: $<$ http://files.bvs.br/upload/S/1983-2451/2011/v36n3/a2664.pdf>. Acesso em: 26 abr. 2019.

2. Diretrizes da Sociedade Brasileira de Diabetes. SBD 2017-2018. Disponível em:<https://edisciplinas.usp.br/pluginfile.php/4232401/mod_resource/ content/2/diretrizes-sbd-2017-2018\%281\%29.pdf>. Acesso em: 26 abr. 2019.

3. Barros FPC; Sousa MF. Equidade: seus conceitos, significações e implicações para o SUS. Saúde. Disponível em: <http://www.scielo.br/pdf/sausoc/v25n1/1984-0470sausoc-25-01-00009.pdf>. Acesso em: 29/04/2019.

4. Cubas MR; Santos OMD; Retzlaff EMA; Telma HLC; Andrade IPSD; Moser ADL; Erzinger AR. Pé diabético: orientações e conhecimento sobre cuidados preventivos. Disponível em: <http://www.scielo.br/pdf/fm/v26n3/a19v26n3.pdf>. Acesso em: 29 abr. 2019. 


\title{
RELATO DE EXPERIÊNCIA SOBRE A INSERÇÃO DO PRÉ-NATAL DO PARCEIRO NA UNIDADE DE SAÚDE
}

\author{
${ }^{1}$ Luíny de Souza Lobato; ${ }^{2}$ Ana Karolina Oliveira Moura; ${ }^{3}$ Ana Carolina Farias Vieira; \\ ${ }^{4}$ Rosa Natália Muniz Carneiro Mota; ${ }^{5}$ Vanessa da Silva Oliveira.
}

${ }^{1}$ Acadêmica do Curso de Bacharelado em Enfermagem; Universidade Federal do Amapá; Unifap; E-mail: luinylobato@gmail.com;

${ }^{2}$ Acadêmica do Curso de Bacharelado em Enfermagem; Unifap;

${ }^{3}$ Acadêmica do Curso de Bacharelado em Enfermagem; Unifap;

${ }^{4}$ Enfermeira. Especialista em Estratégia Saúde da Família; Unifap. Professora Substituta Colegiado do Curso de Bacharelado em Enfermagem;

${ }^{5}$ Enfermeira. Especialista em Enfermagem Cirúrgica. Mestranda em Ciências da Saúde Unifap.

\section{RESUMO}

Introdução: Em Atenção Primária à Saúde (APS), o desafio enfrentado nos últimos anos é a captação e inserção do homem para usufruir dos serviços ofertados, já que o acesso ao Sistema Único de Saúde (SUS) é um direito de todos. A Política Nacional de Atenção Integral à Saúde do Homem (PNAISH) tem promovido ações que contribuam para melhora da qualidade de vida masculina. A PNAISH visa, ainda, sensibilizar gestores e profissionais, incentivando a participação do homem em todas as fases da gestação, incluindo ações de cuidado ao filho, com o intuito de integrá-lo, tornando o processo gestacional um cuidado não apenas da mulher que busca cuidar-se, seguindo orientações de segurança, mas também do parceiro. Entretanto, devido questões culturais, o homem torna-se negligente e negligenciado tratando-se de saúde. De modo que esses fatores são fortalecidos com a falta de incentivo e de execução de estratégias por parte de profissionais e gestores, ferindo um fundamento do SUS: a equidade. Objetivo: Destacar, a partir da experiência vivenciada, as principais dificuldades enfrentadas na rotina da Unidade Básica de Saúde (UBS) no que tange ao pré-natal do parceiro da gestante, relacionando, de forma clara, os direitos do homem no princípio da equidade. Método: Trata-se de um estudo descritivo, com abordagem qualitativa do tipo relato de experiência. Realizado por acadêmicos de enfermagem a partir da vivência no Estágio Supervisionado I, em uma Unidade Básica de Saúde de Macapá, no mês de abril de 2019, durante as consultas de enfermagem de prénatal. Resultados: Ao falarmos em pré-natal, pensa-se em mãe e bebê. Todavia esse momento deve englobar, na mesma proporção, o pai, sendo disposto também a ele o acesso a uma assistência de qualidade durante o período de gestação. A lembrar que o homem também precisa estar vacinado, desfrutando de uma boa saúde física, não sendo canal de transmissão de Infecções Sexualmente Transmissíveis (IST's), e mental, ajudando na construção do vínculo familiar. Fato que pode facilitar a comunicação entre o casal e auxiliar na capacidade de resolubilidade de problemas. Com os dias de prática nas consultas de enfermagem, diversas situações foram observadas, as quais ajudaram a se ter uma visão melhor dos problemas existentes na inserção do companheiro nesse período. Como exemplo, citaremos um momento em que um casal jovem veio para a sua primeira consulta pré-natal, com uma gravidez não planejada, porém sendo bem aceita por ambos e pela família. Nisso relataram algumas queixas a respeito do instante em que foram à sala 
do acolhimento para triagem e os profissionais do local recusaram-se a triar o companheiro da gestante, alegando não haver necessidade. Esse fato serve como evidência de que profissionais mais antigos muitas vezes não possuem o conhecimento necessário acerca do que realmente é preconizado pelo SUS nos manuais do Ministério da Saúde. Outro ponto a destacar na rotina da Unidade é não haver um prontuário para registro das informações pertinentes ao estado clínico e queixas do usuário, cabendo ao enfermeiro que realizou a consulta fazer os registros no prontuário da gestante. Logo, em pequenas atitudes na rotina da Unidade, é perceptível o descaso com a saúde do homem e, ainda, a pouca eficácia na implementação dos direitos do companheiro preconizados por lei, não ferindo o princípio da equidade. Com isso, observou-se que, além das barreiras encontradas para incorporar o homem na realidade de pré-natal, há pouca adesão deles às consultas. Isso sinaliza a urgência da promoção de estratégias que chamem atenção do pai, incumbindo-o da responsabilidade de buscar se inserir no momento da gestante para ajudá-la e apoiá-la, dando o suporte diante dos cuidados com medicações, horários, controle alimentar, repouso, mudança de humor, entre outros fatores que variam de mulher para mulher. Outro exemplo, são as rodas de conversa, realizadas durante as palestras de educação em saúde na Unidade, a fim de orientar sobre o pré-natal e esclarecer dúvidas. Durante essas reuniões há um quantitativo pequeno de parceiros presentes, dos que participam ouve-se relatos do quanto faz diferença a palestra por receber as orientações oferecidas. De modo que a criação de estratégias para melhorar a adesão do parceiro às consultas pré-natais, fazendo com que o homem ganhe seu espaço na promoção de saúde como preconizado pelo SUS, é de suma importância, pois Organismos Internacionais concordam que a equidade provoca a redução de diferenças que podem ser evitadas e de injustiças que podem ser cometidas ${ }^{1}$. Ressalta-se, ainda, que isso pode ser positivo não apenas para crianças e mulheres, mas especialmente para os homens, por aproximá-los definitivamente da arena do afeto e do cuidado ${ }^{3}$. Com isso, confirma-se a necessidade de reflexão no tocante a como o serviço tem sido ofertado, suas falhas e sugestões resolutivas para os problemas destacados. Considerações finais: Observa-se que, apesar de o prénatal do parceiro ser uma estratégia pertinente para dar seguimento aos cuidados do homem e vinculá-lo à unidade, ainda não há participação por parte de profissionais para efetivar a estratégia idealizada pelo MS. Sendo a estratégia significativa para a diminuição da incidência de IST's, detecção precoce de fatores de risco para doenças crônicas e outros agravos, e para o fortalecimento de vínculos familiares e sociais. Os estudos sobre o prénatal do parceiro ainda são incipientes, embora possuam impacto na saúde da mãe, do filho e do próprio pai, tornando-se necessário a construção de procedimentos, fluxogramas e capacitação dos profissionais. A fim de que acolham, encaminhem e tornem o parceiro da gestante participante nas consultas, oferecendo-lhe uma escuta ativa e um momento confortável para o esclarecimento de dúvidas e anseios. Implicações para enfermagem: Verificou-se que ainda há falhas na abrangência e captação do homem para o acompanhamento em nível de APS. Logo, são necessários mais estudos referentes à temática, que tragam maior reflexão aos profissionais da enfermagem, para sensibilizá-los em relação à maneira como exercem sua profissão no atendimento diário à saúde da família, contribuindo com a disseminação de informações pertinentes e significativas para melhora da realidade encontrada. 
Descritores: Atenção Primária; Saúde do Homem; Enfermagem.

\section{Referências}

1. Paim Jairnilson Silva, Silva Lígia Maria Vieira da. Universalidade, integralidade, equidade e SUS. BIS, Bol. Inst. Saúde (Impr.) [periódico na Internet]. 2010 Ago [citado 2019 maio 01]; 12(2): 109-114. Disponível em: http://periodicos.ses.sp.bvs.br/scielo.php?script=sci_arttext\&pid=S1518$18122010000200002 \&$ lng $=$ pt.

2. Ministério da saúde. Secretaria de Atenção à Saúde, departamento de ações programáticas estratégicas. Política Nacional de Atenção Integral à Saúde do Homem. Brasília, 2008.

3. Ministério da Saúde. Secretaria de Atenção à Saúde. Guia do Pré-Natal do Parceiro para Profissionais de Saúde. Brasília, 2016. 


\title{
PRÁTICAS CUIDATIVAS À GESTANTE NA FRONTEIRA OIAPOQUE- TUMUCUMAQUE: UM RELATO DE EXPERIÊNCIA
}

\author{
${ }^{1}$ Maria do Perpétuo Socorro Lima da Silva; ${ }^{2}$ Bruna Cardoso Ranieri; ${ }^{3}$ Germana Teixeira \\ de Sousa; ${ }^{4}$ Ariane Aparecida dos Santos Moraes; ${ }^{5}$ Jacqueline Gonçalves Ramos Wetch; \\ ${ }^{6}$ Lise Maria Carvalho Mendes.
}

${ }^{1}$ Graduada em Enfermagem pela Universidade Federal do Amapá - Unifap; Especializanda em Enfermagem Obstétrica - Fama. Enfermeira por DPAC-Fronteira. E-mail: mapes.lima@gmail.com;

${ }^{2}$ Graduada em Enfermagem - Unifap; Especializanda em Enfermagem Obstétrica - Fama;

${ }^{3}$ Acadêmica do Curso de Bacharelado em Enfermagem; Unifap.

${ }^{4}$ Acadêmica do Curso de Bacharelado em Enfermagem; Unifap.

${ }^{5}$ Acadêmica do Curso de Bacharelado em Enfermagem; Unifap.

${ }^{6}$ Enfermeira. Mestranda em Ciências da Saúde; Unifap. Professora efetiva do Colegiado do Curso de Bacharelado em Enfermagem - Binacional.

\section{RESUMO}

Introdução: Apesar de a Atenção do pré-natal estar no escopo das políticas públicas de saúde e, atualmente, possuir acesso quase universal(1), observam-se algumas lacunas na qualidade da assistência, a exemplo do início do acompanhamento após a décima semana gestacional, do número de consultas realizadas inferior a seis, do abandono e de outros fatores que afetam a qualidade e a continuidade da assistência, trazendo prejuízos aos processos parturitivos, puerperais e ao recém-nascido. Ausência de profissionais qualificados e experientes para 0 atendimento à grávida, os recursos escassos, a infraestrutura inadequada, a dificuldade de acesso aos serviços de saúde em algumas localidades são fatores que determinam a saúde e prejudicam a adesão à assistência prénatal, expondo o binômio a riscos evitáveis ${ }^{(1)}$. Nessa perspectiva, sabe-se que a disponibilidade da assistência de saúde em áreas remotas e longínquas dos grandes centros urbanos e a acessibilidade a ela são deficitárias ${ }^{(2)}$, a exemplo disso, observam-se os contextos da fronteira Amazônica. No entanto, a literatura é escassa quanto às práticas de enfermagem voltadas à saúde da gestante nessa conjuntura. Desse modo, verifica-se a necessidade de compreensão da natureza e da qualidade dessa assistência, em regiões remotas, como a fronteira brasileira situada no extremo norte, na Amazônia Legal. Objetivo: Relatar a utilização da assistência de enfermagem à gestante, com enfoque na Teoria do Cuidado(3), no município de Oiapoque-AP. Método: Estudo descritivo, do tipo relato de experiência, desenvolvido nos serviços de Atenção Primária à Saúde (APS) da gestante, situados na fronteira Oiapoque-Tumucumaque. A coleta de dados ocorreu entre os meses de janeiro e maio de 2019. Este estudo considerou o referencial de boas práticas de parto e nascimento definidas pela Organização Pan-Americana de Saúde ${ }^{(4)}$. Utilizou-se como referencial para a análise a Teoria dos Cuidados de Swanson ${ }^{(3)}$, que se sustenta em cinco processos básicos que validam e dão significado ao cuidado, a saber: conhecer, estar com, fazer por, possibilitar e manter as crenças ${ }^{(3)}$. A Teoria dos Cuidados utiliza-se de cada processo básico para dar significado, visibilidade ao indivíduo que é cuidado e ao ser que cuida. Assim, esse modelo de prática possibilita a identificação das necessidades e prioridades e permite a composição de um plano de cuidados efetivo, que respeite a 
manutenção das crenças $^{(3)}$. Resultados: Através de visitas domiciliares realizadas com a equipe de saúde e consulta de enfermagem integrando a equipe de Estratégia Saúde da Família (ESF), foi possível realizar conhecimento do território, da clientela e de suas redes de apoio. Conhecer as redes das gestantes do município, no contexto da fronteira amazônica, tornou-se imprescindível ao cuidado adequado e eficaz, uma vez que a clientela é composta por mulheres vulneráveis no que concerne à estrutura precária das residências, estas sem saneamento básico, isoladas geograficamente em períodos chuvosos. Mulheres exercem profissões singulares a esse contexto, como garimpeiras, pescadoras, agricultoras, entre outras, expostas às condições do intenso fluxo fronteiriço, como a disseminação de doenças, e aos agravos endêmicos do clima trópico úmido da floresta. A partir do conhecimento dessas redes e da especificidade de cada gestante, foi possível elaborar um plano de assistência de enfermagem que buscasse atender suas principais vicissitudes quanto ao acompanhamento pré-natal. Na obstetrícia, o enfermeiro que realizar a etapa de conhecer a parturiente tem subsídios para formulação de vínculos e de elaboração de um plano de cuidados que contemple a parturiente e sua família em sua integralidade, abordando os aspectos biopsicossociais e espirituais. A falta de conhecimento e de vínculo pode resultar em insegurança à parturiente e sua família(5). $\mathrm{Na}$ etapa conseguinte, iniciou-se a estratégia de estar com as clientes. Foi feito em cada acompanhamento o acolhimento às demandas e a realização da escuta ativa. Muitas das insatisfações referidas pelas gestantes eram transversais à falta de insumos e de disponibilização de exames para o acompanhamento pré-natal. As queixas também se direcionaram às regiões sem cobertura da ESF, em áreas que apresentam acessibilidade limitada, a exemplo de Vila do Cassiporé e Vila Brasil. O meio ambiente desequilibrado, no que se reporta à lixeira pública, que recebe descarte inadequado, sem aterro e que exala uma fumaça com odor, também foi referenciada. Nessa perspectiva, buscou-se sanar as barreiras que dificultam o acesso da gestante à realização das mínimas seis consultas prénatais, além de possibilitar acesso as vacinas e testes rápidos para detecção de doenças infecciosas e exames em tempo hábil e que houvesse a acolhida, respondendo indagações facilitando compreensão a fim de aumentar as possibilidades de efetividade. No entanto, apresentam-se barreiras que transpõem as competências profissionais de fazer por e possibilitar, mas que competem a outras estruturas governamentais, no que se refere à disposição de insumos, recursos humanos, estrutura e redes de referenciamento. A manutenção das crenças no contexto referido - onde há diversidade de povos indígenas, outros povos da floresta e culturas transfronteiriças - deve ser priorizada. Para tanto contínuas atualizações devem ser realizadas a fim de se ter evidências científicas que possibilitem a conciliação das crenças que trazem benefícios, das que não prejudicam o bem-estar materno e fetal e a realização da negociação daquelas que podem causar prejuízos ao trinômio. Considerações finais: $O$ modelo de cuidados proposto por Swanson contribui para uma reflexão acerca das práticas destinadas à saúde da gestante situada em ambiente fronteiriço e amazônico. Nos contextos de povos da floresta e população fronteiriça, esse modelo mostrou-se de extrema importância, uma vez que possibilita o conhecimento ao contexto da gestante e de sua rede de apoio, a manutenção de suas crenças que não tragam prejuízos a sua saúde e a possibilidade de uma gestação segura. Observa-se também, a partir do relato, que as etapas de fazer e possibilitar possuem barreiras que transpõem a prática profissional, mas se inserem em estruturas 
programáticas de ofertas de serviços. Implicações para a enfermagem: $O$ relato apresenta resultados preliminares sobre a assistência em enfermagem à gestante na região de fronteira de Oiapoque-Tumucumaque e suscita a importância de futuras investigações sobre a temática da assistência à saúde da gestante na conjuntura apresentada.

Descritores: Saúde na fronteira; Teoria de enfermagem; Saúde materna.

\section{Referências}

1. Guimarães WSG, Parente RCP, Guimarães TLF, Garnelo L. Access to prenatal care and quality of care in the family health strategy: infrastructure, care, and management. Cad Saúde Pública [Internet]. 2018 [Acesso 2019 Abr 29];34(5). Doi: http://dx.doi.org/10.1590/0102-311X00110417.

2. Oliveira APC, Gabriel M, Poz MRD, Dussault G. Challenges for ensuring availability and accessibility to health care services under Brazil's Unified Health System (SUS). Ciência \& Saúde Coletiva[Internet]. 2017[acesso 2019 Abr 24];22(4):1165-1180. Doi: 10.1590/1413-81232017224.31382016.

3. Swanson KM. Nursing as informed caring for the well-being of others. IMAGE: journal oi Nursing Scholarship. [Internet]1993[acesso 2019 Abr 25];25(4): 352-357. Available from: http://nursing.unc.edu/files/2012/11/ccm3_032549.pdf.

4. Organização Mundial de Saúde - OMS. Maternidade segura. Assistência ao parto normal: um guia prático. [internet] Genebra: OMS, 1996[acesso 2019 Abr 4]. Available from:

http://abenfo.redesindical.com.br/materias.php?subcategoriaid=2\&id=56\&pagina=1\& .

5. Broca PV, Ferreira MA. Communication process in the nursing teama based on the dialogue between Berlo and King. Esc Anna Nery [Internet]. 2015[acesso 2019 Abr 29];19(3):467-474. DOI: 10.5935/1414-8145.20150062. Disponível em: http://www.scielo.br/pdf/ean/v19n3/1414-8145-ean-19-03-0467.pdf. 


\title{
TRABALHANDO EDUCAÇÃO EM SAÚDE NO CONTEXTO DA ATENÇÃO PRIMÁRIA FRENTE ÀS NECESSIDADES DA MULHER
}

\author{
${ }^{1}$ Rafael Nascimento da Silva; ${ }^{2}$ Letícia Santos do Monte; ${ }^{3}$ Viviane de Souza bezerra; \\ ${ }^{4}$ Izabele Grazielle da Silva Pojo; ${ }^{5}$ João Lucas Barbosa Magalhães; ${ }^{6}$ Tatiana do Socorro \\ dos Santos Calandrini.
}

\begin{abstract}
1,2Bolsista do Programa de Educação Tutorial-PET/Enfermagem, Universidade Federal do Amapá Unifap; E-mail: suricato.rafael@gmail.com;

${ }^{3,4}$ Bolsista do Programa de Educação pelo Trabalho para a Saúde/Interprofissional no Curso de Bacharelado em Enfermagem, Unifap;

${ }^{5}$ Graduando do curso de Bacharelado em Enfermagem, Unifap;

${ }^{6}$ Enfermeira; Mestre em Ciências da Saúde; Professora efetiva do Colegiado do Curso de Bacharelado em Enfermagem, Unifap.
\end{abstract}

\section{RESUMO}

Introdução: A educação em saúde é compreendida como o processo que visa conscientizar a população a respeito de seus problemas de saúde. É um método de transformação social em busca de soluções individuais e coletivas para a resolução desses problemas. A principal função da educação em saúde é promover a democratização do acesso ao conhecimento pela população usuária dos serviços de saúde, por isso, deve estar presente diariamente nas ações de saúde em todos os níveis de sistema e em todas as fases do seu processo de organização ${ }^{1}$. No que diz respeito à saúde da mulher, os problemas são agravados pela discriminação nas relações de trabalho e pela sobrecarga das atividades domésticas, além de variáveis como raça, etnia e situação de pobreza que realçam ainda mais as desigualdades. Dessa forma, deve haver esforços no sentido de buscar novas estratégias educativas que fujam da perspectiva biomédica e que atendam às suas particularidades e necessidades ${ }^{2}$. Partindo do princípio de que a equidade em saúde se refere ao princípio de reconhecer as diferenças nas condições de vida e saúde, deve-se entender que o perfil epidemiológico da população feminina apresenta diferenças importantes, sendo necessário um olhar diferenciado a essa população. As mulheres representam 50,77\% da população brasileira e são as principais usuárias do Sistema Único de Saúde (SUS) $)^{2,3}$. Objetivos: Relatar a experiência de prática educativa desenvolvida com mulheres de uma Unidade Básica de Saúde (UBS) de Macapá, com foco em suas realidades e necessidade locais. Método: Estudo caracterizado como relato de experiência, vivenciada na aula prática da disciplina Materno Infantil na Atenção Básica, do Curso de Bacharelado em Enfermagem da Universidade Federal do Amapá (Unifap), no período 22 de outubro a 5 de novembro de 2018, em uma Unidade Básica de Saúde em Macapá. A metodologia utilizada pelos acadêmicos dividiu-se em duas etapas: 1) Elaboração de material educativo: foram produzidas cartilhas educativas e apresentações de powerpoint para auxiliar durante explanação dos conteúdos, porquanto, a linguagem aplicada foi clara e objetiva, de forma a favorecer o entendimento; 2) Palestras e orientações individuais: os temas selecionados foram: câncer do colo de útero; autoexame de mama; prevenção e consequências da sífilis congênita e a importância do pré-natal, escolhidos de acordo com as necessidades apresentadas pelo público-alvo, evidenciadas ao longo da experiência. 
Resultados: De modo geral, observou-se que a abordagem faz toda a diferença na hora de repassar uma informação a esse público e a forma como os profissionais se expressam também é importante, pois, quando ocorreu a aproximação, percebeu-se que a compreensão das mulheres em relação ao tema ministrado aconteceu de maneira acolhedora e agradável por haver um feedback entre ambos, uma vez que elas relatam suas principais dúvidas frente aos assuntos abordados. Souza et al. (2017) ${ }^{4}$ destacam alguns pontos importantes para a efetivação da educação em saúde, como a utilização de linguagem acessível à compreensão da cliente e do familiar, o volume de informações fornecidas que deve ser gradual para facilitar a absorção e a utilização de folhetos explicativos como forma de permitir à cliente voltar às informações quando tiver dúvidas. Vale ressaltar que, com as orientações individuais, obtiveram-se mais benefícios no que diz respeito à adesão da mulher se comparadas às palestras coletivas, evidenciando a pertinência da escuta ativa e do atendimento individual. A intervenção dos acadêmicos mostrou-se pertinente, pois se deu em um momento ocioso, em que as mulheres estão aguardando atendimento. Em meio às orientações, puderam ter voz ativa, esclarecer dúvidas e partilhar suas experiências com os demais. Observou-se que a maioria das mulheres atendidas estão em condições de vulnerabilidade social, estando expostas a fatores de risco específicos, portanto precisam ser atendidas em sua complexidade. Para tal, as ações de atenção à saúde da mulher devem integrar os níveis de promoção, prevenção e assistência, respeitando sua individualidade. Por fim, oportunizou-se uma vivência extremamente enriquecedora para os acadêmicos, em especial no desenvolvimento de habilidades no papel educador de Enfermagem, uma vez que a educação em saúde não é apenas o repasse de informações dos profissionais de saúde para os usuários dos serviços, mas uma troca de conhecimentos e experiências que contribuem para o desenvolvimento de uma reflexão sobre a realidade social, que tem como resultado o fortalecimento da autonomia e do autocuidado ${ }^{3}$. Ressalta-se que a não discriminação, a acessibilidade (física, econômica e de informações) e a aceitabilidade (incluindo as questões éticas e culturais apropriadas) devem fazer parte do cotidiano profissional, pois são aspectos indispensáveis para o cumprimento dos princípios estabelecidos pelo SUS ${ }^{5}$. Considerações finais: Dessa forma, torna-se de extrema importância a garantia do acesso às informações às mulheres através da educação em saúde no contexto da atenção primária, visando à promoção integral da saúde, sendo as informações importantes para o empoderamento da mulher. A escuta ativa nesse contexto tem como finalidade facilitar a aproximação dessas usuárias aos serviços de saúde, dandoIhes autonomia e condições para dialogar sobre suas necessidades e dúvidas. Em consonância a isso, nota-se a necessidade de ser desenvolvidas estratégias que facilitam a comunicação e formação de vínculo entre o profissional e a população em questão, a fim de ser realizado o rastreamento e a busca ativa, objetivando a prevenção, diagnóstico precoce e tratamento imediato das doenças prevalentes nesse grupo, como o câncer de colo de útero e de mama. Implicações para a enfermagem: O papel do enfermeiro se inicia já na atenção primária, na busca ativa e rastreamento das mulheres, principalmente daquelas que se caracterizam como grupo suscetível para o desenvolvimento de determinadas patologias. Nesse âmbito, a comunicação entre ambas as partes tem ação facilitadora para o entendimento do tratamento proposto e favorece sua adesão de forma consciente. Portanto, o contato direto do profissional enfermeiro com o paciente permite 
que as dificuldades durante o processo sejam contornadas. Pode-se, por meio desta pesquisa, constatar a importância da assistência de Enfermagem na atenção primária e como esse cuidado reflete na vida da mulher.

Descritores: Educação em saúde; Mulher; Atenção primária à saúde.

\section{Referências}

1. São Paulo. Secretaria da Saúde. Boletim do Instituto de Saúde № 34 . São Paulo: Instituto da saúde, 2004.

2. Brasil. Ministério da Saúde. Secretaria de Atenção à Saúde. Brasília, DF: Política Nacional de Atenção Integral à Saúde da Mulher: Princípios e Diretrizes; 2011.

3. Souza MRA, Souza CA. A educação em saúde no contexto da atenção primária em saúde. Revi Família, Ciclos de Vida e Saúde no Contexto Social. 2017; 5 (1): 282-288.

4. Fernandes ACUR, Costa DDO, Costa JM, Duarte KMM, Silva MP, Garcia PT et al. Saúde da mulher. EDUFMA. 2017; 2 (10): 1-129.

5. Barros FPC, Sousa MF. Equidade: seus conceitos, significações e implicações para o SUS. Saúde soc. 2016; 25 (1): 9-18. 


\section{EIXO II: PESQUISA EM SAÚDE COMO CAMINHO PARA EQUIDADE}




\title{
CONSTRUÇÃO DE PROTOCOLO DE PESQUISA PARA AVALIAÇÃO DE ACADÊMICOS DE ANATOMIA: RELATO DE EXPERIÊNCIA
}

\author{
${ }^{1}$ Aimê Mareco Pinheiro Brandão; ${ }^{2}$ Larissa Duarte Ferreira; ${ }^{3}$ Rebeca Goés Gonçalves; \\ ${ }^{4}$ Ana Vitória Gonçalves de Oliveira Cruz; ${ }^{5}$ Marina Nolli Bittencourt; ${ }^{6}$ Ana Rita Pinheiro \\ Barcessat.
}

\begin{abstract}
${ }_{1}^{1}$ Acadêmica do Curso de Bacharelado em Enfermagem; Unifap. Bolsista PET-Enfermagem. Grupo de pesquisa em Biofotônica e Neuromodulação - Unifap. E-mail: aimegraduanda@gmail.com;

${ }^{2}$ Enfermeira. Bolsista Capes - Programa de Pós-Graduação em Ciências da saúde - Unifap.

3 Acadêmica do Curso de Bacharelado em Enfermagem; Unifap. Bolsista do Departamento de Extensão (DEX). Grupo de pesquisa em Biofotônica e Neuromodulação - Unifap;

${ }^{4}$ Acadêmica do Curso de Bacharelado em Enfermagem; Unifap. Bolsista do Departamento de Extensão (DEX). Grupo de pesquisa em Biofotônica e Neuromodulação - Unifap;

${ }^{5}$ Enfermeira. Doutora em Ciências da Saúde. Professora do Colegiado do Curso de Bacharelado em Enfermagem e do Programa de Pós-Graduação em Ciências da Saúde - Unifap;

6 Cirurgiã-Dentista. Doutora em Estomatologia Básica e Aplicada - Patologia Bucal; Unifap. Coordenadora do Grupo de Pesquisa em Biofotônica e Neuromodulação - Unifap. Professora efetiva Colegiado em Ciências da saúde - Unifap.
\end{abstract}

\section{RESUMO}

Introdução: O presente relato trata da experiência de uma das linhas de pesquisa do Grupo de Pesquisa em Biofotônica e Neuromodulação da Universidade Federal do Amapá (Unifap) perante a elaboração de um protocolo de pesquisa para a avaliação da Tecnologia REAC (Conversor Rádio Elétrico Assimétrico) que tem como objetivo a otimização Neuropostural (NPO) e Otimização Neuropsicofísica (NPPO), para reabilitar e otimizar a polaridade celular, ou seja, a organização assimétrica de vários componentes celulares. É de utilidade terapêutica, não invasiva, de biomodulação e neuromodulação, indolor, de rápida e fácil administração, que é feita através da emissão de frequência de rádio de potência muito baixa que produz um sinal autógeno. Este sinal, quando adequadamente transportado, concentrando-se em pontos específicos do pavilhão auricular, produzirá respostas biológicas que têm sido objeto de diversos estudos e publicações ao longo dos anos e têm apresentado uma melhoria geral nas características físico-psicológicas dos indivíduos tratados'. Isso será feito em estudantes da disciplina de Anatomia Humana com a implementação de métodos ativos de ensino. Logo, o estudo é importante devido à necessidade de equidade nas pesquisas que envolvem o tema e, dessa maneira, voltou-se para a área da Enfermagem com o intuito de tornar a referida disciplina mais atrativa e de reduzir a evasão acadêmica. Além disso, fez-se necessário avaliar o que um método ativo de ensino poderia causar positivamente no discente e verificar se a tecnologia REAC potencializaria essas mudanças nos acadêmicos. O estudo foi feito por meio de um protocolo de pesquisa inspirado no modelo CONSORT (Padrões Consolidados para Relatar Ensaios), pois se fez necessário um checklist do raciocínio clínico utilizado na pesquisa ${ }^{2}$. Objetivo: Expor a experiência da elaboração de um protocolo de pesquisa sobre a tecnologia REAC como mecanismo de otimização do aprendizado e propor e avaliar a eficácia do uso de métodos ativos no ensino na disciplina de Anatomia Humana como estratégia de ensino para a área da Enfermagem. Método: Trata-se de um estudo 
descritivo, com abordagem qualitativa do tipo relato de experiência, acerca da construção de um protocolo de pesquisa sobre a tecnologia REAC para melhoria do desempenho acadêmico e a utilização de métodos ativos de ensino em estudantes da disciplina de Anatomia Humana com a finalidade de propor novos meios de ensino que possam estimular o aprendizado dos discentes. Logo, foi realizada uma pesquisa por meio da busca na base de dados Pubmed acerca dos protocolos REAC e na Biblioteca Virtual de Saúde (BVS) na procura de descritores sobre método ativo de ensino e anatomia, houve o auxílio do enunciado CONSORT 2010 para descrição do passo a passo do protocolo de pesquisa. Resultados: O processo de construção do protocolo e até mesmo do relato exigiu a consulta de protocolos de pesquisa já estabelecidos (como o enunciado CONSORT 2010), tornando-o complexo e demandando atenção. Durante a construção, observou-se a falta de estudos sobre a temática na área da Enfermagem, o que torna interessante esse processo. Salienta-se a competência do enfermeiro na aplicação do protocolo ao estar à frente da aplicação da tecnologia REAC, porque o enfermeiro é responsável por diversas tarefas dentro dos cuidados com a saúde e o bem-estar humano e o REAC visa à promoção do bem-estar dos indivíduos. Ademais, a ideia da criação do protocolo surgiu da necessidade de acompanhar o aproveitamento do discente frente às atividades e com o objetivo de adaptar e validar o instrumento aplicado para que o mesmo pudesse, além de ser aplicado, ser avaliado dentro do conjunto de protocolos de otimização neuropsicofísica no contexto de aprendizagem ${ }^{3}$. Diversos artigos mostraram que buscar novas estratégias e tecnologias e entender os métodos ativos de ensino se mostra como um princípio de equidade quando essa palavra se traduz no reconhecimento das diferenças nas condições de vida e saúde, assim como nas necessidades individuais, considerando que o direito à saúde passa pelas diferenças sociais e há o dever de atender a diversidade. Cada aluno é um universo que deve ser tratado de maneira imparcial, respeitando a igualdade de direitos. É importante se adequar às necessidades de cada um e procurar modos de trazer conhecimento para futuramente contribuir com a sociedade ${ }^{4}$. Considerações finais: Espera-se que a construção desse protocolo de pesquisa possa ser um mecanismo de ajuda na aplicabilidade e eficácia da avaliação dos métodos ativos consonantes com a tecnologia REAC. Portanto, é importante que o protocolo criado venha avaliar a eficácia da neuromodulação REAC (que se configura como um importante instrumento de otimização de biomodulação e neuromodulação) na potencialização do aprendizado dos acadêmicos de Anatomia Humana. Busca-se ainda aproximar a enfermagem dos diversos estudos existentes nos outros cursos da área da saúde com a temática e incentivar futuras publicações de protocolos de pesquisa, com a intenção de auxiliar a progressão dos estudantes como profissionais na prática assistencial e como futuros pesquisadores. Implicações para a enfermagem: Assim como em outras profissões da área saúde, na enfermagem, a disciplina de Anatomia Humana, em conjunto com outras que compõem as disciplinas básicas, desenvolveu-se com a finalidade de auxiliar na progressão profissional dos discentes, aliando o ensino à prática clínica ${ }^{3}$. 0 princípio da equidade também norteia as necessidades de grupos específicos e com isso atua para reduzir o impacto dos determinantes sociais da saúde aos quais estão submetidos. A partir disso, faz-se necessário que o docente traga novas metodologias de ensino, evitando a evasão acadêmica, de modo que venha estimular o entendimento dos alunos, aumentando sua capacidade de reter conhecimento para que possam posteriormente aplicá-los na prática 
assistencial, reconhecendo as diferenças nas condições de vida e saúde e nas necessidades das pessoas, considerando que o direito à saúde passa pelas diferenciações sociais e deve atender a diversidade. Portanto, é esperado que esse protocolo de pesquisa atue como uma ferramenta de auxílio na proposta de projeto dos métodos ativos consonantes com a tecnologia REAC, visando à criação de novas estratégias para a educação e a saúde e trazendo a enfermagem como contribuinte na aplicação do protocolo e nos estudos já existentes na área da saúde, utilizando essa plataforma terapêutica.

Descritores: Protocolo de Pesquisa; Anatomia; Educação.

\section{Referências}

1. Coelho JP, Rinaldi A, Fontani V, Rinaldi S. REAC neuromodulation treatments in subjects with severe socioeconomic and cultural hardship in the Brazilian state of Pará: a family observational pilot study. NDT [Internet]. Apr 2018; 14: 1047-1054.

2. Martins J, Sousa L, Oliveira A. Recomendações do enunciado CONSORT para o relato de estudos clínicos controlados e randomizados. RMRP [Internet]. 30mar. 2009;42(1):91.

3. Cocce ALR, Silveira LM, Goes FDSN, de Souza ALT, \& Stabile AM. O ensino da anatomia nas escolas de enfermagem: um estudo descritivo. ACS [Internet]. Dez; 24(4), 08-13.

4. Vasconcelos AC, Andrade GLS, Brainer SAB, Soares RM, Santos LDB \& Souza PIC. As estratégias de ensino por meio das metodologias ativas/Teaching strategies through active methodologies. BJD [Internet]. Mar 2019; 5(5), 3945-3952. 


\section{SÍFILIS EM GESTANTES ADOLESCENTES: REALIDADE NO ESTADO DO AMAPÁ}

${ }^{1}$ Amanda Almeida da Silva Carvalho; ${ }^{2}$ Izabele Grazielle da Silva Pojo; ${ }^{3}$ Rafael de Jesus Brito Mendes; ${ }^{4}$ Victor Hugo Oliveira Brito; ${ }^{5}$ Viviane de Souza Bezerra; ${ }^{6}$ Nely Dayse Santos da Mata.

\footnotetext{
${ }_{1}^{1}$ Acadêmica do Curso de Bacharelado em Enfermagem; Universidade Federal do Amapá - Unifap. E-mail: aascsilva@gmail.com;

${ }^{2}$ Acadêmica do Curso de Bacharelado em Enfermagem; Unifap;

${ }^{3}$ Acadêmico do Curso de Bacharelado em Enfermagem; Unifap;

${ }^{4}$ Acadêmico do Curso de Bacharelado em Enfermagem; Unifap;

${ }^{5}$ Acadêmica do Curso de Bacharelado em Enfermagem; Unifap;

6 Enfermeira. Doutora em Ciências; Unifap. Professora efetiva do Colegiado do Curso de Bacharelado em Enfermagem.
}

\section{RESUMO}

Introdução: A sífilis é uma infecção sexualmente transmissível (IST) passível de diagnóstico, tratamento e controle, entretanto continua muito presente em nosso meio, visto que está cada vez mais incidente durante a gestação. Essa infecção, causada pela bactéria Treponema pallidum, pode ser transmitida de maneira vertical e horizontal. Por meio de transmissão horizontal, a gestante, além de poder ser infectada por outros meios, facilmente pode contrair a doença por intermédio de seu parceiro, caso este esteja infectado e mantenham relação sexual desprotegida. De acordo com estudos, o pré-natal do parceiro é uma estratégia importante para a prevenção da sífilis congênita, proporcionando benefícios para o trinômio (gestante-bebê-parceiro) ${ }^{1}$. A sífilis gestacional e congênita está intimamente relacionada com grupos de maior vulnerabilidade social, como mulheres que vivem em condições de extrema pobreza ou que enfrentam condições de risco em seus estilos de vida, podendo esses fatores de risco variar entre as regiões ${ }^{2}$. Na gestação, o Treponema pallidum pode ser transmitido também de maneira vertical por disseminação hematogênica para o concepto por via transplacentária, comprometendo a saúde materna e fetal ${ }^{3}$. No Brasil, estima-se que $3,5 \%$ das gestantes sejam portadoras desta doença, havendo um risco de transmissão vertical da bactéria de aproximadamente $50 \%$ a $85 \%$ e taxas de mortalidade perinatal de até 40 . A oferta de testes rápidos durante o pré-natal facilita o manejo da sífilis, assim como seu diagnóstico e posterior tratamento. Em relação à enfermagem, observa-se a necessidade de equidade de forma holística no atendimento, sendo apontados como fatores importantes para a adesão ao tratamento acolhimento, empatia e comunicação eficaz. Além de fortalecer a adesão ao tratamento, a enfermagem também se faz importante quando se trata de educação em saúde e aplicação dos testes rápidos, haja vista que está continuamente lidando com o público na dispensação de serviços em saúde. Dessa forma, ao se prestar assistência com equidade, que é um dos princípios doutrinários do Sistema Único de Saúde (SUS), coloca-se em evidência o atendimento aos indivíduos de acordo com suas necessidades, oferecendo cuidados proporcionais à demanda das pessoas. Com este princípio, procura-se discernir as diferenças nas condições de vida, saúde e nas particularidades das pessoas, considerando que o direito à saúde passa pelas diferenciações sociais e deve atender a diversidade. Toda 
gestante deve ser testada duas vezes para sífilis durante o pré-natal, uma no primeiro trimestre da gravidez e a próxima no terceiro trimestre, devendo a parceria sexual também ser testada. Além disso, é obrigatória, ainda, a realização de um teste, treponêmico ou não treponêmico, imediatamente após a internação para o parto na maternidade, ou em caso de abortamento ${ }^{4}$. Por conta da rotina preconizada pelo Ministério da Saúde, é realizado por profissionais da saúde o acompanhamento da gestação durante toda sua extensão, incluindo parto e puerpério, visando assegurar qualidade na assistência prestada durante todo o pré-natal, que conta com vários exames laboratoriais incluindo os testes para sífilis, tornando este um período favorável ao diagnóstico e tratamento adequados dessa infecção.

Objetivo: Descrever casos de sífilis em adolescentes grávidas no Estado do Amapá e a importância na assistência de enfermagem. Método: Trata-se de uma pesquisa documental, de natureza quantitativa. O estudo assenta-se eticamente na Resolução no 510, de 07 de abril de 2016, que determina que não será registrada nem avaliada pelo sistema CEP/Conep: pesquisa que utilize informações de domínio público, pesquisa que utilize informações de acesso público, nos termos da Lei $n^{\circ}$ 12.527, de 18 de novembro de 2011 , entre outros tipos de pesquisa. A coleta de dados foi realizada a partir dos casos notificados de sífilis em gestantes no Estado do Amapá, no período de 2014 a 2018, disponíveis no Departamento DST, Aids e hepatites virais da Superintendência de Vigilância em Saúde (SVS), os quais são relatados na ficha de investigação de sífilis em gestante a partir do que preconiza o Sistema de Informação de Agravos de Notificação (Sinan). O tratamento dos dados foi feito por meio do programa Excel 2013, em que foram criadas tabelas para análise do perfil epidemiológico da patologia em questão, cujas informações foram: faixa etária e município de residência. Resultados: no período de 2014 a 2018, foram notificados no Estado do Amapá 998 casos de sífilis em mulheres grávidas. À interpretação dos casos, em nível estadual, identificou-se que mulheres grávidas com idade entre 10 e 29 anos lideram o ranking com a somatória de 777 casos notificados, sendo 17 casos de mulheres com idade entre 10 e 14 anos, 288 casos de mulheres entre 15 e 19 anos, 472 casos com idade entre 20 e 29 anos. Atenta-se para o alto quantitativo de sífilis em adolescentes grávidas, evidenciando uma população socialmente vulnerável, a qual deve ser avaliada pelas transformações hormonais, físicas e biopsicossociais que a adolescência, juntamente com a gravidez, Ihe proporciona. Somente na cidade de Macapá, neste mesmo período, foram notificados 657 casos de sífilis na gestação, seguidos por 118 casos no município de Santana totalizando 775 casos. Para sífilis congênita, foram registrados 304 casos no total, sendo 216 casos em Macapá e 46 casos em Santana. Considerações finais: A assistência de enfermagem na atenção primária é de inigualável importância para a manutenção da saúde materna e fetal, tendo uma visão holística durante o cuidado à gestante e ao seu futuro filho. Portanto esta pesquisa dá base para o atendimento com equidade, voltado para as especificidades de cada pessoa, visando à prevenção de agravos à saúde ou recuperação da saúde o mais rapidamente possível. Somente com a real implicação da equidade no atendimento à gestante será possível atender integralmente essa mulher, de acordo com suas necessidades, fragilidades e potencialidades. Implicações para a enfermagem: $O$ presente estudo permite 0 reconhecimento, por parte dos profissionais de saúde, da população mais vulnerável ao contágio pela sífilis, possibilitando uma prática de saúde baseada em evidências. Ainda favorece a caracterização da epidemiologia da doença nas mulheres grávidas no Estado 
do Amapá, o que pode embasar a construção ou adequação de políticas públicas e campanhas voltadas para essa problemática.

Descritores: Sífilis; Equidade; Gravidez.

\section{Referências}

1. Horta HHL, Martins MFM, Nonato TF, Alves MI. Pré-natal do parceiro na prevenção da sífilis congênita. Rev. APS. 2017; 20(4): 623 - 627.

2. Cabral BTV, Dantas JC, Silva JA, Oliveira DA. Sífilis em gestante e sífilis congênita: um estudo retrospectivo. Rev. Ciênc. Plur. 2017; 3(3): 32-44.

3. Machado I, Silva VAN, Pereira RMS, Guidoreni CG, Gomes MP. Diagnóstico e tratamento de sífilis durante a gestação: desafio para enfermeiras? Revista Saúde e Pesquisa. 2018; 11(2): 249-255.

4. Brasil. Ministério da Saúde. Secretaria de Vigilância em Saúde. Departamento de Vigilância, Prevenção e Controle das Doenças Sexualmente Transmissíveis, Aids e Hepatites Virais. Manual Técnico para Diagnóstico da Sífilis / Ministério da Saúde, Secretaria de Vigilância em Saúde, Departamento de Vigilância, Prevenção e Controle das Doenças Sexualmente Transmissíveis, Aids e Hepatites Virais. - Brasília: Ministério da Saúde, 2016. 52 p. 


\title{
AS PARCERIAS PÚBLICO-PRIVADAS ENQUANTO ESTRATÉGIAS DE AMPLIAÇÃO DO ACESSO À SAÚDE
}

\author{
${ }^{1}$ Ana Carolina Farias Vieira; ${ }^{2}$ Klinger Maxwell Silva Leão; ${ }^{3}$ Gabriela de Souza Amanajás; \\ ${ }^{4}$ Marlucilena Pinheiro da Silva.
}

\begin{abstract}
${ }^{1}$ Acadêmica do Curso de Bacharelado em Enfermagem do $7^{\circ}$ semestre da Universidade Federal do Amapá - Unifap. E-mail: carolina.vieira1997@hotmail.com;

Bacharel e Licenciado em Enfermagem. Bacharel em Direito - Unifap;

3Bacharela e Licenciada em Enfermagem - Unifap. Mestranda em Ciências da Saúde - Unifap;

${ }^{4}$ Enfermeira. Doutora em Educação. Docente efetiva da Unifap. marlucilena@gmail.com.
\end{abstract}

\section{RESUMO}

Introdução: O direito à saúde é constitucional1'. Entretanto, na atual realidade brasileira, o Estado não possui a capacidade de prover todos os serviços necessários para suprir a demanda crescente. Ademais, frequentemente, o acesso à saúde é negado ou dificultado, principalmente em regiões distantes e de vulnerabilidade socioeconômica. Em outras situações, torna-se necessária a judicialização devido à falta de medicamentos e serviços para o usuário do sistema. Portanto, emerge a necessidade do estabelecimento de estratégias capazes de solucionar tais problemas. As Parcerias Público-Privadas (PPP) são regulamentadas pela Lei $n^{\circ} 11.079 / 2004^{2}$ e consistem em contratos administrativos de concessão, em que são estabelecidos vínculos jurídicos entre o Estado e entes do setor privado. O financiamento das ações de saúde torna-se responsabilidade do setor privado e, por sua vez, a empresa privada presta o serviço público com recursos próprios, tendo autonomia e garantias financeiras do Estado. Objetivo: Discutir a eficácia das Parcerias Público-Privadas como estratégia de ampliação do acesso à Saúde Pública. Método: Pesquisa exploratória, de abordagem qualitativa, através de revisão bibliográfica, destacando-se dados primários e fontes secundárias para fundamentar a discussão. Investigaram-se legislações específicas sobre "PPP", doutrinas jurídicas, papers de gestão em saúde, documentos oficiais e pesquisas em saúde nas bases de dados como BVS e Scielo. Os descritores utilizados foram: "Parcerias Público-Privadas"; "Equidade em Saúde"; "Acesso aos Serviços de Saúde". Os critérios utilizados foram: disponibilidade na íntegra, equivalência à temática central do estudo, relevância temática, publicação entre 2009 e 2019, exceto para documentos históricos. Após analisados, foram selecionados os que preenchiam os critérios, totalizando 25 publicações. Já os dados secundários foram decorrentes de citações contidas nas doutrinas, além de modelos aplicados e comparações com a realidade no cenário brasileiro e amapaense. Resultados: A primeira experiência de PPP em saúde no Brasil foi na Bahia. Construído pelo governo baiano, o Hospital do Subúrbio foi administrado, operado e equipado pela empresa Prodal Saúde (empresa que ganhou a concessão por dez anos) desde que foi inaugurado em setembro de 2010, já recebendo prêmios internacionais de excelência. Em 2011, o custo do Hospital do Subúrbio foi cerca de $10 \%$ inferior ao de hospitais similares geridos diretamente pelo governo, de acordo com dados da Secretaria de Saúde do Estado da Bahia (2012), apresentando uma melhor infraestrutura em relação aos demais. Estados como Bahia, São Paulo e Minas Gerais lançaram mão dessa modalidade para expandir a rede de saúde conforme editais 
para adesão às parcerias. No Amapá, pode-se citar o hospital São Camilo e São Luís como parceiro recorrente da gestão estatal. As PPPs demonstram-se eficazes no auxílio à função do Estado de prover serviços de qualidade. Cabe destacar que a PPP não transfere ao parceiro privado a função inerente à gestão estatal, devido ao princípio da indelegabilidade das funções exclusivas do Estado - como a atividade de regulação, jurisdicional, do exercício do poder de polícia e de outras atividades, como demonstra o inciso III do art. 4은 da Lei $n .{ }^{0} 11.079 / 04^{2}$. A PPP almeja, portanto, a mútua colaboração na busca de suprir o interesse coletivo a partir da força de trabalho e prestação de serviço de um ente privado. Neste caso, tal interesse reside na ampliação do atendimento em saúde, e tais serviços podem ser de natureza infraestrutural ou assistencial. Apesar de não ser a única forma de contrato entre o Estado e hospitais privados, as PPPs podem auxiliar no atendimento em saúde pública de forma eficaz, garantindo através de sua forma o melhor instrumento para pactuação entre o ente público e o privado na abordagem em saúde com melhora na qualidade do serviço e redução do custo para o Estado. No modelo preconizado pelo SUS, o maior aporte financeiro deve ser direcionado às políticas de saúde preventivas. Contudo, a realidade demonstra ineficiência gerencial para atuar justamente na fase mais emergente da atividade em saúde pública: a terapia curativa. Os problemas são conhecidos: hospitais mal equipados e superlotados, morosidade burocrática, intervenção política excessiva, ingerência administrativa, entre outros. Ao compartilhar tal competência com o setor privado, o Estado passa a ter maior poder de controle, uma vez que os órgãos reguladores têm autonomia para fiscalizar e autuar as falhas do sócio que realiza o serviço e, sendo prestado por uma empresa terceira, o cidadão tem um aumento substancial no conjunto de direitos, sendo resguardado tanto pela Constituição Federal e Código Civil, mas também por legislações mais específicas, como o Código de Defesa do Consumidor. A sistemática já é amplamente utilizada em outros estados da federação, e tem-se percebido sua real eficácia, resultando em melhoras no gerenciamento e na qualidade do serviço e redução dos custos para o Estado. Considerações finais: A realidade não imprime o romantismo empregado na Carta Magna e, dessa forma, os gestores buscam maneiras de compensar as falhas estruturais do SUS. Tal proposta é consonante com a dicotomia público/privada no modelo de Estado aplicado no Brasil, especialmente após a edição da Lei Federal no 11.079, de 2004, que institui normas gerais para licitação e contratação de parceria públicoprivada no âmbito da administração pública. A PPP representa uma ferramenta moderna e pujante para encarar os novos desafios da gestão pública da saúde no Brasil e na realidade local amapaense. O debate deve ser continuado, não em cunho ideológico, mas sob aspectos técnicos, mensurando e avaliando riscos e benefícios. Afinal, gestores e cidadãos têm um desejo uníssono, que é uma saúde integral, universal, equânime e de qualidade. Implicações para a enfermagem: A administração de serviços de saúde, em proporção crescente nos diversos cenários de saúde, é uma função desempenhada pelo profissional enfermeiro. Administrar a partir do saber fundamentado, investigando e discutindo estratégias que possam ampliar o acesso aos serviços de saúde. Valorizar a equidade e garantir o atendimento do público é fundamental para conduzir intervenções na realidade e provocar mudanças no cenário de saúde.

Descritores: Parcerias Público-Privadas; Equidade em Saúde; Acesso aos Serviços de Saúde. 


\section{Referências}

1. Brasil. Constituição, 1988. Constituição da República Federativa do Brasil. Brasília: Senado Federal; 1988.

2. Brasil. Presidência da República, Subchefia de Assuntos Jurídicos. Lei oㅜ. 11.079/04, de 30 de dezembro de 2004. Institui normas gerais para licitação e contratação de parceria público-privada no âmbito da administração pública. Brasília, DF; 2004.

3. Alvarenga JE. Parcerias público-privadas: breves comentários. In: REDAE. №2, maio, junho/julho de 2005. Salvador: IDPB.

4. Carrera MBM. Parceria Público-Privada Na Saúde No Brasil: Estudo de caso do Hospital do Subúrbio de Salvador [dissertação]. Bahia: Escola de Administração de Empresas de São Paulo; 2012. 


\title{
PERCEPÇÕES DE FAMILIARES NO CUIDADO A UMA CRIANÇA COM MUCOPOLISSACARIDOSE TIPO II
}

\author{
${ }^{1}$ Ana Carolina Farias Vieira; ${ }^{2}$ Mayumi Teixeira Yoshida; ${ }^{3}$ Sâmea Marine Pimentel Verga; \\ ${ }^{4}$ Silvana Rodrigues da Silva; ${ }^{5}$ Maria Virginia Filgueiras de Assis Mello; ${ }^{6}$ Anneli Mercedes \\ Celis de Cárdenas.
}

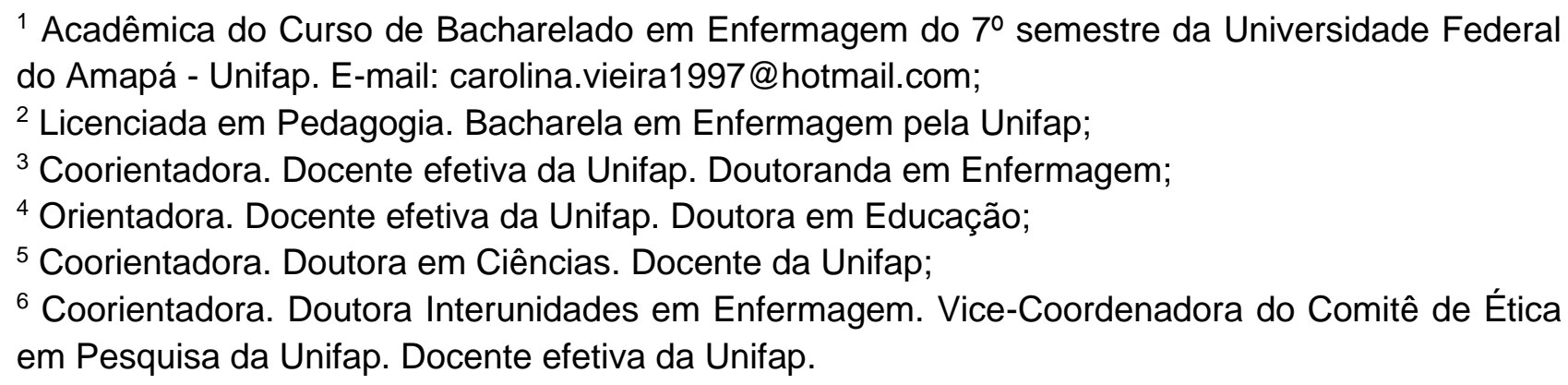

\section{RESUMO}

Introdução: Mucopolissacaridose tipo II (MPS II) é uma condição genética relacionada à deficiência de enzimas responsáveis pela degradação de mucopolissacarídeos, considerada doença rara, grave, limitante, progressiva, crônica de início no período infantil e requer cuidados diversificados. As manifestações clínicas incluem opacificação da córnea, macroglóssio, perda auditiva, hidrocefalia, cardiopatia, problemas respiratórios, hepatoesplenomegalia, hérnia inguinal e umbilical, alterações ósseas e limitações da mobilidade articular'. Nesse contexto, a família é uma unidade estrutural que passa por modificações dinâmicas em relação ao cuidado quando um dos seus membros adoece. Embora a família esteja engajada em oferecer todo o suporte à criança, nem sempre poderá suprir todas as necessidades desse indivíduo, o que requer envolvimento de uma rede de apoio para supri-las ${ }^{2}$ Objetivo: Descrever a percepção de uma família no cuidado a uma criança com mucopolissacaridose tipo II. Método: Estudo exploratório, descritivo, abordagem qualitativa, do tipo estudo de $\mathrm{Caso}^{3}$. Os cenários envolvidos foram: um Hospital localizado em Macapá-AP e um ambiente domiciliar localizado em uma comunidade da área rural de Macapá. Participou da pesquisa uma família de uma criança com MPS II atendida no referido hospital e que recebe o tratamento medicamentoso, a terapia de reposição enzimática. Os dados foram coletados por observação assistemática não participante e entrevista de roteiro semiestruturado, constituído por duas etapas: primeira com questões fechadas e abertas, com foco no perfil sociodemográfico da família; e a segunda, contendo o roteiro de entrevista com questões abertas. No primeiro momento, houve elaboração, em conjunto, de um genograma e um ecomapa da família. Estes foram elaborados manualmente e, posteriormente, utilizou-se o software GenoPro 2016, versão 3.0.1.4. No segundo momento, foram realizadas as entrevistas com os pais, separadamente, as quais foram gravadas em áudio para posterior transcrição e análise. Os dados foram analisados na perspectiva da Análise Qualitativa de Conteúdo de Bardin. Pesquisa fundamentada nos princípios da Resolução no 466/2012 do CNS com Parecer Consubstanciado ํo. 73197617.0.2002.003 do Comitê de Ética e Pesquisa (CEP) da Unifap. Resultados: As categorias que emergiram foram: 1. Genograma: 
representatividade da família da criança com MPS; 2. A criança com MPS: percepções e impactos na família; 3. Ecomapa e rede de apoio: perspectivas e desafios. Constatou-se que a estrutura da família é composta por seis membros, sendo o pai, a mãe e os quatro filhos que residem juntos no Ariri com renda menor que 1 salário mínimo proveniente de benefício social. Observou-se como pontos positivos no seio familiar o amor, o cuidado, as mudanças positivas no comportamento dos pais e a resiliência como enfrentamento. Entretanto, percebe-se o sofrimento e o temor da mãe frente à doença e os impactos presentes na saúde do filho com MPS, bem como a sobrecarga do cuidado e dos afazeres cotidianos, assumindo vários papéis sociais, o que gera desgaste mental. Foram mapeados por meio do ecomapa os serviços utilizados, com os quais os familiares demonstram relações positivas e negativas. Destacam-se como vínculos fortes a Rede Sarah, fundamental na descoberta do diagnóstico que influenciou diretamente a saúde física da criança, por meio do tratamento adequado, e a saúde psíquica dos pais, pois aliviou a angústia da espera de um diagnóstico. A falta de conhecimento dos profissionais de saúde interfere na demora do diagnóstico de doenças raras, fato agravado pela falta de integralidade na assistência, com pouca disponibilidade de exames específicos. $O$ transporte é fundamental para o deslocamento da família, que mora na zona rural, até os centros de tratamento da criança com deficiência, que se localizam na zona urbana. Em contrapartida, identificaram-se relações negativas nas redes de apoio, o que constitui uma barreira para a manutenção do cuidado integral e equânime. Entre as relações hostis apresentadas, destaca-se o relacionamento entre a família e a instituição hospitalar de saúde devido ao não cumprimento da decisão judicial e a falta de preparo e humanização na prestação da assistência. Os pais demonstram angústia quando relatam o descaso das autoridades e determinadas redes de apoio que prestam assistência ao filho. Nos relatos, é possível identificar as dificuldades encontradas desde a parte organizacional-burocrática até as relações negativas marcadas por conflitos que eles estabelecem com a instituição. Observou-se pelas falas a falta de preparo e humanização no atendimento da criança pelos profissionais de saúde, incluindo a equipe de enfermagem e médicos, a família expõe a falta de acompanhamento durante o processo de administração da medicação e de preparo, fatores que a preocupam devido às consequências que podem gerar esse despreparo. Considerações finais: Evidentemente o desafio cotidiano da família na instituição dos cuidados da criança, principalmente no que se relaciona ao acesso ao tratamento, sendo uma família de vulnerabilidade socioeconômica e que vive em área de difícil acesso, desprovida de diversos atendimentos de saúde. Garantir os serviços necessários para diminuir as dificuldades de acesso, portanto, é consolidar o princípio da equidade. Dada a dimensão multifacetada da problemática, tornam-se necessárias intervenções que incluam os poderes político-governamentais, ampla divulgação e cumprimento de políticas públicas voltadas às crianças com doenças crônicas e raras; criação de protocolos operacionais no hospital voltados à terapêutica específica da doença rara identificada, minimizando o receio dos profissionais em instituir a terapêutica e a descentralização do acesso aos serviços de saúde para áreas de difícil acesso. Deve-se ainda favorecer a comunicação das redes de apoio para o atendimento de forma integral, o estabelecimento de estratégias e serviços de inclusão e a acessibilidade para a criança e acompanhamento das condições físicas, psicológicas e emocionais da família, que, muitas vezes, é esquecida como participante do processo. Implicações para 
enfermagem: Suscitam-se reflexões sobre a prática da enfermagem nas condições atípicas de saúde dos indivíduos com a necessidade de atualização e reinvenção da sua prática, atentando para a humanização do atendimento. Ressalta-se a necessidade de valorização da profissão no cenário brasileiro.

Descritores: Família; Cuidado; Equidade.

\section{Referências}

1. Neufeld EF, Muenzer J. The Mucopolysaccharidoses. In: Valle D, Beaudet AL, Vogelstein B, Kinzler KW, Antonarakis SE, Ballabio A, Gibson K, Mitchell G. eds. New York, NY: McGraw-Hill; 2014.

2. Araújo YB, Reichert APS, Oliveira BRG, Collet N. Rede e apoio social de famílias de crianças com doença crônica: revisão integrativa. Cienc Cuid Saude 2011; 10(4):853860.

3. Yin RK. Estudo de Caso: planejamento e métodos. Porto Alegre: Bookman; 2015. p. 146-109. 


\title{
SINTOMATOLOGIA E PARÂMETROS HEMATOLÓGICOS E BIOQUÍMICOS FRENTE À TERAPIA ILIB - RELATO DE CASO CLÍNICO
}

\author{
${ }^{1}$ Ana Vitoria Gonçalves de Oliveira Cruz; ${ }^{2}$ Rebeca Góes Gonçalves; ${ }^{3}$ Larissa Duarte
} Ferreira; ${ }^{4}$ Alana Patrícia Lima Ferreira; ${ }^{5}$ Rafael Pires Moreira; ${ }^{6}$ Ana Rita Pinheiro

Barcessat.

\begin{abstract}
${ }^{1}$ Acadêmica do Curso de Bacharelado em Enfermagem; Universidade Federal do Amapá - Unifap. Bolsista do Departamento de Extensão (DEX); Grupo de Pesquisa em Biofotônica e Neuromodulação. E-mail: cruzvitoria07@gmail.com;

${ }^{2}$ Acadêmica do Curso de Bacharelado em Enfermagem; Unifap. Bolsista do Departamento de Extensão (DEX). Grupo de Pesquisa em Biofotônica e Neuromodulação;

${ }^{3}$ Enfermeira. Bolsista Capes - Programa de Pós-graduação em Ciências da Saúde (PPGCS); Unifap;

${ }^{4}$ Cirurgiã-Dentista. Bolsista Capes - Programa de Pós-graduação em Ciências da Saúde (PPGCS); Unifap;

${ }^{5}$ Farmacêutico. Mestre em Ciências Farmacêuticas; Unifap. Professor efetivo do Colegiado do Curso de Bacharelado em Enfermagem- Campus Binacional;

${ }^{6}$ Cirurgiã-dentista. Doutora em Estomatologia Básica e Aplicada - Patologia Bucal; Unifap. Professora efetiva do Colegiado do Curso de Bacharelado em Enfermagem e do Programa de Pósgraduação em Ciências da Saúde- Unifap.
\end{abstract}

\section{RESUMO}

Introdução: Intravascular Laser Irradiation Of Blood (ILIB) é uma terapia com efeitos fotoquímicos e fotofísicos que através de sua ação em diferentes células é capaz de gerar uma biomodulação por meio da absorção da radiação fornecida com um comprimento de onda específico e energia suficiente para desencadear respostas biológicas. ${ }^{1,2}$ Entre os aspectos fisiológicos mais observados estão: alteração do metabolismo intracelular com intensa da atividade dos leucócitos, assim como bioestimulação da CuZn Superóxido Dismutase (SOD), uma enzima antioxidante endógena capaz de proteger o organismo contra o radical superóxido e sua toxicidade e reatividade ao evoluir para formação do radical hidroxila quando não neutralizado. ${ }^{2}$ Por isso, o ILIB pode tornar-se uma opção terapêutica auxiliar em patologias que sofrem a ação de radicais livres. A artrite psoriásica, por sua vez, é uma doença autoimune que atinge parte dos pacientes com psoríase, acomete a pele e promove alterações articulares. Com o avanço da doença, outras patologias podem se manifestar, como a fibromialgia, síndrome que provoca dores musculoesqueléticas difusas, fadiga e insônia. 3,4 Essa associação pode causar significativa limitação funcional dos indivíduos acometidos. ${ }^{4} \mathrm{O}$ comprometimento, na maioria dos casos, é poliarticular, principalmente com atrofia das articulações interfalangeanas, além de lesões cutâneas extensas. ${ }^{3} \mathrm{O}$ esgotamento de opções para a terapia medicamentosa nesse caso de artrite psoriásica e fibromialgia, assim como o caráter analgésico, anti-inflamatório e antioxidante da ILIB, impulsionou a realização deste trabalho. Objetivo: Testar a capacidade da terapia ILIB de modular aspectos sintomatológicos, hematológicos e bioquímicos do quadro clínico de uma paciente com artrite psoriásica e fibromialgia. Método: Para a realização deste estudo, o protocolo do ILIB (Laser Duo - MM Optics) utilizado foi irradiação na artéria radial de 30 minutos do laser vermelho $(660 \mathrm{~nm})$ e 30 
minutos do infravermelho (808 $\mathrm{nm})$, respectivamente, durante dez dias consecutivos no primeiro ciclo e oito dias consecutivos no segundo ciclo, realizados com um intervalo de 39 dias. Houve a comparação de exames laboratoriais antes da terapia e após os dois ciclos, assim como análise de sintomas relatados pela paciente, através da aplicação de uma escala de intensidade, numerada de 1 a 10 (10 - Muito intenso, 1 - pouco intenso; 0 inexistente), no primeiro dia, no último dia e 20 dias após a aplicação de cada ciclo. Esta pesquisa foi aprovada CEP- Unifap sob o parecer 2.349.365. Resultados: Mulher, 61 anos, com diagnóstico de artrite psoriásica há cinco anos e fibromialgia há dois anos, apresenta fortes manifestações da doença, como lesões cutâneas frequentes, intensas dores difusas musculares e nas articulações, atrofia nos dedos, dormência, principalmente nas extremidades, alterações na pele e no sono. Faz uso de tratamento medicamentoso constante com Leflunomida e Humira desde o diagnóstico. Os principais sinais e sintomas avaliados com a escala de intensidade foram: dormência nas mãos; pele ressecada; dor nos membros inferiores; dor no corpo; coceira das lesões; insônia; fadiga; lesões cutâneas; atrofia nos pés e nas mãos; calafrios. No primeiro ciclo, houve melhora significativa no décimo dia e, após 20 dias, em quase todos os parâmetros, com exceção da atrofia nos membros superiores e inferiores que permaneceu inalterada e da coceira das lesões que diminuiu pouco na escala. No entanto, no segundo ciclo, a melhora foi observada apenas durante a aplicação, assim, após 20 dias, todos os parâmetros se apresentaram iguais ou piores em relação ao estágio inicial, antes do início da terapia. Esse efeito rebote sugere que o estímulo oferecido pela irradiação é temporário, ou seja, apesar de ter impacto positivo na qualidade de vida durante certo período, seus efeitos não se mantêm no organismo. No que diz respeito aos exames laboratoriais, foi notável a diferença na porcentagem de leucócitos nos dois momentos distintos: após a primeira aplicação reduziu em $44 \%$ e, após a segunda, houve um aumento de $284 \%$ em relação ao primeiro ciclo. Esses valores apontam que, apesar de a terapia ter provocado melhora significativa, seu efeito anti-inflamatório não se sustentou com eficácia diante das crises inflamatórias ocasionadas pela patologia após esse período. Outros aspectos bioquímicos analisados foram TGO (AST) e TGP (ALT) que, em condições de estresse oxidativo, tendem a apresentar-se aumentados, assim, após o primeiro estímulo, ambos sofreram redução pela ação antioxidante da terapia em estimular a enzima SOD. No entanto, o efeito sobre esse aspecto também foi passageiro, pois, 30 dias após o fim do segundo ciclo, o aumento observado foi de $288 \%$ para ALT e $63 \%$ para AST. Esse aumento pode ser explicado pelo fato de os efeitos da terapia serem mais eficazes em um intervalo menor que o realizado entre os dois ciclos e na realização dos exames após o último ciclo. Além disso, a Leflunomida, medicamento usado pela paciente, induz a toxicidade no fígado e o estresse oxidativo ${ }^{5}$, a qual, atrelada à ausência do estímulo da ILIB e às crises características da patologia, pode ter alterado significativamente os parâmetros de TGO e TGP. Considerações finais: A partir desse estudo, nota-se que os efeitos analgésicos, antiinflamatórios e antioxidantes da terapia ILIB foram significativos durante as aplicações. Além disso, a melhora dos aspectos sintomatológicos e bioquímicos apenas em curto prazo nesse caso de artrite psoriásica e fibromialgia atribuiu a ela um caráter terapêutico coadjuvante e alternativo que tem como objetivo auxiliar na melhora de quadros clínicos de pacientes em estado crítico através da modulação de inflamações ou da analgesia. No entanto, estudos clínicos randomizados são necessários a fim de testar sua eficácia diante 
de outras patologias similares com protocolos individuais. Implicações para a saúde: A terapia ILIB é uma técnica não invasiva que pode ser utilizada por todos que possuem habilitação em laser. Assim, todos os profissionais de saúde podem usá-la como terapia alternativa no cuidado, principalmente em casos críticos, a fim de promover a analgesia e melhorar a qualidade de vida do paciente. Além disso, a introdução dessa técnica como auxílio para a assistência é capaz de estimular a pesquisa de novas tecnologias pelos profissionais.

Descritores: Terapia a Laser; Artrite Psoriásica; Estresse Oxidativo.

\section{Referências}

1. Gomes CF, Schapochnik A. O uso terapêutico do Laser de Baixa Intensidade (LBI) em algumas patologias e sua relação com a atuação da fonoaudiologia. Distúrb Comun 2017 set; 29 (3): 570- 578.

2. Nuñez SC. Protocolo de Laserterapia e Terapia Fotodinâmica. 2ª ed. 2017.

3. Duarte AA, Pinto JM et al. Artrite Psoriásica E Comorbidades. Consenso Brasileiro De Psoríase. 2009.

4. Weidebach WFS. Fibromialgia: Evidências De Um Substrato Neurofisiológico. Rev Assoc Med Bras 2002.

5. Xuang J, REN Z, Qing T, Couch L, Shi L, Tolleson WH, GUO L. Mitochondrial dysfunction induced by leflunomide and its active metabolite. Toxicology. 2018 Mar 1; 396-397:3345. 


\title{
FATORES ASSOCIADOS E AVALIAÇÃO DA COGNIÇÃO DE UM GRUPO DE IDOSOS INSTITUCIONALIZADOS
}

\author{
${ }^{1}$ Camila Cibele dos Santos Holanda; ${ }^{2}$ Janete Silva Ramos; ${ }^{3}$ Demilto Yamaguchi da \\ Pureza.
}

${ }^{1}$ Enfermeira. Especialista em Urgência e Emergência e UTI. Mestranda do Programa de PósGraduação em Ciências da Saúde - Universidade Federal do Amapá - Unifap. E-mail: camilacsholanda@hotmail.com;

${ }^{2}$ Fisioterapeuta. Mestre em Ciências da Saúde - Unifap. Professora do Colegiado do Curso de Fisioterapia da Faculdade Estácio de Macapá;

${ }^{3}$ Educador Físico. Doutor em Ciências. Professor do Colegiado do Programa de Pós- Graduação em Ciências da Saúde - Unifap.

\section{RESUMO}

Introdução: Nas últimas décadas, tem-se observado um ritmo acelerado no crescimento da população idosa em todo mundo e, como resultado desse crescimento, surgem consequências que afetam diretamente os serviços de assistência social e de saúde da população geriátrica ${ }^{1}$. Mesmo que muitas pessoas continuem ativas e autônomas após os 60 anos, é comum que o estado mental comece a apresentar déficits, entre os mais comuns encontra-se a capacidade cognitiva ${ }^{2}$, que é o que nos define como seres pensantes, capazes de executar atividades com autonomia e conviver em sociedade. Objetivos: Avaliar o nível da capacidade cognitiva de um grupo de idosos institucionalizados e descrever os fatores associados à mesma. Método: Trata-se de uma pesquisa quantitativa de caráter exploratório, realizada com um grupo de idosos residentes em uma Instituição de Longa Permanência para Idosos (ILPI) do Estado do Amapá. O instrumento selecionado para avaliação do estado mental dos idosos foi o Mini Exame do Estado Mental, que fornece informações a respeito de várias áreas da cognição, tais como: orientação em tempo e espaço, memória, raciocínio lógico, atenção e cálculo. A avaliação foi feita no período de uma semana, com 13 idosos residentes na instituição, que aceitaram participar da pesquisa. Este estudo foi submetido ao Comitê de Ética e Pesquisa e aprovado sob o Parecer de no 1.303.750. Resultados: A ILPI é uma instituição que conta com uma equipe multiprofissional para atender às necessidades dos residentes. $O$ ambiente é dividido em vários cômodos, que são ocupados por até cinco idosos, além disso, possui espaço para atividades de lazer, refeitório e enfermaria para realizar atendimentos de baixa complexidade, como curativos e as medicações dos idosos. Entre os idosos residentes na ILPI, 15 aceitaram participar da pesquisa, destes, dois desistiram, restando, dessa maneira, 13 idosos participantes. No que tange à orientação de tempo e espaço, a maioria dos participantes demonstrou um bom desempenho, conseguindo informar sobre o dia, mês, ano, local e hora aproximada, sendo esse um achado positivo, uma vez que vários são os fatores que influenciam na saúde mental do idoso institucionalizado. Entre eles, o fato de estes muitas vezes perderem a sua conexão com a sociedade como um todo, o que afeta a sua orientação de tempo e espaço ${ }^{3}$. Na questão que avaliou a compreensão e atenção, em que o idoso deveria repetir as palavras solicitadas, 11 idosos conseguiram responder de forma satisfatória, devendo ser ressaltado que alguns idosos do grupo possuíam 
problemas de audição, o que pode ser justificativa para a dificuldade de compreensão. No teste para avaliação da memória, foi solicitado ao idoso que repetisse três palavras utilizadas na questão para avaliar compreensão, apenas dois idosos tiveram desempenho positivo, enquanto quatro realizaram o teste parcialmente e sete não conseguiram se lembrar. Relaciona-se isso ao fato de $46 \%$ dos participantes possuírem uma idade avançada, entre 71 e 80 anos e grande parte dos estudos referentes à população idosa aponta que a memória é a área mais afetada pelo envelhecimento, sendo a idade fator determinante nesse cenário ${ }^{3}$. Outros aspectos analisados foram leitura, escrita e cálculo, contudo $60 \%$ dos idosos demonstraram dificuldades para realizar essa etapa, e isso pode ser atribuído ao baixo grau de escolaridade, uma vez que $54 \%$ dos idosos participantes eram analfabetos. Segundo todos os dados apresentados, foi possível traçar um resultado final por meio da tabela de pontos de corte do MEEM em que é permitido dizer se o idoso apresenta perda cognitiva ou não e, de acordo com os cálculos e avaliações, constatou-se que: dos 13 idosos participantes da pesquisa, dez apresentaram perda cognitiva e três não. É comum que, devido a idade, a institucionalização e a qualidade de vida, esses idosos apresentem perda cognitiva ${ }^{2}$, entre os fatores que contribuem para essa realidade, foram encontrados: o tempo de institucionalização, a falta de atividades de lazer e recreação, o grau avançado da idade, as dificuldades de relacionamento e adaptação ao local, entre outros. Considerações finais: Devido ao processo de institucionalização, é muito comum e esperado que os participantes tivessem perda cognitiva, uma vez que os mesmos ficavam grande parte do tempo ociosos, tendo em vista que a ILPI não dispunha de profissionais que realizassem atividades com o objetivo de melhorar a cognição ou até mesmo proporcionar um momento de descontração ao idoso. Como foi observado pelos pesquisadores, isso acaba interferindo na qualidade de vida e no estado mental dos idosos, que muitas vezes se isolam, tendo dificuldades em aceitar sua situação e ficam desmotivados com a própria vida. Durante a realização da pesquisa, as maiores dificuldades relatadas pelos participantes foram os conflitos de convivência, que eram muito frequentes, e a falta de atividades recreativas. Além disso, o tempo ocioso, a falta de profissionais com uma visão holística da situação dos idosos e toda a rotina da institucionalização são fatores que contribuem para que esses idosos venham a apresentar déficits cognitivos. Ao término deste estudo, os resultados foram apresentados para a equipe multiprofissional e, juntamente com eles, foi sugerido um cronograma de treinos cognitivos adaptados de acordo com as áreas da cognição mais afetadas dos participantes.

Implicações para a enfermagem: O enfermeiro enquanto profissional e líder de equipe tem papel fundamental no campo da educação em saúde em todas as esferas da assistência. Como membro da equipe multiprofissional, é importante que este desenvolva uma visão holística em prol do paciente, ainda que este esteja em um contexto de institucionalização. É importante que esse profissional tenha a percepção das necessidades físicas, mas também psicossociais do indivíduo e que, através da equidade, possa desenvolver estratégias de enfrentamento para a problemática em questão, que atendam às necessidades do paciente nos mais diversos graus de complexidade. A enfermagem enquanto ciência precisa usar a pesquisa em saúde para identificar as problemáticas presentes na realidade e, dessa forma, conseguir prestar uma assistência de qualidade, com equidade e igualdade, para toda a população. 
Descritores: Saúde do Idoso; Institucionalização; Capacidade Cognitiva.

\section{Referências}

1. Dantas LCV. et al. Impactos da institucionalização na saúde mental do idoso. Revista Portal de Divulgação. 2013; 36(88): 35-43.

2. Fechine BRA; Trompieri N. O Processo de Envelhecimento: As principais alterações que acontecem com o idoso com o passar dos anos. Revista Cientifica Internacional. Ceará. 2012; 1(07): 106 - 194.

3. Freitas EV, PY L. Tratado de Geriatria e Gerontologia. Rio de Janeiro: Guanabara Koogan, 2011. 


\title{
PROTOCOLO CLÍNICO COM TÉCNICAS FOTOATIVADAS PARA UTILIZAÇÃO EM PACIENTES EM ESTADO CRÍTICO
}

\author{
${ }^{1}$ Carla Emanuela Xavier Silva; ${ }^{2}$ Alana Patrícia Lima Ferreira; ${ }^{3}$ Lucas dos Santos Nunes \\ ${ }^{4}$ José Pedro Gomes Moura; ${ }^{5}$ Aldo Aparecido Proietti Júnior; ${ }^{6}$ Ana Rita Pinheiro \\ Barcessat
}

\begin{abstract}
${ }^{1}$ Acadêmica de enfermagem. Bolsista IC- Superior - Rede Ciências - FAPEAP; UNIFAP. E-mail: carlaexavier98@gmail.com;

2 Cirurgiã-dentista. Mestranda do Programa de Pós-Graduação em Ciências da Saúde da Universidade Federal do Amapá; UNIFAP;

${ }^{3}$ Acadêmico de enfermagem. Bolsista PROBIC- VS - UNIFAP;

${ }^{4}$ Bacharel e licenciado em enfermagem. Mestrando do Programa de Pós-Graduação em Ciências da Saúde da Universidade Federal do Amapá; UNIFAP;

${ }^{5}$ Farmacêutico. Bioquímico. Doutorando pela Rede de Biodiversidade e Biotecnologia da Amazônia Legal - REDE BIONORTE. Professor adjunto do curso de Ciências Farmacêuticas da Universidade Federal do Amapá; UNIFAP;

${ }^{6}$ Cirurgiã-Dentista. Doutora em Estomatologia Básica e Aplicada (FO-USP). Professora efetiva do colegiado de Enfermagem e do programa de Pós Graduação em Ciências da Saúde; UNIFAP.
\end{abstract}

\section{RESUMO}

Introdução: A cavidade oral é apontada por vários estudos como um dos meios de acesso para microrganismos capazes de desencadear infecções sistêmicas. ${ }^{1}$ Essa situação se torna mais preocupante ao considerar os pacientes sob cuidados em unidade de terapia intensiva (UTI), já que esse ambiente é caracterizado pela utilização de medidas terapêuticas invasivas como a intubação endotraqueal e a ventilação mecânica, as quais estão associadas à contaminação da cavidade bucal por patógenos, contribuindo para complicações do estado desse paciente. ${ }^{2}$ Diante disso, torna-se relevante o estudo de técnicas como a Terapia Fotodinâmica (TFD), cujo efeito provoca estresse oxidativo pela associação de uma substância fotoativa, uma fonte de luz e oxigênio, produzindo espécies reativas de oxigênio e exercendo, dessa forma, papel importante no contexto de redução microbiana, demonstrando ainda viabilidade de aplicação no recinto de terapia intensiva. ${ }^{3}$ Objetivo: O presente estudo objetiva descrever gradativamente a construção de um protocolo de descontaminação oral por TFD realizado em ambiente de UTI. Método: Tratase de uma pesquisa de abordagem quantitativa, descritiva, realizada na UTI do Hospital de Clínicas Alberto Lima (HCAL) e no Laboratório Especial de Microbiologia Aplicada (Lema) da Universidade Federal do Amapá (Unifap), no período de maio a novembro de 2018. Após aprovação do Comitê de Ética em Pesquisa sob o parecer de oㅡ 2.349.365, foi dado início à seleção dos pacientes e a um estudo piloto de viabilidade para a construção do protocolo. Os pacientes selecionados e/ou seus respectivos responsáveis foram informados sobre a aplicação da TFD, indicações e inexistência de efeitos colaterais para assinatura do Termo de Consentimento Livre e Esclarecido (TCLE), no momento de admissão da internação na UTI. Foram definidos critérios de elegibilidade, número amostral, alocação randômica, grupos experimentais e cegamento com base no enunciado CONSORT 2010, e os parâmetros da TFD através de um ensaio piloto de viabilidade e referências bibliográficas. ${ }^{4}$ Resultados: Aos pacientes em estado crítico em condições experimentais similares às 
deste estudo, o protocolo proposto está assim caracterizado: 1. Aspectos éticos: os passos que dizem respeito ao registro e à obtenção de parecer ético devem ser o ponto de partida, posto que demandarão providências de logística no local de execução. 2. Critérios de inclusão: pacientes independentemente de gênero, internados na UTI em questão, independentemente de tempo de internação e conscientes uma vez que podem assentir à terapia. 3. Cálculo amostral: a mensuração da amostra foi determinada pelo método aleatório simples: $\mathrm{N} 0=1(\mathrm{E} 0) 2$ e $\mathrm{n}=(\mathrm{N} . \mathrm{N} 0)(\mathrm{N}+\mathrm{N} 0)$, onde: $\mathrm{N}=$ tamanho da população $=20$ (média de novos pacientes admitidos na UTI em uma semana); N0= primeira aproximação do tamanho da amostra $=400 ; E 0=$ erro amostral tolerável $=5 \%$ ou 0,$05 ; n=$ tamanho da amostra $=19$ pacientes. 4. Estudo piloto para análise e definição do protocolo de descontaminação propriamente dito: os pacientes selecionados foram divididos em dois grupos (G1 - AmTFD - Terapia Fotodinâmica mediada pelo azul de metileno e laser e G2 CurTFD - Terapia Fotodinâmica mediada pela curcumina e LED); os aspectos avaliados foram: tempo da técnica, aderência do FS à mucosa, facilidade de aplicação, custo do FS, custo da fonte de luz, conforto do paciente e potencial de redução microbiana. Inicialmente, foi umidificada a cavidade oral dos pacientes com $5 \mathrm{~mL}$ de água destilada para a coleta inicial (C0) com pipeta Pasteur para aspiração do fluido oral. Subsequentemente, foram aplicadas as respectivas modalidades de TFD, gotejando-se o agente FS em região de trígono retromolar, fotoativando-se e realizando-se nova coleta (C1) na mesma região. As amostras de $3 \mathrm{~mL}$ foram inseridas em tubo de ensaio esterilizado e armazenadas em recipiente térmico com gelo e encaminhadas ao Laboratório de microbiologia, em intervalo máximo de 2 horas para evitar a proliferação de microrganismos que poderia contribuir para resultados inverídicos. Para análise microbiológica, procedeu-se à homogeneização das amostras, diluições seriadas de 1:10, 1:100, 1:1.000, 1:10.000 e 1:100.000, sendo a última determinada como referência. Posteriormente, foi realizado inoculação da amostra já diluída em meio Ágar Sangue e incubação em estufa bacteriológica a $35^{\circ} \mathrm{C}$. Após $24 \mathrm{~h}$, procedeu-se à contagem do número total de unidades formadoras de colônia. Verificandose que, de acordo com os aspectos avaliados, as técnicas de TFD eram potencialmente bactericidas e apresentavam viabilidade de execução no ambiente da UTI escolhida. 5 . Critérios de exclusão: estes foram definidos após análise de viabilidade da técnica nas condições propostas, mas relatados junto aos critérios de inclusão, pacientes que tinham realizado higiene oral no dia da coleta, sob intubação orotraqueal, e ainda placas com culturas incontáveis à diluição estabelecida. 6. Alocação randômica e cegamento: optou-se pela randomização determinística, com base na data de admissão, por um pesquisador alheio ao protocolo, que foi diferente daquele que aplicou a técnica e daquele que fez a análise laboratorial, obtendo-se três níveis de cegamento, de forma a garantir a homogeneidade na distribuição de grupos. 7. Grupos Experimentais: G1 - AmTFD - TFD com azul de metileno $(0,01)$ ativado por laser $(660 \mathrm{~nm} ; 90 \mathrm{~J} / \mathrm{cm} 2)$ em modo pontual. ${ }^{3}$ e G2 - CurTFD - TFD pela curcumina (PDT Pharma com concentração de 1,5g/L) e LED azul $\left(660 \mathrm{~nm} ; 90 \mathrm{~J} / \mathrm{cm}^{2}\right)$. Considerações finais: Dessa forma, espera-se que o protocolo de redução microbiana em cavidade oral que se utiliza de TFD para a Unidade de Terapia Intensiva seja capaz de auxiliar na redução microbiana em cavidade oral e consequentemente na diminuição dos casos de infecções sistêmicas que estão relacionados com a contaminação da cavidade bucal. Outros efeitos esperados com a aplicação do protocolo são a melhora da qualidade de vida do paciente em estado crítico e 
maior controle das intercorrências relacionadas à carga microbiana na cavidade bucal. Implicações para a enfermagem: Embora a maioria dos estudos que abordam essa temática se encontrem como publicações da área da odontologia, esse protocolo pode ser utilizado pelo profissional enfermeiro. Além disso, o cuidado integral ao paciente e a finalidade deste protocolo mencionada anteriormente devem ser levados em consideração, visto que o enfermeiro é um dos responsáveis pela prevenção e pelo controle de infecções relacionadas à assistência de saúde.

Descritores: Unidade de Terapia Intensiva; Fototerapia; Descontaminação.

\section{Referências}

1. Morais TMN. et al. A importância da atuação odontológica em pacientes internados em unidade de terapia intensiva. Revista Brasileira de Terapia Intensiva. 2010; 18(4): 412417.

2. Ramirez P, Bassi GL, Torres A. Measures to prevent nosocomial infections during mechanical ventilation. Current opinion in critical care. 2012; 18(1): 86-92.

3. Barcessat, ARP, et al. Effect of topical 5-ALA mediated photodynamic therapy on proliferation index of keratinocytes in 4-NQO-induced potentially malignant oral lesions. Journal of Photochemistry and Photobiology B: Biology. 2013; 126: 33-41.

4. Martins J, Sousa, L. M.; Oliveira, A. S. Recomendações do enunciado CONSORT para o relato de estudos clínicos controlados e randomizados. Medicina (Ribeirao Preto). 2009; 42(1): 9-21.

5. Nunes CSR, Junior AAP, Barcessat ARP. Descontaminação fotoquímica de alvéolos dentários em técnicas distintas de Terapia Fotodinâmica: relato de dois casos clínicos. Estação Científica (UNIFAP). 2018; 8(2): 129-137. 


\title{
ENFERMAGEM FRENTE ÀS CONDIÇÕES DE SAÚDE DOS MOTORISTAS DA UNIVERSIDADE FEDERAL DO AMAPÁ
}

\author{
${ }^{1}$ Larissa Duarte Ferreira; 2 Leilson da Silva Lima; ${ }^{3}$ Carlos Augusto Alves de Lima Junior; \\ ${ }^{4}$ Inake Gomes Marinho; ${ }^{5}$ Rubens Alex de Oliveira Menezes; ${ }^{6}$ Rosana Oliveira do \\ Nascimento*.
}

\begin{abstract}
${ }^{1}$ Acadêmica do Curso de Bacharelado em Enfermagem; Unifap;
${ }^{2}$ Acadêmico do Curso de Bacharelado em Enfermagem; Unifap;

${ }^{3}$ Acadêmico do Curso de Bacharelado em Enfermagem; Unifap. E-mail: aug.limma@gmail.com;

${ }^{4}$ Acadêmico do Curso de Farmácia; Unifap;

${ }^{5}$ Enfermeiro. Doutor em Doenças Infecciosas e Parasitárias - Universidade Federal do Pará UFPA. Professor efetivo do Colegiado do Curso de Enfermagem;

${ }^{6}$ Enfermeira. Mestre em Saúde Coletiva - Universidade de Fortaleza - Unifor. ${ }^{\star}$ Professora efetiva do Colegiado do Curso de Enfermagem.
\end{abstract}

\section{RESUMO}

Introdução: A ocupação profissional de motorista nas instituições universitárias está cada vez mais relacionada a danos à saúde, uma vez que os estilos de vida, assim como as condições de trabalho, estão intimamente relacionados com a presença ou ausência da qualidade de vida $(\mathrm{QV})^{1}$. Após iniciar suas atividades laborais, o motorista tende a suprimir sua subjetividade para cumprir com horários pré-programados ${ }^{2}$. A omissão de suas próprias necessidades, em conjunto com as circunstâncias ergonômicas dos meios de transporte, favorece os fatores de risco para diversas doenças crônicas não transmissíveis, tais como: hipertensão e diabetes. Além disso, o sedentarismo, hábitos alimentares inadequados, excesso de peso e nível de estresse elevado são fatores determinantes para o aparecimento de diversos agravos. Ressalta-se que, entre as doenças prevalentes, destaca-se a Hipertensão Arterial Sistêmica (HAS), considerada um problema de saúde pública pelo risco para doenças cardiovasculares. A HAS pode se manifestar de diversas formas nesse grupo, exatamente pela dinâmica do seu trabalho, que envolve estresse, carga horária excessiva e intensa, culminando com o consumo de comidas industrializadas, frituras, alimentação desregular, obesidade, estresse, consumo de bebidas alcoólicas, entre outras. Esses formam os principais fatores de risco para a $\mathrm{HAS}^{3}$. Vale dizer que outro fator importante é ausência desses indivíduos às consultas subsequentes com o intuito de prevenir agravos e promover a saúde. Objetivo: $O$ objetivo deste estudo foi conhecer a morbidade dos motoristas da Universidade Federal do Amapá e os fatores de risco associados ao desenvolvimento de doenças crônicas não transmissíveis. A pesquisa foi aprovada pelo Comitê de Ética-CEP/Unifap, conforme parecer: 3003159. Método: Tratase de um estudo transversal realizado na Universidade Federal do Amapá (Unifap), em que os motoristas foram abordados ao término de seu turno de trabalho, tendo sido entrevistados individualmente em sala que assegurou o sigilo das informações prestadas. Adicionalmente foram realizados exames com: aferição da pressão arterial (PA), coleta glicêmica, medição da circunferência abdominal e coleta de dados antropométricos: peso, altura e Índice de Massa Corpórea normal (IMC). Os valores de referência foram classificados segundo as recomendações da Associação Brasileira para o Estudo da 
Obesidade (Abeso). Também foram realizados testes rápidos mediante punção digital, para detecção de anticorpos para HIV, sífilis e hepatites $B$ e C e um questionário referente ao grau de estresse vivenciado pelos sujeitos da pesquisa. Resultados: Os investigados representaram um quantitativo amostral de 12 motoristas da universidade supracitada que aceitaram participar da pesquisa. Eram do sexo masculino 100\% dos entrevistados, com faixa etária entre 27 e 68 anos. Quanto aos dados colhidos e valores antropométricos: a pressão arterial sistólica (PAS) variou de 120 a $150 \mathrm{mmHg}$ e diastólica (PAD) de 80 a 100 $\mathrm{mmHg}$. Os níveis glicêmicos destes variaram entre 85 e $112 \mathrm{mg} / \mathrm{dL}$, com IMC de 20.2 a 30.3 e circunferência abdominal entre 87 e 118. A totalidade dos testes rápidos feitos nos entrevistados apresentou como resultado "Não reagente" para as infecções sexualmente transmissíveis investigadas (ISTs) e Hepatite $\mathrm{B}$, o nível de estresse também foi considerado normal pelo questionário aplicado. As prevalências dos principais fatores de risco foram: $100 \%$ para elevado consumo de refrigerante, $66,6 \%$ (8/12) para consumo de carne com gordura, $75 \%$ (9/12) para consumo de frango com pele, $91,6 \%$ (11/12) para baixo consumo de frutas, $58,3 \%(7 / 12)$ para uso de sal diretamente no prato, $41,6 \%(5 / 12)$ para tabagismo, $83,3 \%$ (10/12) para uso excessivo de bebidas alcoólicas, $75 \%$ (9/12) para sedentarismo e $58,3 \%(7 / 12)$ para excesso de peso. Mais da metade dos fatores de riscos avaliados no estudo tiveram resultados positivos entre os trabalhadores assistidos. Com relação às horas de sono, pôde-se verificar que não dormem o suficiente. Quanto aos problemas de saúde, foi informado pressão alta, dor de estômago, frequentes dores de cabeça e problemas de coluna. Estes foram os mais citados. Logo, estes resultados impõem a necessidade de dar continuidade aos estudos com pesquisas qualitativas e quantitativas, amostras ampliadas, com o objetivo de aprofundar o tema ora estudado, bem como outros temas que possam permitir conhecimento abrangente sobre as características psicossociais de motoristas de instituições públicas e privadas. Considerações finais: Através deste estudo observou-se alta prevalência no que diz respeito a hábitos de vida nocivos à saúde, tais como alimentação não saudável, a baixa prática de atividade física, carga horária de trabalho rígida, levando a um tempo insuficiente de descanso. Outro achado importante na pesquisa foi o consumo de bebida alcoólica, tabaco e refrigerantes que ajuda a diminuir o sono, o que pode levar a uma maior incidência de acidentes de trânsito. Resultados também apontam para riscos de doenças crônicas não transmissíveis (DNCTs), tornando-se necessárias intervenções da Enfermagem e equipe multiprofissional diretamente com a população de trabalhadores, com ações educativas intensas que orientem sobre prática de padrões de vida saudável para evitar e/ou amenizar a situação. Nesse cenário, as intervenções de enfermagem serão de grande valia no cotidiano dessa população, uma vez que poderão prevenir os agravos pertinentes a esses trabalhadores. Implicações para a enfermagem: Planejar ações de enfermagem que se adaptem ao tempo livre do profissional motorista faz-se necessário para alcançar de forma integral esse público-alvo com ensinamentos profiláticos. Como exemplos, citam-se atividades para evitar o sedentarismo ao fazer movimentos que ativem a musculatura e melhorem a circulação, mesmo enquanto exerce seu trabalho, além de informações que possam ser aplicadas na realidade em que este vive para conseguir resultados significativos, pois as necessidades pessoais destes trabalhadores acabam sendo deixadas em segundo plano. Quanto aos portadores de DCNTs, levando em conta que a QV depende também de fatores intrínsecos, o presente estudo aponta a necessidade de o profissional fazê-los entender quais as fontes 
dos agravos e desconfortos das doenças observadas e a necessidade de que procurem atenção especializada, já que as atividades de risco para estes profissionais não se limitam apenas ao local de trabalho e seus acessos à atenção de saúde se resumem aos dias de folga, e os mesmos apresentam resistência em procurar um hospital, tornando-se reféns do comodismo.

Descritores: Motoristas; Fatores de riscos; Obesidade; Doenças cardiovasculares; Saúde ocupacional.

\section{Referências}

1. Alcantara V., Silva R., Pereira E, Silva, MA. A qualidade de vida para motoristas de ônibus: entre a saúde e o trabalho. Rev Port Enferm de Saúde Mental 2016 Out;4(no esp.):101-106.

2. Alcantara VCG, Silva RMRCA, Pereira ER. As condições de trabalho e o mundo da vida de motorista de ônibus: estudo fenomenológico. Rev Enf UERJ, 2016; 24(6): 1-4.

3. Brito GMG, Gois CFL, Almeida AFA, Martins AWR, Rodrigues EOL, Gois Junior JP. Fatores de risco para hipertensão arterial entre motoristas de ônibus. Rev Baiana Enf, 2016;30 (2): 1-7. 


\section{SOFRIMENTO MENTAL DE DISCENTES DE PÓS-GRADUAÇÃO STRICTO SENSU}

${ }^{1}$ Ruan Patrick de Oliveira Souza; ${ }^{2}$ Carolina Almeida de Oliveira; ${ }^{3}$ Yuri de Medeiros Souza Lima; ${ }^{4}$ Darci Francisco dos Santos Junior; ${ }^{5}$ Ana Rita Pinheiro Barcessat; ${ }^{6}$ Marina Nolli Bittencourt.

\footnotetext{
${ }^{1}$ Enfermeiro discente do Programa de Pós-graduação em Ciências da Saúde; Universidade Federal do Amapá - Unifap; E-mail: prelude752@hotmail.com;

2 Enfermeira discente do Programa de Pós-graduação em Ciências da Saúde; Unifap;

${ }^{3}$ Farmacêutico discente do Programa de Pós-graduação em Ciências da Saúde; Unifap;

${ }^{4}$ Acadêmico do $7^{\circ}$ do Curso de Bacharelado em Enfermagem; Unifap;

${ }^{5}$ Professora assistente do Curso de Bacharelado em Enfermagem; Unifap;

${ }^{6}$ Professora assistente do Curso de Bacharelado em Enfermagem; Unifap.
}

\section{RESUMO}

Introdução: A pós-graduação é o significado de muitas mudanças na vida do indivíduo, o qual precisa se adaptar a exigências nunca vivenciadas, o que se torna um desafio que afeta a sua relação com o meio acadêmico, as suas relações familiares e o bem-estar físico e psíquico. Quando o indivíduo não possui habilidade para lidar com essas mudanças, elas podem se tornar uma importante fonte de sofrimento psíquico, como ansiedade, depressão e estresse, os quais estão mais em evidência atualmente. Estabelecendo uma relação desses conceitos com a realidade da carreira acadêmica, cerca de um terço dos estudantes de pós-graduação tem o risco de evoluir para um transtorno mental, entre os mais comuns está a depressão. Essa projeção vem crescendo juntamente com os estudos sobre a predominância de problemas mentais na academia ${ }^{1}$. Objetivo: Com base neste cenário, 0 objetivo deste estudo foi investigar os níveis de ansiedade, depressão e estresse em discentes de cursos de Pós-Graduação. Método: Trata-se de um estudo do tipo descritivo, de caráter quantitativo. O estudo foi realizado na Universidade Federal do Amapá (UNIFAP), nos cursos de pós-graduação. Os critérios de inclusão foram: ser maior de 18 anos; ser discente de um dos programas de pós-graduação da Universidade Federal do Amapá; estar ativo no programa. Os critérios de exclusão foram: Ter alguma deficiência que impossibilite responder ao questionário; ser discente de pós-graduação lato sensu. Os discentes foram contatados através do endereço eletrônico (e-mail), e o retorno dos questionários chegou atingiu o total de 139. Para a coleta de dados, foram usados dois instrumentos que foram unidos no formulário on-line juntamente com o Termo de Consentimento Livre Esclarecido (TCLE). O primeiro foi o instrumento de caracterização de aspectos socioeconômicos (idade, renda, ocupação) e acadêmicos (formação, programa, ano de ingresso, satisfação com o programa), o segundo instrumento foi a Escala de Ansiedade, Depressão e Estresse (EADS-21). Esta pesquisa foi submetida ao Comitê de Ética e Pesquisa da Universidade Federal respeitando os preceitos éticos e legais. Com parecer favorável registrado sob o número 3.216.711, expedido no dia 12 de dezembro de 2017. Resultados: Nas variáveis socioeconômicas, a população se mostrou em sua maioria na faixa etária de 20 a 30 anos $(56,1 \%)$, sexo feminino $(61,9 \%)$, de etnia parda $(54,7 \%)$, com renda familiar acima de cinco salários mínimos $(53,2 \%)$, provenientes do Estado do Amapá (45,5\%), e como fonte de renda o trabalho como servidor público (55,4\%). 
Com relação às características acadêmicas, a maioria dos entrevistados eram da área de Ciências da Saúde (48,2\%) e estava no Programa de Pós-graduação em Ciências da Saúde (38,8\%), com nível de formação concluído de especialização (51\%), e 47,5\% ingressaram no programa de pós-graduação no ano de 2017. Quando questionados sobre o nível de satisfação com o curso de pós-graduação, 53,9\% relataram estar satisfeitos com o programa, $74,1 \%$ relataram não ter tido nenhum conflito no programa, porém $25,9 \%$ se dividiram em conflitos com orientador, coordenação e docentes. No que tange à possibilidade de desistir, 56\% disseram não cogitar esta ideia e 44\% já cogitaram essa possibilidade. Entre os subgrupos da EADS-21, o que apresentou maior média de pontuação foi o estresse com $15,99 \pm 11,98$, classificado como grau leve, seguido pela depressão moderada e ansiedade moderada. No subgrupo ansiedade, $51,1 \%$ se enquadraram no nível normal da escala e $21,5 \%$, no nível extremamente grave. Nos sintomas do subgrupo de Depressão, 65\% estavam classificados como normal e 33\% estavam no nível extremamente grave apontado pela escala. No subgrupo de Estresse, $59 \%$ estavam classificados como normal e 19\% moderado. Esses percentuais evidenciam uma crise de saúde mental nos programas de Pós-Graduação, pois enquanto há uma parcela esperada na classificação normal, no segundo maior percentual, estão os classificados como extremamente grave, o que sugere transtornos mentais graves e persistentes já instalados em uma parcela muito significativa dos discentes e esse cenário necessita de intervenções imediatas, uma vez que a Pós-Graduação adoece os discentes e precisa ser tratada. As variáveis que tiveram associação positivas para Ansiedade foram: curso de pós-graduação na área de Ciências Farmacêuticas, Desenvolvimento Regional e História, ou seja, os alunos desses cursos apresentam maior risco de escores positivos nos sintomas ansiedade. A variável Idade no grupo de 41 a 50 anos teve associação negativa com os sintomas de estresse na escala, ou seja, os discentes desse grupo tiveram menos risco de apresentarem sintomas depressivos. Os sintomas de Estresse da escala também tiveram associação significativamente positiva com a variável referente aos alunos que cursavam pós-graduação no programa de Ciências Farmacêuticas, logo, os discentes deste grupo apresentam mais sintomas de Estresse. Entretanto, a variável Ano de Ingresso 2015 mostrou associação negativa, assim, os alunos mais antigos tiveram menores sintomas de Estresse. A variável relacionada ao desejo de desistir do curso teve associação significativa nos três domínios da EADS-21. Dessa forma, os discentes que já pensaram em desistir do curso apresentaram mais sintomas ansiosos, depressivos e de estresse. $E$ esse dado responde aos questionamentos e hipóteses feitas no começo da pesquisa de que discentes insatisfeitos tendem a ter sintomas de ansiedade, depressão e estresse e isso leva a desmotivação e pensamentos de desistência do curso. Considerações finais: De certo, a pós-graduação carrega consigo, ainda, uma bagagem que, para o discente, torna-se um grande fator de desenvolvimento de adoecimento psíquico, causando sintomas como ansiedade, depressão e estresse. As instituições de ensino precisam fomentar políticas assistenciais e de aconselhamento psicológico que sejam voltadas para os discentes de pós-graduação, uma vez que, a inexistência delas é percebida no âmbito das instituições. Além disso, precisam criar grupos de suporte para o compartilhamento de experiências que propiciem a aproximação dos discentes e docentes. Implicações para a enfermagem: Este estudo abre campo de atuação da enfermagem no ambiente acadêmico, tornando-se uma promotora da saúde mental nas Instituições de Ensino 
Superior, bem como no trabalho através da extensão universitária a fim de diminuir o sofrimento psíquico dos estudantes.

Descritores: Ansiedade; Depressão; Estresse; Educação de Pós-graduação.

\section{Referência}

1. Pain E. students face significant mental health challenges. 2017. Science; (4). 


\title{
HIV NA GESTAÇÃO: ESTUDO EPIDEMIOLÓGICO EM UMA MATERNIDADE DO AMAPÁ
}

\author{
${ }^{1}$ Diana Silva de Aguiar; ${ }^{2}$ Sara de Souza Pinto; ${ }^{3}$ Camila Rodrigues Barbosa Nemer; \\ ${ }^{4}$ Rubens Alex de Oliveira Menezes.
}

\begin{abstract}
${ }^{1}$ Acadêmica do Curso de Bacharelado em Enfermagem; Universidade Federal do Amapá - Unifap. E-mail: dianaaguiar0203@gmail.com;

${ }^{2}$ Acadêmica do Curso de Bacharelado em Enfermagem; Unifap;

${ }^{3}$ Enfermeira. Mestre em Enfermagem. Doutoranda em Saúde Pública pela Escola Nacional de Saúde Públia (Ensp)/ Fundação Oswaldo Cruz (Fiocruz). Professora do Colegiado do Curso de Bacharelado em Enfermagem da Unifap;

${ }^{4}$ Enfermeiro. Doutor em Doenças Infecciosas e Parasitárias - Universidade Federal do Pará UFPA. Professor efetivo do Colegiado do Curso de Bacharelado em Enfermagem.
\end{abstract}

\section{RESUMO}

Introdução: O Vírus da Imunodeficiência Humana (HIV) é um agente infeccioso capaz de invadir o organismo e causar a doença clínica chamada Síndrome da Imunodeficiência Humana (Aids), a qual é responsável por deprimir acentuadamente o sistema imunológico, fazendo com que o indivíduo infectado se torne extremamente vulnerável e não tenha defesas para se curar das mais simples enfermidades ${ }^{1}$. A disseminação do HIV tem crescido consideravelmente entre o público feminino e já é uma realidade em nível mundial. Esse quadro traz consigo outras dificuldades, que repercutem fortemente na saúde pública. Uma delas é o aumento do número de gestantes com HIV, o que, por sua vez, eleva o risco de transmissão vertical (TV) do vírus ${ }^{2}$. A essa situação deve ser dada a devida importância, uma vez que a maioria das mulheres que convive com o vírus encontra-se em plena vida reprodutiva, o que pode resultar num aumento do número de crianças infectadas a partir da TV. Isso justifica o fato de que $90 \%$ dos menores de 13 anos com aids no país são infectados por meio da TV ${ }^{2,3}$. A infecção pelo HIV tem se tornado bastante comum em gestantes e vem sinalizando uma tendência de crescimento nesse grupo, principalmente nas regiões Norte e Nordeste, até mesmo por conta de uma mais ampla detecção da doença, possibilitada por um maior preparo do sistema de saúde que atualmente conta com testes-rápidos de HIV disponibilizados pela Rede Cegonha. No período de 2000 a 2017, foram notificados 108.134 casos de gestantes infectadas pelo HIV. Além disso, dentro desse grupo predominam mulheres com idade entre 20 e 24 anos e com baixa escolaridade, sendo que a maioria reside na Região Sudeste 4 . Estima-se que cerca de 17.200 gestantes são infectadas pelo HIV no Brasil, a cada ano ${ }^{5}$. Objetivo: Traçar o perfil epidemiológico de gestantes com HIV atendidas em um Hospital de Macapá-AP, no período de 2008 a 2018. Método: Trata-se de um estudo descritivo, documental e quantitativo, no qual foi utilizado para a coleta de dados o Sistema de Informação de Agravos de Notificação (Sinan). Para a realização da pesquisa, foram incluídas todas as mulheres atendidas em um Hospital de Macapá-AP, no período de 2008 a 2018. As variáveis estudadas foram: ano de notificação, raça, escolaridade, momento do diagnóstico, realização do pré-natal e tipo de parto. A pesquisa foi aprovada pelo Comitê de Ética-CEP/Unifap, sob o parecer: 3.171.715. Resultados: Conforme os dados disponibilizados pelo Sinan, foi registrado um 
total de 228 casos de gestantes com HIV no hospital dentro do período de 2008 a 2018, o que resultou em uma média de 20,7 casos notificados por ano. Os anos com maior número de notificações foram 2013, 2014 e 2016 com respectivamente, 30, 27 e 28 casos. A maioria dessas gestantes são da cor parda 74,5\% (170/228) e possuem baixo grau de escolaridade, que, em sua maioria, alcança, no máximo, o nível fundamental, 39,9\% (91/228). Com relação ao momento do diagnóstico, 38,1\% (87/228) dessas mulheres foram diagnosticadas como portadoras do vírus HIV durante o pré-natal e 33,3\% (76/228) delas, antes do pré-natal. Há de se comentar que o número de diagnósticos de HIV durante o parto também foi considerável, representando $25,8 \%$ dos casos (59/228). No que concerne à realização do pré-natal, os dados revelam que a grande maioria das gestantes foi beneficiada por este serviço, com representação de $82 \%$ de cobertura (187/228). Por fim, a escolha pelo tipo de parto se deu, na maioria das ocorrências, pela cesárea eletiva, que correspondeu a 53,5\% dos casos (122/228). Em síntese, observou-se que as gestantes portadoras do vírus HIV atendidas no hospital, no período de 2008 a 2018, caracterizamse por serem majoritariamente pardas, terem um baixo grau de escolaridade, com diagnóstico da doença principalmente durante o pré-natal, possuírem uma cobertura de pré-natal satisfatória e pela escolha de cesárea eletiva como tipo de parto para a maioria dos casos. Considerações finais: As estratégias utilizadas pela epidemiologia são fundamentais para realizar o monitoramento do HIV nos grupos populacionais para se conhecer o comportamento das pessoas, quais delas se apresentam mais vulneráveis a essa infecção e as mudanças que ocorrem ao longo do tempo no perfil epidemiológico da doença. Através deste estudo, percebeu-se que, entre o grupo de gestantes atendidas no hospital no período em questão, há uma maior vulnerabilidade para a infecção do vírus HIV entre aquelas que possuem cor da pele parda e com baixa escolaridade. A falta de informações e conhecimentos decorrentes da pouca instrução pode ser fator que determina a contração dessa patologia, uma vez que muitas pessoas desconhecem o seu comportamento e formas de prevenção. Nesse sentido, a realização do pré-natal é imprescindível para que gestantes com HIV, a partir do seu diagnóstico, tenham acesso ao tratamento adequado, sejam orientadas e acompanhadas por conta das restrições à amamentação e quanto à escolha do melhor tipo de parto. Felizmente, este estudo demonstrou que o pré-natal é acessível à maioria dessas mulheres. O combate ao HIV continua sendo um desafio para os serviços de saúde pública, requerendo ações intensivas de prevenção. $\mathrm{O}$ conhecimento das características que permeiam esse grupo específico pode subsidiar a elaboração de políticas e ações de combate ao vírus em mulheres com o mesmo perfil epidemiológico, bem como prevenir a transmissão vertical desse vírus através da detecção precoce e adesão ao tratamento adequado. Implicações para a enfermagem: Estudos epidemiológicos como este são ferramentas importantes para demonstrar como se encontra o cenário atual de determinada doença, identificando fatores como comportamentos de risco, determinantes socioeconômicos, sociodemográficos e mecanismos de transmissão. Para o enfermeiro, tanto na condição de prestador de cuidados como na de gestor, tais informações são significativas para direcionar corretamente suas ações. Podendo assim subsidiar o planejamento de sua assistência, o estabelecimento de prioridades, a alocação de recursos e de pessoal, a produção de ações de promoção, prevenção e combate ao HIV, entre outras.

Descritores: HIV; Gravidez; Epidemiologia. 


\section{Referências}

1. Carvalho GS. Pessoas vivendo com HIV/AIDS: vivências do tratamento antirretroviral. [Dissertação Mestrado do Curso de Mestrado em Saúde Coletiva]: Londrina: Universidade Estadual de Londrina (UEL); 2008.

2. Paes ALV, Gomes HG, Ribeiro ARS, Lima MMB, Araújo, BB, Smith NA. Perfil epidemiológico de gestantes com HIV acompanhadas em um serviço de assistência especializada em Belém-PA. Revista Interdisciplinar. 2017; 10(3): 100-109.

3. Ramos JIM, Menezes LS, Sousa DS. Perfil das Gestantes HIV/AIDS Admitidas em uma Maternidade de Alto Risco no Município de Aracaju/SE. Cadernos de GraduaçãoCiências Biológicas e da Saúde. 2013; 1(17): 27-38.

4. Brasil. Ministério da Saúde. Secretaria de vigilância e saúde. Boletim epidemiológico HIV/AIDS 2017. Ministério da saúde: 2017.

5. Silva RAR, Duarte FHS, Nelson ARC, Holanda JRR. A Epidemia Da Aids No Brasil: Análise Do Perfil Atual. Revista de Enfermagem UFPE Online. 2013; 7(10): 6039-8. 


\title{
DOENÇAS CRÔNICAS NÃO TRANSMISSÍVEIS EM UMA POPULAÇÃO RIBEIRINHA DE MACAPÁ, AMAPÁ
}

\author{
${ }^{1}$ Inakê Gomes Marinho; ${ }^{2}$ Carlos Augusto Alves de Lima Junior; ${ }^{3}$ Risomar Carréra de \\ Menezes Júnior; ${ }^{4}$ Rosana Oliveira do Nascimento; ${ }^{5}$ Rosemary Ferreira de Andrade; \\ ${ }^{6}$ Rubens Alex de Oliveira Menezes.
}

\footnotetext{
${ }^{1}$ Acadêmico do Curso de Bacharelado em Enfermagem; Universidade Federal do Amapá - Unifap. E-mail: inakemarinho@gmail.com;

${ }^{2}$ Acadêmico do Curso de Bacharelado em Enfermagem; Unifap;

${ }^{3}$ Acadêmico do Curso de Farmácia; Unifap;

${ }^{4}$ Enfermeira. Mestre em Saúde Coletiva - Universidade de Fortaleza - Unifor. Professora efetiva do Colegiado do Curso de Bacharelado em Enfermagem;

5 Enfermeira. Doutora em Ciência: desenvolvimento socioambiental pelo Programa em Desenvolvimento Sustentável do Trópico Úmido - NAEA/Universidade Federal do Pará - UFPA. Professora efetiva do Colegiado do Curso de Enfermagem;

${ }^{6}$ Enfermeiro. Doutor em Doenças Infecciosas e Parasitárias; Unifap. Professor efetivo Colegiado do Curso de Enfermagem.
}

\section{RESUMO}

Introdução: A prevalência de doenças crônicas não transmissíveis (DCNTs) alcançou índices alarmantes nas últimas décadas no Brasil e no mundo. Sua manifestação tardia influencia no aumento da expectativa de vida da população, visto que estas doenças são passíveis de prevenção e de controle de agravos por meio de ações que englobam desde a transformação de fatores mutáveis, como hábitos de vida e alimentares, até a adaptação do indivíduo ao quadro patológico e a aceitação da necessidade de intervenção intersetorial e pluridisciplinar'. A vulnerabilidade socioeconômica, política, cultural, comportamental e educacional predispõe indivíduos e populações ao risco maior de adquirir certas patologias. Portanto, o estímulo à transformação dos motores de uma comunidade vulnerável às DCNTs torna-se a essência das estratégias de Enfermagem que visam impulsionar o desejo do autocuidado e autorrealização do cliente. As DCNTs manifestam-se de diversas formas de modo a interferir na qualidade de vida do portador, sendo este mais um amplo alvo dos cuidados de Enfermagem, objetivando proporcionar o alívio dos sintomas e garantir o bem-estar do indivíduo². A vulnerabilidade de comunidades pouco assistidas por serviços preventivos de saúde juntamente com fatores de risco individuais e comunitários, como sexo, renda, faixa etária, ocupação e moradia corrobora o perfil de morbimortalidade por doenças crônicas de uma localidade, tais como as cardiovasculares, as neoplásicas, as do aparelho respiratório e a diabetes mellitus (DM). Além da perda da qualidade de vida, as DCNTs são causas, muitas vezes, de mortes prematuras ${ }^{3}$. Objetivo: $O$ objetivo deste estudo foi conhecer a morbidade da população ribeirinha em um distrito de Macapá, Amapá, e os fatores de risco associados ao desenvolvimento de doenças crônicas não transmissíveis. Método: Estudo transversal realizado no município de Macapá, no Estado do Amapá, com as seguintes variáveis consideradas: aferição da pressão arterial (PA), coleta de índice glicêmico e coleta de dados antropométricos: peso, altura e Índice de Massa Corpórea (IMC). Os valores de referência seguiram a classificação e 
recomendações da Associação Brasileira para o Estudo da Obesidade (Abeso). A pesquisa foi aprovada pelo Comitê de Ética-CEP/Unifap, conforme parecer: 3.003.159. Resultados: As amostras foram colhidas de 115 moradores do distrito, no município de Macapá, que vivem em torno do rio. Entre os entrevistados, 76,5\% (88/115) eram do sexo feminino e $23,5 \%(27 / 115)$ do sexo masculino, com faixa etária predominantemente maior que 30 anos de idade em 71,3\% (82/115); quanto à escolaridade, percebeu-se que os que tinham ensino fundamental incompleto foram mais prevalentes nesta amostra, sendo 85,2\% (98/115) dos participantes do estudo. Em relação aos dados colhidos e valores antropométricos: a pressão arterial sistólica (PAS) variou de 90 a $200 \mathrm{mmHg}$ e a pressão arterial diastólica (PAD) de 50 a $100 \mathrm{mmHg}$, com IMC de 12.8 a 48.2. Os níveis glicêmicos variaram de 78 a $438 \mathrm{mg} / \mathrm{dL}$, estando cinco entrevistados com risco elevado para DM. O predomínio dos principais fatores de risco foi: $60 \%$ (69/115) para consumo elevado de refrigerante, $80 \%$ (92/115) para consumo de carne com alto percentual de gordura, 88,7\% (102/115) para consumo de carne de frango com pele, 76,5\% (88/115) para baixo consumo de frutas, $27,8 \%$ (32/115) para uso de sal diretamente no prato de refeição, 81,7\% (94/115) para tabagismo, 59,1\% (68/115) para ingestão excessiva de bebidas alcoólicas, 97,3\% (112/115) para sedentarismo e 64,3\% (74/115) para excesso de peso. Pode-se verificar pelos resultados apresentados a elevada prevalência de fatores de risco para DCNTs na comunidade avaliada. A morbidade autorreferida foi mais prevalente para pessoas acima de 30 anos e baixa escolaridade. Considerações finais: $O$ estudo revelou que a maioria dos entrevistados não pratica exercícios físicos e possui uma alimentação de pouca ou baixíssima qualidade ou, ainda, hábitos comportamentais pouco saudáveis, apresentando resistência em buscar meios de prevenção para as doenças crônicas, as quais possuem associação positiva para fatores de risco. Nesse contexto, observa-se a necessidade de intervenções da equipe multiprofissional, principalmente do enfermeiro e de agentes comunitários de saúde (ACSs) que lidem rotineiramente com a população para a realização de ações educativas e assistenciais, visando ao combate da situação de vulnerabilidade observada neste estudo. A união da comunidade a fim de superar os paradigmas que a fragilizam frente às necessidades que acarretam mazelas para sua saúde fortalece a vontade de promoção e proteção da saúde de forma solidária e fundamental para o estímulo de mudança de hábitos e reequilíbrio do convívio em sociedade. Implicações para a enfermagem: Realizar ações profiláticas (prevenção primária) em uma população de risco e a detecção precoce do processo doença (prevenção secundária) são tão importantes quanto a implementação de intervenções para a redução dos danos advindos da patologia e a garantia da qualidade de vida do cliente (prevenção terciária), uma vez que a essência do cuidado de Enfermagem não está somente atrelada ao transcurso da reabilitação quando a afecção já se encontra instalada, mas também no olhar clínico antes das mazelas no indivíduo ou comunidade, abrindo espaço para educação em saúde. A necessidade de encorajar o paciente a participar de forma ativa e autossuficiente do seu plano de cuidado põe o profissional e o cliente em papéis de mútua responsabilidade, aproxima-os e facilita o vínculo entre estes, tornando o ambiente mais aprazível e estimulando o desejo de autocuidado no indivíduo. As necessidades do portador de DCNTs vão além da sintomatologia das doenças, abrangem outros aspectos do convívio em sociedade que interferem na satisfação das necessidades básicas humanas, como as necessidades fisiológicas de sono, repouso, alimentação, exercício, a segurança do corpo, da família e 
saúde, necessidades psicológicas, como autoestima e confiança, e necessidades de autorrealização, como autonomia, solução de problemas e aceitação dos fatos como são. O enfermeiro deve ampliar a compreensão da problemática depositada sobre cada indivíduo em particular amparado pelo holismo, visando às melhores soluções para seus problemas, de forma a educar o indivíduo e estimulá-lo a agir em prol de sua saúde de maneira consciente e coesa, para que se possa transformar a sua realidade e a de sua família.

Descritores: Doença crônica; Fatores de risco; Educação; Saúde.

\section{Referências}

1. Santos JC, Duarte KMM, Farias SP, Nascimento AAJ, Ferreira CO, Almeida DM, et al. Promoção da saúde e qualidade de vida para populações ribeirinhas do Vale do São Francisco. In: IX Mostra de Extensão UNIVASF; 2014; Petrolina (PE): Universidade Federal do Vale do São Francisco; 2015.

2. Lima IFP, Resende DF, Oliveira ESS, Conceição ICS, Santos GN, Coutinho ML. Atuação do enfermeiro no cuidado de pacientes portadores de doenças crônicas. In: Anais 2017 da 19ª Semana de Pesquisa da Universidade Tiradentes: Matemática para o desenvolvimento da Ciência; 2017 out. 23-27; Aracajú (SE): Universidade Tiradentes, 2017.

3. Mariosa DF, Ferraz RRN, Santos-Silva EM. Influência das condições socioambientais na prevalência de hipertensão arterial sistêmica em duas comunidades ribeirinhas da Amazônia, Brasil. Manaus (AM): [s.n.]; [2018?]. 


\title{
CONSTRUÇÃO DE UM PROTOCOLO DE PESQUISA EM MODELO EXPERIMENTAL ANIMAL COM TERAPIA FOTODINÂMICA
}

\author{
${ }^{1}$ Italo Soares Eneias; ${ }^{2}$ Alana Patrícia Lima Ferreira; ${ }^{3}$ Lucas dos Santos Nunes; ${ }^{4}$ Carla \\ Emanuela Xavier Silva; ${ }^{5}$ Ana Rita Pinheiro Barcessat.
}

${ }^{1}$ Acadêmico do Curso de Bacharelado em Enfermagem; Universidade Federal do Amapá - Unifap. Grupo de pesquisa em Biofotônica e Neuromodulação. E-mail: iseneias@hotmail.com;

${ }^{2}$ Cirurgiã-Dentista. bolsista Capes -Programa de Pós-Graduação em Ciências da Saúde -Unifap;

${ }^{3}$ Acadêmico do Curso de Bacharelado em Enfermagem; Unifap. Grupo de pesquisa em Biofotônica e Neuromodulação;

${ }^{4}$ Acadêmica do Curso de Bacharelado em Enfermagem; Unifap. Grupo de pesquisa em Biofotônica e Neuromodulação. Bolsista Rede Ciências - Fundação de Amparo à Pesquisa do Amapá Fapeap;

5 Cirurgiã-Dentista. Doutora em Estomatologia Básica e Aplicada- Patologia Bucal; Unifap. Professora efetiva Colegiado do Curso de Bacharelado em Enfermagem.

\section{RESUMO}

Introdução: O efeito fotodinâmico consiste na liberação de espécies reativas de oxigênio a partir de uma reação fotoquímica entre uma substância fotossensível, uma fonte de ativação e o oxigênio. A terapia fotodinâmica (TFD) é utilizada para redução microbiana e morte celular, descontaminação oral e descontaminação de feridas. $O$ protocolo em questão faz parte da segunda etapa do projeto denominado: "Eficácia da terapia fotodinâmica na redução da Candida SP na cavidade oral de pacientes internados em Unidade de Terapia Intensiva: ensaio clínico randomizado". A parte experimental (animal) desse estudo busca o efeito em tecido oral, que não pode ser executada em humanos por se tratar de uma biópsia. Objetivo: Descrever o passo a passo da construção de um protocolo de pesquisa em modelo animal para o estudo do efeito da TFD no tecido oral. Método: A elaboração do protocolo foi embasada nas mesmas fontes científicas utilizadas na pesquisa com humanos (na parte clínica do projeto), que são os protocolos préexistentes de TFD ${ }^{1} 23$. Além disso, baseou-se em protocolos de manipulação animal. Comissão de Ética animal - CEUA (Resolução Normativa no 27 do CONCEA ${ }^{4}$ ), sendo aprovado sob o protocolo no 005/2015 (CEUA/UNIFAP). Resultados: Adaptação do protocolo semelhante ao usado na pesquisa com humanos com os passos a seguir: 1 . Escolha do animal: a cobaia foi o rato wistar (rattus norvegicus), porque são resistentes e de fácil manuseio. 2.Obtenção, transporte e aclimatação dos animais: Os animais adquiridos do Instituto Evandro Chagas em Belém - PA, biotério central de instituição de pesquisa, próximo geograficamente, importante para a redução do elemento estresse das cobaias. O transporte aéreo seguindo as normas vigentes Associação Internacional de Transportes Aéreos (IATA). Os animais serão aclimatados em gaiolas individuais em ambiente com refrigeração própria, por uma semana, obedecendo ciclos de 24 horas de claro e escuro. 3. Alocação randômica e definição de grupos: realizada aleatoriamente. G1 -Experimental com Azul de Metileno e irradiação laser vermelho; G2 - Experimental com fotossensibilizador curcumina e irradiação por LED azul; G3- Grupo controle apenas fotossensibilizador azul de metileno; G4- Grupo controle apenas fotossensibilizador curcumina. 4. Sedação animal: Feita com relaxante muscular xilazina e quetamina. 5. 
Protocolo de Terapia Fotodinâmica: Os fotossensibilizadores serão gotejados sobre a língua dos animais pelo tempo definido de pré-irradiação. G1- Azul de Metileno a 0,5\% como fotossensibilizador, aplicado durante 2 minutos seguido de irradiação por laser vermelho (660 nm, $40 \mathrm{~mW}, 90 \mathrm{~J} / \mathrm{cm} 2,1,5 \mathrm{~min}) . \mathrm{G} 2$ - Fotossensibilizador curcumina (PDTPharma com concentração $1,5 \mathrm{~g} / \mathrm{L}$ ) seguida de irradiação pelo LED azul ( $770 \mathrm{~nm}+/-25$, $250 \mathrm{MW}, 45 \mathrm{~J} / \mathrm{cm} 2)^{12}$. G3 - Fotossensibilizador azul de metileno com fonte laser desligada. G4- Fotossensibilizador curcumina com a fonte LED desligada. 6. Biópsias e eutanásia: imediatamente após a terapia fotodinâmica, ainda sob sedação, os animais serão submetidos à biópsia excisional da língua com tesoura cirúrgica. Procedendo-se a eutanásia por superdosagem anestésica por via intraperitoneal. 7. Processamento da amostra- Análise histológica básica e Colorações especiais realizar-se-á análise descritiva a partir de 2 patologistas cegos às técnicas. Os parâmetros observados à microscopia óptica e coloração de rotina em hematoxilina e eosina serão inicialmente: integridade de epitélio, migração linfocitária, análise de infiltrado inflamatório. Cinco cortes histológicos de cada grupo e tempo experimental serão submetidos a colorações especiais para estudo morfológico complementar, a saber: Análise do colágeno tissular; através da coloração especial denominada Tricrômio de Marson será analisada a densidade de colágeno tecidual, através do Software Image J com conversão da cor azul absorvida pelo colágeno neoformado. Densidade e morfologia de mastócitos: Coloração com azul de toluidina para análise da morfologia e degranulação dos mastócitos e estudo do processo inflamatório local. Análise imuno-histoquímica: morte celular e formação de neovasos $O$ método da estreptavidina-biotina será utilizado para o estudo imuno-histoquímico com os anticorpos anti-caspase3, anti-Anti-Cd44, para análise de morte celular e formação de vasos sanguíneos respectivamente. Os protocolos utilizados para cada anticorpo seguirão as recomendações dos fabricantes. Para se obter um dado quantitativo da expressão imunohistoquímica, utilizar-se-á o método de contagem manual avaliando-se o percentual de células positivas num universo de 1000 células por amostra. As células consideradas positivas para os anticorpos serão as que exibirem marcação nuclear nítida, sendo quantificados esses núcleos. A contagem será realizada em aumento de 400X, utilizandose zoom de aproximação de até 200X e ferramenta de contagem manual de partículas do software Image J. Todo o procedimento será realizado por um único operador de modo cego. 8: Análise estatística. Adotar-se-á a estatística descritiva utilizando média e desviopadrão para os dados numéricos obtidos na medida da língua/lesão, área do epitélio e as porcentagens obtidas na quantificação das células. Para os dados de intensidade dos elementos presentes na análise histopatológica, pretende-se adotar mediana e valores mínimo e máximo. Será realizado teste de Kruskal-Wallis, para comparações múltiplas, e teste não-paramétrico de Mann-Whitney, para análises dois-a-dois, com nível de significância de 5\%, considerando-se a grande probabilidade de dados não paramétricos após teste de normalidade. Considerações finais: A presente proposta configura-se como uma importante colaboração à ciência com impactos imediatos e de médio prazo em processos, serviços e assistência à saúde. Consolida-se como uma técnica de terapêutica de alta relevância e de eficiência comprovada, que necessita apenas ser testada e adaptada ao contexto das Unidades de Terapia Intensiva no Estado do Amapá. Espera-se estudar experimentalmente em modelos animais os efeitos complementares da terapia sobre os elementos celulares e de matriz extracelular dos tecidos como fibras de colágeno, 
vasos sanguíneos e células inflamatórias, fornecendo assim um panorama geral dos efeitos fotodinâmicos de interesse clínico. A devolutiva social e culminância do estudo estabelecerse-á num protocolo de utilização da Terapia Fotodinâmica em UTI adulto como parte dos cuidados com o paciente. Implicações para a Enfermagem: Os procedimentos usados na experiência com animais também darão um embasamento maior para futuras pesquisas de terapia fotodinâmica in vivo especialmente para a descontaminação de feridas, ao mesmo tempo em que essa utilização sistemática da TFD também teria o potencial de engajar novas produções e tecnologias nesse ramo e a modernização do tratamento, impulsionando a comunidade científica amapaense de enfermagem.

Descritores: Fotoquimioterapia; Experimentação Animal; Protocolos.

\section{Referências}

1. Nunes C, Proietti Junior A, Barcessat A. Descontaminação fotoquímica de alvéolos dentários em técnicas distintas de Terapia Fotodinâmica: relato de dois casos clínicos. Estação Científica (UNIFAP). 2018;8(2):129.

2. Moura J, Brandão L, Barcessat A. Estudo da Terapia Fotodinâmica (PDT) no reparo de lesões teciduais: estudo de casos clínicos. Estação Científica (UNIFAP). 2018;8(1):103.

3. Barcessat A, Huang I, Rosin F, dos Santos Pinto D, Maria Zezell D, Corrêa L. Effect of topical 5-ALA mediated photodynamic therapy on proliferation index of keratinocytes in 4-NQO-induced potentially malignant oral lesions. Journal of Photochemistry and Photobiology B: Biology. 2013; 126:33-41.

4. CONCEA - Conselho Nacional de Controle de Experimentação Animal - Instrução Normativa no 27, D.O.U., seção 01, n. 205, p.10-14, 2015. 


\title{
POTENCIAL BIOMARCADOR NA PREDIÇÃO DO DESENVOLVIMENTO DE DCNT EM PACIENTES CONTAMINADOS POR MERCÚRIO
}

\author{
${ }^{1}$ Izabele Grazielle Da Silva Pojo; ${ }^{2}$ Josimar Dornelas Moreira; ${ }^{3}$ Tânia Mara Pinto Dabés \\ Guimarães; ${ }^{4}$ Lise Maria Carvalho Mendes; ${ }^{5}$ Heluza Monteiro Oliveira; ${ }^{6}$ Rafael Pires \\ Moreira.
}

\begin{abstract}
${ }^{1}$ Acadêmica do Curso de Bacharelado em Enfermagem; Universidade Federal do Amapá - Unifap. E-mail: izabele.pojo@gmail.com;

${ }^{2}$ Farmacêutico. Doutor em Análises Clínicas e Toxicológicas; Universidade Federal de Minas Gerais - UFMG;

${ }^{3}$ Farmacêutica. Doutora em Parasitologia; UFMG;

${ }^{4}$ Enfermeira. Especialização em Enfermagem do Trabalho, Universidade Federal do Ceará - UFC. Professora efetiva Colegiado do Curso de Bacharelado em Enfermagem - Unifap Campos Binacional;

${ }^{5}$ Enfermeira. Especialização em Gestão em Saúde, Unifap. Professora efetiva Colegiado do Curso de Bacharelado em Enfermagem - Unifap Campos Binacional;

${ }^{6}$ Farmacêutico. Mestre em Ciências Farmacêuticas, Universidade de São Paulo - USP. Docente efetivo e Pesquisador na Universidade Federal do Amapá; Unifap.
\end{abstract}

\section{RESUMO}

Introdução: Demonstra-se que, no Amapá, há rios e peixes contaminados por mercúrio, entre os quais está o Rio Araguari, que apresentou concentrações de mercúrio acima do que é preconizado pela Organização Mundial de Saúde (OMS), sugerindo exposição direta da população, já que esta, além de fazer consumo da água, possui perfil de grande consumo de peixe1. O mercúrio como contaminante de pescado determina uma forma de exposição não ocupacional, cuja concentração se dá na forma orgânica de metilmercúrio $(\mathrm{MeHg})$. Há evidências de que as comunidades ribeirinhas que consomem regularmente peixes na dieta apresentam concentrações de exposição ao $\mathrm{Hg}$ que oferecem impactos negativos à saúde ${ }^{2}$. Já é bem demonstrado que o aumento do estresse oxidativo no organismo e a instalação da disfunção endotelial causada pelo mercúrio e seus derivados contribuem para o desenvolvimento de Doenças Crônicas não Transmissíveis (DCNTs). $O$ desenvolvimento de doenças cardiovasculares, como infarto agudo do miocárdio, aterosclerose, hipertensão e doença arterial coronariana, está associado à exposição aguda e crônica ao mercúrio. Além das doenças cardiovasculares, estudos demonstram que jovens e adultos altamente expostos ao mercúrio podem ter risco elevado de desenvolvimento de diabetes mellitus (DM) em uma idade mais avançada ${ }^{3,4}$. Estudos também mostram a detecção de micropartículas que funcionam como biomarcadores, pois são encontradas no plasma de indivíduos saudáveis, que têm sua quantidade aumentada sob condições patológicas. Níveis elevados são encontrados em síndromes coronárias agudas, na hipertensão grave com lesão nos órgãos, diabetes, trombose imunomediada, doenças renais, doença inflamatória sistêmica, condições associadas a lesão endotelial, entre outras ${ }^{5}$. Atualmente, são usados biomarcadores para o desenvolvimento de DCNTs, geralmente biomarcadores de exposição como dosagem de mercúrio de cabelo, sangue e urina, entretanto, não existem trabalhos que relacionem os níveis de mercúrio ao aumento dos níveis de micropartículas circundantes. Dessa forma, torna-se de suma importância a 
identificação de biomarcadores potenciais relacionados com o desenvolvimento de DCNTs frente à exposição ao mercúrio e seus derivados, sendo possível, assim, a adoção de medidas preventivas. Objetivos: Avaliar o potencial das micropartículas como biomarcador na predição do desenvolvimento de doença crônica renal em pacientes contaminados por mercúrio. Método: Foi realizada coleta de material biológico (sangue e cabelo) de indivíduos, moradores de uma região de garimpo localizada em um distrito do Amapá e de um grupo controle. Com as amostras biológicas, foram realizadas análises bioquímicas, bem como quantificação de mercúrio, quantificação de micropartículas pela técnica de citometria de fluxo, cultura de células embrionárias e expressão gênica, utilizando a técnica de Reverse transcription polymerase chain reaction quantitative real time (PCR-RT). Além disso, foi aplicado questionário sociodemográfico. A referida pesquisa foi desenvolvida de acordo com as normas da Resolução no 466/2012 do Conselho Nacional de Saúde (CNS), tendo sido aprovada pelo Comitê de Ética em Pesquisa (CEP) da Universidade Federal do Amapá, mediante parecer № 2.248.512. Resultados: No presente estudo, foi observado que cerca de $99 \%$ dos entrevistados fazem consumo de peixes, sendo que, entre os espécimes citados em termos de nível trófico, 52,3\% se enquadram em carnívoros e $33,33 \%$ em onívoros. No que tange à quantificação de mercúrio total, observou-se que as concentrações de $\mathrm{Mg}$ total entre os pacientes contaminados correspondem a 10,23 $\mu \mathrm{g} . \mathrm{g}-1$

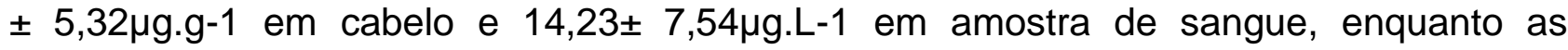

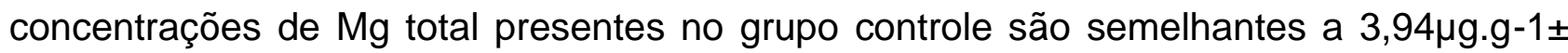

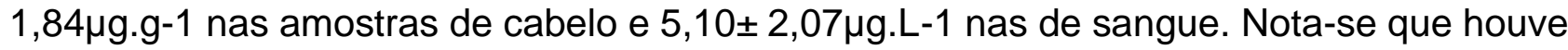
uma diferença altamente significativa $(p<0,01)$ entre os grupos avaliados. As altas concentrações de $\mathrm{Mg}$ presente nas amostras biológicas dos entrevistados expostos ao mercúrio podem ser explicadas pelo cardápio alimentar dos ribeirinhos, levando em consideração que uma das principais vias de exposição ao mercúrio na Amazônia é através da ingestão de alimentos contaminados, mais precisamente do pescado. Além disso, o acúmulo do MeHg se faz por meio da cadeia trófica, apresentando-se aumentado em peixes no alto da cadeia alimentar, o que condiz com o perfil alimentar dos ribeirinhos estudados ${ }^{2}$. Os pacientes contaminados com mercúrio apresentaram um aumento significativo ( $p<$ $0,01)$ na produção das micropartículas em relação ao grupo controle, correspondendo a $615,00 \pm 38,67 \mathrm{Mps} / \mu \mathrm{L}$ e $1.050 \pm 122 \mathrm{Mps} / \mu \mathrm{L}$ respectivamente. Micropartículas de pacientes contaminados com mercúrio induziram um aumento da transcrição de COX2 e NOX4 em células do rim humano (Células embrionárias do Rim Humano- HEK-293), quando comparados com pacientes controles. As micropartículas podem induzir aumento da transcrição de proteínas pró-inflamatórias e contribuir para um possível aumento do estresse oxidativo. De fato, o aumento das micropartículas pode favorecer 0 desenvolvimento de nefropatia diabética. É relatado também que as micropartículas podem levar à resistência à insulina e promover a IR possivelmente influenciando a sinalização de Akt / PI3K relacionada à insulina e bloqueando a captação de glicose, impedindo o transportador de glicose (GLUT). Podem também aumentar a produção de ROS citosólicas, que ativa o estresse oxidativo de organelas de mitocôndrias e desencadeia respostas inflamatórias. Considerações finais: As micropartículas podem, portanto, ser usadas como biomarcadores para avaliar a exposição ao Mercúrio e para identificar o risco de desenvolvimento de complicações renais, principalmente de nefropatia diabética, uma das complicações mais graves, como também detectar de forma precoce o possível 
desenvolvimento de diabetes do tipo II em pacientes contaminados pelo mercúrio. Implicações para enfermagem: Diante dos achados, o enfermeiro poderá propor estratégias de promoção da saúde e prevenção de doenças decorrente dos agravos provenientes da contaminação por mercúrio em esferas superiores da gestão, também poderá apresentar estratégias de assistência que contemplem essa parcela da população que está exposta a condições de vulnerabilidade, abrangendo ações de promoção e proteção da saúde, como prevenção de agravos, reabilitação e a manutenção da saúde. De forma geral, deve respeitar as necessidades, reconhecendo as diferenças e fatores que impactam diretamente a saúde dessa determinada população, promovendo, dessa forma, a equidade em saúde.

Descritores: Intoxicação por Mercúrio; Mercúrio; Toxicidade.

\section{Referências}

1. Venturieri R, Costa OM, Gama C, Jaster CB. Mercury Contamination within Protected Areas in the Brazilian Northern Amazon-Amapá State. Rev American Journal of Environmental Sciences. 2017; 13 (1).

2. Costa Junior JMF, Lima AAS, Rogrigues Junior D, Khouryl EDT, Souza GSS, Siveiral LCL et al. Manifestações emocionais e motoras de ribeirinhos expostos ao mercúrio na Amazônia. Rev Bras Epidemiologia. 2017; 20(2): 212-224.

3. Genchi G, Sinicropi MS, Carocci A, Lauria G, Catalono A. Mercury Exposure and Heart Diseases. Int. J. Environ. Res. Public Health. 2017; 14 (1).

4. He K, Xun P, Liu K, Morris S, Reis J, Guallar E. Mercury exposure in young adulthood and incidence of diabetes later in life: the CARDIA Trace Element Study. Diabetes Care, 2013; 36 (6): 1584-9.

5. Chironi GN, Boulanger CM, Simon A, George FD, Freyssinet JM, Tedgui A. et al. Cell Tissue Res. 2009; 335: 143. 


\section{EXAME DOS PÉS NO DIABETES MELLITUS REFLETIDO ATRAVÉS DA PESQUISA COMO CAMINHO PARA EQUIDADE}

${ }^{1}$ Jéssica Gomes da Silva; ${ }^{2}$ Luan Andrade de Souza; ${ }^{3}$ Adriane Stefanny Rocha Ribeiro;

${ }^{4}$ Edicilene Marinho Ferreira; ${ }^{5}$ Vanessa da Silva Oliveira; ${ }^{6}$ Francineide Pereira da Silva Pena.

1 Enfermeira. Residente de Enfermagem; Universidade Federal do Amapá - Unifap. E-mail: jsgoms10@gmail.com;

${ }^{2}$ Acadêmico do Curso de Enfermagem; Fama;

${ }^{3}$ Enfermeira. Residente de Enfermagem; Unifap;

${ }^{4}$ Acadêmica do Curso de Enfermagem; Estácio Macapá;

${ }^{5}$ Enfermeira. Mestranda em Ciências da Saúde; Unifap; Professora efetiva do Colegiado do Curso de Bacharelado em Enfermagem;

${ }^{6}$ Enfermeira. Doutora em Ciências da Saúde; Unifap. Professora efetiva do Colegiado do Curso de Bacharelado em Enfermagem.

\section{RESUMO}

Introdução: O Diabetes Mellitus (DM) é um problema crescente de saúde global considerado Condição Sensível à Atenção Primária. Evidências demonstram que o bom manejo desse agravo na Atenção Básica evita hospitalizações e óbitos ${ }^{1}$. A evolução não controlada do diabetes provoca complicações agudas e crônicas. As agudas geralmente provêm de eventos esporádicos, e as crônicas têm origem no mau controle glicêmico ao longo dos anos ${ }^{2 ; 3}$. O pé diabético é uma complicação crônica definida como infecção, ulceração e/ou destruição de tecidos moles associada a alterações neurológicas e vários graus de doença arterial periférica (DAP) nos membros inferiores. Pesquisas elencam que a grande proporção de ocupação dos leitos hospitalares em emergência, ocorre com pacientes com úlceras de pés diabéticos ${ }^{4}$. Apesar da grande proporção, os dados são escassos, os sistemas de saúde não são organizados, o conhecimento dos profissionais sobre pé diabético é crítico, o que redunda no desfecho da amputação. Assim, surge a necessidade de realizar este trabalho para propagar informações relacionadas ao exame de pés de pessoas com diabetes. Associando isso ao conceito etimológico de equidade, "busca pela Justiça, que trate cada pessoa segundo sua natureza particular", observa-se que as legislações apresentam caráter universal. Este caráter universal pode sujeitar ao erro essas legislações. As pessoas são diferentes e isso pode revelar uma lacuna na legislação, por exemplo, no que tange ao atendimento ao paciente com o pé diabético, pois é uma complicação crônica do DM, há casos específicos em que a rede de saúde a pessoas com doenças crônicas, para ser efetiva, terá que utilizar do princípio da equidade. Se tratando de Macapá, o Sistema Único de Saúde (SUS) se encontra desprovido de exames que favoreçam o diagnóstico precoce dessa complicação. Nesse sentido, tem-se o desafio de prevenir e/ou postergar a ocorrência do pé diabético com o exame dos pés das pessoas com DM. Objetivo: Avaliar e classificar o risco para desenvolvimento do pé diabético em pessoas participantes de um programa de promoção da saúde de Macapá. Método: Estudo descritivo de abordagem quantitativa do tipo transversal. Realizado no programa de promoção da saúde para pessoas com DM, em Macapá-AP, após avaliação e aprovação 
do Comitê de Ética da Universidade Federal do Amapá (Unifap) (N: 2.853.437/CAEE 95595718.4.0000.0003) e após o consentimento livre e esclarecido dos participantes. Para realização do estudo, foi utilizada uma amostra não probabilística de conveniência constituída por 21 pessoas com Diabetes Mellitus (DM). Para coleta dos dados, foram realizadas durante o período de fevereiro a abril de 2019 consultas de enfermagem, nas quais foi investigado o risco de cada pessoa para desenvolver o pé diabético, tomando por base a Ficha Clínica para avaliação e o rastreamento de dor neuropática, perda da sensibilidade protetora e DAP para a atenção básica (Grupo de Trabalho Pé diabético) com blocos para avaliação: dor neuropática, intensidade do sintoma neuropático, inspeção dos pés, deformidades, limitação da mobilidade articular, perda da sensibilidade protetora, DAP, amputação, úlcera prévia e ativa, classificação do risco e seguimento. A análise estatística foi realizada por meio da construção de distribuições de frequências, utilizando o software Excel 2010. Resultados: Dos 21 participantes, houve predominância 85,71\% $(n=18)$ do sexo feminino e $14,29 \%(n=3)$ do sexo masculino. Média de idade de 64,71 anos. Identificação da dor neuropática: dos sintomas neuropáticos: $33,33 \%(n=7)$ informaram queimação, formigamento ou dormência, $57,14 \%(n=12)$ relataram fadiga, câimbras ou dor, $9,52 \%(n=2)$ assintomáticos. Dos $90,47 \%(n=19)$ que referiram alteração na identificação de dor neuropática, $14,27 \%(n=3)$ relataram alteração nos pés e nas pernas; $23,78 \%(n=5)$ apenas nos pés, $52,33(n=11)$ apenas nas pernas. Deformidades: $4,76 \%(n=1)$ pé neuropático típico; 9,52\% ( $n=2)$ valgismo; $85,71 \%(n=18)$ ausência de deformidades. Limitação da mobilidade articular: em $38,09 \%(n=8)$ foram identificadas alterações e $61,91 \%(n=13)$, ausência de alteração. Perda da sensibilidade protetora - Monofilamento: 9,52\% ( $n=2)$ alteração e 90,47\% $(n=19)$ sem alteração. Sensibilidade vibratória: 9,52\% $(n=2)$ diminuída ou ausente no pé direito e esquerdo, $90,47 \% \quad(n=19)$ sem alteração. Sensibilidade dolorosa: $4,76 \%$ ( $n=1)$ diminuída ou ausente no pé direito, $9,52 \%(n=2)$ no pé esquerdo, $85,71 \%(n=18)$ sem alteração. Reflexo de aquileu: $23,80 \%(n=5)$ diminuído ou ausente no pé direito e $28,57 \%(n=6)$ no pé esquerdo, $47,61 \%(n=10)$ presente. Índice Tornozelo-Braço (ITB) 9,52\% ( $n=2)<0.9,90,47 \%(n=19)>0.9$. Classificação de Risco: $90,47 \%(n=19)$ Grau 0; 0,0\% ( $n=0)$ grau I; 4,76\% $(n=1)$ grau II e 4,76\% $(n=1)$ grau III. Considerações finais: Os resultados evidenciam que a maioria dos participantes apresentam classificação de risco grau 0 , o que significa sensibilidade protetora preservada e ausência de evidências de DAP, que são os parâmetros que somam todos os sinais de complicações de DM para o desfecho do pé diabético. Concluiu-se com este trabalho que as políticas públicas constituídas para o pé diabético estão sendo construídas a passos lentos. Percebe-se que as políticas em si não apresentam resolubilidade para esta temática, e o quantitativo de pessoas amputadas e/ou internadas por esta complicação, como evidenciado em estudos, encontra-se crescente. Com tudo, o cuidado de enfermagem deve ser planejado e orientado para prevenção e promoção de saúde dos pés das pessoas com DM, subsidiado na equidade e não apenas em diagnóstico e tratamento de lesões. Implicações para enfermagem: Na rotina da consulta de enfermagem na atenção primária à saúde, a realização do exame dos pés em pessoas com DM implica grande potencial para o conhecimento das carências de saúde dessas pessoas que estão inseridas em diferentes grupos sociais. Isso contribui para um atendimento diferenciado conforme as necessidades de cada paciente, que resulta no cumprimento do princípio da equidade dentro das organizações do cuidado em saúde, visando à inter-relação entre as 
necessidades de saúde e a promoção dos cuidados com os pés. A equipe de enfermagem necessita ter um olhar integral para o paciente, tanto quanto para as complicações que o DM causa, visto que a realização do exame dos pés na consulta de enfermagem, que é uma atividade privativa do enfermeiro, preveniria tais complicações.

Descritores: Diabetes Mellitus; Enfermagem; Pé Diabético.

\section{Referências}

1. Alfradique ME, Bonolo PDF, Dourado I, et al. Internações por condições sensíveis à atenção primária: a construção da lista brasileira como ferramenta para medir o desempenho do sistema de saúde (Projeto ICSAP-Brasil). Cad. Saúde Pública. [Internet]. 2009; 25(6):1337-49.

2. Dom M, Calder A, Mat R. Características clínico epidemiológicas de las complicaciones agudas de la diabetes en el servicio de urgencias del Hospital General de Atizapán. Rev la Fac Med [Internet]. 2013;56(2):25-36.

3. Daiani de Bem BorgesJosimari Telino de Lacerda, Ações voltadas ao controle do Diabetes Mellitus na Atenção Básica: proposta de modelo avaliativo. Saúde debate 2018 [Internet];42 (116).

4. DIRETRIZES DA SOCIEDADE BRASILEIRA DE DIABETES-SBD (2017-2018)/ organização José Egidio Paulo de Oliveira, Renan Magalhães Montenegro Junior, Sérgio Vencio -- São Paulo: A.C. Farmacêutica. 2017.

5. Diretrizes da sociedade brasileira de diabetes-SBD (2017-2018)/organização José Egidio Paulo de Oliveira, Renan Magalhães Montenegro Junior, Sérgio Vencio -- São Paulo: A.C. Farmacêutica. 2017. 


\title{
PERFIL NUTRICIONAL MATERNO DE UM GRUPO DE APOIO A ADOLESCENTES PRIMIGESTAS
}

\author{
${ }^{1}$ Katiciane Rufino da Silva; ${ }^{2}$ Michelle Paolla Souza da Gama; ${ }^{3}$ Hiago Rafael Lima da \\ Silva; ${ }^{4}$ Anderson Rodrigues Ribeiro; ${ }^{5}$ Nely Dayse Santos da Mata; ${ }^{6}$ Tatiana do Socorro \\ dos Santos Calandrini.
}

${ }^{1}$ Enfermeira. Residente em Saúde Coletiva; Universidade Federal do Amapá - Unifap. E-mail: katicianyap@gmail.com;

${ }^{2}$ Professora de Educação Física Especialista em Saúde Coletiva;

${ }^{3}$ Acadêmico do Curso de Bacharelado em Enfermagem; Unifap;

${ }^{4}$ Acadêmico do Curso de Bacharelado em Enfermagem; Unifap;

${ }^{5}$ Enfermeira; Doutora em Ciências. Professora efetiva do Colegiado do Curso de Bacharelado em Enfermagem, Unifap;

6 Enfermeira. Mestre em Ciências da Saúde. Professora efetiva do Colegiado do Curso de Bacharelado em Enfermagem, Unifap.

\section{RESUMO}

Introdução: O período gestacional é caracterizado por uma fase da vida da mulher em que ocorrem diversas mudanças físicas, emocionais, sociais e comportamentais. Com isso, é importante que o profissional de saúde esteja atento a essas alterações e saiba identificar os fatores de risco que podem influenciar na evolução da gravidez. O estado nutricional pode comprometer a promoção da saúde materna e infantil. É de grande importância o acompanhamento do índice de massa corporal (IMC) no pré-natal de risco habitual, pois o registro identifica de forma eficaz possíveis agravos ${ }^{1}$. Objetivo: Analisar o perfil nutricional de gestantes adolescentes primigestas que compõem o Grupo de Extensão de Apoio a Grávidas Adolescentes (GEAGA) da Universidade Federal do Amapá através de dados do índice de massa corpórea (IMC) coletados no livro de registro do referido grupo no período de setembro de 2017 a março de 2019. Método: Estudo descritivo com abordagem, com coleta de dados realizada no livro de registros do Geaga, com anuência da coordenadora do grupo, selecionando para o estudo os dados coletados no período de setembro de 2017 a março de 2019. Os programas utilizados para análise dos dados da pesquisa foram Microsoft Office Excel versão 2010 e Bioestat versão 5.0.2. A análise dos dados deu-se por meio da tabulação dos dados no programa Microsoft Office Excel versão 2010 e descrição estatística realizada pelo Software Bioestat versão 5.0.2. Foi utilizado como base para a avaliação do IMC o gráfico de acompanhamento nutricional da caderneta da gestante do Ministério da Saúde que apresenta as definições baixo peso, adequado, sobrepeso e obesa de acordo com a idade gestacional. Aprovado pelo Comitê de Ética em Pesquisa da UNIFAP, parecer de número 2.865.676. Resultados: A amostra inicial do estudo foi de 29 gestantes atendidas pelo grupo Geaga no período de setembro de 2017 a março de 2019, porém três apresentavam-se com dados incompletos, devido a isso, a amostragem final para análise foi de 26 gestantes. As gestantes possuíam idades entre 14 e 18 anos e a maioria apresentava nível de escolaridade ensino fundamental incompleto. Inicialmente os dados foram transcritos para o programa Microsoft Office Excel versão 2010, foi realizado cálculo do IMC e classificado entre os níveis baixo peso, adequado, sobrepeso e obesa de 
acordo com o resultado do cálculo da fórmula do IMC com base nos dados da idade gestacional das participantes. Desta forma, puderam-se obter os seguintes dados: 12 $(46,1 \%)$ enquadraram-se no peso adequado, 7 (26,9\%) no baixo peso, $5(19,2 \%)$ no sobrepeso e $2(7,6 \%)$ em obesidade. Em seguida, foi utilizada a estatística descritiva do software Bioestat versão 5.0.2 dos dados do IMC, tendo como resultado os seguintes valores: média com 24,1; desvio-padrão 4,5; erro padrão 1,2; mínima 18,9; máxima 32,6; faixa 13,7; coeficiente de variação 0,18; desvio médio 3,71; média geométrica 23,7; média harmônica 23,4; mediana 22,3; variação 20,2 erro mediano 0,43. A partir desses pressupostos, compreende-se a importância de se avaliar e conhecer as ações fisiológicas dos nutrientes durante esse período. Os micronutrientes são importantes no período gestacional, a saber: cálcio, ferro, zinco, ácido fólico, vitamina $A$, vitamina $C$ e vitamina $E$. Nessa fase, cada micronutriente se apresenta com uma função que contribui tanto para a saúde materna como também pode ser essencial para a saúde e o desenvolvimento do feto. Pesquisas demonstram que o cálcio, principalmente no terceiro trimestre, contribui para a mineralização óssea do bebê; a partir do segundo trimestre e até o final da gravidez, a necessidade de ferro aumenta devido à maior exigência de oxigênio tanto pela mãe quanto pelo feto ${ }^{3}$. $\mathrm{O}$ zinco traz benefícios consideráveis através da boa funcionalidade de enzimas que auxiliam no crescimento celular e cicatrização. A vitamina $A$ possui ação benéfica no sistema imunológico e a vitamina $C$ também e ainda participa da produção de colágeno e manutenção de membranas. Desse modo, verifica-se a relevância de orientar a gestante, durante os atendimentos, quanto à importância da ingesta nutricional com qualidade ${ }^{3}$. Com isso, o estado nutricional da gestante pode influenciar no peso ao nascer, principalmente nos casos de baixo peso, podendo estar associado também a fatores genéticos, biológicos, ambientais e sociais. Já a obesidade materna e o sobrepeso aumentam os riscos de diabetes mellitus gestacional, cesárea, parto prolongado, préeclâmpsia, cesárea e depressão e, no neonato, há o aumento da incidência de obesidade, sobrepeso e distúrbios metabólicos no futuro ${ }^{4}$. Estudos semelhantes a este revelam uma frequência consideravelmente elevada de mulheres jovens com sobrepeso e obesidade no final da gestação, da mesma forma demonstram também como resultado a ingestão alimentar inadequada por grávidas que apresentam menos de quatro anos de estudo, aumento de consumo de sal, açúcares, gorduras e óleos em mulheres jovens, bem como ausência de prática de atividades físicas ${ }^{1}$. Considerações finais: Observa-se que a evolução do peso na gestação deve ocorrer de acordo com a idade gestacional do feto e que o simples cálculo do índice de massa corporal pode indicar a situação nutricional. Podese concluir, com base nos dados apresentados neste estudo, que o número de gestantes com baixo peso e sobrepeso foi consideravelmente alto e o referente àquelas inseridas no grau de peso adequado foi menor do que $50 \%$, o que significa que as orientações sobre alimentação saudável e o acompanhamento nutricional precisam ser intensificadas, principalmente no período do pré-natal. Implicações para a enfermagem: Faz-se necessário que o profissional de enfermagem saiba identificar, durante o pré-natal e atendimento à gestante, os riscos e deficiências nutricionais de forma a exercer a equidade por meio da sugestão de alimentos saudáveis e que sejam de fácil acesso à população com condições socioeconômicas menos favorecidas. Para aquelas que apresentam baixa escolaridade, deve oferecer informação por meio de educação em saúde, avaliando o estado nutricional e levando em consideração a necessidade de cada gestante, para, 
assim, orientar, prescrever cuidados e medicamentos e encaminhar a equipe multiprofissional as gestantes com diagnóstico de baixo peso, sobrepeso e obesas, a fim de evitar danos à saúde gestacional e ao feto e prevenir complicações durante o trabalho de parto.

Descritores: Gestante; Estado nutricional; Índice de massa corporal.

\section{Referências}

1. Silva MG, Holanda VR, Lima LSV, Melo GP, Estado Nutricional e Hábitos Alimentares de Gestantes Atendidas na Atenção Primária de Saúde. Revista Brasileira de Ciências da Saúde. 2018; 24 (4): 349-356.

2. Bastos MCP. Metodologia Científica.1. Ed. Londrina: Kroton; 2015.

3. Paiva LV, Nutrição da gestante portadora de anemia falciforme, complicações maternas e resultados perinatais. São Paulo. tese [doutorado em Ciências] Faculdade de Medicina da USP; 2016.

4. Oliveira ACM, Pereira LA, Ferreira LC, Clemente APG. Estado nutricional materno e sua associação com o peso ao nascer em gestações de alto risco. Ciência \& Saúde Coletiva. 2018; 23 (7): 2373-2382. 


\title{
PROCESSO SAÚDE-DOENÇA SOB A ÓTICA DE ADOLESCENTES GRÁVIDAS MORADORAS DE ÁREA DE RESSACA
}

\author{
${ }^{1}$ Katiciane Rufino da Silva; ${ }^{2}$ Hiago Rafael Lima da Silva; ${ }^{3}$ Izabele Grazielle da Silva Pojo; \\ ${ }^{4}$ Viviane de Souza Bezerra; ${ }^{5}$ Luzilena de Sousa Prudêncio; ${ }^{6}$ Nely Dayse Santos da Mata. \\ ${ }^{1}$ Enfermeira. Residente em Saúde Coletiva, Universidade Federal do Amapá - Unifap. E-mail: \\ katicianyap@gmail.com; \\ ${ }^{2}$ Acadêmico do Curso de Bacharelado em Enfermagem; Unifap; \\ ${ }^{3}$ Acadêmica do Curso de Bacharelado em Enfermagem; Unifap; \\ ${ }^{4}$ Acadêmica do Curso de Bacharelado em Enfermagem; Unifap; \\ ${ }^{5}$ Enfermeira. Doutora em Saúde Coletiva. Professora efetiva do Colegiado do Curso de \\ Bacharelado em Enfermagem, Unifap; \\ ${ }^{6}$ Enfermeira. Doutora em Ciências. Professora efetiva do Colegiado do Curso de Bacharelado em \\ Enfermagem, Unifap.
}

\section{RESUMO}

Introdução: O atual modelo de atenção à saúde pressupõe que o processo saúde-doença é resultante de fatores socioeconômicos, culturais, étnico-raciais, psicológicos e comportamentais, que podem contribuir para o surgimento de doenças e constituem fatores de risco para a população, delineando seus índices de qualidade de vida. Assim, a qualidade de vida e saúde dos indivíduos pode sofrer interferência em função das desigualdades sociais presentes em diversos ambientes de seu contexto social, como residência, trabalho, assim como suas experiências de vida ${ }^{1}$. Nesse contexto, observa-se que o estudo das representações sociais do processo saúde-doença mostra-se relevante, posto que fundamenta práticas e ações de seus atores, assim como as relações por eles estabelecidas, em seu contexto social, ou com o que lhe ocorre e/ou o cerca ${ }^{2}$. O conceito atual de saúde está associado à subjetividade do interior da relação entre o corpo e o ambiente, conceito este que se opõe ao modelo biomédico clássico ${ }^{3}$. Objetivos: Analisar os termos saúde e doença sob a ótica de adolescentes grávidas. Método: Estudo descritivo com abordagem qualitativa, sendo que a coleta de dados foi realizada no período de setembro a novembro de 2018, com a utilização de um roteiro de entrevista aprofundada. Participaram da pesquisa nove adolescentes, gestantes, residentes em área de ressaca, selecionadas pelos seguintes critérios de inclusão: ser adolescente, gestante, residir em área de ressaca e realizar acompanhamento de pré-natal na Unidade Básica de Saúde da Universidade Federal do Amapá. Todos os aspectos éticos da Resolução no 466/2012 do Conselho Nacional de Saúde foram respeitados neste estudo, com aprovação do Comitê de Ética em Pesquisa da Universidade Federal do Amapá sob o número CAAE: 95602518.9.0000.003. Para análise de dados, foi utilizada a técnica de Análise de Conteúdo proposta por Laurence Bardin, a qual defende a organização da análise em três fases: a pré-análise, que é a leitura do material produzido, em seguida, exploração do material e, posteriormente, o tratamento e interpretação dos resultados. Objetivando o anonimato, os discursos das adolescentes foram identificados com a letra $G$ (gestante) seguida de um número que significa a ordem das entrevistas. Resultados: A análise dos dados possibilitou a construção de duas categorias, quais sejam: o entendimento das 
grávidas adolescentes sobre a definição do termo saúde; o conhecimento das participantes sobre adoecimento. Categoria 1: o entendimento das grávidas adolescentes sobre a definição do termo saúde: de acordo com os relatos das participantes, pode-se observar que o entendimento do termo saúde está fortemente associada ao modelo histórico biomédico em que propõe o conceito de saúde como a ausência de patologias, não levando em consideração outros aspectos como, por exemplo, os fatores condicionantes e determinantes da saúde, sendo eles alimentação, moradia, meio ambiente, trabalho, transporte, lazer, entre outros. Além deste predomínio, houve forte relação com a predisposição do indivíduo em realizar afazeres diários. Percebe-se tal situação nos seguintes relatos: "É tipo uma pessoa estar bem, ter a sua saúde própria, é tipo não estar doente, isso que é ter saúde. É se alimentar bem, praticar exercícios que fortalecem a saúde dela. Ela é alegre, não é desmotivada pra fazer nada, é uma pessoa que tem disposição" (G6). "É uma pessoa disposta, uma pessoa que sempre tá podendo fazer as coisas, tá sempre com disposição, tá sempre lavando roupa, os afazeres da casa, afazeres domésticos, tudinho. Uma pessoa com saúde de ferro que pode fazer tudo, que tá sempre, vamos dizer que tá sempre alegre, acho que é isso, não tenho muito que falar, porque é uma pessoa que tem disposição pra tudo, não tá muito fraca, que tá forte com uma saúde forte" (G8). Categoria 2: o conhecimento das participantes sobre adoecimento: Ao serem indagadas sobre o entendimento do que seria estar doente, os diversos relatos estão associados ao estado de dor e comprometimento dos variados sistemas do corpo, tendo como ênfase o sistema mecânico. Pode-se identificar isso no seguinte discurso: "É estar triste, acho que é estar dependente de outras pessoas quando a pessoa tá doente. Eu fiquei doente, fiquei com um problema na coluna e aí eu não podia andar, então eu pedia às pessoas para me ajudar, eu nem saía de casa, só quando eu desmaiava de dor, eu sentia muita dor mesmo, nas costas, aí essas dores, às vezes, eram extremamente fortes, aí as pessoas que me levavam, meu pai me levava carregada" (G1). Historicamente o estado patológico era considerado como um desvio de normas previamente fixadas e definidas. Com a evolução das ciências sociais e da saúde, geraram-se definições mais atualizadas sobre o assunto, podendo o conceito de adoecimento ser considerado como uma experiência individual e subjetiva, e não ser medido por nenhum parâmetro externo, tendo como base para compreensão deste fenômeno o diálogo aprofundado com aquele que vivencia esse processo ${ }^{3}$. Atualmente sabe-se que o processo saúde-adoecimento está associado a diversos aspectos complexos, em que se faz necessário que os setores da área da saúde e os demais setores organizem-se de forma intersetorial, considerando os riscos e as potencialidades e as vulnerabilidades que influenciam na vida da população, responsabilizando-se assim pela elaboração de políticas públicas voltadas à promoção da saúde 4 . Neste estudo, observou-se que o entendimento das adolescentes sobre saúde e doença apresenta-se como fator importante para instrumentalizar o profissional de saúde para o manejo dos diferentes nas suas singularidades, sendo primordial a assistência integral às adolescentes. Considerações finais: $O$ estudo possibilitou compreender que o protagonismo dessa população é fortemente influenciado pelo entendimento construído sobre saúde e doença, envolvendo fatores culturais, socioeconômicos, nível escolar, entre outros, resultando assim, nas diversas formas de lidar com a promoção da saúde e o adoecimento. Implicações para a enfermagem: Faz-se necessário que o profissional de enfermagem busque identificar e compreender esse fenômeno para, assim, contribuir 
melhor com suas práticas de atenção à saúde voltadas a esse grupo populacional, fortalecendo o acesso a um serviço de saúde que possibilite a construção de saberes coletivos, envolvendo usuários e profissionais de saúde.

Descritores: Processo saúde-doença; Adolescentes; Grávidas.

\section{Referências}

1. Costa BVL, Mendonça RD, Santos LC, Peixoto SV, Alves M, Lopes ACS. Academia da Cidade: um serviço de promoção da saúde na rede assistencial do Sistema Único de Saúde. Ciênc Saúde Coletiva. 2013;18(1):95-102.

2. Câmara AMCS, Melo VLC, Gomes MGP, Pena BC, Silva APD, Oliveira KD, Moraes APS, Coelho GR, Victorino, LR et al. Percepção do processo saúde-doença: significados e valores da educação em saúde. Rev bras educ med. 2012; 36 (1):40-50.

3. Gamarra TPN. Conceitos de saúde e doença: análise das tendências em teses e dissertações brasileiras. Arq. Cienc. Saúde UNIPAR. 2019; 23 (1):49-55.

4. Brasil. Ministério da Saúde. Política Nacional de Promoção da Saúde. Brasília, DF: O ministério; 2015. 


\title{
PROTOCOLO DE ENSAIO CLÍNICO RANDOMIZADO COM TECNOLOGIA REAC NO ESTUDO DE BIOMARCADORES DE ESTRESSE
}

\author{
${ }^{1}$ Larissa Duarte Ferreira; ${ }^{2}$ Rebeca Góes Gonçalves; ${ }^{3}$ Ana Vitória Gonçalves de Oliveira \\ Cruz; ${ }^{4}$ Aimê Mareco Pinheiro Brandão; ${ }^{5}$ Marina Nolli Bittencourt; ${ }^{6}$ Ana Rita Pinheiro
}

Barcessat.

\begin{abstract}
${ }^{1}$ Enfermeira. Bolsista Capes - Programa de Pós-Graduação em Ciências da Saúde - Universidade Federal do Amapá - Unifap. E-mail: larissadrt16@gmail.com;

${ }^{2}$ Acadêmica do Curso de Bacharelado em Enfermagem; Unifap. Bolsista do Departamento de Extensão (DEX). Grupo de Pesquisa em Biofotônica e Neuromodulação;

${ }^{3}$ Acadêmica do Curso de Bacharelado em Enfermagem; Unifap. Bolsista do Departamento de Extensão (DEX). Grupo de Pesquisa em Biofotônica e Neuromodulação;

${ }^{4}$ Acadêmica do Curso de Bacharelado em Enfermagem; Unifap. Grupo de Pesquisa em Biofotônica e Neuromodulação;

${ }^{5}$ Enfermeira. Doutora em Ciências da Saúde; Unifap. Professora Efetiva Colegiado do Curso de Bacharelado em Enfermagem e Programa de Pós-Graduação em Ciências da Saúde - Unifap;

6 Cirurgiã-Dentista. Doutora em Estomatologia Básica e Aplicada- Patologia Bucal; Unifap. Professora Efetiva Colegiado do Curso de Bacharelado em Enfermagem e Programa de PósGraduação em Ciências da Saúde - Unifap.
\end{abstract}

\section{RESUMO}

Introdução: O período universitário é um momento de transição e mudanças na vida dos indivíduos, em que novas necessidades são criadas e a pessoa precisa se adaptar ao novo ambiente. Esse processo pode se tornar estressor e causar impactos na saúde dos estudantes. Pesquisas indicam que os alunos universitários são vulneráveis ao desenvolvimento de diversos transtornos mentais, entre eles depressão, ansiedade e estresse ${ }^{1}$. A tecnologia Radio Electric Asymmetric Conveyer (REAC) para uso terapêutico é uma plataforma tecnológica para biomodulação e neuromodulação que está demonstrando efetividade em doenças neuropsicológicas. A REAC e os protocolos terapêuticos aplicados ativam diversos processos de otimização com o objetivo de recuperar, por parte do organismo, os corretos mecanismos neurobiológicos, neuropsíquicos e psicofísicos, alcançando uma resposta terapêutica sobre disfunções, sintomatologias e patologias. A tecnologia REAC catalisa um processo terapêutico autônomo que se desenvolve sempre na direção da autocura espontânea, aspecto que garante a eficácia terapêutica totalmente natural e com a ausência de qualquer efeito biologicamente nocivo e ou evento colateral adverso. Os tratamentos REAC, que são radiofrequências passadas por meio de uma ponteira em pontos da região auricular para Otimização Neuropostural (NPO) e Otimização Neuropsicofísica (NPPO), são não invasivos, são indolores e de rápida e fácil administração. A velocidade, especificidade e eficácia, sem efeitos indesejáveis e adversos, são características bastante valorizadas na atividade clínica, que possibilitam a promoção do uso desses tratamentos em projetos de promoção da saúde neuropsíquica, mesmo que sejam administrados em comunidades sociais extensas ${ }^{2}$. Objetivo: Descrever o passo a passo da construção de um protocolo de pesquisa clínica do tipo ensaio clínico randomizado - ECR com base no enunciado CONSORT 2010, para a otimização neuropsicofísica (NPPO) em depressão, estresse e 
ansiedade, associado a estudos bioquímicos. Método: Trata-se de um estudo descritivo, exploratório, experimental de abordagem quantitativa do tipo ensaio clínico randomizado ECR, com análise comportamental, hematológica, bioquímica frente a uma intervenção clínica com os protocolos de NPO e NPPO da Plataforma REAC. Realizado através da pesquisa na base de dados Pubmed acerca dos protocolos de neuromodulação REAC do Instituto Rinaldi e Fontani com os descritores "REAC" e "Rinaldi", totalizando 44 artigos publicados de 2010 até 2019. Ainda como revisão integrativa da literatura para a composição do protocolo, pesquisaram-se quais os principais biomarcadores viáveis para estudo de estresse psicológico e quais exames bioquímicos que expressam esses biomarcadores. Para isso, chegaram-se a 2.599 artigos na base de dados Pubmed, encontrando o Cortisol como um biomarcador de estresse e assim este foi escolhido para o protocolo clínico. A análise de exames bioquímicos será através de coleta de sangue para hemograma simples, taxa de cortisol no sangue e glicemia em jejum. Compatibilizaram-se ainda os critérios descritos na lista de checagem do "Enunciado CONSORT 2010", consistindo em um guia com mais de vinte itens para a descrição de um ensaio clínico randomizado duplo cego ${ }^{3}$. Resultados: $O$ protocolo se direciona pelos passos a seguir: 1 . Local de estudo: Universidade Federal do Amapá (Unifap), Rod. Juscelino Kubitschek, km 02 - Campus Jardim Marco Zero, Macapá - AP. 2. Sujeitos do estudo e cálculo amostral: os participantes do estudo são os alunos da Unifap, maiores de 18 anos, tanto da graduação quanto pós-graduação. Serão incluídos no grupo de intervenção com 0 protocolo REAC, para efeito de delimitação da amostra, os indivíduos classificados na escala EADS-21, em um dos três domínios psicológicos (ansiedade, depressão e estresse), dentro dos quadros de moderado a extremamente grave. A mensuração da amostra determinada pelo método aleatório simples: $\mathrm{N}_{0}=\frac{1}{(E 0) 2}$ e $\mathrm{n}=\frac{(N . N 0)}{(N+N 0)}$, onde: $\mathrm{N}=$ tamanho da população de alunos de saúde; $\mathrm{N}_{0}=$ primeira aproximação do tamanho da amostra $=400$; $\mathrm{E}_{0}=$ erro amostral tolerável $=5 \%$ ou 0,$05 ; n=$ tamanho da amostra $=118$ (cento e dezoito participantes). 3. Intervenções realizadas nos grupos de participantes. 4. Medidas de resultados/variáveis primárias e secundárias. 5. Randomização (geração de sequência e mecanismo de ocultação de alocação). 6. Implementação (quem gerou a alocação aleatória, inscreveu participantes e atribuiu intervenções). 7. Cegamento. 8. Métodos estatísticos utilizados para comparar os grupos. 9. Recrutamento. 10. Números analisados. 11. Resultados e estimativas. 12. Efeitos Adversos. 13. Limitações do estudo. 14. Generalização. 15. Interpretação dos dados. Considerações finais: Portanto, espera-se que a construção do protocolo clínico seja uma ferramenta facilitadora para a investigação da eficácia e benefícios que os protocolos da bioneuromodulação REAC podem oferecer, como terapêutica inovadora e indolor. Além de servir como incentivo para que surjam futuros estudos que investiguem mais esse método de terapia, principalmente na área de Enfermagem, a qual não possui estudos sobre a plataforma REAC. Acerca da devolutiva para a sociedade, o protocolo analisa a técnica do REAC como um redutor e possivelmente um método curativo para os transtornos mentais não psicóticos (depressão, estresse e ansiedade), distúrbios psicológicos que possuem grande repercussão na vida do indivíduo desde as relações sociais, profissionais e até na saúde física, interferindo nos processos cognitivos, impossibilitando o processamento de informações de relações de causa-efeito e tomadas de decisão, incapacitando na resolução de problemas do dia a dia, com que 0 ser humano precisa se confrontar. Implicações para a enfermagem: Diversos estudos 
com esse método geralmente são publicados para área da medicina ou psicologia, porém o profissional enfermeiro também é apto para tratamentos e terapias na área da saúde mental, na identificação de sinais e sintomas, além de ser o primeiro profissional que o usuário encontra nas unidades de saúde. Logo, por se tratar de um método indolor, não invasivo, rápido e não produtor de efeitos colaterais, o enfermeiro pode ser treinado não só para investigá-lo, como também para aplicar os protocolos de bioneuromodulação da tecnologia REAC e gerar evidências científicas acerca desta plataforma terapêutica.

Descritores: REAC; Saúde Mental; Ensaio Clínico; Neuromodulação REAC.

\section{Referências}

1. Bayram N, Bilgel N. The prevalence and socio-demographic correlations of depression, anxiety and stress among a group of university students. Soc Psychiatry Psychiatr Epidemiol. [Internet]. 2008; 43(8): 667-672.

2. Rinaldi A, Rinaldi C, Pereira JAC, Margotti ML, Bittencourt MN, Barcessat ARP, et al. Radio electric asymmetric conveyer neuromodulation in depression, anxiety, and stress. Neuropsych Dis Treat [Internet]. 2019; 15:469-480.

3. Martins J, Sousa LM, Oliveira AS. Recomendações do enunciado CONSORT para o relato de estudos clínicos controlados e randomizados. Medicina (Ribeirao Preto.Online) [Internet]. 2009; 42(1): 9-21. 


\title{
REPARO DE LESÕES CUTÂNEAS INDUZIDAS FRENTE A DUAS TÉCNICAS: ESTUDO CLÍNICO E HISTOPATOLÓGICO
}

\author{
${ }^{1}$ Lucas dos Santos Nunes; ${ }^{2}$ Charton Frankson Madureira Nascimento Júnior; ${ }^{3}$ Erick \\ Souza Neri; ${ }^{4}$ Rafael Pires Moreira; ${ }^{5}$ Taynara Camille Guilherme Lima; ${ }^{6}$ Ana Rita Pinheiro \\ Barcessat.

\begin{abstract}
${ }^{1}$ Acadêmico do Curso de Bacharelado em Enfermagem. Bolsista Probic-VS; Universidade Federal do Amapá - Unifap. E-mail: lucasnunes900@outlook.com;

${ }^{2}$ Acadêmico do Curso de Bacharelado em Enfermagem Unifap. Grupo de pesquisa em Biofotônica e neuromodelação;

${ }^{3}$ Acadêmico do Curso de Bacharelado em Enfermagem Unifap. Grupo de pesquisa em Biofotônica e neuromodelação;

${ }^{4}$ Enfermeira. Especialista em Saúde Coletiva;

${ }^{5}$ Farmacêutico. Mestre em Ciências. Professor efetivo do Colegiado do Curso de Bacharelado em Enfermagem- Unifap;

5 Cirurgiã-Dentista. Doutora em Estomatologia Básica e Aplicada- Patologia Bucal; Unifap. Graduação em Ciências da Saúde - Unifap.
\end{abstract} \\ Professora efetiva Colegiado do Curso de Bacharelado em Enfermagem e Programa de Pós-
}

\section{RESUMO}

Introdução: Após ocorrer lesões teciduais que necessitam de reparo, o organismo dos animais vertebrados inicia sequências bioquímicas que busquem a reconstrução desse tecido. Essas sequências divididas nas fases do processo de reparo, possuem as fases proliferativa e de remodelamento como ponto principal a ativação fibroblásticas. Sendo essas produtoras de colágeno, protagonistas no reparo do tecidual. Protocolos diversos têm sido utilizados para auxiliar na modulação do processo de cicatrização e o laser de baixa potência figura como um deles, logo tem sido amplamente estudado em suas aplicabilidades clínicas. O colágeno, por sua vez, é a principal proteína presente no processo de cicatrização, sendo a ativação dos fibroblastos a chave para a sua síntese. A palavra laser da sigla "light amplification by stimulated emission of radiation", que significa "amplificação da luz por emissão estimulada de radiação". Tem potencial para proporcionar ao organismo uma melhor resposta à inflamação, com consequente redução de edema, minimização da sintomatologia dolorosa e bioestimulação celular, a terapia a laser mostrase como uma alternativa para processos que apresentem reação inflamatória, dor e necessidade de regeneração tecidual. ${ }^{1}$ A partir disso, a laserterapia atuaria sobre os fibroblastos tendo em vista o aumento da síntese de fibras colágenas, acelerando o reparo tecidual. Porém, tal afirmativa se pode questionar na medida em que esse efeito pode ser comparado ao que já se preconiza como padrão com uma pomada cicatricial comercial por exemplo. Portanto, este estudo tem como propósito a comparação entre a laserterapia e uma pomada cicatricial comercial no processo de cicatrização, por meio da densidade tecidual do colágeno. Objetivo: Comparar os efeitos cicatriciais do laser vermelho de baixa potência com os de uma pomada cicatricial comercial. Método: Foram utilizados dez camundongos da espécie Mus musculus, que foram alimentados com ração comercial (Labina $\AA^{\circledR}$, Purina, Bayer, Brasil) e com água ad libitum, submetidos a ciclos de 12 horas de claro e escuro e mantidos em gaiolas individuais durante todo o experimento. Foram 
divididos em dois grupos, a saber: G1- Laser ( $n=5$ ) cujas feridas foram tratadas com Laser vermelho, com parâmetros de luz: Comprimento de onda $-\Lambda-=660 \mathrm{~nm}$; Potência $=$ 40mW; Energia= 3,6(J/ponto); Densidade de energia por ponto= $90(\mathrm{~J} / \mathrm{cm} 2)$; Área do ponto= 0,04(cm2); Tempo por ponto=1,5(min); № de irradiações $=1$; № de pontos irradiados=2; Densidade de potência $1.000 \mathrm{~mW} / \mathrm{cm} 2, \mathrm{G} 2$ - Pomada contendo uma associação de $1 \mathrm{U}$ de Fibrinolisina, 666U/g Desoxirribonuclease e 10mg de Cloranfenicol. Cada um recebeu duas lesões induzidas no dorso, utilizando como instrumento um punch cirúrgico de dimensões $6 \times 6 \mathrm{~mm}$ de altura e largura até a profundidade de fibras musculares em torno de $3 \mathrm{~mm}$, que foi mensurada por uma sonda milimetrada. Os animais foram submetidos a anestesia geral intraperitoneal precedida de tricotomia com instrumento apropriado e descartável, resultando ao todo em 17 lesões nos dois grupos. As lesões foram biopsiadas em $72 \mathrm{~h}$ após o tratamento, seccionadas longitudinalmente e fixadas em paraformaldeído a $20 \%$ em solução tampão de fosfato de sódio dibásico anidro e monobásico de pH 7,0, preparada no mesmo dia da utilização, e os fragmentos foram enviados para processamento histológico convencional. Foram feitos cortes de $5 \mu \mathrm{m}$ obtidos em micrótomo, posteriormente sendo corados por hematoxilina e eosina e pela coloração especial Tricrômico de Masson para análise das fibras colágenas em microscopia de luz convencional. Para a análise da área de colágeno e para as medidas das feridas, foi utilizado o Software Image J, que analisa a diferença da tonalidade da imagem, que expressou em pixels $/ \mathrm{cm}^{2}$ a área corada de cada lâmina. Procedeu-se à análise histopatológica subjetiva realizada por um patologista alheio ao protocolo de pesquisa. Foram avaliados ainda parâmetros clínicos visuais de hiperemia, secreção e resposta a dor, por avaliador alheio ao protocolo. Esta pesquisa utiliza-se do parecer 2.349.365 do CEP- Unifap. Resultados: Observou-se que, apesar de serem utilizados tratamentos distintos, os grupos apresentaram parâmetros clínicos equivalentes de hiperemia, resposta à dor e ausência de secreção. Os aspectos visuais de vermelhidão, edema, retração da ferida e tecido de granulação foram mais favoráveis no grupo laser em relação ao grupo pomada. Histologicamente, no grupo laser, os cortes revelaram corte de pele com epitélio pavimentoso estratificado, paraqueratinizado, descontínuo, com o conjuntivo em pequena área, que apresenta infiltrado inflamatório intenso de caráter misto sub e intraepitelial, podendo ser evidenciados: plasmócitos, linfócitos, eosinófilos e macrófagos. A lâmina própria de tecido conjuntivo denso não modelado exibe o mesmo infiltrado em áreas focais, vasos congestos. $\mathrm{Na}$ análise histológica do grupo tratado com pomada, a amostra de pele com epitélio pavimentoso estratificado, paraqueratinizado, com úlcera extensa em início de processo de reparo, o conjuntivo subjacente é denso do tipo não modelado e apresenta discreto infiltrado inflamatório de caráter misto, sialoadenite e hemorragia, além dos vasos congestos que também podem ser observados. A análise histológica de comparação entre os grupos, em relação à maior densidade de fibras de colágeno evidencia que o tratamento realizado com laser de baixa potência auxilia no aumento da produção de colágeno pelos fibroblastos, o que favorece a cicatrização. Essa bioestimulação se dá pelo aumento na cadeia respiratória das mitocôndrias, que, se mais bem ativadas ou estimuladas, geram mais adenosina trifosfato, favorecendo as atividades celulares. Observou-se ainda um adensamento de fibras de colágeno significativo no grupo laser $(p=0,05)$ em relação ao grupo pomada. Considerando-se que a análise foi feita ainda no período inflamatório do processo de reparo, pode-se concluir pela redução do tempo de reparo com a ativação laser. Considerações finais: A comparação realizada no modelo 
deste trabalho demonstrou que o tratamento com laser de baixa frequência é promissor e apresenta melhoras significativas, considerando a redução de dimensões de feridas induzidas durante o processo de cicatrização e a redução da área da lesão, pois apresentou proliferação tecidual diferenciada em comparação ao outro tratamento. Implicações para a enfermagem: Este estudo mostra a importância da busca por novas técnicas utilizadas como curativas ou regenerativas de tecido lesado, que não sejam invasivas e que busquem a homeostasia.

Descritores: Regeneração tecidual; Laserterapia; Colágeno.

\section{Referência}

1. Maluf AP, Ughini GC, Maluf RP, Pagnoncelli RM. Utilização de laser terapêutico em exodontia de terceiros molares inferiores. RGO. 2006;54(2):182-184. 


\title{
PREDIÇÃO DA CLASSE DE GORDURA VISCERAL UTILIZANDO MACHINE LEARNING EM PESSOAS COM DIABETES MELLITUS
}

\author{
${ }^{1}$ Marluci de Souza Lédo Santos; ${ }^{2}$ Júlio Lédo Santos; ${ }^{3}$ Kaila Corrêa Santos; ${ }^{4}$ Vanessa da \\ Silva Oliveira; ${ }^{5}$ Francineide Pereira da Silva Pena. \\ ${ }^{1}$ Acadêmico do Curso de Bacharelado em Enfermagem; Universidade Federal do Amapá - Unifap. \\ E-mail: marluci.santos93@gmail.com; \\ ${ }^{2}$ Engenheiro Eletricista - Universidade Federal do Pará - UFPA. Especialista em Engenharia \\ Biomédica com Ênfase em Engenharia Clínica - UES; \\ ${ }^{3}$ Acadêmico do Curso de Bacharelado em Enfermagem; Unifap; \\ ${ }^{4}$ Professora Especialista em Enfermagem Cirúrgica. Docente da Universidade Federal do Amapá; \\ ${ }^{5}$ Professora Doutora em Ciências - Universidade de São Paulo - USP. Docente da Universidade \\ Federal do Amapá.
}

\section{RESUMO}

Introdução: A gordura visceral (GV) é o acúmulo interno de tecido adiposo sob os músculos superficiais abdominais, entre os órgãos internos. Esse acúmulo influencia negativamente na sensibilidade à insulina e no metabolismo lipídico; logo, valores $\geq 10$ de gordura visceral estão associados a hipercolesterolemia e o aumentam do risco de doenças cardiovasculares e de diabetes mellitus tipo $2^{1,5}$. O diagnóstico por imagem do acúmulo de GV é eficiente, mas possui alto custo, logo, não está disponível para maioria da população, principalmente a que vive em maior vulnerabilidade econômica². Diversas tecnologias são capazes de auxiliar nesse diagnóstico e torná-lo menos oneroso, um exemplo que pode ser empregado com essa finalidade é a técnicas de predição de Machine Learning (ML) que é uma área da inteligência artificial, na qual determinado sistema aprende por um padrão de associação dos dados, ao invés da programação tradicional e explícita. Por meio da utilização de algoritmos matemáticos, são criados modelos capazes de predizer resultados e descrever o comportamento de dados. Objetivo: Avaliar o desempenho do algoritmo $K$ Nearest Neighbors (KNN) para a determinação das classes de gordura visceral em adultos com diabetes mellitus. Método: Trata-se de um estudo quantitativo, transversal, com abordagem descritiva. Participaram deste estudo 63 pessoas de ambos os sexos, participantes do Programa de Promoção da Saúde para Pessoas com Diabetes Mellitus da Universidade Federal do Amapá, sendo aprovado pelo Comitê de Ética em Pesquisa sob o parecer número CEP local 2000853437/CAAE e CAI 95595718.4.0000.0003. Foi realizada a coleta de dados utilizando-se a balança de bioimpedância Onrom $\AA$ modelo HBF-514C, as medidas de circunferência da cintura e do quadril. As variáveis preditoras foram a circunferência da cintura e do quadril e o índice de massa corporal (IMC). A variável-alvo foi a classe de gordura visceral. Para a construção do modelo, utilizou-se o algoritmo de aprendizagem supervisionada baseada em instâncias, o KNN. Quando utilizado para classificar algum dado em determinada categoria, este algoritmo busca um número $k$ de vizinhos mais próximos ao dado analisado e assim, pela maioria de vizinhos pertencentes a uma classe, determina que o dado em questão pertence à mesma classe daquela maioria. Os $\mathrm{k}$ vizinhos mais próximos são determinados através da distância euclidiana $(d(y, x)=$ $\left.\sqrt{\sum_{i=1}^{n}\left(y_{i}-x_{i}\right)^{2}}\right)$ entre os dados, também chamados de "instâncias"4. Primeiramente foi 
determinado o valor de $k$, em seguida, a partir de todos os dados observados, foi feita a divisão em dados de treino e dados de teste. Os dados de treino são aqueles em que 0 algoritmo KNN conhece a classe das variáveis preditoras, enquanto os de teste são aqueles que ele conhece somente as variáveis preditoras, sem conhecer suas classes. Então, para uma determinada instância $y_{i}$ pertencente aos dados de teste, é medida a distância $d\left(y_{i}, x_{i}\right)$ em relação aos $k x_{i}$ de treino mais próximos. Assim, $y_{i}$ é classificado de acordo com a classe mais frequente dos $k x_{i}$. O modelo foi implementado na linguagem de programação Python versão 3.6 com a utilização da biblioteca de código aberto scikit-learn versão 0.20.3, bem como o software Orange versão 3.17.0. Após o particionamento do conjunto de dados em conjunto de treinamento e de teste, foi executada a etapa de treinamento do algoritmo. A fim de se obter a generalização do modelo e evitar "sobreajuste (overfitting)" de dados, foi empregada a técnica de generalização de "validação cruzada", mais especificamente o método $k$-Fold, com $\mathrm{k}=10$. O modelo foi avaliado segundo as métricas de avaliação: "Acurácia de Classificação (AC)", "Precisão (P)" e "Área sob a Curva ROC (AUC)". Foi utilizado o método "GridSearchCV" da biblioteca scikit-learn para determinação do melhor valor de $k$ dentro do algoritmo $K N N$. Os participantes foram divididos em duas classes: Classe 0 (nível de gordura visceral <10) e Classe 1 (nível de gordura visceral $\geq 10$ ). Resultados: $O$ estudo contou com 63 participantes de ambos os sexos, 52 (82,5\%) mulheres e 11(17,5\%) homens, com idade média de 63,4 $\pm 11,6$ anos. Vinte e dois (34,9\%) participantes estão presentes na classe 0 (nível de gordura visceral [NGV] <10) e 41 $(65,1 \%)$ participantes na classe 1 (NGV $\geq 10)$. Com relação às variáveis preditoras distribuídas por classe, observou-se: média da circunferência da cintura na classe $0=85,1$ \pm 9,4 cm; média da circunferência da cintura na classe $1=102,5 \pm 10,9 \mathrm{~cm}$; média da circunferência do quadril na classe $0=92,0 \pm 7,6 \mathrm{~cm}$; média da circunferência do quadril na classe $1=107,8 \pm 13,4 \mathrm{~cm}$; média do IMC na classe $0=23,65 \pm 3,13 \mathrm{Kg} / \mathrm{m}^{2}$; média do IMC na classe $1=31,51 \pm 5,16 \mathrm{~kg} / \mathrm{m}^{2}$. A execução do método $k$-Fold, com $\mathrm{k}=10$ apresentou os seguintes valores para as duas classes do modelo: $A C=0,937, P=0,937$ e $A U C=0,912$. Os valores obtidos na métrica de avaliação são para um k=8 (8 vizinhos) do classificador baseado no algoritmo KNN. Observa-se que o modelo construído apresentou uma alta taxa de acertos obtida após a execução do método de validação cruzada, com quatro erros de classificação, como mostram as métricas. Considerações finais: Este modelo se apresenta como uma possível e importante ferramenta que ajuda a detectar a classe de gordura visceral em adultos diabéticos, visto que apresentou uma acurácia de classificação de $93,7 \%$ e precisão de 93,7\%, revelando ser um modelo eficiente para auxiliar na determinação da classe da gordura visceral e o risco cardiovascular. Ao utilizar as técnicas de ML, a enfermagem usufrui de diagnósticos mais rápidos, tratamentos mais assertivos e determinação de riscos, de modo que passa a assistir o paciente com equidade, o que contribui para a evolução do modelo de aprendizado e assistência de enfermagem. Implicações para a enfermagem: Os algoritmos de ML se apresentam como uma nova metodologia para direcionar e auxiliar de forma acessível os diagnósticos de enfermagem de obesidade, sobrepeso e perfusão tissular cardíaca diminuída, contribuindo nas tomadas de decisão frente às pessoas com diabetes na atenção primária e possibilitando uma intervenção mais precoce e precisa.

Descritores: Aprendizado de máquinas; Gordura intra-abdominal; Diabetes mellitus. 


\section{Referências}

1. Eickemberg M, Oliveira CC, Roriz AKC, Fontes GAV, Mello Adriana Lima, Sampaio LR. Bioimpedância elétrica e gordura visceral: uma comparação com a tomografia computadorizada em adultos e idosos. Arq Bras Endocrinol Metab [Internet]. 2013; 57( $1)$ : 27-32.

2. Oliveira MAM, Fagundes RLM, Moreira EAM, Trindade EBSM, Carvalho T. Relação de indicadores antropométricos com fatores de risco para doença cardiovascular. Arq. Bras. Cardiol. [Internet]. 2010; 94(4): 478-485.

3. Albrecht CAM, Rosa RS, Bordin R. O conceito de equidade na produção científica em saúde: uma revisão. Saude soc. [Internet]. 2017; 26(1): 115-128.

4. Akhil MJ, Deekshatulu BL, Chandrac P. Classification of Heart Disease Using K- Nearest Neighbor and Genetic Algorithm. Procedia Technology. 2013; 10: 85-94.

5. Gu D, Ding Y, Zhao Y, Qu Q.Visceral Adiposity Index was a useful Predictor of Prediabetes. Exp Clin Endocrinol Diabetes. 2018; 126(10): 596-603. 


\section{DEFICIÊNCIA E FAMÍLIA: RELATO DE EXPERIÊNCIA}

${ }^{1}$ Mércia Gabrielle Bruno Bastos; ${ }^{2}$ Álefe Mateus Sena Guimarães; ${ }^{3}$ Verônica de Azevedo Mazza; ${ }^{4}$ Camila Rodrigues Barbosa Nemer; ${ }^{5}$ Sâmea Marine Pimentel Verga; ${ }^{6}$ Érika

Tatiane de Almeida Fernandes Rodrigues.

${ }^{1}$ Acadêmica do Curso de Bacharelado em Enfermagem; Universidade Federal do Amapá Unifap. E-mail: merciagbbastos@gmail.com;

${ }^{2}$ Acadêmico do Curso de Bacharelado em Enfermagem; Unifap;

${ }^{3}$ Enfermeira. Doutora em Enfermagem. Universidade Federal do Paraná - UFPR. Professora Associada do Departamento de Enfermagem e do Programa de Pós-Graduação em Enfermagem; ${ }^{4}$ Enfermeira. Mestre em Enfermagem. Doutoranda em Saúde Pública pela Escola Nacional de Saúde Pública Ensp/Fundação Oswaldo Cruz - Fiocruz. Professora do Colegiado do Curso de Bacharelado em Enfermagem da Unifap;

${ }^{5}$ Docente efetiva da Unifap. Doutoranda em Enfermagem;

${ }^{6}$ Enfermeira. Doutora em Enfermagem; Unifap. Professora efetiva no Colegiado do Curso de Bacharelado em Enfermagem.

\section{RESUMO}

Introdução: Em censo demográfico realizado em 2010, o Brasil apresentava 2.611.536 pessoas portadoras de alguma deficiência mental/intelectual, definidas como aquelas que possuem limitações intelectuais, mentais, físicas ou sensoriais de curto ou longo período ${ }^{1}$. Percebendo a grande prevalência de casos e implicações de saúde e sociais que estão envolvidas nas limitações que as deficiências estabelecem, ressalta-se a importância de se dar atenção ao contexto familiar, tendo em vista as diversas transformações que a dinâmica familiar sofre devido às adversidades impostas pela deficiência e pela sociedade, principalmente pela não aceitação ou não reconhecimento ${ }^{2}$. Objetivo: Relatar experiência de acadêmicos do Curso de Bacharelado em Enfermagem da Universidade Federal do Amapá - UNIFAP em coleta de dados de pesquisa em uma escola de educação especial de Macapá. Método: Estudo descritivo de abordagem qualitativa do tipo relato de experiência, realizado a partir de coleta de dados com vínculo ao projeto de pesquisa - "Vivências de famílias constituídas de crianças com deficiência: organização, práticas e necessidades", cujo objetivo geral é compreender a organização das famílias de crianças com deficiência, tendo como critérios de inclusão familiares de crianças de 4 a 10 anos diagnosticadas com Síndrome de Down (SD), Transtorno do Espectro do Autismo (TEA) ou Paralisia Cerebral (PC) e de exclusão familiares menores de 18 anos. Para o início da entrevista, realizou-se apresentação e leitura Termo de Consentimento Livre e Esclarecido (TCLE). Nele estão esclarecidos os objetivos, riscos e benefícios da pesquisa. A coleta dos dados foi realizada por meio de entrevista semiestruturada e registrada em áudio com um gravador digital que ocorreram em 29/03/2019, em uma escola do município de Macapá - AP. Os acadêmicos que a realizaram puderam vivenciar dois momentos diferentes, sendo a Primeira Entrevista (E1) com familiar de criança com SD e a Segunda Entrevista (E2) com familiar de portador de TEA. Este estudo está em consonância com Resolução no 0466/2012 do Conselho Nacional de Saúde (CNS) /MS e aprovada pelo Comitê de Ética em Pesquisa sob o parecer consubstanciado $\mathrm{n}^{0}$ 2.327.633. 
Resultados: Após análise, emergiram duas categorias de maior destaque. "Aceitação do diagnóstico": a chegada de uma criança por si só provoca grandes mudanças no seio familiar, sobretudo se a criança for diagnosticada com alguma deficiência, o que pode acontecer logo ao nascer ou mais tardiamente, causando grandes impactos na vida familiar, principalmente nos pais. Poderão vir à tona diversos sentimentos como formas de reagir à revelação do diagnóstico, principalmente se forem levadas em consideração as expectativas que os pais criam desde antes do nascimento de seus filhos ${ }^{2}$. $\mathrm{Na} \mathrm{E1}$, familiar relatou que, ao receber o diagnóstico logo ao nascer de sua filha, apesar do impacto da notícia e da preocupação sobre como seria a vida da criança, ocorreu 0 conformismo, seguido de aceitação, justificada por já ter contato com pessoa com deficiência em sua família. Estes foram sentimentos predominantes, além do alívio pelo nascimento com vida devido parto com riscos para mãe e bebê. Na E2, o diagnóstico foi de difícil aceitação, houve choro e preocupação, principalmente quanto ao futuro da criança, sendo necessária a busca de informações na internet para melhor conhecimento da situação. "Mudança na dinâmica organizacional familiar": um filho com diagnóstico de uma deficiência exige uma readaptação na organização familiar, há maior demanda de cuidados em relação às condutas diárias, os cuidados passam a ser voltados exclusivamente para a criança, sempre na prerrogativa de estimular suas potencialidades e desenvolvimento, a criança torna-se o centro do cuidado ${ }^{3,4}$. $\mathrm{Na} \mathrm{E1}$, notou-se que a família, apesar de ter seu funcionamento voltado para as necessidades da criança, não deixou de realizar suas atividades de forma geral, sendo exemplificado no relato da mãe, ao explicar a rotina da família, ocorrendo adaptação da família em seu convívio e permitindo realização das atividades de todos os membros da família. $\mathrm{Na}$ E2, notou-se a mudança completa da rotina, a partir do diagnóstico, com abandono do trabalho e dedicação exclusiva à criança, ocorrendo mudança drástica no contexto familiar, podendo gerar desgaste físico e deterioração da saúde mental do familiar que assume a maior parte dos cuidados com a criança. Além de ocasionar no orçamento da família, uma vez que um familiar precisa abandonar o emprego para se dedicar inteiramente aos cuidados da criança com deficiência. Considerações finais: A família de crianças com deficiências passa por um processo gradual de enfrentamento em que, em primeiro momento, experienciam sofrimento e estresse devido impacto do diagnóstico e falta de conhecimento acerca das deficiências, o que acaba gerando difícil aceitação do diagnóstico. É perceptível a grande mudança organizacional que as famílias sofrem devido nova realidade. As falas dos familiares que cuidam diretamente demonstraram que o cuidado fica centrado na criança, suas necessidades, principalmente quando não há o apoio de outros componentes da família e as necessidades do cuidador são postas em segundo plano. Essas implicações incitam a importância e necessidade de um profissional capacitado que possua uma abordagem menos focada nas dificuldades da criança e mais nas suas potencialidades e qualidades, influenciando positivamente no processo de aceitação e entendimento da deficiência para um cuidado adequado, com consideração às diferentes necessidades de suporte que essas famílias apresentam, proporcionando um atendimento com equidade ${ }^{5}$. Implicações para a enfermagem: As deficiências estudadas necessitam de um diagnóstico precoce devido complexidade de condutas e cuidados que são essenciais para o prognóstico e qualidade de vida dessas famílias. Assim, urge a necessidade de que profissionais da saúde e da educação tenham 
competências e habilidades para $o$ tratamento e condutas assertivas para desenvolvimento da integralidade dessas crianças e suas famílias. E, principalmente, que esses profissionais estejam aptos a identificar e intervir o mais precocemente possível. Tal demanda é necessária em todas as esferas da atenção à saúde. É de suma importância que a Enfermagem saiba trabalhar estratégias para o melhor enfrentamento dessas famílias, atendendo às diferentes necessidades de cada membro familiar.

Descritores: Família; Crianças com deficiência; Assistência Integral à Saúde.

\section{Referências}

1. Ministério da Saúde [Internet]. Política Nacional de Saúde da Pessoa com Deficiência. Brasília (DF): Ministério da Saúde; 2017.

2. Silva CCB; Ramos LZ. Reações dos familiares frente à descoberta da deficiência dos filhos. Cad. Ter. Ocup. UFSCar [Internet]. 2014; 22: 15-23.

3. Cavalcanti GA. Stress e qualidade de vida dos cuidadores de crianças portadoras de Síndrome de Down. Recife. Dissertação [Mestrado]. Universidade Católica de Pernambuco. 2013.

4. Mapelli LD, Barbieri MC, Castro GVDZB, Bonelli MA, Wernet M, Dupas G. Criança com transtorno do espectro autista: cuidado na perspectiva familiar. Esc. Anna Nery Rev. Enferm. 2018; 22 (4): 9.

5. Espinazola CC, Cia F, Azevedo TL, Gualda DS. Crianças com Deficiência Física, Síndrome de Down e Autismo: Comparação de Características Familiares na Perspectiva Materna na Realidade Brasileira. Rev. Bras. Educ. Espec. 2018; 24 (2): 199-212.

Financiamento da pesquisa:

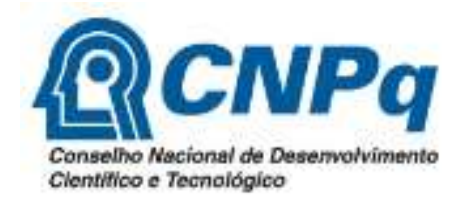




\title{
PERFIL SOCIODEMOGRÁFICO E OS ASPECTOS CLÍNICOS DOS PROFISSIONAIS OURIVES NO MUNICÍPIO DE OIAPOQUE
}

\author{
${ }^{1}$ Nathanni Queiroz dos Santos Marques; ${ }^{2}$ Germana Teixeira de Sousa; ${ }^{3}$ Ariane \\ Aparecida dos Santos Moraes; ${ }^{4}$ Jacqueline Gonçalves Ramos Wetch; ${ }^{5}$ Fabio Rodrigues \\ Trindade; ${ }^{6}$ Carlos Manuel Dutok Sánchez.
}

\begin{abstract}
${ }_{1}^{1}$ Acadêmica do Curso de Bacharelado em Enfermagem; Universidade Federal do Amapá - UnifapCampus Binacional. E-mail: nathyq.26@gmail.com;

${ }^{2}$ Acadêmica do Curso de Bacharelado em Enfermagem; Unifap - Campus Binacional;

${ }^{3}$ Acadêmica do Curso de Bacharelado em Enfermagem; Unifap - Campus Binacional;

${ }^{4}$ Acadêmica do Curso de Bacharelado em Enfermagem; Unifap - Campus Binacional;

5 Enfermeiro. Doutor em Enfermagem; Unifap. Professor efetivo do Colegiado do Curso de Bacharelado em Enfermagem- Campus Binacional;

${ }^{6}$ Bioquímico. Doutor em Biodiversidade e saúde; Unifap. Professor efetivo do Colegiado do Curso de Bacharelado em Enfermagem - Campus Binacional.
\end{abstract}

\section{RESUMO}

Introdução: A ourivesaria é uma das artes mais antigas do mundo, alguns registros mostram que há 2.500 a.C já se fabricavam joias e outros ornamentos valiosos que eram feitos com ouro, entre outros metais preciosos. ${ }^{1}$ Essa profissão era vista com muito glamour no período da idade moderna, considerada de enorme prestígio entre as realezas. Os ourives eram também muitas vezes considerados artistas, pois atuavam como artesãos, trabalhando com ouro, criando delicadas joias, que teriam um valor tanto monetário como artístico. Hoje no Brasil, é uma profissão muito controversa por trazer certas dificuldades, exigências e habilidades na manipulação das joias e certos riscos ocupacionais, o que motivou a realização do presente estudo. No munícipio de Oiapoque, no Estado do Amapá, é considerável o número de profissionais ourives, pois esta é uma zona de garimpo que possui muito ouro em sua redondeza, o que torna a profissão bem presente na região. As ações de políticas públicas voltadas a estes profissionais devem existir, pois são necessárias para proteção desses trabalhadores, buscando melhorias das condições de trabalho e a regularização da profissão por mais complexo e lento que seja esse processo..$^{2,3} \mathrm{~A}$ regularização da profissão diminui a vulnerabilidade e protege o trabalhador, pois o mesmo desfrutará de direitos e normativas que contribuirão para um melhor estilo de vida e perfil sociodemográfico. ${ }^{4}$ Objetivo: Traçar o perfil sociodemográfico e aspectos clínicos dos profissionais ourives no município de Oiapoque. Método: Foi realizado um estudo transversal, quantitativo, descritivo e exploratório que visou uma primeira aproximação do pesquisador com o tema da pesquisa para uma melhor familiarização com os fatos relacionados ao tema, com o fim de buscar o máximo de conhecimento para traçar o perfil dos profissionais ourives no município de Oiapoque. Este está localizado na parte Norte do Brasil e do Estado do Amapá, constituído por uma extensão superficial equivalente a $22.725,70 \mathrm{~km}^{2}$, faz fronteira com a Guiana Francesa e limita-se com os municípios de Calçoene, Serra do Navio, Pedra Branca do Amapari e Laranjal do Jari. Foi aplicado um questionário semiestruturado com perguntas que contribuíram para um melhor resultado na pesquisa. No momento da entrevista, foi realizada a aferição da pressão arterial (PA), 
glicemia capilar e índice de massa corpórea - IMC. Para critério de inclusão, selecionaramse os profissionais com mais de um ano de trabalho no ramo e maiores de 18 anos. Foi realizado um levantamento de todos os profissionais no município de Oiapoque, tendo sido encontrados 38 profissionais ao todo, 32 participaram da pesquisa e seis se recusaram a participar. O estudo foi aprovado no CEP Unifap com CAAE: 87074218.7.0000.0003. Resultados: Participaram da pesquisa 32 profissionais ourives no município de Oiapoque, sendo que $100 \%$ deles são do sexo masculino. Com $34,38 \%$ representando uma faixa etária de 31 a 40 anos, 25\% entre 21 e 30 anos, 18,75\% entre 41 e 50 anos, 18,75\% de 51 a 60 anos e 3,12 de 18 a 20 anos. No que tange à escolaridade, 50\% deles concluíram o ensino fundamental, 43,75\% o ensino médio, 3,12\% curso técnico e 3,12\% nível superior. Em relação à cor de pele, 65,63\% autodeclararam-se pardos, 21,87\% brancos, 9,38\% pretos e 3,12\% amarelos. No quesito religiosidade, 46,87\% relataram ser católicos, 43,75\% evangélicos e 9,38\% não ter religião. Quanto ao estado civil, 40,62\% são solteiros, 34,38\% amigados e $25 \%$ casados. A Renda familiar da população pesquisada foi de $40,62 \%$ destes profissionais na faixa de $R \$ 649,00$ a $R \$ 1,164,00 ; 37,5 \%$ informaram renda entre $R \$$ $1.765,00$ e $R \$ 2.564,00 ; 12,5 \%$ informaram estar na faixa entre $R \$ 1.165,00$ e $R \$ 1.764,00$ e os outros $9,38 \%$ informaram renda entre $R \$ 2.565,00$ e $R \$ 4.076,00$. Quanto aos aspectos clínicos pesquisados, $50 \%$ dos profissionais apresentaram o valor de glicemia inferior ou igual a 99mg/dL (Parâmetro dentro do normal), 25\% entre 100 e 125mg/dL (Possível prédiabetes) e $25 \%$ um valor acima de $126 \mathrm{mg} / \mathrm{dL}$ (Possível risco de diabetes). Em relação à pressão arterial (PA), 81\% apresentaram, no momento da entrevista, valor da pressão arterial normal (Sistólica 120 a <139 e diastólica 80 a <99) e, para 19\%, o valor estava elevado (Sistólica >140 e diastólica >100) segundo classificação do Ministério da Saúde MS. Como resultados também se verificou que $38 \%$ dos participantes apresentam sobrepeso $(25 \leq \mathrm{IMC}<30)$, já $34 \%$ têm peso adequado $(18,5 \leq \mathrm{IMC}<25)$ e $28 \%$ com obesidade (IMC $\geq 30$ ). Considerações finais: $\mathrm{O}$ estudo foi de grande importância para traçar o perfil destes profissionais no município de Oiapoque, e se percebe que a maioria apresenta seus aspectos clínicos normais, apesar de, no aspecto de índice de massa corpórea, a maior parte dessa população seja considerada com índice elevado, enquadrando-se na classificação de sobrepeso e obesidade. Ressalta-se que, como toda a população de ourives do estudo são homens, faz-se importante traçar novas ações e promoções de saúde para esse público, pois estudos comprovam que homens estão mais vulneráveis a doenças porque não procuram o serviço de saúde primário. Deve-se buscar a prevenção de agravos evitáveis. Destarte, é fundamental criar ou inovar políticas públicas voltadas para esse grupo em estudo. Salienta-se a importância da realização de novas pesquisas para melhor compreender a temática e contribuir para melhoria do perfil sociodemográfico e educação em saúde dessa população. Implicações para a enfermagem: $O$ estudo é uma ferramenta valiosa que poderá contribuir para que os profissionais de saúde conheçam o perfil desses trabalhadores usuários do Sistema Único de Saúde (SUS) e, por conseguinte, efetuem ações de prevenção de doenças e promoção da saúde, por meio de educação em saúde, pois o SUS foi concebido como uma política para toda a população, independentemente de condição socioeconômica. $O$ estudo também possibilita chamar atenção dos profissionais de saúde sobre a importância de contribuir com essa classe trabalhadora para prevenção de futuras manifestações clínicas que tenham relação com o seu perfil sociodemográfico e aspectos clínicos apresentados 
nos resultados deste estudo. Cabe ressaltar que o enfermeiro tem o papel fundamental em saúde pública, principalmente na atenção básica.

Descritores: Ourives; Saúde Coletiva; Ocupacional.

\section{Referências}

1. Guimarões D, Cabral P. O que é Ourives. Acessado em: significados.com.br em: 30.11.2017 as 08:14h. (7Graus 2011-2018).

2. Ferreira APSS. Famílias inseridas no arranjo produtivo informal da produção de joias e bijuterias de limeira, SP: a exposição ocupacional a contaminantes químicos em ambiente domiciliar. Dissertação (Mestrado), Programa de pós-graduação em saúde pública da faculdade de saúde pública da universidade de São Paulo. São Paulo 2018.

3. Lacorte LEC. A construção de políticas públicas em rede Inter. Setorial para a Erradicação do Trabalho Infantil em Limeira São Paulo. Dissertação (mestrado). Programa de pós-graduação em saúde pública, Universidade de São Paulo, São Paulo 2012.

4. Ministério da Saúde (BR). Secretaria de Políticas de Saúde. Brasília. Política Nacional de Saúde do Trabalhador. 2000. 


\section{IMPACTO BIOQUÍMICO DA TERAPIA ILIB EM SITUAÇÕES CLÍNICAS DISTINTAS}

${ }^{1}$ Rebeca Góes Gonçalves; ${ }^{2}$ Ana Vitoria Gonçalves de Oliveira Cruz; ${ }^{3}$ Larissa Duarte Ferreira; ${ }^{4}$ Erick Souza Neri; ${ }^{5}$ Rafael Pires Moreira; ${ }^{6}$ Ana Rita Pinheiro Barcessat.

${ }^{1}$ Acadêmica do Curso de Bacharelado em Enfermagem. Bolsista Departamento de ExtensãoUniversidade Federal do Amapá - Unifap. E-mail: rebecagoes018@gmail.com;

${ }^{2}$ Acadêmica do Curso de Bacharelado em Enfermagem. Bolsista Departamento de ExtensãoUnifap;

${ }^{3}$ Enfermeira. Bolsista Capes-Programa de Pós-Graduação em Ciências da Saúde - Unifap;

${ }^{4}$ Acadêmico do Curso de Bacharelado em Enfermagem. Bolsista Pibic- CNPQ;

${ }^{5}$ Farmacêutico. Mestre em Ciências. Professor efetivo do Colegiado do Curso de Bacharelado em Enfermagem-Unifap;

${ }^{6}$ Cirurgiã-Dentista. Doutora em Estomatologia Básica e Aplicada- Patologia Bucal. Professora efetiva do Colegiado do Curso de Bacharelado em Enfermagem- Unifap.

\section{RESUMO}

Introdução: A técnica Intravascular Laser Irradiation of Blood (ILIB) traduz-se em uma irradiação direta do sangue através de um laser de baixa potência, que emite uma onda eletromagnética em geral nos comprimentos de onda vermelho $(660 \mathrm{~nm})$ e infravermelho $(880 \mathrm{~nm})$, ponto-chave para determinar o protocolo da terapia, ou seja, a interação entre a luz e o sangue. A ILIB possui a finalidade de estimular as células do corpo, e essa modulação ocorre porque a luz de baixa intensidade utilizada incide uma energia sobre os fotorreceptores das células sanguíneas; logo, eles armazenam tal energia e a transmitem para outras moléculas, desencadeando uma série de alterações bioquímicas e bioelétricas no organismo. A partir disso, os efeitos mais característicos dessa terapia descritos na literatura são: o anti-inflamatório, pois a luz interfere na cascata do ácido araquidônico, pela interrupção na síntese de prostaglandinas, substâncias que são essenciais na regulação do processo inflamatório, e o efeito antioxidante, por conta da sua atuação contra os radicais livres por meio da estimulação da enzima CuZn Superóxido Dismutase (SOD). Essa enzima inibe a ação das espécies reativas de oxigênio e leva proteção às células contra metaplasias e envelhecimento, e o efeito analgésico, porque a radiação também incita a liberação de betaendorfinas através da sua ação sobre os receptores periféricos e - Sistema Nervoso Central. ${ }^{1,2}$ A aplicação dessa terapia é realizada, de maneira geral, na região do punho (artéria radial), pois a espessura da derme e da epiderme nesse local são mais finas, e, dessa forma, facilita o alcance da luz nos vasos sanguíneos. ${ }^{1}$ Por conseguinte, o uso da terapia ILIB neste estudo teve como princípio a busca por alternativas não medicamentosas e não invasivas que pudessem levar ao paciente um bem-estar físico e bioquímico, independentemente de sua doença. Objetivo: Identificar o impacto da terapia ILIB sobre parâmetros hematológicos e bioquímicos em dois pacientes com casos clínicos distintos. Método: Paciente 1- Feminino, 65 anos, com diagnóstico de artrite psoriásica e fibromialgia. Paciente 2- Masculino, 60 anos, submetido à radioterapia na cabeça e no pescoço, apresentava osteorradionecrose de maxilares associada à dor mandibular. Nos dois pacientes utilizou-se, de forma equivalente e comparável, um protocolo de irradiação de baixa potência na artéria radial da mão esquerda, de 30 minutos do laser vermelho (660 
$\mathrm{nm}$ ) e 30 minutos do infravermelho $(808 \mathrm{~nm}$ ) por dez dias. Cada um realizado pelo profissional responsável por cada caso, quais sejam um médico no caso do paciente 1 e um cirurgião-dentista no caso do paciente 2. Após a aplicação do laser, realizou-se a comparação entre os exames laboratoriais anteriores e posteriores ao protocolo, com enfoque naqueles com maior percentual de redução ou aumento, além da análise dos sintomas descritos pelos pacientes antes e depois da terapia, por meio de uma escala de intensidade, numerada de 1 a 10 (10 - Muito intenso, 1 - pouco intenso; 0 - inexistente), sendo realizada no primeiro dia, no último dia e 20 dias após a aplicação do ciclo. Esta pesquisa utiliza-se do parecer 2.349.365 do CEP- Unifap. Resultados: Os parâmetros que sofreram maior impacto após a terapia ILIB foram colesterol total (redução de 13,6 \% em média para os dois pacientes) e triglicerídeos (redução de 17,2\%). Essa redução ocorreu porque a ILIB oferece um papel importante na regulação do metabolismo lipídico, no qual ela melhora o catabolismo e reduz a oxidação do LDL e aumenta os níveis de HDL. ${ }^{3}$ No âmbito individual, a ureia reduziu $32 \%$ em um paciente e, no outro, teve aumento de 9,4\%. Em um dos pacientes, foi observada redução nos parâmetros das transaminases AST $(44,7 \%)$ e ALT $(36,70 \%)$ respectivamente. É importante ressaltar também que, em condições de estresse oxidativo, é observado um aumento na produção de ALT e AST. Desse modo, a terapia ILIB contribuiu para a redução das transaminases através do seu efeito antioxidante, estimulando principalmente a síntese da SOD. Além disso, de maneira inesperada, ocorreu uma redução $(7,06 \%)$ de glicose no paciente 1 e um aumento $(2,95 \%)$ de glicose no paciente 2. A técnica ILIB age sobre a produção de arginina, o aminoácido responsável por favorecer a liberação de hormônios, e, no caso, é a insulina, diminuindo a glicose $^{4}$, o que se presumia constatar nos dois pacientes. Foram observadas alterações substanciais nos linfócitos. Não houve impacto sobre a creatinina. No que concerne ao estado geral, ambos os pacientes relataram melhora no sono e no bem-estar geral, como a diminuição de dor e fadiga, que, no entanto, retornaram ao estado inicial após a retirada da terapia. Considerações finais: A terapia ILIB impactou a redução de parâmetros metabólicos e de estresse oxidativo em pacientes em estado crítico, demonstrando grande efetividade clínica, pois reduziu principalmente as inflamações e as dores dos pacientes. No entanto, a ILIB deve ser considerada para cada caso individualmente, conforme os protocolos, e ainda estudada em método de ensaio clínico em estudos de aplicabilidade. Portanto, é necessário frisar que a terapia possui efeitos temporários, sendo assim utilizada como tratamento coadjuvante, alternativo e não invasivo, a fim de melhorar o quadro clínico do paciente através de processos como a modulação de inflamações ou o fomento da analgesia. Implicações para a enfermagem: A técnica ILIB é mais conhecida para tratamentos estéticos, por conta do seu alto efeito cicatrizante, e pouco conhecida no âmbito clínico. Dessa forma, a ILIB não requer uma especialização em alguma área da saúde, apenas uma habilitação em laser para o seu uso, e, desse modo, a enfermagem também possui livre manejo do aparelho, desde que esteja habilitada para tal, utilizando-o conforme o protocolo escolhido. Além disso, e ainda mais importante, essa terapia é um método alternativo à medicação, pois não contém contraindicações ou efeitos colaterais. Isso acontece porque ela oferece ao paciente uma biomodulação, ou seja, o próprio organismo irá responder ao que o está afetando, melhorando, assim, o seu desempenho. Por conseguinte, o paciente terá uma evolução mais rápida e efetiva, diminuindo principalmente os sintomas que causam o seu desconforto e mal-estar. 
Descritores: Laser de baixa potência; Estimulação celular; Analgesia.

\section{Referências}

1. MMO tecnologia para a saúde [homepage na internet]. ILIB- A terapia da vitalidade.

2. Gomes CF, Schapochnik, A. O uso terapêutico do Laser de Baixa Intensidade (LBI) em algumas patologias e sua relação com a atuação da fonoaudiologia. Distúrb Comun 2017 set; 29 (3): 570- 578.

3. Huang S, Tsai Y, Wu S, Wei Y, Tsai P, Chuang T. Efeitos da Irradiação intravascular a laser do sangue na disfunção mitocondrial e estresse oxidativo em adultos com lesão medular crônica. Photomed Laser Surg 2012; 30 (10): 579-586.

4. Khoo NK, Iravani A, Arjmand M, Vahabi F, Lajevardi M, Akrami SM, Zamani Z. Um estudo metabolômico do efeito do laser de irradiação intravascular sanguínea em pacientes diabéticos tipo 2. Lasers Med Sci 2013; 28: 1527-1532. 


\title{
ANEMIA ASSOCIADA AO ESTADO NUTRICIONAL E PARASITOSES INTESTINAIS EM UMA COMUNIDADE RIBEIRINHA DE MACAPÁ, AMAPÁ
}

\author{
${ }^{1}$ Risomar Carréra de Menezes Júnior; ${ }^{2}$ Inake Gomes Marinho; ${ }^{3}$ Raimunda dos Santos \\ Pereira Lima; ${ }^{3}$ Vani Hoyos Figueira; ${ }^{3}$ Tatiana Ferreira de Souza Santos; ${ }^{4}$ Rubens Alex de \\ Oliveira Menezes.
}

\footnotetext{
1 Acadêmico do Curso de Farmácia; Universidade Federal do Amapá - Unifap. E-mail: risomarjunior@gmail.com;

${ }^{2}$ Acadêmico do Curso de Bacharelado em Enfermagem; Unifap;

3 Técnico de Laboratório; Unifap; vinculado ao Colegiado do Curso de Bacharelado em Enfermagem;

${ }^{4}$ Enfermeiro. Doutor em Doenças Infecciosas e Parasitárias - Universidade Federal do Pará UFPA. Professor efetivo do Colegiado do Curso de Bacharelado em Enfermagem.
}

\section{RESUMO}

Introdução: Segundo a Organização Mundial da Saúde (OMS), a anemia é um dos problemas mais comuns de saúde pública em todo o mundo, manifestando-se tanto em países desenvolvidos como em desenvolvimento. No âmbito da Amazônia Brasileira, a anemia é uma patologia de grande incidência, em especial onde os indicadores socioeconômicos remetem a condições menos favoráveis e o acesso à alimentação adequada para infantes ainda se mostra deficitário ${ }^{1}$. Este conjunto de fatores influencia diretamente para que esta moléstia seja ainda mais pungente entre as comunidades ribeirinhas amazonidas ${ }^{2}$. Nos casos de desnutrição, é comum haver uma redução crônica nas taxas de ferro sérico, ocasionada pela deficiência de sua ingestão através da dieta, diminuindo assim a sua oferta, o que, por conseguinte, acarreta deficiência na síntese de hemoglobina, que culmina na diminuição desta e sua oferta nos eritrócitos. Essa desordem nutricional é muito comum, em especial nas crianças entre 0 e 5 anos, mas também podem afetar consideravelmente idosos e mulheres gestantes ${ }^{1,2,3}$. Outra relação importante da anemia é sua associação com as parasitoses intestinais, o que se constitui em tema de crescente interesse para a saúde pública, principalmente ao correlacionar com crianças em idade escolar. Objetivo: Verificar a incidência de anemia associada ao estado nutricional e parasitoses intestinais em uma comunidade ribeirinha do município de Macapá, Amapá. Método: Estudo transversal realizado em uma comunidade no município de Macapá, através de exame hematológico (hemograma completo), utilizando para análise equipamento automatizado (Mindray-BC-3000plus), teste de quimiluminescência para quantificação de ferritina sérica, exames coprológicos pelos métodos direto, Hoffman e de Faust, para quantificação e qualificação de parasitoses. A coleta de dados antropométricos: peso, altura e Índice de Massa Corpórea normal (IMC) foi obtida através de cadastro de triagem, no momento da colheita de amostras biológicas, tanto de crianças quanto de adultos. Na oportunidade, também foram colhidas, por meio de questionário estruturado e com perguntas pertinentes ao objetivo do estudo, informações sobre: situação demográfica, socioeconômica e ambiental. Tanto as crianças quanto os adultos tiveram seu peso mensurado pela utilização de balança portátil digital eletrônica, com capacidade de $150 \mathrm{~kg}$ e precisão de $100 \mathrm{~g}$. A estatura foi medida em fita métrica, e a obtenção das medidas 
antropométricas seguiu os cálculos de divisão do peso pela altura elevada ao quadrado. Os valores de referência foram classificados segundo as recomendações da Associação Brasileira para o Estudo da Obesidade (Abeso). O período de estudo ocorreu entre os meses de março a abril de 2019. A pesquisa foi aprovada pelo Comitê de Ética-CEP/Unifap, conforme parecer: 3.003.159. Resultados: Foram analisados 119 residentes da comunidade, com idades entre 0 e 63 anos, a princípio, foram estudados apenas os índices da taxa de hemoglobina, o que demonstrou uma elevada parcela de indivíduos com resultados fora do valor de referência, dos 119, um total de 56 apresentou índices hematimétricos sugestivos de anemia, ou seja, uma incidência de 47,05\% dos casos sugestivos para anemia, sendo, destes, 73,21\% (41/56) de crianças e adolescentes. A faixa etária entre 0 e 2 anos apresentou incidência de 7,14\% (04/56), 3 e 10 anos 41,08\% (23/56), 11 e 18 anos 25\% (14/56) e acima de 19 anos 26,78\% (15/56). Após este estudo, foram analisados os valores de índice de massa corpórea (IMC) de todos os 56 indivíduos com hemoglobina deficitária e observou-se que 39,28\% (22/56) apresentavam-se abaixo do peso, destes, $100 \%$ (22/22) eram crianças e adolescentes com faixa etária entre 0 e 15 anos. Na avaliação dos demais índices hematimétricos, observou-se uma relação de 35,7\% (21/56) de valores de volume corpuscular médio (VCM) e 71,48\% (40/56) de hemoglobina corpuscular média (HCM) que estavam abaixo dos valores de referência. Estes índices hematimétricos quantitativos, associados a $50 \%(28 / 56)$ de hematócrito abaixo da normalidade, foram os indicativos de anemia microcítica e hipocrômica, acompanhada de anisocitose, observáveis na morfologia dos eritrócitos através dos esfregaços sanguíneos. Os resultados qualitativos de ferritina sérica por quimiluminescência variaram entre 5,6 e $153 \mathrm{ng} / \mathrm{mL}$, foram detectados três casos de anemia ferropriva, todos de adultos do sexo feminino. Com relação aos resultados coprológicos, foi observada uma positividade de 95,7\% (114/119) do total das amostras analisadas, sendo elevada aos sujeitos com índices hematimétricos sugestivos de anemia 100\% (56/56). Quanto à intensidade das infecções, o poliparasitismo, 55,3\% (31/56), prevaleceu frente ao monoparasitismo, 44,7\% (25/56). Para protozoários, foram observados 21,4\% (12/56), helmintos 14,2\% (8/56) e associação parasitária de $64,2 \%$ (36/56). Os agentes etiológicos mais frequentes entre os protozoários patogênicos encontrados foram: Entamoeba histolytica/E. díspar 26,7\% (15/56) e a Giardia intestinalis $16 \%(9 / 56)$, para os helmintos, o Ascaris lumbricoides $12,5 \%(7 / 56)$, Ancilostomídeos 3,57\% (2/56) e Trichuris trichiura 1,78\% (1/56) foram os mais prevalentes. Foi encontrada uma elevada prevalência de protozoários não patogênicos como: Entamoeba coli, Endolimax nana, lodamoeba butschlii, Chilomastix mesnili e Blatocistis hominis, espécies de protozoários que vivem no intestino humano, sem nenhuma evidência de ação nociva, sendo importante indicativo de contaminação da água ou dos alimentos (contaminação oro-fecal). Das morbidades investigadas no questionário, a diarreia foi a mais prevalente, $67,07 \%$ (34/56), possivelmente pela alta infestação de protozoários ameboides identificados pelos exames coprológicos. Em todo o estudo, o gênero feminino prevaleceu sobre o masculino com 64,28\% (36/56) dos casos. Considerações finais: Os resultados demonstram uma elevada prevalência de anemia em crianças e jovens com necessidade de acompanhamento médico e nutricional. Destaca-se a importância do diagnóstico e da descrição dos enteroparasitas encontrados a fim de programar medidas preventivas, além da relação dos fatores sociodemográficos e ambientais da comunidade, com proposta de palestras educacionais a fim de contribuir para o esclarecimento das 
condições de saúde dessa população. Implicações para a enfermagem: Este estudo contribui para a prática multiprofissional, agregando e aglutinando conhecimento científico sobre a população estudada, reforça o papel da saúde nas investigações epidemiológicas que fundamentaram ações educativas, fortalecendo o diagnóstico, o tratamento e a prevenção dessas enfermidades.

Descritores: Índices hematimétricos; Anemia; Enteroparasitoses; Saúde pública.

\section{Referências}

1. Faria FC, Sucasas HTF, Costa EGD, Silva JS. A relação de dados antropométricos e hematológicos com a anemia ferropriva em idade jovem. IV Seminário científico da FACIG/ II Jornada de Iniciação Cientifica da FACIG; Manhuaçu: Minas Gerais: 2018.

2. Castro TJ, Nunes MS, Conde WL, Muniz PT, Cardoso MA. Anemia e deficiência de ferro em pré-escolares da Amazônia Ocidental brasileira: prevalência e fatores associados. Caderno de Saúde Pública. 2011; 27(1): 131-142.

3. Marinho GL, Borges GM, Paz EPA, Santos RV. Mortalidade infantil de indígenas e não indígenas nas microrregiões do Brasil. Rev. Bras. Enferm. 2019; 72(1): 57-63.

4. Silva MBM. A Ocorrência de Parasitoses Intestinais em alunos do ensino fundamental na zona rural rede Municipal de São Luís-Maranhão e sua relação com os hábitos alimentares. [Dissertação Mestrado do Curso de Mestrado em educação para saúde]: Coimbra: ESCOLA Superior de educação de Coimbra (ESTeSC) e à escola Superior de Tecnologia da Saúde (ESEC); 2018. 


\title{
USO DE ÁLCOOL E OUTRAS DROGAS EM DISCENTES DE PÓS-GRADUAÇÃO STRICTO SENSU
}

\author{
${ }^{1}$ Ruan Patrick de Oliveira Souza; ${ }^{2}$ Carolina Almeida de Oliveira; ${ }^{3}$ Yuri de Medeiros \\ Souza Lima; ${ }^{4}$ Ana Rita Pinheiro Barcessat; ${ }^{5}$ José Luís da Cunha Pena; ${ }^{6}$ Marina Nolli \\ Bittencourt.
}

\footnotetext{
${ }^{1}$ Enfermeiro discente do Programa de Pós-graduação em Ciências da Saúde; Universidade Federal do Amapá - Unifap;

${ }^{2}$ Enfermeira discente do Programa de Pós-graduação em Ciências da Saúde; Unifap. E-mail: carolinaalmeida527@gmail.com;

${ }^{3}$ Farmacêutico discente do Programa de Pós-graduação em Ciências da Saúde; Unifap;

${ }^{4}$ Professora assistente do Curso de Bacharelado em Enfermagem; Unifap;

${ }^{5}$ Professor assistente do Curso de Bacharelado em Enfermagem; Unifap;

${ }^{6}$ Professora assistente do Curso de Bacharelado em Enfermagem; Unifap.
}

\section{RESUMO}

Introdução: As drogas são definidas como substâncias consumidas por diversas vias de administração que causam alteração do humor, do nível de percepção ou do funcionamento do sistema nervoso central ${ }^{1}$. São classificadas como lícitas e ilícitas; entre as lícitas têmse: álcool, tabaco, ansiolíticos, anfetaminas e solventes, e as ilícitas: os derivados da cocaína e a maconha ${ }^{2}$. O uso de sustâncias psicoativas tem provocado uma grande preocupação nas autoridades mundiais, ocasionada pelo aumento no quantitativo de usuários e suas consequências sobre os indivíduos, familiares e sociedade, sendo caracterizado com um problema de saúde pública ${ }^{3}$. Atualmente há a preocupação no que tange ao uso de álcool e drogas entre estudantes, uma vez que o ambiente universitário parece propiciar essa prática e os estudos que fazem essa avaliação na pós-graduação são escassos. Alguns estudos apontam o alto uso de substâncias por estudantes de mestrado e doutorado, entre elas estão o álcool, maconha e outras drogas ilegais 4 . Objetivo: Com base neste cenário, o objetivo deste estudo foi investigar o perfil de uso de álcool e outras drogas em discentes de cursos de Pós-Graduação da Universidade Federal do Amapá. Método: Os dados deste estudo foram retirados da dissertação de mestrado intitulada "Adoecimento psíquico, uso de álcool e drogas e satisfação: avaliação de discentes de pós-graduação stricto sensu". Trata-se de um estudo do tipo descritivo, de caráter quantitativo, que foi realizado na Universidade Federal do Amapá (Unifap) nos cursos de pós-graduação. Os critérios de inclusão foram: ser maior de 18 anos; ser discente de um dos programas de pós-graduação da Universidade Federal do Amapá; estar ativo no programa. Os critérios de exclusão foram: ter alguma deficiência que impossibilite responder ao questionário; ser discente de pós-graduação lato sensu. Os discentes foram contatados através do endereço eletrônico (e-mail), e o retorno dos questionários chegou ao total de 139. Para a coleta de dados, foram usados dois instrumentos que foram unidos no formulário on-line juntamente com o Termo de Consentimento Livre Esclarecido (TCLE). O primeiro foi o instrumento de caracterização de aspectos socioeconômicos (idade, renda, ocupação) e acadêmicos (formação, programa, ano de ingresso, satisfação com o programa), o segundo instrumento foi a Alcohol, Smoking and Substance Involvement 
Screening Test (ASSIST). Esta pesquisa foi submetida ao Comitê de Ética e Pesquisa da Universidade Federal, respeitando os preceitos éticos e legais. Com parecer favorável registrado sob o número 3.216.711, no dia 12 de dezembro de 2017. Resultados: A pesquisa consistiu em levantar o perfil de uso de substâncias psicoativas pelos discentes de pós-graduação através do instrumento ASSIST, o cenário encontrado foi um perfil de baixo risco para o uso na maioria dos entrevistados. As sustâncias mais consumidas entre eles foram: álcool, tabaco, hipnóticos e sedativos respectivamente. Com uma média de consumo mais baixa, porém presentes, estão: maconha, opioides, anfetaminas e alucinógenos, as substâncias mais raras foram a cocaína e crack e os inalantes. Nas variáveis socioeconômicas, a população se mostrou em sua maioria na faixa etária de 20 a 30 anos $(56,1 \%)$, sexo feminino $(61,9 \%)$, de etnia parda $(54,7 \%)$, com renda familiar acima de cinco salários mínimos (53,2\%), provenientes do Estado do Amapá (45,5\%), e como fonte de renda o trabalho como servidor público $(55,4 \%)$. Com relação às características acadêmicas, a maioria dos entrevistados eram da área de Ciências da Saúde $(48,2 \%)$, e a maioria estava no Programa de Pós-graduação em Ciências da Saúde (38,8\%), com nível de formação concluído de especialização (51\%), e 47,5\% ingressaram no programa de pósgraduação no ano de 2017. Quando questionados sobre o nível de satisfação com o curso de pós-graduação, $53,9 \%$ relataram estar satisfeitos com o programa, $74,1 \%$ relataram não ter tido nenhum conflito no programa, porém $25,9 \%$ se dividiram em conflitos com orientador, coordenação e docentes. Quanto à possibilidade de desistir, $56 \%$ disseram não cogitar esta ideia e $44 \%$ já cogitaram essa possibilidade. No que se refere ao perfil de uso de substâncias psicoativas, a substância com a maior média no ASSIST foi o álcool $(4,82$ $\pm 6,38)$, seguido do tabaco $(1,37 \pm 4,56)$. Em relação à distribuição dos discentes conforme a classificação do ASSIST, a maioria ficou em perfil de baixo risco para todas as substâncias, no médio e alto risco as bebidas alcóolicas apresentaram a maior porcentagem com $15,1 \%$ e $2,8 \%$ respectivamente. Para as substâncias, os resultados estatísticos mostram que não há diferença significativa entre os programas de pósgraduação, somente para bebidas alcoólicas houve diferença entre os grupos com $p$-valor $<0,05$. As outras substâncias mostraram um perfil de uso igual entre os grupos. Considerações finais: Acredita-se que o ambiente acadêmico pode ser um fator de risco e espaço que propicie o uso de substâncias por estudantes por características muito inerentes, como o alto estresse psicológico a que são submetidos pela carga excessiva de atividades e também os encontros, eventos, festas que acontecem entre os grupos nos quais ocorre o compartilhamento de drogas. A conclusão que se tem é de que as instituições são omissas com relação ao uso de substâncias, dentro das universidades não existem espaços para discussão sobre os riscos do uso de substâncias. São inexistentes também políticas de prevenção ou programas de assistência estudantil para recuperação de discentes em situação de uso abusivo. Além disso, o consumo é livre dentro desse espaço, sem que se tenha qualquer tipo de fiscalização e controle, e todos esses fatores elevam o risco de uso abusivo. As universidades devem aprimorar seus programas de prevenção e controle do abuso de drogas, focando nos grupos de risco. Implicações para a enfermagem: $O$ presente estudo considera a atuação frente ao uso de álcool e outras drogas. Dessa forma, a enfermagem pode atuar com estratégias de intervenção breve, que é um componente previsto no ASSIST, voltado para indivíduos com baixo risco para uso de substâncias, que foi o perfil apresentado pelos estudantes. A intervenção breve se mostra 
como uma estratégia estruturada com foco no problema e apresenta resultados positivos nesse tipo de população.

Descritores: Ansiedade; Depressão; Estresse; Educação de Pós-graduação.

\section{Referências}

1. Zeitoune RCG, Ferreira VS, Silveira HS, Domingos AM, Maia AC. O conhecimento de adolescentes sobre drogas lícitas e ilícitas: uma contribuição para a enfermagem comunitária. Esc Anna Nery Rev Enf 2012; 16(1): 57-63.

2. Fernandes TF, Monteiro BMDM, Silva JBM, Oliveira KMD, Viana NAO, Gama CAPD et al. Uso de substâncias psicoativas entre universitários brasileiros: perfil epidemiológico, contextos de uso e limitações metodológicas dos estudos. Cad saúde colet 2017; 25(4): 498-507.

3. Monteiro CFDS, Araújo TMED, Sousa CMMD, Martins MDCDC, Silva LLL. Adolescentes e o uso de drogas ilícitas: um estudo transversal. Rev. enferm. UERJ 2012; 20(3): 344348.

4. Melo MCA, Buin VMS, Medeiros FC, Santana JAP, Lima AB, Daher EF. Health of Psychiatry Residents: Nutritional Status, Physical Activity, and Mental Health. Acad Psy 2016; 40 (1): 81-84.

5. Zvauya R, Oyebode F, Day EJ, Thomas CP, Jones LA. comparison of stress levels, coping styles and psychological morbidity between graduate-entry and traditional undergraduate medical students during the first 2 years at a UK medical school. BMC res notes $2017 ; 10(1): 93$. 


\section{CONTRIBUIÇÕES DA PESQUISA E EXTENSÃO NO PROCESSO DE FORMAÇÃO DO ACADÊMICO DE ENFERMAGEM}

${ }^{1}$ Viviane de Souza Bezerra; ${ }^{2}$ Victor Hugo Oliveira Brito; ${ }^{3}$ Amanda Almeida da Silva Carvalho;

${ }^{4}$ Francisca Evelen Suelen Silva de Aguiar; ${ }^{5}$ Hiago Rafael Lima da Silva; ${ }^{6}$ Nely Dayse Santos da Mata.

\footnotetext{
${ }^{1}$ Acadêmica do Curso de Bacharelado em Enfermagem; Universidade Federal do Amapá - Unifap. E-mail: vivibezerra1996@gmail.com;

${ }^{2}$ Acadêmico do Curso de Bacharelado em Enfermagem; Unifap;

${ }^{3}$ Acadêmica do Curso de Bacharelado em Enfermagem; Unifap;

${ }^{4}$ Acadêmica do Curso de Bacharelado em Enfermagem; Unifap;

${ }^{5}$ Enfermeira. Doutora em Ciências; Unifap. Professora efetiva do Colegiado do Curso de Bacharelado em Enfermagem.
}

\section{RESUMO}

Introdução: Com o intuito de formar profissionais qualificados e implicados com o mundo do trabalho, as universidades disponibilizam projetos de pesquisa e extensão para os estudantes se inserirem e desenvolverem habilidades investigativas diferenciadas $e$ fundamentadas ${ }^{1}$. A pesquisa é uma prática comum e necessária na profissão da enfermagem, pois permite a agregação de novos saberes e amplia o conhecimento teóricoprático. A extensão universitária é um processo educativo, científico e cultural que busca a articulação entre ensino e pesquisa. Através dela, a Universidade retorna para a comunidade o aprendizado que foi submetido à reflexão teórica por seus inegrantes ${ }^{2}$. É um ambiente fecundo para aprender a valorizar diferentes saberes construídos por contextos e atores sociais diversos e integra docentes e demais trabalhadores, discentes e população, mesclando saberes populares e científicos ${ }^{3}$. Objetivo: Retratar as contribuições que a participação em projetos de pesquisa e extensão tem no processo de formação dos acadêmicos de enfermagem e a experiência vivenciada por estes no Grupo de Extensão de Apoio a Grávidas Adolescentes (Geaga) e de Pesquisa /Núcleo de Pesquisa Materno Infantil (NPMI) da Universidade Federal do Amapá - Unifap. Método: Trata-se de um estudo descritivo, caracterizado como relato de experiência, de acadêmicos de enfermagem sobre a vivência como extensionistas em um grupo de apoio a grávidas adolescentes, experiência no grupo de pesquisa vinculado ao de extensão e a influência que os mesmos têm no processo de formação dos acadêmicos. $O$ Geaga surgiu a partir do projeto de extensão "Educação para o parto: cinesioterapia e exercícios respiratórios para adolescentes primigestas". O grupo, atualmente, atende grávidas adolescentes que estão no início da gestação e está em execução desde 2015. É constituído por uma equipe multiprofissional. $\mathrm{O}$ objetivo principal do grupo de extensão é prestar assistência às gestantes e favorecer que essas tenham parto normal. Utiliza-se uma variedade de recursos materiais e didáticos para que sejam alcançados os objetivos das atividades propostas. As atividades são realizadas quinzenalmente, aos sábados, no período matutino, com duração média de 3 horas. O grupo de Pesquisa NPMl é vinculado ao grupo de extensão, tem como objetivo geral avaliar os impactos que as ações de promoção ao parto natural trazem para as participantes do Geaga e como objetivos específicos 
caracterizar o perfil sociodemográfico e obstétrico das participantes, identificar a eficácia dos exercícios respiratórios e de fortalecimento do assoalho pélvico e analisar sob a ótica das gestantes como as ações de promoção ao parto natural auxiliam no processo partonascimento. As reuniões acontecem semanalmente e motivam a continuidade das pesquisas realizadas pelo grupo, possibilitando recorrentemente o estudo de literaturas atualizadas e embasadas cientificamente para a dispensação, cada vez mais qualificada, da assistência às grávidas. São discutidos os resultados do grupo de extensão, prestação de contas de trabalhos que estão sendo produzidos e orientações aos acadêmicos pelas docentes, além de oficinas e palestras a fim de melhorar as habilidades de pesquisa dos participantes do grupo e a distribuição de temáticas que serão abordadas e pesquisadas ao longo do semestre. Resultados: Evidentemente a participação em atividades extensionistas e de pesquisa contribui para o desenvolvimento pessoal e acadêmico, agregando conhecimentos e habilidades para a formação dos acadêmicos de enfermagem. A discussão baseia-se nas competências e habilidades que os acadêmicos adquiriram no Geaga e no NPMI. As principais a serem destacadas são: 1) melhoria do trabalho em equipe; 2) autonomia; 3) papel educador; 4) senso crítico; 5) olhar holístico e humanizado e 6) articulação da pesquisa. A extensão universitária possibilita a melhoria do trabalho em equipe, haja vista que as atividades no grupo são realizadas pelos acadêmicos em conjunto com outros profissionais, possibilitando assim a interdisciplinaridade na prática e 0 enriquecimento científico a partir da agregação de outras ciências. O envolvimento na extensão e pesquisa permite aos acadêmicos a adoção de uma visão mais crítica e aumenta-lhes a capacidade de perceber os fatos e analisá-los em um contexto mais abrangente. $O$ aluno começa a vislumbrar a sociedade com olhar mais holístico e humanizado, devido ao fato de estar mais próximo da comunidade assistida e a partir de sua prática, podendo verificar resultados que trarão consigo mudanças significativas. Contribui para ampliar o repertório e prática social dos estudantes. Dessa maneira, qualifica a formação cidadã dos futuros profissionais ${ }^{4}$. Tal resultado deve-se à possibilidade de estudantes vivenciarem com a comunidade problemas locais e juntos atuarem para solucioná-los. Outra contribuição da extensão e pesquisa é o aprimoramento da comunicação, estimulando o papel educador do acadêmico de enfermagem, pois são incentivados a realizar palestras, cursos e outros eventos para a comunidade participante do grupo, tornando a comunidade dispersora do conhecimento a outras pessoas da sua rede de interação social. A extensão e a pesquisa também possibilitam aos acadêmicos a participação em eventos científicos, envolvendo o aprendizado na elaboração de resumos, na confecção de pôsteres, em apresentações e na produção de artigos científicos. A pesquisa oportuniza o confronto dos diversos textos científicos, despertando o potencial crítico capaz de desencadear a construção de representações que se refletirão na perpetuação desse hábito e na qualificação do exercício profissional ${ }^{5}$. Para que a extensão seja transformadora, é importante que o ensino e a pesquisa interajam com a sociedade, para que a universidade reúna as contribuições e críticas ${ }^{3}$. Considerações finais: Conclui-se que a participação em grupos de extensão universitária e pesquisa possibilita o desenvolvimento de habilidades e competências adormecidas nos acadêmicos e influencia a evolução dessas características. A extensão e a pesquisa, representadas aqui pelo Geaga e o NPMI, possibilitam o acompanhamento complementar a um público vulnerável da sociedade na qual estão inseridas grávidas adolescentes. Implicações para a enfermagem: Implica o 
estabelecimento de uma relação entre a enfermagem e sociedade, uma atuação que colabore efetivamente para a mudança social, voltada para os interesses e necessidades da maioria da população. Por fim, torna-se essencial o debate, em nível governamental, a respeito da adequação das políticas públicas às reais necessidades da população.

Descritores: Pesquisa; Estudantes de Enfermagem; Enfermagem.

\section{Referências}

1. Oliveira D, Bueno JFB, Sperling SG, Sobrinho RF, Rosanelli CLSP, Loro MM. A importância de acadêmicos em projeto de pesquisa- um relato de experiência. In: Anais 21. Seminário de Iniciação Científica; 2013 set 10-13; Unijuí, Brasil. Unijuí: Revistas Eletrônicas Unijuí; 2013.

2. Nogueira MDP (Organizadora), Santos SEM, Meirelles FSC, Sousa Al, Cunha EP, Guimarães MB, et al. Avaliação da Extensão Universitária: práticas e discussões da comissão Permanente de Avaliação da Extensão. 8 ed. - Belo Horizonte: FORPROEX/CPAE; PROEX/UFMG, 2013. 165 p.

3. Biscarde DGS, Pereira-Santos M, Silva LB. Formação em saúde, extensão universitária e Sistema Único de Saúde (SUS): conexões necessárias entre conhecimento e intervenção centradas na realidade e repercussões no processo formativo. Interface Comunic Saúde Educ. 2014; 18(48): 177-86.

4. Oliveira CS, Brêtas ACP, Rosa AS. A importância da extensão universitária na graduação e prática profissional de enfermeiros. Currículo sem Fronteiras. 2017; 17(1): 171-186.

5. Cruz ICF. Pesquisar se aprende pesquisando...relato da experiência de um programa de metodologia da pesquisa de enfermagem. Rev Enferm UERJ. 2001; 9 (3): 270-6. 


\section{EIXO III: O PRINCÍPIO DA} EQUIDADE BASEADO NAS NECESSIDADES DE SAÚDE DA POPULAÇÃO E NA ESTRUTURAÇÃO DA POLÍTICA DE ATENÇÃO BÁSICA NO CONTEXTO AMAZÔNICO 


\title{
DIAGNÓSTICO SITUACIONAL DE PUERICULTURA EM UM MUNICÍPIO DA AMAZÔNIA: RELATO DE EXPERIÊNCIA
}

\author{
${ }^{1}$ Bruna Carvalho da Rocha; ${ }^{2}$ Leidilene Pinheiro Pantoja Alves; ${ }^{3}$ Maicon Serrão dos \\ Santos; ${ }^{4}$ Bruna Corrêa Amoras; ${ }^{5}$ Raphaela Monteiro Chaves; ${ }^{6}$ Luzilena de Sousa \\ Prudêncio.
}

${ }^{1}$ Enfermeira Residente em Saúde Coletiva - área de concentração em Saúde da Criança e do Adolescente; Universidade Federal do Amapá - Unifap; E-mail: brunaa.carvalho.ap@gmail.com;

${ }^{2}$ Enfermeira Residente em Saúde Coletiva; área de concentração em Saúde da Criança e do Adolescente; Unifap;

${ }^{3}$ Enfermeiro Residente em Saúde Coletiva - área de concentração em Saúde da Criança e do Adolescente; Unifap;

${ }^{4}$ Enfermeira Residente em Saúde Coletiva - área de concentração em Saúde da Criança e do Adolescente; Unifap.

${ }^{5}$ Fonoaudióloga. Coordenadora de Saúde da Criança da Secretaria Municipal de Saúde de Macapá (AP); Semsa;

6 Enfermeira. Doutora em Enfermagem; Unifap. Professora efetiva Colegiado do Curso de Bacharelado em Enfermagem.

\section{RESUMO}

Introdução: A consulta de puericultura é preconizada pelo Ministério da Saúde (MS) como uma medida que visa diminuir o índice de mortalidade infantil na primeira infância, sendo primordial que essas consultas ocorram preferencialmente entre 0 e 18 meses de vida, pois possibilitam cuidados desde o nascimento, entre os quais se destacam: orientação para manter o aleitamento materno exclusivo, cuidados com o Recém-Nascido (RN), vínculo afetivo criança/ família, acompanhamento de medidas antropométricas, identificação de doenças prevalentes, avaliação do desenvolvimento neuropsicomotor, acompanhamento do crescimento para prevenir doenças evitáveis, orientações para alimentação saudável, além do acompanhamento do calendário vacinal ${ }^{1}$. As ações realizadas na atenção primária à saúde, voltadas para crianças são essenciais para as atividades de prevenção e de intervenção, por terem potencial para detectar precocemente possíveis alterações e diminuir os riscos de morbimortalidade ${ }^{2}$. Nessa perspectiva de vigilância à saúde da criança, cada contato entre esta e o serviço de saúde, independentemente do motivo, deve ser tratado como uma oportunidade para análise integrada e preditiva de sua saúde e para uma ação resolutiva, de promoção da saúde e com forte caráter educativo ${ }^{3}$. $\mathrm{O}$ enfermeiro é fundamental na realização da puericultura, pois esta envolve uma sequência de etapas que direcionam as ações de modo que haja um atendimento eficaz às necessidades da saúde da criança e aos anseios da família ${ }^{4}$. Objetivo: Relatar experiência vivenciada na elaboração do diagnóstico situacional da puericultura no município de Macapá, tendo como referência o Protocolo Municipal de Atendimento à Saúde da Criança. Método: Estudo descritivo, do tipo relato de experiência das vivências durante o estágio de Enfermeiros Residentes da Universidade Federal do Amapá (Unifap) na Coordenação Municipal de Saúde da Criança. Resultados: Constatou-se que todas as UBSs do município de Macapá oferecem, em suas rotinas de atendimento, a consulta de Puericultura. No entanto, observaram-se falhas no atendimento de livre demanda a esse público. Quanto à utilização 
do Protocolo de Atendimento à Saúde da Criança instituído pelo Programa de Atenção Integral à Saúde de Criança, observou-se que boa parte dos profissionais já o utilizam na rotina de atendimento. Entretanto, percebe-se que alguns profissionais sentem dificuldades para a adoção do protocolo nas UBSs, quais sejam: espaço físico inadequado, ineficiência de recursos materiais, sobrecarga de trabalho, bem como insuficiente capacitação técnica. A primeira consulta do recém-nascido é realizada pelo profissional enfermeiro. Entretanto, as consultas subsequentes não são intercaladas entre os profissionais enfermeiro e médico, contrariando as ações que preconizam a integralidade e a longitudinalidade da atenção à saúde da criança. A prática de alimentação dos registros relacionados ao preenchimento da caderneta, exame físico, avaliação do crescimento e desenvolvimento e orientações à genitora foi observada em maioria dos profissionais com propriedade de entendimento. Observou-se ainda que os profissionais demonstram fragilidade no processo de encaminhamento da criança ao atendimento nutricional e odontológico. Em alguns casos, o profissional parecia desconhecer o protocolo de consultas $e$ as demandas/situações/possível diagnóstico que implicavam a necessidade de atendimento destes profissionais. No contexto de práticas de educação em saúde, boa parte das unidades possuem grupos de roda de conversa que trabalham a temática de saúde da criança de forma regular, embora não seja específico. Considerações finais: A implementação do Protocolo de Atendimento à Saúde da Criança constitui-se como estratégia fundamental para sistematização da assistência e padronização do atendimento no contexto da puericultura, revelando a necessidade de reorganização do sistema de saúde. A adoção deste instrumento contribui para um atendimento mais abrangente, multidisciplinar, desfragmentado e potencialmente resolutivo. Um número significativo de profissionais atuantes na atenção primária à saúde parecera pouco capacitados e inseguros frente à atenção à saúde da criança. Esta fragilidade na capacitação profissional é fator relevante para o baixo nível de adesão dos usuários à puericultura, o que ressalta a relevância do investimento em qualificação profissional, favorecendo a efetiva inserção das atividades de atenção integral à saúde da criança. $\mathrm{O}$ comprometimento, a autonomia e a responsabilidade no acompanhamento do crescimento e desenvolvimento infantil pelo enfermeiro implicam diretamente a redução da morbimortalidade e a promoção da qualidade de vida dessas crianças. A consolidação de acompanhamento periódico e continuidade da puericultura visam ao fortalecimento do vínculo e estímulo à adesão dos familiares, que muitas vezes desconhecem a importância deste processo. Salienta-se também a necessidade do uso de tecnologias educativas, que promovam a superação dessas fragilidades e o apoio dos gestores de saúde, por meio da garantia de condições materiais e estruturais adequadas para o desenvolvimento das atividades e atendimento à demanda populacional. Implicações para a enfermagem: Reconhecendo o profissional enfermeiro como participante ativo no processo de acompanhamento da puericultura, entende-se como imperativas a implantação e a implementação de protocolos como instrumentos norteadores da prática profissional. Logo, busca-se, por meio deste diagnóstico situacional, promover a intensificação de estratégias que permitam a compreensão e a consolidação do protocolo de saúde da criança, de modo a estabelecer um atendimento integral, pautado na prevenção de doenças e na promoção, proteção e recuperação da saúde, contribuindo para a melhoria dos indicadores de saúde. 
Descritores: Saúde da Criança; Atenção Primária à Saúde; Enfermagem.

\section{Referências}

1. Brasil. Ministério da Saúde. Secretaria de Políticas de Saúde. Departamento de Atenção Básica. Saúde da criança: crescimento e desenvolvimento infantil - Brasília. Brasília; 2012.

2. Reichert APS, Almeida AB, Souza LC, Silva MEA, Collet N. Vigilância do crescimento infantil: conhecimento e práticas de enfermeiros da atenção primária à saúde. Rev Rene 2012; 13(1):114-126.

3. Ministério da Saúde (BR). Saúde da criança: acompanhamento do crescimento e desenvolvimento infantil. Brasília: Ministério da Saúde; 2002.

4. Assis WD, Collet N, Reichert APS, Sá LD. Processo de trabalho da enfermeira que atua em puericultura nas unidades de saúde da família. Rev Bras Enferm. v.64, n.1, p. 38-46, 2011.

5. Campos FCC, Faria HP, Santos MA. Planejamento e avaliação das ações em saúde. $2^{\underline{a}}$ ed. Belo Horizonte: Coopmed; 2010. 


\title{
COBERTURA VACINAL DE HPV NO ESTADO DO AMAPÁ
}

\author{
${ }^{1}$ Bruno Raphael da Silva Feitosa; ${ }^{2}$ Ana Cláudia Paiva Cardoso; ${ }^{3}$ Mariana Matias de \\ Sousa; ${ }^{4}$ Érika Tatiane de Almeida Fernandes Rodrigues; ${ }^{5}$ Rubens Alex de Oliveira \\ Menezes; ${ }^{6}$ Camila Rodrigues Barbosa Nemer.
}

\begin{abstract}
1 Acadêmico do Curso de Bacharelado em Enfermagem da Universidade Federal do Amapá Unifap, Macapá, Amapá, Brasil. E-mail: brunofeitosa7@gmail.com;

${ }^{2}$ Acadêmica do Curso de Bacharelado em Enfermagem da Unifap;

${ }^{3}$ Acadêmica do Curso de Bacharelado em Enfermagem da Unifap;

4 Enfermeira. Doutora em Ciências. Professora do Colegiado do Curso de Bacharelado em Enfermagem da Unifap;

${ }^{5}$ Enfermeiro. Doutor em Doenças Infecciosas e Parasitárias pela Universidade Federal do Pará UFPA. Professor do Colegiado do Curso de Bacharelado em Enfermagem da Unifap;

${ }^{6}$ Enfermeira. Mestre em Enfermagem. Doutoranda em Saúde Pública ENSP/FIOCRUZ. Professora do Colegiado do Curso de Bacharelado em Enfermagem da Unifap.
\end{abstract}

\section{RESUMO}

Introdução: O Papilomavírus Humano (sigla em inglês HPV) é um vírus que infecta pele ou mucosas (oral, genital ou anal), tanto de homens quanto de mulheres, provocando verrugas anogenitais (região genital e no ânus) e câncer, sendo considerada a infecção sexualmente transmissível (IST) com maior prevalência no mundo. De acordo com dados da Organização Mundial da Saúde (OMS), o câncer de colo de útero é o segundo mais comum em mulheres que vivem em países subdesenvolvidos, atrás apenas do câncer de mama. Esses dados contabilizam um número de 445 mil novos casos por ano nesses países, equivalente a $84 \%$ dos novos casos no mundo. Diante desse contexto epidemiológico, foram desenvolvidas três vacinas, a primeira com intuito profilático, chamada de quadrivalente Gardasil, produzida pela MERCK e liberada pelo US Food and Drug Administration (FDA) em 2006 e, no mesmo ano, pela Agência Nacional de Vigilância Sanitária (Anvisa) no Brasil, para distribuição privada. A segunda é a vacina bivalente Cervarix, produzida pela GSK. Com avanços de pesquisas e a obtenção de resultados mais eficazes, recentemente, no final de 2014 , foi desenvolvida a vacina nonavalente, ainda não disponível no Brasil. A primeira campanha anti-HPV no Brasil foi realizada entre 10 de março e 14 de abril de 2014, disponibilizando inicialmente a vacina do tipo quadrivalente para meninas entre 11 e 13 anos, tendo como meta a vacinação de 4,2 milhões de meninas, número correspondente a $80 \%$ do público-alvo. Contudo, os números registrados foram menores que o valor estipulado. ${ }^{1}$ Sem considerar os tumores de pele não melanoma, o câncer do colo do útero é o primeiro mais incidente na Região Norte (25,62/100 mil). ${ }^{2} \mathrm{O}$ câncer de colo de útero tem relação intrínseca com as desigualdades regionais, lugares menos desenvolvidos e com os menores níveis socioeconômicos. Este requer a reformulação de ações de controle como a organização e o desenvolvimento de serviços de saúde, mecanismos de formulação de políticas públicas e mobilização da sociedade. Visando perspectivas futuras, a incorporação da vacina contra HPV no Programa Nacional de Imunizações do Brasil poderá alterar a incidência e a mortalidade por esse tipo de câncer nos estados no Brasil, servindo de ferramenta ao controle desse tipo de câncer. ${ }^{3} \mathrm{O}$ Estado 
do Amapá é dividido em 16 municípios, e sua população, segundo o censo 2010, era de 669.526 habitantes. ${ }^{4}$ Objetivo: Analisar a cobertura vacinal de HPV no Estado do Amapá nos anos de 2014 a 2018. Método: Trata-se de um estudo descritivo, quantitativo, epidemiológico de base populacional, com unidade de análise o Estado do Amapá e em comparação com os demais estados da região Norte. Foram incluídos na pesquisa dados sobre cobertura vacinal (HPV-Q) de meninas de 9 a 14 anos e meninos de 9 a 15 anos residentes no Amapá e dados dos demais estados da região Norte e da cobertura vacinal do Brasil. Foram utilizadas as bases de dados da Estratégia de Vacinação contra HPV, no ano de 2014 a 2018, obtidos através do Sistema de Informação do Programa Nacional de Imunizações (SI-PNI) e da base de dados do Departamento de Informática do SUS (DATASUS). Dados da atualização realizada em fevereiro 2019. Os dados foram analisados através da estatística descritiva. Resultados: Na região Norte, durante o ano de 2014, foram aplicadas 519.961 doses da vacina HPV-Q em meninas; em 2015, foram administradas 483.919 doses em meninas; em 2016, administradas 246.002 doses em meninas; já em 2017, foram 329.801 doses em meninas, sendo este ano já disponibilizado para o sexo masculino com 293.282 doses; em 2018, foram aplicadas 229.082 doses da vacina para o sexo feminino e 232.595 doses para o sexo masculino. No Estado do Amapá, essa vacina representou para o sexo feminino em 2014 (5,37\%) 27.948 doses administradas, sendo em 2015 (5,18\%) 25.112 doses, 2016 (5,89\%) 14.491 doses, 2017 $(5,62 \%) 18.537$ doses para o sexo feminino e $(4,62 \%) 13.573$ doses para o masculino. Em 2018, foram administradas (4.70\%) 10.768 doses para o feminino e (4,18\%) 9.728 doses para o masculino. Ao comparar o Amapá com os demais estados da região Norte, a cobertura vacinal do estado em 2014, para meninas na faixa etária de 11 a 13 anos $1^{\underline{1}}$ dose, ocupou o segundo lugar ao ser avaliada (107,68\%), ficando atrás apenas do Tocantins. Para meninas na faixa etária de 11 a 14 anos $2^{\mathrm{a}}$ dose, ocupou o primeiro lugar ao ser avaliada $(70,19 \%)$. Em 2015, $1^{\underline{a}}$ e $2^{\mathrm{a}}$ doses para meninas ocuparam o quinto lugar, 50,88\% e $26,67 \%$ respectivamente. Em 2016, $1^{\text {a }}$ dose para meninas ocupou o quarto lugar $(16,69 \%)$, a $2^{\mathrm{a}}$ dose ocupou o primeiro lugar $(19,23 \%)$. Em $2017,1^{\mathrm{a}}$ dose para meninas ocupou o segundo lugar $(24,41 \%)$ e a $2^{\mathrm{a}}$ dose, o terceiro lugar $(17,48 \%)$, para meninos, a $1^{\text {a }}$ dose ocupou o quarto lugar $(21,90 \%)$ e a $2^{\mathrm{a}}$ dose, o terceiro lugar $(4,66)$. No ano de 2018 , $1^{\mathrm{a}}$ e $2^{\mathrm{a}}$ doses para meninas ocuparam o terceiro lugar, $14,02 \%$ e $11,27 \%$ respectivamente, para meninos a $1^{\underline{a}}$ dose ocupou o quarto lugar $(10,32 \%)$, a $2^{\underline{a}}$ dose ocupou o penúltimo lugar (7,97\%). Considerações finais: Aponta-se queda das doses aplicadas e cobertura vacinal do Estado do Amapá esteja da cobertura vacinal no Estado do Amapá. Vários são os motivos que podem influenciar nessa diminuição da cobertura vacinal ao longo dos anos: falhas na comunicação do governo; falhas na estratégia de vacinação nas escolas; existência de um público crítico e contrário à imunização; pais de adolescentes que alegaram que a vacina incentivaria a iniciação sexual precoce; medo de eventos adversos; conhecimento limitado sobre transmissão, desenvolvimento de doenças associadas ao HPV e formas de prevenção; questões culturais; movimento antivacina; questões de gênero no que se refere à sexualidade feminina, entre outros. Implicações para a enfermagem: O enfermeiro tem papel importante na mobilização dos pais e usuários, visando à sensibilização para aceitação da vacina contra HPV. Deve-se propor ações educativas de acordo com a capacidade dos diferentes estratos sociais para assimilarem tais informações, 
tendo em vista as desigualdades sociais no nosso país, especialmente no âmbito da educação.

Descritores: Papillomaviridae; Imunização; Enfermagem.

\section{Referências}

1. Zanini N, Prado B, Hendges R, dos-Santos C, Callegari F, Bernuci M. Motivos para recusa da vacina contra o Papilomavírus Humano entre adolescentes de 11 a 14 anos no município de Maringá-PR. Revista Brasileira de Medicina de Família e Comunidade [Internet]. 2017 Out 3; [Citado em 2019 Abr 15]; 12(39): 1-13. Disponível em: https://www.rbmfc.org.br/rbmfc/article/view/1253.

2. Ministério da Saúde (BR). Secretaria de Vigilância em Saúde. Departamento de Vigilância de Doenças Transmissíveis. Coordenação-Geral do Programa Nacional de Imunizações. Informe técnico da ampliação da oferta das vacinas papilomavírus humano 6,11, 16 e 18 (recombinante) - vacina HPV quadrivalente e meningocócica C (conjugada). Brasília: Ministério da Saúde, 39 p. 2018.

3. Barbosa IR, Souza DLB de, Bernal MM, Costa I do CC. Desigualdades regionais na mortalidade por câncer de colo de útero no Brasil: tendências e projeções até o ano 2030. Ciênc. saúde coletiva [Internet]. 2016 Jan [citado 2019 Abr 15]; 21(1): 253262. Disponível em: http://www.scielo.br/scielo.php?script=sci_arttext\&pid=S1413$81232016000100253 \& \operatorname{lng}=$ pt.

4. IBGE. Sinopse do Censo Demográfico 2010. Disponível em: https://censo2010.ibge.gov.br/sinopse/index.php?dados=P6\&uf=00. Acesso em $01 \mathrm{de}$ fevereiro de 2019. 


\title{
PERFIL DOS IDOSOS RESIDENTES EM UMA INSTITUIÇÃO DE LONGA PERMANÊNCIA DO ESTADO DO AMAPÁ
}

\author{
${ }^{1}$ Camila Cibele dos Santos Holanda; ${ }^{2}$ Janete Silva Ramos; ${ }^{3}$ Demilto Yamaguchi da
} Pureza.

${ }^{1}$ Enfermeira. Especialista em Urgência e Emergência e UTI. Mestranda do Programa de PósGraduação em Ciências da Saúde - Universidade Federal do Amapá - Unifap. camilacsholanda@hotmail.com;

${ }^{2}$ Fisioterapeuta. Mestre em Ciências da Saúde - Unifap, Professora do Colegiado de Fisioterapia da Faculdade Estácio de Macapá;

${ }^{3}$ Educador Físico. Doutor em Ciências, Professor do Colegiado do Programa de Pós-Graduação em Ciências da Saúde - Unifap.

\section{RESUMO}

Introdução: O envelhecimento demográfico é um fenômeno social que tem se acentuando nas últimas décadas ${ }^{1}$. Essas transformações na sociedade contribuíram para que os idosos ou os familiares destes recorressem cada vez mais aos cuidados das Instituições de Longa Permanência para Idosos (ILPI)2. Objetivos: Descrever o perfil dos idosos que residem em uma instituição de longa permanência do Estado do Amapá. Método: Trata-se de uma pesquisa descritiva, de caráter exploratório, realizada em uma ILPI da cidade do Estado do Amapá, onde foi analisado, por meio da aplicação de um questionário semiestruturado de dados sociodemográficos, o perfil clínico e epidemiológico dos residentes no período de novembro de 2017 a fevereiro de 2018. A avaliação foi feita no período de uma semana, com todos os idosos moradores do local, sendo que algumas informações foram respondidas pelos próprios participantes e outras pelos profissionais. Este estudo foi submetido ao Comitê de Ética e Pesquisa, sendo aprovado sob o Parecer no 1.303.750. Resultados: A ILPI em questão é localizada na cidade de Macapá, sendo a maior instituição de permanência destinada a idosos no estado. A instituição conta com uma equipe multiprofissional. $O$ ambiente é dividido em vários cômodos que são compartilhados por até cinco idosos. Além disso, possui espaço para atividades de lazer, refeitório e enfermaria para realizar atendimentos de baixa complexidade, bem como uma piscina, que, no momento da pesquisa, estava inativa, sala de estar e setores administrativos. $O$ abrigo contava ainda com dois automóveis para realizar as saídas necessárias. Durante o período de realização da pesquisa, a instituição contava com 62 idosos residentes. No que tange ao perfil sociodemográfico, constatou-se que $77 \%$ dos idosos eram do sexo masculino, isso pode ser atribuído a vários fatores, entre eles, o fato de a mulher possuir mais vínculos com a família, possuir mais autonomia e consequentemente mais bem estado de saúde. No que diz respeito à escolaridade, $54 \%$ dos idosos eram analfabetos, $15 \%$ estudaram até quatro anos, $23 \%$ até oito anos e apenas $8 \%$ mais de oito anos. Em relação à idade, $23 \%$ não souberam informar, $16 \%$ possuem entre 60 e 70 anos, $46 \%$ dos idosos possuíam entre 71 e 80 anos e $15 \%$ de 81 a 90 anos. Com o acelerado processo de envelhecimento dos últimos anos, é muito comum encontrar entre os idosos institucionalizados indivíduos com idade mais avançada e, por isso, é esperado que estes cada vez mais apresentem déficits de saúde. Quanto à etnia, 15\% dos idosos eram brancos, 69\% pardos, 16\% pretos, de 
acordo com a autodeclaração dos mesmos. No que se refere ao estado civil, $62 \%$ dos idosos se declararam solteiros, $15 \%$ casados, $8 \%$ viúvos e $15 \%$ separados. A presença de um (a) companheiro (a) na vida do (a) idoso (a) que está em uma ILPI é de extrema importância ${ }^{3}$. O idoso institucionalizado muitas vezes passa por um processo de abandono, inclusive da própria família. Acaba perdendo seu vínculo com a sociedade, tendo que se adaptar a uma nova vida, o que nem sempre Ihe agrada. Ter alguém para dividir seus medos, angústias e receios acaba sendo fundamental nesse momento. No que diz respeito ao tempo de institucionalização, $54 \%$ dos idosos estavam na instituição há mais de cinco anos, $31 \%$ estavam de três a quatro anos e $15 \%$, de um a dois anos. Como se pode observar, o tempo de institucionalização de todos os idosos asilados é grande, de acordo com a literatura ${ }^{3}$, o perfil do idoso institucionalizado é caracterizado pelo sedentarismo, pela falta de atividades sociais e de lazer, consequentemente pelo aumento de doenças. Isso tudo pode ser atribuído ao tempo de institucionalização desse idoso, uma vez que, quanto mais tempo ele fica ocioso, maior probabilidade de déficits tanto em seu estado cognitivo quanto em seu estado funcional. Quanto ao responsável pela institucionalização, $54 \%$ dos idosos foram internados por um familiar, 31\% optaram pela própria institucionalização e $15 \%$, por algum órgão de proteção. Entre os motivos que levam o idoso a ser institucionalizado, normalmente está a falta de condições da família de arcar com as necessidades do mesmo, tanto no aspecto do tempo para oferecer os devidos cuidados, quanto no financeiro para dar o suporte de que o idoso necessita, principalmente se este tiver algum problema crônico de saúde². É muito comum que, após a institucionalização, a família abandone o idoso na ILPI, deixando de fazer visitas até esquecê-lo por completo. Isso pode contribuir para que esse idoso perca referências importantes de sua vida, levando-o a outras complicações posteriores, como a depressão ou a desorientação no tempo e espaço. Considerações finais: A institucionalização de idosos conduz a um distanciamento da família às vezes resultando no abandono. No entanto, antes de apenas enumerar as críticas, deve-se analisar o contexto familiar em que o idoso estava inserido anteriormente. Em muitos casos, é melhor que ele viva sob as regras de uma instituição do que em casa com a família. Não se pode desconsiderar a importância das ILPIs para idosos, afinal elas se tornam um lar, um lugar de proteção e cuidado. No entanto, observa-se a necessidade de fiscalização desses locais para que sejam cumpridas as normas mínimas exigidas para o funcionamento adequado, além da presença de profissionais qualificados, que possam oferecer cuidados biopsicossociais aos idosos. Implicações para a enfermagem: $O$ idoso institucionalizado muitas vezes visualiza 0 profissional de enfermagem como sendo alguém de sua própria família, uma vez que a instituição é o seu lar. É importante que esse profissional esteja atento às necessidades do mesmo, buscando avaliar os impactos da institucionalização e, se possível, traçar estratégias para minimizálos. Ressalta-se, portanto, a importância de o profissional, por meio da pesquisa em saúde, buscar encontrar as problemáticas que envolvem a população, para que sejam traçadas estratégias de enfrentamento das mesmas, a fim de garantir uma assistência de qualidade pautada nos princípios do SUS.

Descritores: Saúde do Idoso; Saúde Coletiva; Institucionalização. 


\section{Referências}

1. Amaro MMG. A transformação da Identidade em idosos institucionalizados: um estudo de casos múltiplos. 2013. 123 f. Dissertação (Mestrado em Educação Social). Escola Superior de Educação de Bragança. Bragança. 2013.

2. Carvalho AR. Aprimoramento da Capacidade Funcional de idosos submetidos a uma intervenção por insostreting. Revista Brasileira de Fisioterapia, São Carlos, 12(04): 268273. 2013. Disponível em: < www.scielo.br/pdf/rbfis/v12n4/a04v12n4.pdf>. Acesso em: 13 abr. 2019.

3. Freitas MAV; Scheicher ME. Qualidade de vida de idosos institucionalizados. Revista Brasileira de Geriatria e Gerontologia. São Paulo, 13(03): 24-29, 2014. 


\section{ALGUNS PASSOS A MENOS PARA UM PRÉ-NATAL DE QUALIDADE EM MACAPÁ}

${ }^{1}$ Darci Francisco dos Santos Junior; ${ }^{2}$ Luana Jandira Weber Silva; ${ }^{3}$ Victor Hugo oliveira Brito; ${ }^{4}$ Bruna Cardoso Ranieri; ${ }^{5}$ Rosinete Almeida dos Santos; ${ }^{6}$ Rosana Oliveira do Nascimento

${ }^{1}$ Acadêmico do Curso de Bacharelado em Enfermagem; Universidade Federal do Amapá - Unifap. E-mail: darcijunior100799@gmail.com;

${ }^{2}$ Acadêmica do Curso de Bacharelado em Enfermagem; Unifap;

${ }^{3}$ Acadêmico do Curso de Bacharelado em Enfermagem; Unifap;

${ }^{4}$ Enfermeira - Unifap. Especializanda em Enfermagem Obstétrica - Fama;

${ }^{5}$ Acadêmico do Curso de Bacharelado em Enfermagem; Unifap;

${ }^{6}$ Enfermeira. Mestre em Saúde Coletiva pela Universidade de Fortaleza - Unifor; Unifap. Professora efetiva Colegiado do Curso de Bacharelado em Enfermagem.

\section{RESUMO}

Introdução: A gravidez para a mulher, de qualquer idade, representa grandes mudanças físicas, psicológicas, emocionais e sociais ${ }^{1,2}$. Dessa maneira, necessita de suporte familiar e profissional para que o desejo de vivenciar uma gestação de qualidade seja realizado. Diante disso, o Ministério da Saúde (MS), por meio do Caderno de Atenção Básica № 32 $(2012)^{3}$, preconiza dez recomendações para o atendimento de pré-natal de qualidade na atenção básica. Entre elas, a garantia de transporte público gratuito da gestante para o atendimento de pré-natal, quando necessário. Esse é um dos passos fundamentais para que a mulher grávida usufrua de um serviço integral, principalmente quando ela não possui condições de arcar com o custo de um transporte público como o ônibus. Essa realidade é condizente com a de clientes da Unidade Básica de Saúde (UBS) da Universidade Federal do Amapá (Unifap), já que uma grande parte das gestantes atendidas em sua área de captação apresenta renda familiar menor que um salário mínimo, dados evidenciados em um estudo ${ }^{4}$ realizado em 2017, que afirma que $32 \%$ das gestantes que realizaram o prénatal na unidade durante o período de outubro de 2016 a outubro de 2017 apresentavam renda familiar de até um salário mínimo. Ademais é possível inferir que essa situação não afeta somente o pré-natal, mas também outros programas como o planejamento familiar, pois a não utilização de métodos contraceptivos após a primeira gravidez ou em idade fértil da mulher, somada à ausência do contato usuário-serviço de saúde, impossibilita, até certo ponto, o usuário de utilizar a prevenção adequada. A falta de orientação sexual adequada, o não uso, uso inadequado e dificuldade de acesso aos métodos anticoncepcionais cooperam para a rejeição ou abandono dos métodos contraceptivos, o que gera uma gestação sem planejamento, dessa maneira, repetindo todo o ciclo. Objetivo: Descrever situações referentes às consultas de pré-natal sustentadas no princípio da equidade, baseadas nas necessidades de saúde da população e na estruturação da política de atenção básica no contexto amazônico, preconizadas pelo Ministério da Saúde, desenvolvidas durante o período de Estágio Supervisionado do Curso de Bacharelado em Enfermagem da Unifap, em uma UBS do município de Macapá. Método: Trata-se de um estudo descritivo, de caráter qualitativo, caracterizado como relato de experiência de acadêmicos de enfermagem da Unifap do Campus Marco Zero durante a prática de Estágio 
Supervisionado, em uma UBS localizada na referida universidade. Nessa disciplina, os estudantes passam a praticar competências do enfermeiro na atenção básica, como realização de teste rápido, vacinação, atividades administrativas e, entre outras, o foco do estudo: a consulta de pré-natal. $\mathrm{O}$ estudo traz as experiências desses acadêmicos durante a realização de consultas de pré-natal, com a percepção de dificuldades comuns apresentadas por gestantes no que se refere à realização e seguimento do pré-natal de maneira assídua. Resultados: Entre as atividades realizadas durante as consultas de enfermagem, em especial na de acompanhamento pré-natal, foi realizada a anamnese através da escuta qualificada, ferramenta que permite a investigação de diversos aspectos do indivíduo a fim de possibilitar o trabalho a partir de uma visão mais holística, compreendendo e adequando-se aos seus anseios, necessidades e realidade. À vista disso, no decorrer das consultas, foi constatado que um importante quantitativo de grávidas atendidas pela UBS-Unifap não possui condições de arcar com o valor das passagens de ônibus e não tem acesso ao transporte público gratuito durante o período gravídico, que facilitaria seu o acesso ao pré-natal. Essa situação ocorre, pois não há leis que isentem gestantes do pagamento do transporte até a UBS, apesar de isso ser preconizado pelo MS. Perante essa realidade, é possível inferir que as dificuldades de locomoção e acesso à unidade de saúde propiciam a redução da assiduidade nas consultas em período estimado ou a continuidade do pré-natal, comprometendo sua qualidade, o que oportuniza possíveis complicações à mulher, à gestação e ao feto. Entre elas, citam-se: as malformações congênitas evitáveis a partir de sequelas de doenças não identificadas e/ou tratadas precocemente, como rubéola, sífilis, toxoplasmose, malária, zika, entre outras; diagnóstico tardio de classificação de risco da gestação. Dessa maneira, a perda de consultas e a carência na disponibilidade de exames gratuitos implicam a não realização dos mesmos, o que se torna uma realidade, ainda que desagradável e prejudicial ao desenvolvimento dos demais passos para o pré-natal de qualidade, consequentemente, à gravidez e ao feto. Considerações finais: Destarte, é perceptível que o município de Macapá, no Estado do Amapá, não atende completamente as recomendações do Ministério da Saúde para a promoção de um pré-natal de qualidade e os princípios doutrinários do Sistema Único de Saúde (SUS), a equidade, ocasionando displicência na integralidade e consequentemente a transgressão na universalidade. À vista disso, nota-se a necessidade, não apenas de voltar os olhos de maneira minuciosa à realidade e às peculiaridades da população, mas, sobretudo, da criação de políticas públicas com o intuito de assegurar o direito dessas gestantes ao transporte público gratuito, a fim de garantir o cuidado equânime e o pré-natal de qualidade. Como possível sugestão de intervenção para a minimização dessa problemática, o enfermeiro, diante suas experiências da prática, pode realizar um projeto de iniciativa popular, juntamente com a equipe profissional e a população atendida, para que o que é preconizado se torne lei, dessa maneira, evitando complicações para a mãe, o feto e transformando-se no agente modificador de sua realidade e promotor da equidade. Implicações para enfermagem: $O$ enfermeiro necessita conhecer as necessidades do público utilizador do serviço de saúde, devido ao fato de ser um indivíduo promotor da saúde e um agente político na região em que atua. Portanto, para que ocorra modificação na realidade e uma melhor estruturação das políticas públicas, deve ficar atento às demandas e aos problemas ao seu redor. Dessa maneira, juntamente com a população atendida e os 
profissionais de saúde, precisa lutar por direitos e promover uma enfermagem mais engajada na busca da resolubilidade.

Descritores: Gestantes; Política Pública.

\section{Referências}

1. Santos CKB, Silva JC. Fatores que influenciam a gravidez na adolescência[internet]. Porto Velho: Centro Universitário São Lucas; 2018. [citado 2019 abr. 30]. Disponível em: http://repositorio.saolucas.edu.br:8080/xmlui/bitstream/handle/123456789/2923/Carolin e\%20Kaiane\%20Brasil\%20dos\%20Santos,\%20Janisson\%20Cardozo\%20da\%20Silva $\% 20-$

\%20Fatores\%20que\%20influenciam\%20a\%20gravidez\%20na\%20adolesc\%C3\%AAnci a.pdf? sequence $=1$.

2. Souza de Oliveira Hartur. Políticas públicas voltadas para gravidez na adolescência: revisão integrativa da literatura [internet]. Brasília: Universidade de Brasília, Faculdade de Ciências da Saúde - Departamento de Enfermagem. 2018. [citado 2019 abr. 30]. Disponível em: http://bdm.unb.br/bitstream/10483/21099/1/2017_HarturOliveiraDeSouza_tcc.pdf.

3. Brasil. Ministério da Saúde. Secretaria De Atenção à Saúde. Departamento de Atenção Básica. Atenção ao pré-natal de baixo risco. Cadernos de Atenção Básica, n. 32. Brasília; 2012.

4. Sales BLD, Ranieri BC, Lemos LL. Representações Sociais de Gestantes sobre HIV e Teste Rápido para HIV: Estrutura e Conteúdo[monografia]. Macapá: Universidade Federal do Amapá; 2017. 


\title{
EDUCAÇÃO POPULAR EM SAÚDE COMO PRÁTICA DA EQUIDADE EM UM GRUPO DE GESTANTES ADOLESCENTES
}

\author{
${ }^{1}$ Hiago Rafael Lima da Silva; ${ }^{2}$ Victor Hugo Oliveira Brito; ${ }^{3}$ Katiciane Rufino da Silva; \\ ${ }^{4}$ Francisca Evelen Suelen Silva de Aguiar; ${ }^{5}$ Nely Dayse Santos da Mata; ${ }^{6}$ Marlucilena \\ Pinheiro da Silva.
}

\begin{abstract}
${ }^{1}$ Acadêmico do Curso de Bacharelado em Enfermagem; Universidade Federal do Amapá - Unifap. E-mail: hiagorafaellima6@gmail.com;

${ }^{2}$ Acadêmico do Curso de Bacharelado em Enfermagem; Unifap;

${ }^{3}$ Enfermeira. Residente em Saúde Coletiva; Unifap;

${ }^{4}$ Enfermeira. Residente em Saúde Coletiva; Unifap;

${ }^{5}$ Enfermeira. Mestre em Desenvolvimento Regional, Unifap. Doutora em Ciências (Cuidado em Saúde). Professora efetiva Colegiado do Curso de Bacharelado em Enfermagem, Unifap;

${ }^{6}$ Enfermeira. Mestre em Saúde Coletiva, Unifor. Doutora em Educação, Universidade Federal de Uberlândia - UFU. Professora efetiva Colegiado do Curso de Bacharelado em Enfermagem, Unifap.
\end{abstract}

\section{RESUMO}

Introdução: A Política Nacional de Educação Popular em Saúde (PNEPS) veio ratificar os princípios do Sistema Único de Saúde (SUS) e a garantia do direito ao acesso à saúde através de políticas que auxiliem na qualidade de vida, além da redução de desigualdades sociais, sendo fundamentadas no processo democrático no âmbito da saúde. A PNEPS recomenda a utilização de práticas político-pedagógicas que advém das ações voltadas para a promoção, proteção e recuperação da saúde da população, empregando princípios, permitindo a troca dos saberes populares por meio da ancestralidade e cultura dos indivíduos ${ }^{1}$. O profissional da saúde, principalmente o enfermeiro, deve trabalhar com as diferenças da comunidade, identificando nos indivíduos, necessidades merecedoras de atenção, o que remete ao conceito de equidade, que diz respeito à redução das diferenças entre os indivíduos. Em vista disso, a equidade tem diversos significados e, durante muitos anos, no Brasil, essa palavra foi correlacionada à igualdade. Entretanto, deve-se atentar para ações cuidadosas de grande rigor deste, correlacionando-o com a justiça social durante a contemporaneidade ${ }^{2}$. A gravidez na adolescência, embora constantemente debatida como um fenômeno singular, associado principalmente às classes mais desvalidas e menos escolarizadas, exige a compreensão das mais variadas realidades, além das diferenças experimentadas pelas adolescentes. Isso exige do profissional conhecimento dos princípios do SUS vigentes no país, sendo, portanto, um desafio frequente para a formação do enfermeiro, bem como para o exercício da enfermagem pautado no enaltecimento da equidade em particular. Deve ser considerado que, na contemporaneidade, estudantes, profissionais e adolescentes grávidas, experimentam diferentes momentos de transição em suas vidas, mudanças que se fazem necessárias para a construção de conhecimento, sendo que, para estas adolescentes, este momento é intermediado pelas realidades sociais como as diferenças de classes. Assim as adolescentes estão mais propensas a cobranças da família e da sociedade, uma vez que, na maioria das vezes, uma gravidez considerada fora do momento ideal, afasta as adolescentes grávidas da escola, as quais se encarregam de papéis mais restritos ao 
cuidado no lar. Além disso, boa parte dessas adolescentes, mesmo após a fase da gravidez e assumido o papel de mãe, ainda permanecem com resquícios distintos de dependência de seus pais e família de origem ${ }^{3}$. Objetivo: Relatar a experiência vivenciada sobre as principais atividades de educação em saúde desenvolvidas em um grupo de extensão de apoio a gestantes adolescentes. Método: Estudo descritivo, de natureza qualitativa, caracterizado como relato de experiência acerca das atividades educativas elaboradas e otimizadas por acadêmicos de enfermagem juntamente com a equipe multidisciplinar do Grupo de Extensão de Apoio a Grávidas Adolescentes (GEAGA). As oficinas do GEAGA ocorrem quinzenalmente aos sábados. Entre as atividades desenvolvidas, é realizado o acolhimento das gestantes, com verificação de pressão arterial; peso e estatura; cálculo de idade gestacional, data provável do parto e índice de massa corpórea. Além disso, são feitas palestras de educação em saúde para promover a sensibilização das gestantes adolescentes participantes do grupo. As palestras abordam temas relacionados à saúde da mulher na gestação, modificações físicas e fisiológicas na gravidez, puerpério, aleitamento materno exclusivo e cuidados com o bebê. A escolha de temas é feita por meio da interação com as gestantes; a equipe do GEAGA promove conversas em grupo com as participantes atentando às suas falas, onde expressam suas curiosidades, anseios e perguntas relativas à gravidez. Os acadêmicos tomam nota dos assuntos e, com orientação das professoras coordenadoras do projeto, criam materiais didáticos para serem utilizados nas oficinas seguintes. Para que elas obtenham o entendimento dos assuntos tratados, além da comunicação dinâmica e produtiva, a educação em saúde é sempre realizada por meio do método estratégico de roda de conversa. A educação em saúde desempenhada pelo GEAGA tem como objetivo principal proporcionar o diálogo e troca de experiência entre a equipe e as participantes, objetivando compartilhar saberes e conhecimentos empíricos e científicos. Resultados: A partir das atividades desenvolvidas, deu-se a compreensão por parte das gestantes sobre o conhecimento técnico, e por meio da educação em saúde apresentada, as participantes assimilaram o empirismo e o conhecimento científico expostos nas apresentações. A cada oficina realizada, é importante que toda a equipe seja receptiva ao conhecimento empírico que as participantes trazem consigo a partir da sua vivência e de familiares mais próximos. Além disso, para que seja mantido o respeito e a proposta de um atendimento com equidade, a equipe do GEAGA procura estender o diálogo e os olhares particularizados e no coletivo, nas relações, no cuidado prestado a essas gestantes adolescentes e também nas ações educativas realizadas pelos acadêmicos, considerando tudo que pode ser observado durante esses eventos, de forma a contribuir com o crescimento do seu conhecimento. Considerações finais: Ao que diz respeito à Educação Popular em Saúde e ao princípio da Equidade, aqueles que trabalham diretamente com os usuários dos serviços de saúde, devem sempre desenvolver atividades aplicando em suas ações o empirismo que a população traz consigo das gerações de suas famílias. Tal conhecimento vem de experiências culturais passadas e deve ser aplicado e assimilado no contexto social em que cada indivíduo se insere. Implicações para a enfermagem: Partindo dos pressupostos da PNEPS, um dos principais instrumentos que o enfermeiro deve utilizar nas ações educativas de saúde é o princípio do diálogo. Este visa, de forma respeitosa, à intersubjetividade de cada indivíduo promovendo a junção de conhecimentos construídos a partir das singularidades e da cultura popular, colocando em prática a equidade nos serviços de saúde. 
Descritores: Gravidez na adolescência; Educação da População; Equidade em saúde.

\section{Referências}

1. Brasil. Ministério da Saúde. Portaria $n^{\circ} 2.761$, de 19 de novembro de 2013. Institui a Política Nacional de Educação Popular em Saúde no âmbito do Sistema Único de Saúde (PNEPS-SUS). Diário Oficial da União. 2013.

2. Rocha DG, Souza DH, Cavadinha E. Equidade nos cursos de graduação em Saúde: marco legal, desafios políticos e metodológicos. Interface (Botucatu) 2019; 12.

3. Vieira EM, Bousquat A, Barros CRS, Alves MCGP. Gravidez na adolescência e transição para a vida adulta em jovens usuárias do SUS. Rev Saúde Pública. 2017; 51(25). 


\title{
GESTANTES RIBEIRINHAS: DESAFIOS E BARREIRAS NO PRÉ-NATAL
}

\author{
${ }^{1}$ Ingrid Souza Reis Santos; ${ }^{2}$ Larissa Duarte Ferreira; ${ }^{3}$ Marlucilena Pinheiro da Silva; \\ ${ }^{4}$ Camila Rodrigues Barbosa Nemer.
}

\begin{abstract}
${ }^{1}$ Mestranda em Ciências Farmacêuticas; Universidade Federal do Amapá - Unifap; E-mail: reisingrid19@gmail.com;

${ }^{2}$ Mestranda em Ciências da Saúde; Unifap;

${ }^{3}$ Enfermeira. Doutora em Educação. Professora do Colegiado do Curso de Bacharelado em Enfermagem da Unifap;

${ }^{4}$ Enfermeira. Mestre em Enfermagem. Doutoranda em Saúde Pública pela Escola Nacional de Saúde Pública (ENSP)/ Fundação Oswaldo Cruz (Fiocruz). Professora do Colegiado do Curso de Bacharelado em Enfermagem da Unifap.
\end{abstract}

\section{RESUMO}

Introdução: A busca por equidade no sistema de saúde entre as regiões brasileiras ainda é um grande desafio para ampliação da proteção social no Brasil. ${ }^{1}$ Ao se levar em consideração as particularidades da região amazônica, as desigualdades sociais encontram-se em níveis preocupantes. Cerca de apenas 20\% da Amazônia possui cobertura de prestação de serviços se comparada às demais regiões do país ${ }^{2}$, sendo comum o deslocamento intrarregional para atendimento, principalmente de gestantes para realização do pré-natal/parto. No Brasil, $26,1 \%$ das gestantes iniciam de forma tardia o prénatal. Considerando que os municípios ribeirinhos são cercados por rios e igarapés e que o conhecimento da importância do pré-natal é precário, associado ao fato de a população ser economicamente desfavorecida, este índice pode ser mais alarmante, situação que dificulta o acesso ao serviço de saúde de forma adequada, podendo acarretar em mais riscos materno-fetais. O Estado do Amapá em 2017 obteve o último lugar, entre todos os estados brasileiros, em percentual de nascidos vivos cujas mães realizaram seis ou mais consultas de pré-natal, com um percentual de $39,9 \%$ de nascidos vivos ${ }^{3}$. Objetivo: Descrever a realidade das regiões ribeirinhas do Pará em relação aos serviços de saúde do Amapá e o impacto no atendimento pré-natal. Método: Trata-se de um estudo descritivo, transversal, quantitativo, com gestantes registradas em uma Unidade Básica de Saúde (UBS) do município de Macapá - Amapá, após 12 semanas de gestação, selecionadas por amostragem por conveniência. Os dados foram coletados por meio de um formulário adaptado com as variáveis socioeconômicas, dados gestacionais e aspectos institucionais e de acesso à UBS. A análise dos dados se deu com base na estatística descritiva e inferencial no programa STATA versão 13.0. As gestantes foram agrupadas em dois grupos considerando o Índice de Adequação da Utilização do Cuidado Pré-natal (Adequacy of Prenatal Care Utilization- APNCU). Neste estudo, foi trabalhada somente a adequação do início do cuidado do pré-natal, que considera que, quanto mais precoce, mais adequado o cuidado pré-natal. O índice APNCU estabelece a distribuição da gestação em quatro grupos: a adequação do início do cuidado pré-natal corresponde a: ótimo - quando a gestante iniciou o pré-natal no primeiro ou segundo mês; adequado - terceiro ou quarto mês; intermediário - quinto ou sexto mês; inadequado - sétimo mês ou mais tarde ou sem assistência pré-natal. Para fins de análise, as categorias ótimo e adequado foram 
consideradas como pré-natal adequado, enquanto as categorias intermediária e inadequada foram consideradas como pré-natal inadequado. Vale destacar a ausência de gestantes da categoria ótimo para serem agrupadas, tendo em vista que o critério para inclusão era ter iniciado o pré-natal acima de 12 semanas, ou seja, já haviam passado do primeiro e segundo mês. O estudo foi aprovado sob parecer no 2.759.060 CEP/Unifap. Resultados: Das gestantes entrevistadas, 22,95\% foram provenientes dos municípios de Afuá, Breves e Chaves. As gestantes residentes nas ilhas do Pará deslocam-se para municípios vizinhos para realizar essa assistência pela falta de serviço em seus municípios, principalmente para Macapá-AP pelo fato de ser mais próximo do que a capital de seu estado e por possuírem parentes naquela cidade. Das gestantes que moram em municípios em ilhas do Estado do Pará, 78,57\% tiveram início do pré-natal inadequado (a partir do quinto mês de gestação). Na análise multivariada para a variável município, foi tomada como referência a categoria "Ilhas do Pará" que gerou um Odds de 5.05, ( $p=0.044)$, o que leva a inferir que as mães que são residentes na região das Ilhas do Pará têm cerca de cinco vezes mais chances de fazer um pré-natal inadequado do que as mães que residem em Macapá. O SUS ainda enfrenta um grande desafio, o acesso da população aos serviços de saúde, principalmente nas regiões Norte e Nordeste. Entre esses desafios, estão as grandes distâncias entre a residência e os serviços de saúde, a precariedade dos serviços locais e a falta de capacitação dos profissionais de saúde ${ }^{4}$. Em relação às diferenciações entre capital e interior, as regiões Norte e Nordeste apresentam grandes diferenças sociais e espaciais com implicação extraordinária na situação de saúde, que se torna ainda mais grave, tendo em vista que, quando comparadas às regiões Sul/Sudeste/Centro-oeste, apresentam um "excesso de saúde ruim" segundo pesquisas nacionais, com grandes desigualdades internas que influenciam a saúde da população ${ }^{5}$. A necessidade de buscar outro estado para realização de um serviço básico de saúde demonstra a permanência de barreiras existentes nos serviços de saúde que agravam a situação de saúde brasileira com consequências alarmantes. Além disso, ao se levar em consideração que o principal meio de transporte para essas gestantes são as embarcações e que se faz necessário o custeio para o deslocamento e, principalmente, pela ausência de condições financeiras para obtenção de passagem, estas gestantes buscam o serviço apenas ao notarem alterações na gestação ou próximo ao parto. Considerações finais: A inexistência de unidades de saúde nos municípios adjacentes às capitais, como também de serviços básicos nesses locais, demonstra a precariedade da saúde e a deficiência no processo de regionalização. O impacto dessa conjuntura sob o pré-natal pode ser avaliado pelo momento em que a assistência pré-natal é iniciada, revelando o desconhecimento da importância dessa assistência e as condições nas quais as gestantes estão inseridas no contexto socioeconômico, o que explicita a ausência de equidade entre as regiões nos serviços de saúde. Implicações para a enfermagem: Lugares de difícil acesso interferem tanto na quantidade de profissionais nessas áreas quanto no deslocamento dessas gestantes para as capitais, assim se aponta a urgência de políticas públicas para garantir a equidade de atendimento às necessidades de saúde dessas regiões. Destarte, ressalta-se a importância de a enfermagem, pelo contato próximo às usuárias, realizar/manter a sensibilização das gestantes ribeirinhas para ingressarem precocemente no pré-natal, criar estratégias para captação precoce destas e reafirmar a criação do vínculo para não abandono dos serviços, principalmente de atenção primária para prevenção de complicações. 
Descritores: Equidade no acesso aos serviços de saúde; Cuidado pré-natal; Cuidado de enfermagem.

\section{Referências}

1. Viana ALA, Machado CV, Baptista TWF, Lima LD, Mendonça MHM, Heimann LS et al. Sistema de saúde universal e território: desafios de uma política regional para a Amazônia Legal. Cadernos de Saúde Pública [internet]. 2007 [cited 2019 Apr 29]; 23 (Sup 20): S117-S131. Available from: <https://www.scielosp.org/scielo.php?pid=S0102311X2007001400002\&script=sci_arttext\&tlng=en>.

2. Aguiar GFS. Nutrição e adaptação humana em áreas de pesca na Amazônia: sugestões para políticas em saúde. Boletim do Museu Paraense Emílio Goeldi Ciências Humanas [internet]. 2006 [cited 2019 Apr 29]; 1(2):129-138, 2006. Available from: <http://www.scielo.br/scielo.php?pid=S1981 $81222006000200010 \&$ script=sci_abstract\&tIng=pt>.

3. Avaliação do Desempenho do Sistema de Saúde [homepage na internet]. Percentual de nascidos vivos cujas mães fizeram mais de 6 consultas de pré-natal, segundo local de residência das mães no ano considerado [acesso em 20 abr 2019]. Available from: $<h t$ tps://www.proadess.icict.fiocruz.br/index.php?pag=fic_r\&cod=G08\&tab=1>.

4. Teixiera SVB, Rocha CR, Moraes DSD, Marques DM, Villar ASE. Educação em saúde: a influência do perfil sócio-econômico-cultural das gestantes. Revista de Enfermagem UFPE. [internet] 2010 [cited 2019 Apr 29]; 4(1):133-141. Available from: $<$ www.revista.ufpe.br/revistaenfermagem/index.php/revista/.../1179>.

5. Santos JAF. Classe Social, território e desigualdade de saúde no Brasil. Saúde e Sociedade [internet]. 2018 [cited 2019 Apr 29]; 27(2): 556-572. Available from: <https://www.scielosp.org/article/sausoc/2018.v27n2/556-572/pt/>. 


\title{
PROPOSTA DE ENSAIO CLÍNICO RANDOMIZADO PARA TRATAMENTO FOTOQUÍMICO DE DEISCÊNCIAS CIRÚRGICAS PÓS-CESARIANA
}

\author{
1 José Pedro Gomes Moura; ${ }^{2}$ Alana Patrícia Lima Ferreira; ${ }^{3}$ Larissa Duarte Ferreira; \\ ${ }^{4}$ Ítalo Soares Enéas; ${ }^{5}$ Lethicia Barreto Brandão; ${ }^{6}$ Ana Rita Pinheiro Barcessat.
}

\begin{abstract}
${ }^{1}$ Enfermeiro. Mestrando no Programa de Pós-Graduação em Ciências da Saúde. Universidade Federal do Amapá, Unifap;

${ }^{2}$ Cirurgiã-Dentista. Bolsista Capes. Mestranda no Programa de Pós-Graduação em Ciências da Saúde, Unifap. E-mail: aalanapatricia@gmail.com;

${ }^{3}$ Enfermeira. Bolsista Capes. Mestranda no Programa de Pós-Graduação em Ciências da Saúde; Unifap;

${ }^{4}$ Acadêmico do Curso de Bacharelado em Enfermagem; Unifap. Grupo de Pesquisa em Biofotônica e Neuromodulação;

${ }^{5}$ Enfermeira. Mestre em Ciências Farmacêuticas. Doutoranda do Programa de Pós-Graduação em Ciências Farmacêuticas; Unifap;

${ }^{6}$ Cirurgiã-Dentista. Doutora em Estomatologia Básica e Aplicada - Patologia Bucal; USP. Professora efetiva do Colegiado do Curso de Bacharelado em Enfermagem e Programa de Pós-Graduação em Ciências da Saúde; Unifap.
\end{abstract}

\section{RESUMO}

Introdução: $O$ ensaio clínico randomizado (ECR) é uma modalidade de estudo amplamente utilizada para a obtenção de evidências do cuidado à saúde. Apesar de algumas possíveis variações, baseia-se na comparação entre duas ou mais intervenções, as quais são controladas pelos pesquisadores e aplicadas de forma aleatória em um grupo de participantes. ${ }^{1}$ No contexto da classificação dos estudos científicos em saúde, pode-se dizer que os ECRs são, entre os estudos primários, os de maior relevância para a clínica². Objetivo: Avaliar a aplicabilidade na Terapia Fotodinâmica para utilização clínica no reparo cicatricial em deiscências cirúrgicas de cesarianas. Método: Ensaio Clínico Controlado Randomizado de abordagem quantitativa, exploratória, experimental, com base no Enunciado CONSORT 2010. ${ }^{3}$ Resultados: A pesquisa dar-se-á pela avaliação do efeito da TFD mediada por Azul de Metileno (AM) e Curcumina (CR) em deiscências cirúrgicas póscesárea, infectadas e não infectadas, atendidas em um hospital da cidade de Macapá-AP. Todas as pacientes selecionadas para participar do estudo serão informadas sobre a TFD, sua aplicabilidade, indicações e efeitos esperados, bem como lhes será apresentado o Termo de Consentimento Livre e Esclarecido para assinatura. O estudo foi aprovado pelo Comitê de Ética em Pesquisa da Universidade Federal do Amapá (Unifap), parecer no 3.749.477. A população será composta por pacientes que possuam deiscência cirúrgica total ou parcial, não eviscerada de cesariana e que estejam internadas para tratamento no Hospital da Mulher Mãe Luzia. A seleção das participantes dar-se-á por meio de anamnese e exame físico, e serão divididas em quatro grupos experimentais: 1) Grupo de Tratamento mediado pelo Azul de Metileno (GT-AM); 2) Grupo de Tratamento mediado pela curcumina (GT-CR); 3) Grupo controle Azul de Metileno (GC-AM) e 4) Grupo Controle Curcumina (GC$\mathrm{CR}$ ). Após a avaliação e a realização de desbridamento das feridas, proceder-se-á à realização da coleta de material para análise microbiológica do centro da lesão, de acordo com o protocolo estabelecido pelo Laboratório Central de Macapá, seguido da marcação 
da largura e profundidade da lesão utilizando régua milimetrada e registro fotográfico a uma distância média de $0,5 \mathrm{~m}$. Será feita a limpeza das lesões conforme protocolo, seguida de gotejamento do FS em quantidade e tempo necessário para cobrir toda a extensão da lesão. Para a troca do curativo, estabeleceu-se um período de 24 horas, sendo as intervenções realizadas nos grupos a cada 48 horas. Para a categorização dos dados, definiram-se quatro grupos, estando estes divididos em: 1) Grupo experimental (G1), no qual será realizada a Terapia Fotodinâmica mediada pelo Azul de Metileno a 0,5\% nas lesões com pré-irradiação de 3 minutos; 2) Grupo experimental (G2) - nele será realizado a Terapia Fotodinâmica mediada pela Curcumina (PDT - Pharma com [ ] 1,5g/L), seguida de irradiação pelo LED azul com parâmetros e tempo descritos no estudo; no Grupo Controle (G3), as pacientes terão o Azul de Metileno administrado em suas lesões de igual maneira como as pacientes alocadas no grupo de intervenção G1 e permanecerão com 0 mesmo tempo de pré-irradiação; no entanto, no momento da irradiação da luz, a fonte laser estará com a emissão desligada, estando ativado somente seu sinal sonoro; 4) Grupo Controle (G4) - as pacientes terão a Curcumina administrada em suas lesões da mesma forma que as pacientes alocadas no grupo de intervenção G2 e permanecerão com o mesmo tempo de pré-irradiação; no entanto, no momento da irradiação, a fonte LED estará com a emissão de luz desligada, estando ativado somente seu sinal sonoro. Ao final da irradiação (ou não) de luz, as feridas dos grupos receberão igual cobertura conforme protocolo de curativos descritos no estudo. As lesões serão avaliadas e mensuradas no primeiro e sétimo dia após o início do tratamento para verificar seu percentual de redução do volume das lesões, bem como presença ou não de sinais flogísticos. Para a análise microbiológica, será coletado amostra do centro das lesões no primeiro e sétimo dia após a realização das intervenções. Para a coleta, será necessário swab e tubo para transporte. Os dados do paciente, como região da coleta, momento da coleta, técnica utilizada, constarão no mapa de alocação. Após coleta, as amostras deverão ser encaminhadas ao Laboratório e os tubos contendo as amostras serão homogeneizados com $2 \mathrm{~mL}$ de solução salina em agitador tipo Vortex. Imediatamente após essa homogeneização, será realizada a diluição de $10^{-5}$ para que posteriormente sejam semeados $50 \mu \mathrm{L}$ das soluções em meio de ágar sangue. Todos esses procedimentos serão realizados sob fluxo laminar. Subsequentemente, as placas serão codificadas e incubadas a $37^{\circ} \mathrm{C} \mathrm{em}$ microaerofilia em estufa bacteriológica, por 24 horas, para ocorrer a contagem total de Unidades Formadoras de colônia (UFC). As colônias serão classificadas de acordo com sua morfologia e coloração de Gram para que assim possam ser selecionadas para sua identificação. $O$ estudo é quadruplo cego, garantindo não interferência nas intervenções das amostras para que se obtenham resultados fidedignos. Na análise estatística, será utilizado o teste de Shapiro-Wilk para verificar a normalidade da amostra, para os dados referentes ao volume das feridas e redução microbiana entre grupos. Uma vez estabelecida a normalidade ou não dos dados, serão aplicados os testes adequados para dados paramétricos ou não paramétricos. Considerações finais: Estudos afirmam que a PDT apresenta indícios positivos no processo de cicatrização e reparo tecidual, emergindo como uma ferramenta terapêutica viável de utilização em feridas. As perspectivas futuras apontam para estudos do efeito tecidual em relação à migração de células de defesa ou ativação de cascatas imunológicas como possíveis vantagens agregadas dessa modalidade terapêutica. Implicações para a enfermagem: Importante que o enfermeiro tome posse de ferramentas 
que o auxiliem na execução da implementação dos cuidados de enfermagem a pacientes com deiscências cirúrgicas. Micro-organismos patogênicos, em especial os de ambiente hospitalar, estão se tornando cada vez mais resistentes a diversos tipos de tratamentos. Nesse sentido, novas tecnologias para o cuidado devem acompanhar o trabalho dos profissionais de enfermagem para qualificação da assistência terapêutica dispensada.

Descritores: Fotoquimioterapia; Fotossensibilizador; Cicatrização.

\section{Referências}

1. Oliveira MAP, Velarde LGC, Sá RAM. Ensaios clínicos randomizados: Série Entendendo a Pesquisa Clínica 2. Feminina. 2015. 43 (1): 7-11.

2. Kenny SE, Shankar KR, Rintula R, Lamont GL, Lloyd DA. Evidence-based surgery: interventions in a regional paediatric surgical unit. Arch Dis Child. 2017. 12 (2): 50-3.

3. Martins J, Sousa LM, Oliveira AS. Recomendações do enunciado CONSORT para o relato de estudos clínicos controlados e randomizados. Medicina (Ribeirão Preto). 2009; 42(1): 9-21. 


\title{
PUERICULTURA E PUERPÉRIO NA REGIÃO AMAZÔNICA: ATENÇÃO À VULNERABILIDADE PROGRAMÁTICA DAS POPULAÇÕES RIBEIRINHAS
}

\author{
${ }^{1}$ Larissa Leite Pelaes; ${ }^{2}$ Camila Igreja Barroso; ${ }^{3}$ Felipe Batista e Silva; ${ }^{4}$ Mirely Gabriely da \\ Silva Medeiros; ${ }^{5}$ Silly Emanuela do Socorro das Mercês Marques; ${ }^{6}$ Nádia Cecília Barros \\ Tostes.
}

\begin{abstract}
${ }_{1}^{1}$ Acadêmica do Curso de Bacharelado em Enfermagem; Universidade Federal do Amapá - Unifap. E-mail: larissa.leite.pelaes@gmail.com;

${ }^{2}$ Acadêmica do Curso de Bacharelado em Enfermagem; Unifap;

${ }^{3}$ Acadêmico do Curso de Bacharelado em Enfermagem; Unifap;

${ }^{4}$ Acadêmica do Curso de Bacharelado em Enfermagem; Unifap;

${ }^{5}$ Acadêmica do Curso de Bacharelado em Enfermagem; Unifap;

${ }^{6}$ Enfermeira. Mestre em Ciências da Saúde; Unifap. Professora efetiva do Colegiado do Curso de Bacharelado em Enfermagem.
\end{abstract}

\section{RESUMO}

Introdução: Notoriamente, a puericultura e o puerpério precoce se constituem na principal medida preventiva e educativa do desenvolvimento infantil, capaz de prevenir e rastrear diversas doenças e promover técnicas que auxiliam no desenvolvimento psicofisiológico da amamentação e maternal ${ }^{1}$. Entretanto, esse serviço é, por vezes, inconcebível na realidade das mulheres de regiões ribeirinhas e rurais, que vivenciam o deslocamento no período gravídico-puerperal para receberem a assistência mais qualificada ${ }^{2}$. Nesse cenário, pode significar a ocupação de ambientes que dificultam o conforto e desenvolvimento dessa nova fase na vida da mulher, além de apresentar, após o parto, um contexto vulnerável para o retorno puerperal à assistência. Objetivo: Descrever as estratégias utilizadas na situação vivenciada diante das abordagens dos profissionais para com a mulher ribeirinha, visando à compreensão. Método: Nesse contexto, a experiência ocorreu durante o estágio supervisionado em saúde pública, realizado em uma Unidade Básica de Saúde (UBS), na cidade de Macapá. Os acadêmicos estavam organizados entre os serviços da unidade de saúde, realizando os procedimentos rotineiros da unidade e facilitando a comunicação e contato entre os setores. Excepcionalmente, na sala de vacina, onde são encontradas as mais diversas situações e relatos que representam a fragilidade da assistência, foi realizado um acolhimento a uma família que compareceu para realizar a vacinação da filha de 6 dias de vida, nascida por parto cesáreo. Diante da análise da situação, os profissionais comunicaram que a imunização não poderia ser realizada devido ao calendário de rotina da unidade e orientaram a família a retornar à UBS no dia seguinte, contudo, a puérpera informou a inviabilidade de fazê-lo, pois estaria retornando ao seu município. Durante esse diálogo com a equipe de profissionais e acadêmicos, ela informou que sentia dor ao amamentar, o que tomou atenção dos acadêmicos, intervindo no acolhimento, realizando uma anamnese aprofundada e assim identificaram os problemas de enfermagem para estabelecer uma linha de cuidados. Para motivar a criação de um vínculo com a puérpera, foi realizada breve educação em saúde relacionada à pega correta na amamentação. Com o estabelecimento da confiança entre usuária e profissional, foi então relatado um período de internação no hospital de referência à saúde da mulher e gestante para tratamento de 
sintomas que indicavam pré-eclâmpsia (informação confirmada pelos documentos de saúde apresentados), além de ter recebido receita médicas para o tratamento da complicação no pós-parto, porém, não possuía condições para comprá-los. Assim, o grupo realizou o atendimento mesmo sem o agendamento prévio. Considerando o histórico clínico e as limitações de abordagem e de tecnologias de assistência, a mulher foi encaminhada ao hospital para avaliação da situação clínica e vacinação da recém-nascida, assim como foi orientada para que a família permanecesse na cidade, visando ao bem-estar de sua saúde e da recém-nascida. Resultados: A situação apontou ausência do olhar holístico da enfermagem nos setores da unidade não voltados para a consulta, excepcionalmente na sala de vacina. Este, por ser um setor de alto fluxo de caráter preventivo, poderia ressignificar-se em uma porta de entrada para 0 atendimento de livre demanda das consultas de puerpério e puericultura, principalmente para o público materno-infantil similar ao encontrado neste relato. Desde o ocorrido, mudaram-se as observações realizadas pelo grupo de estágio, deixando de relacionar a desinformação dessas mulheres como problema principal para a realização da consulta pós-natal. Direcionando a problemática para a região na qual a UBS está inserida, localizada próxima à área portuária da cidade, verifica-se a existência de retratos sociais e culturais que revelam prioridades sociais divergentes das elencadas pelos profissionais de saúde, considerando as peculiaridades tradicionais do público de saúde, como, por exemplo: atividades voltadas para agricultura e/ou residências isoladas ou em áreas de várzea que impedem a substituição desses personagens ou seu distanciamento. Após essa mudança de reflexão, observou-se que a vulnerabilidade social, caracterizada pela condição social ou regional que dificultam o acesso à saúde, é menos significante do que a vulnerabilidade programática encontrada, que é definida pela forma como os serviços de saúde lida para reduzir contextos de vulnerabilidade de sua população ${ }^{3}$. Uma das responsabilidades comuns na atenção básica é garantir amplo escopo de ações e serviços ofertados de modo compatível com a necessidade da população ${ }^{4}$. É inegável na realidade da UBS o fluxo considerável de mulheres ribeirinhas que procuram os serviços com preocupações acerca do parto, porém há baixa procura pelos serviços de puerpério e puericultura, de modo que é preciso enfatizar a importância desse momento nos atendimentos não relacionados às consultas. Considerações finais: A vulnerabilidade das populações tradicionais, tal qual a das interioranas, reflete-se nos acessos aos serviços e informações de saúde. Enquanto a universalidade oferta o serviço a todos, o princípio da equidade faz traçar um caminho justo por meio da compreensão da multiplicidade de populações, deixando o Sistema Único de Saúde (SUS) singular na sua prática. Os profissionais de enfermagem são ensinados durante a graduação quanto à relevância dos princípios norteadores, porém, durante a prática, encontram barreiras para a efetividade principalmente da equidade, como foi percebido durante a prática. Essa barreira estabelecida na unidade mostra a dificuldade que os profissionais possuem em relação ao estado em que a mulher se encontra, não ocorrendo um acolhimento efetivo, deixando-a muitas vezes sem informações que são valiosas para que assim possa ocorrer um bom desfecho. Com a devida avaliação, podem-se prevenir possíveis complicações pós-parto para o binômio mãe-filho. Implicações para a enfermagem: A diretriz da longitudinalidade do cuidado se refere à relação entre os profissionais e os pacientes em suas unidades de saúde, com orientações para o indivíduo e não para a doença, propiciando o melhor reconhecimento dos problemas da população ${ }^{5}$. Assim, o grupo 
apresentou a proposta de um fluxograma de acolhimento de livre demanda para consultas de puerpério e puericultura para mulheres interioranas e ribeirinhas, com o objetivo de proporcionar o estabelecimento de vínculo durante a atualização vacinal da criança ou da mulher no período puerperal.

Descritores: Equidade no acesso aos serviços de saúde; Atenção primária à saúde; Vulnerabilidade em saúde.

\section{Referências}

1. Gauterio DP, Irala DA, Cezar-vaz MR. Puericultura em Enfermagem: perfil e principais problemas encontrados em crianças menores de um ano. Rev Bras Enferm. 2012; 65(3):508-13.

2. Souza NMP. Política de saúde da mulher no município de Melgaço/Marajó/PA: a perspectiva das mulheres atendidas na Unidade Básica de Saúde "RAIMUNDO DAS GRAÇAS" no rio Tajapuru. VIII Jornada Internacional de políticas públicas, Maranhão, ago 22-25, Cidade Universitária da Universidade Federal do Maranhão. Maranhão, 2017.

3. Oviedo RAM, Czeresnia D. O conceito de vulnerabilidade e seu caráter biossocial. Interface-Comunicação, Saúde e Educação. 2015; 19(53):237-49.

4. Brasil. PORTARIA № 2.436, de 21 de setembro de 2017. Política Nacional de Atenção Básica, estabelecendo a revisão de diretrizes para a organização da Atenção Básica, no âmbito do Sistema Único de Saúde (SUS). Diário Oficial da União, novembro 2017; Seção 1, p.68.

5. Starfield B; Ministério da saúde: UNESCO. Atenção Primária: equilíbrio entre necessidades de saúde, serviços e tecnologia. 1eed. Brasília: UNESCO; 2004. 


\title{
PROPOSTA DE INTERVENÇÃO PARA O ENFRENTAMENTO DA DOENÇA DIARREICA AGUDA: UM RELATO DE EXPERIÊNCIA
}

\author{
${ }^{1}$ Leidilene Pinheiro Pantoja Alves; ${ }^{2}$ Bruna Carvalho da Rocha; ${ }^{3}$ Maicon Serrão dos \\ Santos; ${ }^{4}$ Ingrid Clayse Damasceno Martins; ${ }^{5}$ Nely Dayse Santos da Mata; ${ }^{6}$ Luzilena de \\ Sousa Prudêncio.
}

\begin{abstract}
${ }^{1}$ Residente do Programa Multiprofissional em Saúde Coletiva, Universidade Federal do Amapá Unifap, Macapá/Amapá/Brasil. E-mail: leidilene.pinheiro@gmail.com;

${ }^{2}$ Residente do Programa Multiprofissional em Saúde Coletiva, Universidade Federal do Amapá Unifap, Macapá/Amapá/Brasil;

${ }^{3}$ Residente do Programa Multiprofissional em Saúde Coletiva, Universidade Federal do Amapá Unifap, Macapá/Amapá/Brasil;

4 Enfermeira Especialista em Vigilância em Saúde. Diretora do Departamento de Vigilância Epidemiológica da Secretaria Municipal de Saúde de Macapá/Amapá/Brasil;

${ }^{5}$ Doutora em Ciências, Universidade Federal do Amapá. Docente do Curso de Bacharelado em Enfermagem, Macapá/Amapá/Brasil;

${ }^{6}$ Enfermeira. Doutora em Saúde Coletiva; Universidade Federal do Amapá. Docente do Curso de Bacharelado em Enfermagem, Macapá/Amapá/Brasil.
\end{abstract}

\section{RESUMO}

Introdução: A Doença Diarreica Aguda (DDA) está inserida no grupo de doenças infecciosas gastrointestinais. Caracteriza-se como uma síndrome em que ocorrem no mínimo três episódios de diarreia aguda em 24 horas. A doença é causada por diferentes microrganismos infecciosos (bactérias e suas toxinas, vírus, parasitos, toxinas naturais). Objetivo: Relatar a experiência de enfermeiros residentes na elaboração de um plano de intervenção como estratégias de prevenção, monitoramento e controle da Doença Diarreica Aguda em um município da Amazônia. Método: Trata-se de um estudo descritivo, com abordagem qualitativa, do tipo relato de experiência, a partir da vivência na elaboração de um plano de intervenção como estratégia de prevenção, monitoramento e controle da DDA em um município da Amazônia. Este trabalho resultou de uma atividade desenvolvida por enfermeiros residentes em Saúde Coletiva no período de 10 de abril a 7 de maio de 2018, no Departamento de Vigilância Epidemiológica (DVE) da Secretaria Municipal de Saúde de Macapá (SEMSA), em parceria com técnicos deste setor. O processo de construção deste plano iniciou-se com a busca de referências bibliográficas para contextualizar a temática, bem como dados epidemiológicos sobre o agravo à saúde em estudo, consolidando o total de casos de DDA, estratificados por faixa etária, ocorridos no município de Macapá, no ano de 2017. Para a coleta e organização destes dados, utilizou-se o Programa de Planilha eletrônica Microsoft Excel 2013, por meio da estatística descritiva, com valores absolutos e de porcentagem Resultados: Foram registrados 12.381 casos de DDA no município de Macapá/AP, no ano de 2017. Esses casos foram estratificados por faixa etária da seguinte forma: menores de 1 ano apresentaram 1.467 casos (11,84\%); de 1 a 4 anos registraramse 3.314 (26,76\%); de 5 a 9 anos notificaram-se 1.506 casos (12,16\%); na faixa etária de 10 anos ou mais, foram registrados 6.081 casos $(49,11 \%)$ e apenas 13 casos $(0,10 \%)$ foram ignorados por falta de informações contundentes. Dessa forma, a alta incidência de DDA no município acometeu principalmente a faixa etária de 10 anos ou mais. Após o 
levantamento desses dados, elaborou-se o plano de intervenção, que foi estruturado a partir de três níveis de atuação, sendo que, em cada um destes, foram propostos: objetivos, competências e estratégias respectivas. O primeiro nível voltou-se para "Promoção e Prevenção da Saúde" e seus objetivos consistem em modificar hábitos/estilos de vida e reduzir a incidência de DDA em todas as faixas etárias. Esse nível de atuação compete à prefeitura por meio das ações do DVE, bem como dos profissionais da saúde (ESF, UBS, Nasf- Núcleo de apoio a saúde da família). Para a efetivação dos referidos objetivos, apresentaram-se as seguintes propostas: programa de tratamento de água e esgoto no domicílio; campanha educativa sobre alimentação saudável e medidas de higiene na preparação de alimentos; palestras na sala de espera; rodas de conversa entre grupos/escola, intensificação das atividades da Estratégia Saúde na Escola; incentivo ao aleitamento materno durante o pré-natal como medida preventiva da DDA e apoio do Nasf/nutricionista em programas desenvolvidos na UBS e comunidade. Quanto ao segundo nível de atuação, suas ações voltaram-se ao "monitoramento e avaliação", com os seguintes objetivos: identificar o número de casos da doença por meio da coleta, registro, análise e consolidação periódica dos dados; detectar mudanças no padrão epidemiológico da DDA; alimentar o Sistema Informatizado de Vigilância Epidemiológico das DDAs (SivepDDA); reduzir a incidência do agravo, através de medidas de vigilância; estabelecer áreas prioritárias de atuação e identificar/investigar a ocorrência de surtos. Cabe destacar que esse nível de atuação é de competência do DVE, cujas estratégias de implementação são: capacitação dos profissionais envolvidos através de treinamentos e supervisão; sensibilização dos profissionais quanto à importância do uso e preenchimento correto dos impressos referentes à DDA, bem como a notificação dos casos de surto; garantia do fortalecimento do fluxo de alimentação e retroalimentação entre unidades notificadoras e DVE; designação de profissionais responsáveis pelo desempenho de atividades referentes à alimentação do sistema e investigação de casos; relatórios de análise situacional bimestrais, demonstrando pontos fortes e fragilidades; instituição de metas para melhoria dos indicadores. No que se refere ao terceiro e último nível de atuação, estes se voltaram ao "controle" dessas ações, com os seguintes objetivos: melhorar a estrutura do serviço para o atendimento dos pacientes com diarreia, assim como aprimorar medidas de assistência a pacientes com casos confirmados de DDA. Esses níveis envolvem uma articulação intersetorial (Estado e município), bem como de gestores e profissionais da saúde. No âmbito das estratégias propostas para a efetivação deste nível, foram apresentadas: oferta de exames clínicos para diagnóstico oportuno da DDA; contratação de profissionais para consultas especializadas; capacitação de pessoal; implantação de protocolos e fluxos do manejo do paciente com diarreia e oferta de medicamentos antidiarreicos sob prescrição. Considerações finais: A construção desse Plano permitiu constatar inúmeros fatores que corroboram para a incidência e agravo da doença: baixa cobertura na rede de saneamento básico, falhas no fornecimento de água potável em adequadas condições, hábitos e estilos de vida inadequados e subnotificação de casos. Vale ressaltar que o Amapá, como um estado pertencente à Amazônia, possui como particularidade sociodemográfica a existência de áreas de ressaca, nas quais a DDA se configura como problema de saúde pública que atinge, principalmente, indivíduos domiciliados nesses ambientes, cabendo inferir que tal situação se apresenta como desafio para efetivação da equidade. Implicações para a enfermagem: A enfermagem como 
ciência da saúde possui um leque de competências entrelaçadas e interdependentes, isto é, gestão, assistência, educação, entre outros aspectos, apresentam-se como dispositivos essenciais para o aprimoramento dessa ciência e firmação de uma prática com equidade. O plano de intervenção é uma importante ferramenta metodológica que facilita a visualização de uma determinada situação-problema, permitindo traçar objetivos e estratégias que visam uma resolução coerente e concisa.

Descritores: Diarreia; Vigilância Epidemiológica; Enfermagem.

\section{Referências}

1. Brasil. Ministério da Saúde. Secretaria de Vigilância em Saúde. Departamento de Vigilância Epidemiológica. Portal Ministério da Saúde. Doenças Diarreicas Agudas. Brasília, 2019. Disponível em: <http://portalms.saude.gov.br/saude-de-a-z/doencasdiarreicas-agudas>. Acesso em 19 abr. 2019.

2. Brasil. Ministério da Saúde. Secretaria de Vigilância em Saúde. Doenças Diarreicas Agudas Departamento de Vigilância das Doenças Transmissíveis Coordenação Geral de Doenças Transmissíveis. Brasília, 2018. Disponível em: $<$ http://portalarquivos2.saude.gov.br/images/pdf/2018/maio/09/Apresenta----o-DDAAbril-2018.pdf>. Acesso em 19 abr. 2019. 


\title{
EQUIDADE DE ACESSO: VISITA DOMICILIAR ÀS FAMÍLIAS RESIDENTES EM ÁREA DE RESSACA
}

\author{
${ }^{1}$ Letícia Santos do Monte; ${ }^{2}$ Viviane de Souza bezerra; ${ }^{3}$ João Lucas Barbosa Magalhães; \\ ${ }^{4}$ Lucas dos Santos Nunes; ${ }^{5}$ Rafael Nascimento da Silva; ${ }^{6}$ Débora Prestes da Silva Melo. \\ ${ }^{1,5}$ Bolsistas do Programa Tutorial-PET/Enfermagem, Universidade Federal do Amapá - Unifap. E- \\ mail: leticiamonte15@gmail.com; \\ ${ }^{2}$ Bolsista do Programa de Educação pelo Trabalho para Saúde/Interprofissional; Unifap; \\ ${ }^{3,4}$ Acadêmicos do Curso de Bacharelado em Enfermagem; Unifap; \\ ${ }^{6}$ Enfermeira. Mestre em Ciências da Saúde; Unifap. Professora efetiva do Colegiado do Curso de \\ Bacharelado em Enfermagem.
}

\section{RESUMO}

Introdução: As condições de saúde de uma população estão fortemente associadas ao padrão de disparidades existentes na sociedade, enquanto as desigualdades sociais relacionadas ao acesso e à utilização de serviços são expressão direta das características do sistema de saúde. ${ }^{5} \mathrm{~A}$ visita domiciliar (VD) realizada pelos profissionais de saúde na Estratégia Saúde da Família favorece uma maior aproximação com a realidade vivenciada pelo indivíduo e pela população, caracterizada pelo desenvolvimento de ações de prevenção de doenças e promoção e reabilitação da saúde do indivíduo por meio de orientações quanto aos riscos que podem acontecer ${ }^{1}$. Frente às diversidades geográficas e diferenças socioeconômicas em todo o país, surge a necessidade de buscar experiências vivenciadas em localidades distantes do Serviço Básico de Saúde, com a finalidade de aperfeiçoamento dessas ações, a partir da reflexão a respeito das dificuldades e vantagens dessa modalidade de atenção, além de buscar soluções para problemas comuns entre os diversos serviços e, sobretudo, incentivar a troca de experiências entre gestores e trabalhadores que atuam na Atenção Domiciliar ${ }^{1}$. A visita domiciliar é um importante recurso para interagir, conhecer o ambiente, as dificuldades de locomoção, e, sobretudo, proporcionar educação em saúde de forma a viabilizar uma melhora na promoção e qualidade de vida do indivíduo. Ela precisa ser considerada como uma ferramenta importante e capaz de contribuir para as práticas de saúde, promovendo a qualidade de vida, com foco na prevenção de doenças e na promoção e reabilitação da saúde, assim contribuindo para a melhoria das condições de acesso à saúde da população ${ }^{2}$. O envolvimento do profissional no espaço domiciliar proporciona um olhar sobre as diferentes dimensões do cuidado familiar e possibilita uma atenção específica, com a captação da dimensão singular da família para que possa subsidiar e intervir em condutas voltadas às necessidades reais desta. Ressalta-se que o domicílio é um espaço de desenvolvimento das ações de promoção da saúde e prevenção das doenças ${ }^{3}$. Objetivo: Relatar experiências dos acadêmicos de enfermagem durante visitas domiciliares em uma área de ressaca em Macapá-AP, mostrando uma vivência diferenciada de todas as práticas, dando ênfase para as dificuldades de acesso desta população aos serviços de saúde, sobretudo às informações em saúde. Método: Trata-se de um estudo descritivo do tipo relato de experiência e tem como referencial a familiarização do aluno com a atenção básica durante aula prática da disciplina de Saúde do Adulto e do Idoso I, no $4^{\circ}$ semestre do Curso de 
Bacharelado em Enfermagem da Universidade Federal do Amapá, nas áreas abrangentes da Unidade Básica de Saúde do Perpétuo Socorro, em Macapá-AP. Durante as visitas, foram realizadas intervenções propedêuticas, como verificação de pressão arterial, orientações e asculto terapia. A carga horária das atividades práticas era de 60 horas semanais, e, nesse período, os acadêmicos eram estimulados a refletir sobre a prática do enfermeiro e buscavam aproveitar da melhor forma as oportunidades em campo prático. Foi oportunizada a realização de visitas domiciliares e ações de educação em saúde com os usuários deste serviço de saúde. As participações nas visitas foram durante os períodos entre o dia 08 a 13 de outubro de 2018. As aulas práticas foram acompanhadas e supervisionadas por uma docente da universidade, auxiliada por um agente comunitário de saúde - ACS. Resultados: Durante as visitas, foram percebidos os empecilhos que a comunidade assistida tinha para o acesso aos serviços de saúde, pelo fato de residirem em um espaço geográfico com difícil deslocamento em destino à unidade básica de saúde, levando em consideração as condições socioeconômicas e até mesmo certos impasses que impedem o acesso, como alguma deficiência física relacionada à idade ou com alguma necessidade de locomoção. Assim, percebeu-se que essa assistência está intimamente ligada ao modo de abordagem a essa população, pois o estabelecimento de vínculo com essa família faz toda diferença na adesão ao tratamento, na prevenção de doenças crônicas não transmissíveis (DCNTs) e outros agravos de saúde. Verificou-se a importância de os profissionais levarem informações básicas e adequadas sobre realização de alguns exames e de bons hábitos alimentares para essa localidade que é carente de atendimento, devido à precariedade de acesso. É possível compreender com maior intensidade a magnitude de uma assistência domiciliar, pois, apenas dessa maneira, pode-se vivenciar mais de perto a rotina familiar, as relações que estabelecem no ambiente doméstico, as condições de adoecimento daquela família, visando desenvolver habilidades e conhecimento científico para compreendê-la e acolhê-la, além de promover as ações em saúde e apoiar os membros da família. Durante a prática, foi possível garantir uma aproximação com o ambiente familiar, baseando-se na escuta qualificada, no acolhimento e na compressão de modo a entender que cada família possui uma história de vida, cultura, religião e com diferentes condições socioeconômicas. Considerações finais: Desse modo, o acolhimento de enfermagem desenvolvido durante a visita domiciliar contribuiu como objeto de investigação para o aprendizado teórico-prático e familiarização com a temática da disciplina em estudo. Essa oportunidade permitiu reconhecer e identificar as necessidades das famílias que foram acompanhadas, além de aprender e participar das estratégias de intervenção ajustadas à realidade para o desenvolvimento de ações em saúde. Implicações para a enfermagem: A realização de visitas domiciliares em áreas de ressaca é de fundamental importância no processo da trajetória acadêmica, pois é essencial um novo olhar frente às necessidades dessa população, uma experiência ímpar no que tange à dimensão social e relevante para o futuro profissional. As aulas práticas nesses ambientes possibilitaram perceber que as visitas domiciliares trazem pontos positivos por suceder trocas de informações dos familiares e prestar orientações e acolhimento a uma parcela da população que normalmente não teria acesso aos serviços de saúde, devido a sua condição peculiar, como os acamados ou pessoas com limitações físicas. Destarte, isso resulta em um cuidado mais humanizado, permitindo uma construção de vínculo na medida em que se estabelece uma relação de confiança. 
Descritores: Visita Domiciliar; Equidade no Acesso aos Serviços de Saúde; Cuidados de Enfermagem.

\section{Referências}

1. Souza IVB, Marques DKA, Guedes DRS, Silva KL. Proposta de protocolo para enfermeiros da estratégia da saúde da família para primeira visita domiciliar ao recémnascido. Rev Cuidado é Fundamental Online. 2018; 10(3): 197-192.

2. Martins GS, Pereira FC, Sousa, ICA. A visita domiciliar como instrumento para humanização: revisando a literatura. Rev Cultura e Científica do Unifacex. 2013; 11(1): 206-196.

3. Reis G, Silva S, Soares DJ. A visão do enfermeiro sobre a visita domiciliar no âmbito da Estratégia de Saúde da Família. Rev Científicas de América Latina y el Caribe, España y Portugal. 2018; 19-1.

4. Azevedo ACF, Okada KK, Lima GZ, Buriola AA. Visita domiciliar na atenção à saúde mental: relatando a experiência de um projeto de extensão universitária. Rev Uningá. 2017; 52(1): 43-40.

5. Corgozinho MM, Oliveira AAS. Equidade em saúde como marco ético da bioética. Saúde e Soc. 2016; 25 (2): 431-441. 


\section{SAÚDE SEXUAL E REPRODUTIVA DE MULHERES EM ÁREAS DE GARIMPAGEM}

${ }^{1}$ Lise Maria Carvalho Mendes; ${ }^{2}$ Rosemary Ferreira de Andrade.

${ }^{1}$ Enfermeira. mestranda em Ciências da Saúde, Universidade Federal do Amapá - Unifap. Professora efetiva Colegiado do Curso de Bacharelado em Enfermagem - Campus Binacional. Email: lisedemendes@gmail.com;

${ }^{2}$ Enfermeira. Doutora em Desenvolvimento do Trópico Úmido; Unifap. Professora efetiva Colegiado do Curso de Bacharelado em Enfermagem - Campus Marco Zero.

\section{RESUMO}

Introdução: A população garimpeira exerce uma alta mobilidade entre países e não é fácil ser acessada devido a questões logísticas, administrativas e de segurança. A dificuldade de acesso pelas equipes de saúde, somada à persistente migração pendular, impulsiona uma intensa e desordenada mobilidade populacional que favorece a rápida disseminação de doenças ${ }^{1}$. A intersecção das características inerentes à anatomia feminina, combinada às desigualdades de gênero, estigma, clandestinidade e isolamento geográfico, aumentam a vulnerabilidade de mulheres que exercem atividade ilegal em garimpos às Infecções Sexualmente Transmissíveis (ISTs)/Vírus da Imunodeficiência Humana (HIV) e as expõe a outras fragilidades no âmbito da saúde sexual e reprodutiva ${ }^{1,2}$. Objetivo: Identificar o perfil de história sexual e reprodutiva de mulheres brasileiras que exercem atividades laborais em áreas de garimpagem. Método: Estudo descritivo, com referencial metodológico da Teoria Transcultural ${ }^{4}$. Foi realizado em Ilha Bela, considerada um lugar de apoio logístico aos garimpeiros. Como critérios de inclusão adotou-se ser do sexo feminino e vivenciar a rotina de trabalho em garimpos clandestinos. Não participaram da pesquisa mulheres que estivessem sob efeito de álcool ou outras drogas. O recrutamento foi realizado mediante a técnica de snowball ${ }^{3}$. Foram encontradas 20 mulheres elegíveis. No entanto, uma entrevista foi descartada mediante ruídos ambientais provocados no áudio. Portanto, a população do estudo foi composta por 19 mulheres. A coleta ocorreu em abril de 2018 e o período da pesquisadora no campo foi de 15 dias. As entrevistas estruturadas foram realizadas com agendamento prévio, mediante o auxílio de uma moradora da ilha e ocorreu nos barrancos das colaboradoras para garantir privacidade. $O$ instrumento foi elaborado pelas pesquisadoras e testado com três mulheres para ajustes. As variáveis abordaram questões referentes ao histórico de saúde sexual e reprodutiva. Os dados foram apresentados mediante estatística descritiva, em que foi observada a frequência relativa. Utilizou-se como referencial analítico a Teoria Transcultural da Diversidade e da Universalidade do Cuidado, em que foram utilizados os conceitos de cultura, visão de mundo, contexto ambiental e cuidado cultural ${ }^{4}$. Este estudo respeitou as exigências nacionais e internacionais regulamentadoras de pesquisas envolvendo seres humanos, com CAAE de número 87073818.9.0000.0003. Resultados: Predominaram mulheres heterossexuais (94,8\%). A maioria das participantes relatou ter parceiro fixo nos últimos três meses $(75,9 \%)$. Todas as mulheres que se recordavam da idade que tinham por ocasião da coitarca informaram que tinham menos de 17 anos de idade (100\%). Mais da metade das mulheres tiveram a sua primeira experiência sexual com menos de 15 anos de idade (89,5\%). Duas (10,5\%) mulheres não recordaram a idade da coitarca. Uma $(5,2 \%)$ delas relatou que sua primeira 
relação sexual foi um estupro realizado pelo patrão, enquanto exercia a profissão de doméstica e babá, antes de migrar para o trabalho no garimpo. As participantes predominantemente não utilizaram preservativo $(94,8 \%)$ durante a coitarca. A maioria das mulheres informou utilizar preservativo masculino atualmente $(57,8 \%)$, mas que interrompem o uso com a estabilidade da relação $(68,5 \%)$. Uma colaboradora $(5,2 \%)$ relatou nunca ter usado nenhum tipo de preservativo. Nenhuma das mulheres referiu ter feito uso de preservativo feminino. Quanto à paridade, predominaram mulheres com filhos $(78,8 \%)$. Sobre a testagem rápida para IST, o número de mulheres que nunca realizaram nenhum tipo de teste rápido para IST foi elevado $(42,2 \%)$. Quase metade das participantes relatou ter vivenciado pelo menos um aborto espontâneo e/ou provocado (42,2\%). Destas, metade referenciou ter realizado o procedimento na Guiana Francesa. Entre os fatores associados ao abandono do preservativo entre garimpeiros, a literatura cita que os métodos de barreiras são onerosos em locais de mineração, chegando à quantia de 10 euros por preservativo ${ }^{(1)}$. Outro fator elencado para o abandono do preservativo em relações estáveis é a confiança no parceiro como fator predominante ${ }^{5}$. A confiança provoca um sentimento de segurança, que pode advir de um relacionamento estável. Este sentimento estabelecido em relação ao parceiro pode ser visto pelas mulheres como um cuidado cultural referente à prevenção às ISTs/HIV. Propor a utilização do preservativo em um relacionamento estável poderia gerar desconfiança de infidelidade entre o casal (30). A prática de sexo não seguro e/ou do comércio sexual, nas regiões caracterizadas por iniquidade social e por violências, expõe mulheres jovens, com pouca escolaridade, ou nenhuma, às ISTs/HIV ${ }^{1}$. A propósito da não realização de testagem rápida para IST/HIV, entre os fatores preditivos na região, verifica-se a falta de conhecimento dos locais que realizam a testagem, sentir-se em risco de contágio pelo HIV e ausência de avaliação do risco de contágio pelo HIV ${ }^{1}$. Observa-se ainda que garimpeiros podem ser menos informados sobre os benefícios da testagem e têm menos oportunidades de fazer o teste do que as populações urbanas ${ }^{1}$. Ressalta-se, diante da mobilidade da população em questão e das taxas baixas de uso contínuo do preservativo e de testagem para IST/HIV, a importância da concentração de esforços à disponibilização gratuita dos métodos contraceptivos de barreira, bem como para realização de testagem rápida a fim de facilitar o acesso ao diagnóstico. Considerações finais: A precocidade da coitarca, a interrupção do uso de preservativo, a não realização de testagem rápida para verificação de IST, abortamento, histórico de violência, exploração sexual e tráfico humano configuraram os principais contextos ambientais que necessitam ter seus cuidados reestruturados. Verifica-se que estratégias de promoção da saúde sexual nestas áreas devem englobar a complexidade das especificidades da rotina e congregar os contextos ambientais, sociais e culturais. Implicações para a enfermagem: $O$ isolamento geográfico e os fluxos migratórios desafiam os sistemas tradicionais de saúde e requerem estratégias inovadoras de assistência em saúde. Medidas de prevenção como o uso de preservativos e o diagnóstico precoce muitas vezes parecem não ser utilizadas e deveriam ser promovidas. Embora haja migração pendular, percorrendo várias áreas de mineração, os locais de descanso podem ser estratégicos à assistência de saúde. Destaca-se ainda que as consequências de epidemias silenciosas frente às características peculiares dessa população e sua relação com os agravos mencionados neste estudo podem repercutir para além dos locais de mineração clandestina. 
Descritores: Saúde sexual e reprodutiva; Saúde na fronteira; Mineração.

\section{Referências}

1. Douine M, Mosnier E, Le Hingrat Q, Charpentier C, Corlin F, Hureau L, et al. Illegal gold miners in French Guiana: a neglected population with poor health. BMC Public Health. 2017;18(1):23. doi:10.1186/s12889-017-4557-4.

2. Miranda AE, Merçon-de-Vargas PR, Corbett CEP, Corbett JF, Dietze R. Perspectives on sexual and reproductive health among women in an ancient mining area in Brazil. Rev Panam Salud Publica. 2009;25(2):157-61.

3. Sadler GR, Lee H-C, Lim RS-H, Fullerton J. Research article: recruitment of hard-toreach population subgroups via adaptations of the snowball sampling strategy: hard-toreach populations. Nurs Health Sci. 2010;12(3):369-374. doi: 10.1111/j.14422018.2010.00541.x.

4. Leininger M, Farland MR. Transcultural nursing: concepts, theories, research \& pratice. $3^{\underline{a}}$ ed. New York (USA): Mac Graw-Hill; 2002.

5. Nacher M, Vantilcke V, Parriault MC, Hanf M, Romeo M, Adriouch L, Carles M, Couppié P. What is driving the HIV epidemic in French Guiana? Int J STD AIDS. 2010. 21(5):359-61. doi: 10.1258/ijsa.2010.009570. 


\title{
A PRÁXIS FREIRIANA COMO FERRAMENTA À PROMOÇÃO DA SAÚDE MATERNO- INFANTIL
}

\author{
${ }^{1}$ Lise Maria Carvalho Mendes.
}

1 Enfermeira. Mestranda em Ciências da Saúde; UNIFAP. Professora efetiva Colegiado de Enfermagem - Binacional. E-mail: lisedemendes@gmail.com.

\section{RESUMO}

Introdução: $O$ método Círculo de Cultura ${ }^{1}$ é uma estratégia de educação baseada na liberdade, em que todos têm a palavra e partilham conhecimentos vivenciados em seu cotidiano e que possibilita a elaboração coletiva do conhecimento. Este estudo buscou utilizar a práxis freireana, com ênfase no círculo de cultura, para elaboração de atividades de educação em saúde às puérperas sobre os cuidados que promovam e previnam a saúde do recém-nascido. Objetivo: Relatar a operacionalização da utilização do círculo de cultura sobre cuidados ao recém-nascido. Método: Estudo descritivo, do tipo relato de experiência, realizado em um hospital na cidade de Oiapoque. Este hospital é uma instituição pública de média complexidade. Os participantes do estudo foram mulheres, maiores de 18 anos de idade, no período de puerpério imediato, que se encontravam no ambiente hospitalar. Foram excluídas puérperas que apresentaram problemas de saúde mental e/ou complicações obstétricas e neonatais durante 0 trabalho de parto e parto. Foram convidadas 29 puérperas, das quais 24 destas concordaram em participar do estudo. Entre os motivos de recusa evidenciou-se a presença de melancolia, angústia e impotência pela dificuldade para a iniciação do aleitamento materno e conciliação do sono com o papel de maternidade. A coleta de dados ocorreu em novembro de 2017, realizada pela pesquisadora principal, mediante de atividade de educação em saúde a partir do método círculo de cultura de Paulo Freire ${ }^{1}$, que propõe três fases dialéticas e interdisciplinares: investigação temática; codificação e descodificação; e desvelamento crítico. A atividade foi realizada no período matutino, após a visita de profissionais de saúde, com duração de 1 hora e 30 minutos. Este estudo respeitou as exigências nacionais e internacionais regulamentadoras de pesquisas envolvendo seres humanos, de acordo com a Resolução no 466/2012 por meio da assinatura do termo de consentimento livre e esclarecido. Esse estudo foi aprovado sob o parecer 2.155.712 do Comitê de Ética em Pesquisa da Universidade Federal do Amapá. Resultados: A atividade foi dividida em três momentos, conforme a teoria preconiza. Na etapa de investigação temática os facilitadores dispuseram as puérperas em uma roda de conversa e distribuíram, aleatoriamente, algumas imagens referentes aos cuidados com recém-nascido para motivar o diálogo entre elas, que principiaram a comentá-las. Todas as participantes se apresentaram e elencaram seus saberes sobre as situações demonstradas nas figuras. A partir de suas falas ocorreu a codificação e decodificação do conteúdo. Durante a roda de conversa as puérperas expuseram fatos do cotidiano, como a dificuldade do aleitamento materno exclusivo diante da rotina de trabalho e cuidados com o lar. A codificação e decodificação possibilitou a percepção de que as puérperas possuíam algum conhecimento prévio sobre o assunto, bem como a identificação da linguagem utilizada pelas mesmas, o que permitiu uma comunicação mais efetiva pelos facilitadores. Muitas dúvidas surgiram no decorrer da 
estratégia. As dúvidas referentes ao aleitamento materno estavam distribuídas principalmente quanto à oferta de água e chás para os recém-nascidos, principalmente em episódios de cólicas. Foram levantados alguns mitos e crenças acerca da amamentação, a exemplo de que o leite materno é fraco, que não mata a sede do recém-nascido ou que é insuficiente para atender às demandas de hidratação e nutricionais da criança. Esta insegurança quanto ao valor nutritivo do leite materno faz com que haja a introdução de alimentos artificiais antes do período recomendado, atitude esta que afeta diretamente 0 aleitamento exclusivo, podendo ter como principal consequência o desmame precoce ${ }^{2}$. Quanto aos cuidados com o sono do recém-nascido, observou-se dificuldades para transpor o cuidado adequado, uma vez que muitas puérperas relataram não ter lugar próprio e adequado para o sono do recém-nascido, os quais compartilhariam a cama com os pais ou dormiriam de rede. $\mathrm{Na}$ fase de desvelamento crítico foram repassadas evidências científicas quanto à morte súbita do lactente e dos métodos preventivos a este agravo, o qual é denominado por elas de "mal dos 7 dias". Sobre os cuidados de higiene e com o coto umbilical as dúvidas elencadas foram referentes às práticas culturais referentes à região, como a utilização de moedas e faixas compressivas sob o coto umbilical. Neste aspecto buscou-se demonstrar que tais práticas podem ser prejudiciais, expondo o recémnascido a infecções. Destacamos, que algumas práticas de sabedoria popular auxiliam a saúde, ou ainda, em nada prejudicam a saúde do recém-nascido. No entanto, existem àquelas que o colocam sob risco de contrair infecção localizada no coto umbilical, a exemplo do tétano neonatal, podendo levar a sepse ${ }^{3}$. As dúvidas que surgiram foram discutidas com os participantes conforme a realidade de cada uma, buscando identificar a disponibilidade para negociação de crenças prejudiciais e consolidação daquelas que trazem benefícios à saúde. Considerações finais: A partir das etapas da práxis freiriana, que consiste na utilização do círculo de cultura como ferramenta para a investigação, codificação e desvelamento crítico, foi possível observar as lacunas no conhecimento, os conhecimentos prévios, os valores culturais, as crenças das puérperas e sua disponibilidade para a mudança. Implicações para a enfermagem: $O$ círculo de cultura contribui para reflexão acerca da educação em saúde destinada à puérpera e ao recémnascido. Nos contextos de povos da floresta e população fronteiriça, esse modelo mostrouse eficaz, uma vez que possibilita o conhecimento às singularidades do cliente, bem como permite que o mesmo compartilhe os conhecimentos prévios com os demais participantes da roda de conversa, além de buscarem uma assistência ao recém-nascido de forma segura. Suscita-se a necessidade de programar, ampliar e qualificar métodos de educação em saúde às puérperas e recém-nascidos nesta região do país, que possui valores culturais singulares à localidade em que estão inseridos.

Descritores: Educação em saúde; Saúde na fronteira; Período Pós-Parto.

\section{Referências}

1. Heidemann ITSB, Sartori DI, Fernandes RPC, Costa CC, Costa MBFNA, Durand M. Reflexões sobre o itinerário de pesquisa de Paulo Freire: contribuições para a saúde. Texto contexto - enferm. [Internet]. 2017 [Acesso 2019 abr 29] 26(4). Doi: 10.1590/010407072017000680017. 
2. Tenório, MCS, Mello CS, Oliveira ACM. Fatores associados à ausência de aleitamento materno na alta hospitalar em uma maternidade pública de Maceió, Alagoas, Brasil. Ciência \& Saúde Coletiva [Internet]. 2018[Acesso 2019 abr 29];23(11):3547-3556. Doi: $10.1590 / 1413-812320182311.25542016$.

3. Miranda JOF, Santos DV, Camargo CL,Rosa DOS,Sobrinho CLN, Mussi FC. Evidence for umbilical stump care practices: integrative review. Rev enferm UFPE [Internet]. 2016[Acesso 2019 abr 29];10(2):821-9. Doi: 10.5205/reuol.6884-59404-2-SM1.1002 sup201617. 


\title{
BAIXA ADESÃO DO EXAME CITOPATOLÓGICO NAS COMUNIDADES RIBEIRINHAS: RELATO DE EXPERIÊNCIA
}

\author{
${ }^{1}$ Monique Melo Gomes; ${ }^{2}$ Claudiane dos Santos Saraiva; ${ }^{3}$ Joicileide Fonseca da Paixão; \\ ${ }^{4}$ Camila Cibele dos Santos Holanda.
}

\begin{abstract}
${ }^{1}$ Acadêmica do Curso de Enfermagem; FAMA. E-mail: monyquecf@gmail.com;
${ }^{2}$ Acadêmica do Curso de Enfermagem; FAMA;

${ }^{3}$ Acadêmica do Curso de Enfermagem; FAMA;

${ }^{4}$ Orientadora. Enfermeira. Especialista em Urgência e Emergência e UTI. Mestranda do Programa de Pós-Graduação em Ciências da Saúde - Universidade Federal do Amapá - Unifap. Professora do Colegiado de Enfermagem da Faculdade de Macapá (FAMA).
\end{abstract}

\section{RESUMO}

Introdução: O câncer de colo uterino apresenta altas taxas de prevalência e mortalidade, e a principal estratégia para seu rastreamento é o exame citopatológico ou Papanicolau. A adesão ao exame ainda está distante da cobertura preconizada. O exame consiste no esfregaço de células oriundas da ectocérvice e da endocérvice, extraídas por raspagem do colo do útero². Objetivo: Relatar a experiência sobre a percepção da adesão de mulheres ao exame citopatológico (Papanicolau) e citar os principais motivos observados para a falta de adesão à realização dele. Método: Trata-se de um relato de experiência de caráter observacional, que ocorreu através da prática de uma ação social que proporcionou um momento de educação em saúde na comunidade do Igarapé do Amazonas, localizada em área rural do munícipio de Macapá, na qual foi observada a rotina de uma unidade de saúde e de mulheres moradoras da referida comunidade ribeirinha. Optou-se por uma revisão narrativa, em que os autores analisaram e interpretaram a literatura publicada e fizeram uma análise crítica e pessoal. Foram utilizados estudos publicados nos últimos cinco anos através de pesquisa na base de dados Scientific Electronic Library Online (SciELO), Literatura Latino-americana e do Caribe em Ciências da Saúde (LILACS) e livros do Ministério da Saúde. Resultados: A manutenção das altas taxas de mortalidade por câncer do colo uterino levou o Ministério da Saúde a elaborar estratégias de enfrentamento para a problemática. Contudo, apesar dos avanços de todo o Sistema Único de Saúde (SUS), continuar a reduzir a mortalidade por câncer do colo do útero no Brasil ainda é um desafio a ser vencido ${ }^{5}$. Pesquisas evidenciam que, mesmo com a facilidade de acesso ao exame que é disponibilizado nas unidades básicas de saúde pelo Ministério da Saúde por meio do SUS, a cobertura ainda não é satisfatória, existem barreiras que comprometem a busca das mulheres para realizar ${ }^{3}$. Através da observação, foi possível perceber que as diferenças socioeconômicas ainda são consideradas obstáculos para que todas as pessoas tenham acesso a serviços de saúde, visto que muitas mulheres ribeirinhas, para chegar à UBS, precisavam de embarcações, pois o único meio de acesso era por via fluvial. O baixo nível socioeconômico das mulheres também contribuía para tal situação, pois à medida que diminui o nível socioeconômico, aumenta significativamente a prevalência de mulheres sem cobertura pelo exame Papanicolau². Observou-se também que, apesar dos avanços na saúde, meios de comunicação que possibilitam a fácil transferência de informações, ainda existem mulheres que desconhecem o exame, não sabem sua finalidade e importância. $\mathrm{A}$ 
literatura é pródiga em sinalizar que a desinformação, o conhecimento errôneo ou insuficiente constitui barreiras para a não realização do exame ${ }^{2}$. Observou-se que o sentimento de vergonha apresentava grande impacto se o exame tiver que ser realizado por um profissional do sexo masculino. Muitas o realizam somente na condição de grávidas, quando o exame é solicitado no pré-natal. A exposição do corpo no momento do procedimento faz com que existam resistências que são geralmente manifestadas através de vergonha e constrangimento, ademais as relações de gênero historicamente construídas na sociedade definem as práticas referentes ao corpo e à sexualidade, de maneira que a exposição da genitália feminina e a manipulação da mesma pelo profissional de saúde podem gerar vergonha e constrangimento às mulheres, que consideram essa ação moralmente incorreta, o que as leva, muitas vezes, a não realizarem o exame, principalmente quando o profissional é do sexo masculino ${ }^{2}$. Embora o exame represente $o$ instrumento mais adequado, prático e de baixo custo para o rastreamento do câncer de colo de útero, devido à forte influência na redução da morbimortalidade por este tipo de câncer, a adesão ao exame ainda está distante da cobertura preconizada pelo Ministério da Saúde, que é de $80 \%$ a $85 \%{ }^{2}$. Considerações finais: O presente estudo buscou compreender a complexidade do fenômeno que envolve a não realização do exame Papanicolau das mulheres em uma comunidade ribeirinha. Conhecimento insuficiente acerca do exame e da sua finalidade, sentimentos como vergonha e constrangimentos constituem barreiras à realização do mesmo, contribuindo para as mulheres se tornarem mais vulneráveis e dificultando o estabelecimento de ações eficazes no âmbito da prevenção. É importante discutir sobre o tema, por ser considerado um método preventivo que contribui diretamente para detecção e o tratamento precoce do câncer do colo do útero e, consequentemente, para elevado percentual de cura, assim, o papel da atenção primária é de desenvolver ações para prevenção por meio de ações de educação em saúde e detecção precoce do câncer e de suas lesões precursoras por meio de seu rastreamento. Implicações para a enfermagem: Em decorrência da baixa adesão ao exame, a enfermagem deve criar estratégias para incentivar essas mulheres a realizarem o exame. Entre as estratégias para aumentar a cobertura de realização do exame nessa população, citam-se: divulgar por meio de visitas domiciliares de agentes comunitários de saúde a importância do exame a fim de convencer as mulheres a realizá-lo periodicamente; devemse fazer palestras, entregar panfletos, orientando-as para a realização do exame, além disso, seria interessante o desenvolvimento de ações sociais para que as mulheres que não possuem acesso à UBS possam realizar o exame. Notou-se também que é necessário que os enfermeiros fiquem atentos às necessidades da educação em saúde da comunidade, pois, por meio do diálogo e informações necessárias à paciente, pode-se evitar constrangimento, medo e o nervosismo que as mulheres enfrentam antes de fazer 0 exame. É importante que o enfermeiro adquira uma postura técnica e ética no sentido de preservar a integridade da paciente. Desse modo, o profissional ganha confiança da paciente e a mesma fica mais segura quanto ao procedimento a ser realizado ${ }^{3}$.

Descritores: Exame citopatológico; Saúde da Mulher; Atenção Primária à Saúde. 


\section{Referências}

1. Brasil. Ministério da Saúde. Portaria no. 2.436 de 21 de setembro de 2017. Brasília: Diário Oficial [da] República Federativa do Brasil. 2017. [acesso em 27 abr. 2019] Disponívelem:<http://bvsms.saude.gov.br/bvs/saudelegis/gm/2017/prt2436_22_09_20 17.html>.

2. Aguiar RP, Soares DA. Barreiras à realização do exame Papanicolau: perspectivas de usuárias e profissionais da Estratégia de Saúde da Família, Physis Revista de Saúde Coletiva, [internet]. 2015 [acesso em 20 abr. 2019]; 25 [2]: 359-379. Disponível em:< www.scielo.br/pdf/physis/v25n2/0103-7331-physis-25-02-00359.pdf.

3. Dantas PVJ, Leite KNS, César ESR, Silva SCR, Souza TA, Nascimento BB. Conhecimento das mulheres e fatores da não adesão acerca do exame Papanicolau, Rev enferm UFPE on line, [internet]. 2018 [acesso em 20 abr 2019]; 12(3):68491.Disponívelem:https://periodicos.ufpe.br/revistas/revistaenfermagem/article /download/22582/28066.

4. Suarez AET. Exame citopatológico na unidade Básica de saúde Jardim Alborada, Belo Horizonte: Plano de intervenção para aumentar a adesão sua realização. Belo Horizonte. Tese [Especialização em Estratégia Saúde da Família] - Universidade Federal de Minais Gerais; 2015.

5. Brasil. Ministério da Saúde. Diretrizes brasileiras para o rastreamento do câncer do colo do útero / Instituto Nacional de Câncer Jose Alencar Gomes da Silva. Coordenação de Prevenção e Vigilância. Divisão de Detecção Precoce e Apoio a Organização de Rede. [livro online] Brasília: MS, 2016. [acesso em 27 set. 2019]. Disponível em: www.citologiaclinica.org.br/.../diretrizes-para-o-rastreamento-do-cancer. 


\section{RELATO DE EXPERIÊNCIA SOBRE O $1^{\circ}$ SIMPÓSIO INTERDISCIPLINAR DA SAÚDE - "ABRAÇANDO A DIVERSIDADE"}

${ }^{1}$ Rodolfo Napoleão Nogueira; ${ }^{2}$ Ingrid Maira Brito Gibson; ${ }^{3}$ Marina Nolli Bittencourt.

1 Acadêmico do Curso de Medicina da Universidade Federal do Amapá -Unifap. E-mail: rodolfo.napoleao1994@gmail.com;

${ }^{2}$ Acadêmica do Curso de Bacharelado em Enfermagem da Universidade Federal do Amapá Unifap;

${ }^{3}$ Professora Doutora do Curso de Bacharelado em Enfermagem da Universidade Federal do Amapá -Unifap.

\section{RESUMO}

Introdução: A saúde da população LGBT começou a ser discutida quando o Ministério da Saúde e movimentos sociais, convergiram forças para implementar estratégias contra a epidemia do (a) HIV/Aids'. Porém hoje essa população ainda vive em condição de vulnerabilidade. Uma pesquisa chamada "Transexualidades e Saúde Pública no Brasil", realizada pelo Núcleo de Direitos Humanos e Cidadania LGBT (NUH-UFMG) e pelo Departamento de Antropologia e Arqueologia (DAA-UFMG) revela que $85 \%$ dessa população evitam os serviços de saúde, mesmo quando precisam². A descrição da experiência do $1^{\circ}$ Simpósio Interdisciplinar da Saúde fomenta a discussão acerca da formação dos profissionais da saúde para que realizem seus cuidados, prevenção de doenças e promoção da saúde com compreensão acerca da realidade do atendimento e assistência a comunidade LGBT. Objetivo: Relatar a experiência de acadêmicos da área da saúde sobre a idealização e realização do 1ํㅗำósio de Saúde da Universidade Federal do Amapá (UNIFAP), com o tema "Abraçando a diversidade". Método: Trata-se do relato de experiência acerca do $1^{\circ}$ Simpósio Interdisciplinar da Saúde (SIS) na UNIFAP. O evento começou a ser planejado em outubro de 2017 por alunos dos Cursos de Enfermagem, Medicina, Farmácia e uma docente do Curso de Enfermagem. Surgiu da necessidade de se proporcionar diálogo entre a comunidade acadêmica, comunidade LGBT, profissionais da saúde e sociedade civil, ofertando um espaço para esclarecimentos acerca de temáticas de interesses comuns, desenvolvendo um evento que levasse reflexão ao público e fomentasse a discussão sobre um sistema de saúde de qualidade, justo e equânime, como previsto na Constituição Federal de 1988. O processo contou com reuniões mensais em grupo, objetivando discutir a organização do evento, analisar 0 desempenho das ações e traçar planos para captação de recursos. Com o intuito de ampliar e aproveitar os espaços do campus Marco Zero, homenageamdo um símbolo do movimento Trans do Amapá, foi idealizado a construção de um espaço de vivência sustentável denominado Praça Lara Fabyan. Para tanto, as atividades se iniciaram no dia 14 e março com a convocação dos monitores que atuaram juntamente com a equipe do SIS e finalizaram com a entrega da praça no dia 19 de maio. Os materiais reciclados para a construção foram arrecadados em uma campanha, e doados por colaboradores, sendo também reaproveitado restos de construção espalhados por lixões a céu aberto no campus Marco Zero. Resultados: O evento principal ocorreu nos dias 13 e 14 de abril de 2018, das 14 às 18 horas, com certificação de 10 horas, no auditório de enfermagem no campus 
Marco Zero. As inscrições se deram por meio da entrega de $2 \mathrm{~kg}$ de alimentos não perecíveis, que foram coletados e doados para famílias carentes moradoras das proximidades da Unifap. No dia 13, o tema das mesas-redondas foi "Gênero e sexualidade na assistência à saúde", contou com a participação de uma professora do Curso de Bacharelado em Enfermagem/Unifap, que apresentou o tema "Adolescentes LGBT e as relações familiares"; um professor do Jornalismo/Unifap, que discursou sobre o tema "Corpo, gênero e desejos"; uma componente da Associação de Lésbicas e Bissexuais do Amapá, falando sobre "A política LGBT no estado", e uma enfermeira do Consultório na Rua, falando de sua "Experiência com transexuais moradoras de rua de Macapá"; a segunda mesa-redonda foi sobre "Ética" e contou com um representante do Conselho Federal de Enfermagem que abordou a "ética no cuidado em saúde da população LGBT". No dia 14 de abril, a terceira mesa teve a temática "Farmacoterapias" e contou com professores do Curso de Farmácia/Unifap e de um endocrinologista do estado do Amapá que trabalha com terapia hormonal; a quarta mesa trouxe o tema "Transexualidade em foco", contou com a participação de uma psicóloga, relatando sua experiência de prevenção de HIV/Aids com travestis em pontos de prostituição de Macapá, e uma ativista LGBT que contou sua experiência de vida. Também ocorreram apresentações de 14 trabalhos científicos com o intuito de ampliar o espaço para participação de acadêmicos e técnicos da área da saúde da Unifap. O ciclo de minicursos ocorreu nos dias 10 e 17 de março de 2018, das 8 às 12 horas, com certificação de 10 horas para cada minicurso ofertado, com inscrições no valor de 15 a 30 reais. Foram ofertados ao todo seis minicursos: Interpretação de eletrocardiograma; Aplicação de injetáveis; Compostagem; Qualidade na atenção a pessoas com ISTs; Técnicas básicas de Massoterapia e APH. A Praça Lara Fabyan foi construída e possibilitou um novo ambiente de inclusão social na Universidade, enaltecendo um símbolo do movimento LGBT, a ativista Lara Fabyan. Os palestrantes foram reconhecidos por proporcionarem debates aprofundados em vários eixos temáticos, além disso, o espaço para apresentação dos trabalhos científicos foi elogiado. Ao que tange à Praça Lara Fabyan, ocorreram problemas relacionados à captação de recursos e de mão de obra qualificada para execução do projeto. Considerações finais: $O 1^{\circ}$ SIS contribuiu para o cenário social e acadêmico, estimulando debates a partir das atividades programadas, capacitando os acadêmicos por meio dos minicursos ofertados. O evento também viabilizou a distribuição dos alimentos arrecadados. O evento foi uma experiência de humanização no atendimento e das políticas públicas voltadas para a população LGBT. A temática "Abraçando a Diversidade" combateu o preconceito e ampliou o conhecimento sobre o contexto demarcado pela violência institucional, além de haver apontado mudanças que visam à redução das desigualdades relacionadas à exclusão no processo de saúdedoença dessa população. Quanto aos organizadores observou-se que durante o planejamento e execução o trabalho interdisciplinar e multiprofissional, com acadêmicos de diferentes eixos da área da saúde, proporcionou uma vivência diferente do modelo biomédico tradicional. Implicações para a enfermagem: O SIS foi planejado e executado e forma interdisciplinar e multiprofissional, desenvolvendo habilidades como: cooperação, comunicação horizontal, liderança e gerência. Portanto, contribuindo para a área da enfermagem com a construção de saberes alinhados com o pensamento interdisciplinar. Somado a isso, ocorreram qualificações dos acadêmicos para o atendimento humanizado, inclusivo e equânime, conforme preconiza o Ministério da Saúde. 
Descritores: Saúde; Pessoas LGBT; Fóruns de discussão.

\section{Referências}

1. Brasil. Ministério da Saúde. Secretaria de Gestão Estratégica e Participativa. Departamento de Apoio à Gestão Participativa. Política Nacional de Saúde Integral de Lésbicas, Gays, Bissexuais, Travestis e Transexuais; 1를 edição 2013; 5-31.

2. Núcleo de Direitos Humanos e Cidadania LGBT (NUH-UFMG). Departamento de Antropologia e Arqueologia (DAA-UFMG); Projeto transexualidades e saúde pública no Brasil: entre a invisibilidade e a demanda por políticas públicas para homens trans, 2015; 3-108. 


\title{
ORGANIZAÇÃO DO PROCESSO DE TRABALHO DA ESF: ATENDIMENTO À DEMANDA ESPONTÂNEA - UBS NOVO HORIZONTE
}

\author{
${ }^{1}$ Rosa Maria Guimarães Brito; ${ }^{2}$ Kellem Raquel Brandão Torres.
}

\begin{abstract}
${ }^{1}$ Enfermeira. Mestranda em Ciências da Saúde; Unifap. E-mail: rosagbrito@hotmail.com;
2 Enfermeira. Mestre em Saúde Pública; Escola Nacional de Saúde Pública (Ensp)/Fundação Oswaldo Cruz (Fiocruz). Professora de formação e acompanhamento pedagógico de tutores e orientadores Ensp/Fiocruz de Enfermagem.
\end{abstract}

\section{RESUMO}

Introdução: A Atenção Primária à Saúde (APS) representa o primeiro nível de contato dos indivíduos, da família e da comunidade com o sistema nacional de saúde e se caracteriza por um conjunto de ações, no âmbito individual e coletivo, que abrange a promoção e a proteção da saúde, a prevenção de agravos, o diagnóstico, o tratamento, a reabilitação, a redução de danos e a manutenção da saúde, com o objetivo de desenvolver uma atenção integral que impacte positivamente a qualidade de vida das coletividades ${ }^{1}$. Nesse panorama, a ESF busca converter o modelo tradicional da APS, representando o contato prioritário por meio do qual o sujeito deve ser inserido na rede de atenção à Saúde ${ }^{1}$, e, quando funcionando adequadamente, é capaz de resolver a maioria dos problemas de saúde no seu território de abrangência, prevenindo doenças, evitando internações desnecessárias e melhorando a qualidade de vida da população. Dessa maneira, o cuidado à demanda espontânea na APS deve ser baseado no acolhimento e na escuta qualificada à população, assegurando atendimento humanizado, com resolubilidade dos serviços e promoção da saúde ${ }^{2}$, por meio de ações que traduzam a valorização da dignidade do profissional e do usuário. Objetivo: Organizar o processo de trabalho das equipes da Saúde da Família em uma Unidade Básica de Saúde (UBS) em Macapá-AP, voltado ao atendimento da demanda espontânea. Método: Pesquisa aplicada materializada em um Projeto de Intervenção que se baseia nos pressupostos da pesquisa-ação. Com revisão bibliográfica, para fundamentação do tema, compreendendo artigos científicos na base eletrônica de dados da Biblioteca Virtual em Saúde (BVS), indexados na Scientific Electronic Library (SCIELO) e Literatura Latino-Americana e do Caribe em Ciências da Saúde (LILACS) e Base de Dados em Enfermagem (BDENF), com critério temático e cronológico, visando ao alcance dos objetivos propostos, bem como ao enfrentamento do problema citado. O percurso metodológico eleito foi estruturado em uma matriz de ação. Foram realizadas reuniões com a gerência municipal da ESF de Macapá-AP e as equipes de Saúde da Família (eSF) vinculadas à UBS. Resultados: Todas as eSFs da UBS foram orientadas quanto ao projeto, por meio de reunião realizada para apresentação do mesmo; a fim de conhecer e avaliar o perfil e o volume da demanda para a definição de melhores formas de organização, identificação das principais queixas relacionadas pela clientela no acolhimento; garantindo a realização da triagem de pacientes de demanda espontânea por classificação de risco, com organização do processo de trabalho das equipes, baixando 0 tempo de espera do usuário e a organização da agenda; equipes de SF orientadas para distinção de risco e grau de sofrimento, permitindo a organização da fila de espera e garantindo o atendimento imediato do usuário com grau de risco elevado; sensibilização 
dos profissionais quanto a um atendimento mais humanizado e de qualidade, diminuindo a ocorrência de reclamações por parte da comunidade; ampliação do vínculo entre o agente comunitário de saúde (ACS) e a comunidade da sua área de abrangência; preparo técnico dos profissionais para atuar na recepção da UBS; monitoramento das equipes de ESF e UBS quanto ao atendimento à demanda espontânea, por meio de visitas técnicas. Considerações finais: $O$ atendimento à demanda espontânea requer uma atenção criteriosa aos usuários, pois muitos destes já não são contemplados com 0 acompanhamento de uma eSF por residirem fora de área de cobertura, portanto precisam ser acolhidos, tendo como objetivo central a escuta qualificada e ações que os levem a suprir suas necessidades, respeitando o princípio da equidade. É imprescindível considerar que a cobertura populacional das equipes no bairro Novo Horizonte é bastante baixa, referenciando somente quatro equipes para acompanhamento de um total de 14.370 pessoas, o que significa um percentual de apenas $59 \%$ de cobertura populacional, considerando que cada equipe possui seu território de abrangência delimitado com uma média de 3 mil a 4 mil pessoas e o bairro possui cerca de 24.360 habitantes de acordo com o Instituto Brasileiro de Geografia e Estatística (IBGE) ${ }^{3}$, ou seja, permitindo que o equivalente a $41 \%$ da população fique sem cobertura, provocando uma demanda espontânea expressiva. Assim, para aperfeiçoar a assistência, com priorização da promoção da saúde e prevenção de doenças, é imperativa a ampliação do número de eSFs neste bairro, majorando a garantia de penetração na APS de maneira organizada e avalizada, além da estrutura física da unidade que também deve estar preparada para acolher o usuário, proporcionando ambiência/conforto, acesso adequado e filas de espera ordenadas e breves. Quando o acolhimento é bem implantado, com todas as ações e levantamentos propostos, e se integra como parte da prática diária dos profissionais de saúde, é possível assegurar a organização do fluxo, acarretando diminuição do número de pessoas sem orientações que circulam em busca de direcionamento na unidade, aumentando o impacto das ações e consequentemente a satisfação da clientela e o sentimento de bem-estar da comunidade adscrita. Ressalta-se que a produção de conhecimentos científicos e técnicos em saúde deve corroborar as necessidades sociais, culturais, políticas e econômicas da região em que se encontram estes serviços. Assim, a pesquisa em saúde é uma ferramenta com a finalidade de auxiliar o processo de análise do setor, compreendendo a tomada de decisões e o planejamento em saúde, concebendo melhoria nas ações de promoção, proteção, recuperação e reabilitação da saúde e diminuição das desigualdades sociais. Implicações para a enfermagem: A organização inadequada das diversas interfaces que envolvem uma UBS contribui para um ambiente desfavorável tanto para os usuários quanto para os profissionais, contribuindo assim para maior estresse e comprometimento da qualidade do serviço ofertado ${ }^{4}$. Dessa forma, é imprescindível a organização da demanda espontânea na APS, proporcionando um atendimento humanizado e resolutivo, em que as necessidades/aflições apresentadas pelos usuários possam ser acolhidas, escutadas, problematizadas e reconhecidas como legítimas, resultando em maior satisfação dos usuários e dos profissionais envolvidos no atendimento, diminuindo as queixas, reclamações, retornos repetidos e a sensação de frustração dos profissionais 5 .

Descritores: Estratégia Saúde da Família; Demanda espontânea; Acolhimento. 


\section{Referências}

1. Ministério da Saúde (BR). Portaria no. 2.436, de 21 de setembro de 2017. Aprova a Política Nacional de Atenção Básica, estabelecendo a revisão de diretrizes para a organização da Atenção Básica, no âmbito do Sistema Único de Saúde (SUS). Diário Oficial [da] República Federativa do Brasil; 2017.

2. Ministério da Saúde (BR). Secretaria de Atenção à Saúde. Atenção à demanda espontânea na APS. Brasília: Ministério da Saúde; 2010.

3. Instituto Brasileiro de Geografia e Estatística (BR). Bairros de Macapá e suas Criações, (IBGE, 2010). [Acesso em 2017 jun 20]. Disponível em: https://pt.wikipedia.org/wiki/Novo_Horizonte_(Macap\%C3\%A1).

4. Biazini H, Carvalho L, Miranda MM, Rezende AC, Santos C. Diagnóstico Situacional da Unidade Básica de Saúde Barreiro de Cima. Belo Horizonte: Ed.UFMG, 2010. [Acesso em 2017 jun 28].

Disponível em: https://www.ufmg.br/portalprosaudebh/images/pdf/BC_diagnostico.pdf.

5. Ministério da Saúde (BR). Secretaria de Atenção à Saúde. Departamento de Atenção Básica. Acolhimento à demanda espontânea. Brasília: Ministério da Saúde; 2013. 


\title{
PAPEL DA ENFERMAGEM NO CONTEXTO AMAZÔNICO: VALORIZANDO A DIVERSIDADE CULTURAL ATRELADA AO CONHECIMENTO CIENTÍFICO
}

\author{
${ }^{1}$ Rosinete Almeida dos Santos; ${ }^{2}$ Darci Francisco dos Santos Junior; ${ }^{3}$ Victor Hugo Oliveira \\ Brito; ${ }^{4}$ Nádia Cecília Barros Tostes. \\ ${ }^{1}$ Acadêmica do Curso de Enfermagem da Unifap; E-mail: nete.tony11@gmail.com; \\ ${ }^{2}$ Acadêmico do Curso de Enfermagem da Unifap; \\ ${ }^{3}$ Acadêmico do Curso de Enfermagem da Unifap; \\ ${ }^{4}$ Enfermeira. Mestre em Ciências da Saúde pela UNIFAP. Docente do Colegiado do Curso de \\ Enfermagem da Unifap.
}

\section{RESUMO}

Introdução: A Região Amazônica é composta por uma diversidade cultural que surpreende qualquer pessoa. Essa diversidade tem sua origem pautada nos ocorridos históricos em que povos distintos se miscigenaram ao longo dos anos. Tendo em vista isso, toda essa pluralidade trás consigo a necessidade de um cuidado transcultural, de maneira que haja um ajuste entre as crenças, os valores culturais, porém, nao deixando de lado o conhecimento baseado na ciência, pelo contrário, unindo os conhecimentos popular e científico. A valorização do suporte empírico, que o cidadão amazônico carrega, faz com que ele se aproxime mais da equipe multiprofissional, e o torna o protagonista de todo 0 processo do "cuidar" que a rede pública venha a lhe ofertar. Objetivo: Proporcionar a prática reflexiva, acerca da formação acadêmica do profissional enfermeiro, como dispositivo para o desenvolvimento de competências para a promoção da saúde da comunidade amazônica; e mostrar como a realidade da população amazônica, ao procurar atendimento em saúde pelo SUS, é dotada de toda uma singularidade que perpassa todo um contexto cultural. Método: Trata-se de relato de experiência do estágio supervisionado em enfermagem na saúde pública, praticado em uma Unidade Básica de Saúde do município de Macapá. Durante esse estágio pode-se trabalhar o foco da atenção primária em atendimento à saúde, que é a prevenção. Logo, a prática da educação em saúde estava presente diariamente na rotina do grupo de acadêmicos. O momento em que eram trabalhadas as palestras, para início de atendimento de pré natal, podia-se observar a relevância desse ato para a melhoria e garantia da saúde da grávida, bem como de seu companheiro. As rodas de conversas eram o momento em que as mulheres grávidas se sentiam à vontade para falar de temas como a amamentação cruzada ou a prática de "puxar barriga", muito conhecida e praticada na região amazônica e que pode acarretar em danos irreverssíveis. Foi nesse contexto que pudemos perceber o quão importante se fazia nossas orientações para que essas mulheres pudessem levar uma gravidez sem riscos. A linguagem utilizada era bem singular e acessível, pois vinham usuárias de algumas ilhas do Pará, próximas ao município de Macapá, bem como, mulheres que residem na capital Macapá. Os companheiros ou acompanhantes dessas pacientes eram convidados a participarem das rodas de conversas, a fim de que eles fossem inseridos nesse processo de educação. A percepção de que essa população carrega consigo uma gama de conhecimentos empíricos e uma educação pautada na oralidade e na reprodução de atitudes, dos mais velhos, é mais que notória. São pessoas que possuem suas crenças e 
suas culturas bem afloradas e que a maneira com que vamos lidar com isso faz total difença na adesão do acompanhamento que podemos proporcionar. Resultados: Há diversidades e singularidades que transcorrem pelo cenário amazônico. Mas em uma coisa devemos concordar, quando a linguagem do profissional se torna acessível e confiável ao seu usuário, é quando se pode haver a formação de vínculo entre os dois. Mas do que a procura pelo atendimento, nas unidades de saúde que são porta de entrada para o cidadão, o maior objetivo da equipe multiprofissional deve ser a adesão ao serviço, por parte desse usuário. O cliente amazônico, muitas vezes, depende de transportes nada convencionais e o rio se torna a sua forma de locomoção, por meio de pequenas embarcações, em que o seu deslocamento, até uma unidade de atendimento mais próxima, pode durar horas ou até mesmo dias. Geralmente essas populações possuem um modo de vida bem peculiar. Nessas populações ocorre uma constante propagação de saberes através das gerações, como maneira de eternizar a identidade de seu grupo, seus saberes e cultura. É importante que o enfermeiro reconheça a necessidade de valorizar o saber do outro, por meio da escuta e da participação ativa dos sujeitos nas ações de saúde, propiciando assim uma reflexão crítica, problematizadora, ética, estimulando a curiosidade, o diálogo, a escuta e a construção do conhecimento compartilhado. O profissional enfermeiro deve saber escutar os anseios, os receios, as dúvidas e as queixas de seu cliente, para que assim, possa se formar um elo. A partir de então, a troca de conhecimentos se torna mais eficaz, pois ambos exercem o direito de dialogar sobre determinado assunto, discordando, se posicionando, a fim de possibilitar a percepção do outro sobre seu ponto de vista. Existe a necessidade de buscar articulação entre conhecimento científico e a prática profissional, associando o saber ao fazer e incorporando ao serviço de enfermagem, práticas educativas realmente transformadoras. Tal metodologia favorece a criação de vínculos e estimula a construção do processo de autonomia, apesar de que essa abordagem ainda é um desafio para os enfermeiros atuantes na atenção básica. Considerações finais: Ao cuidarmos da saúde do ser humano, não devemos somente nos limitar aos conceitos de prevenção, diagnóstico, tratamento e reabilitação. É importante conhecermos o contexto cultural, os valores, as crenças e o modo de vida do indivíduo e de sua família. A educação em saúde é uma relevante estratégia de disseminação de saberes, destinada a transformar a realidade dos indivíduos. Vale ressaltar que essa ação é um processo de aprender e ensinar e não é restrito somente ao indivíduo, mas à família e à comunidade. Implicações para a enfermagem: Nesse contexto, cabe ao profissional de enfermagem conduzir a mediação dos saberes científico e dos conhecimentos oriundos da comunidade, para que não se despreze ou se faça juízo de valor em relação a essas duas vertentes de conhecimento. A educação popular valoriza os saberes prévios da população, importando-se com suas realidades culturais, passadas por gerações, para que assim haja a formação de novos saberes, pautados na ciência e nas evidências de práticas. A interação da educação popular com os serviços em saúde possibilita uma relação mais participativa entre o cidadão e o sistema, contando com o apoio da enfermagem como possível mediadora da formação de opinião crítica, democrática e científica.

Descritores: Educação em Saúde; Participação Popular; Enfermagem. 


\section{Referências}

1. Moura MAV, Chamilco RASI, Silva LR. A teoria transcultural e sua aplicação em algumas pesquisas de enfermagem: uma reflexão. Esc Anna Nery R Enferm 2005 dez; $9(3): 434-40$.

2. Prado E, Falleiro LM, Mano MA. Cuidado, Promoção de Saúde e Educação Popular Porque Um Não Pode Viver Sem Os Outros. Rev APS. 2011 out/dez; 14(4): 464-471.

3. Mourão EV. Educação Popular: de uma Prática Alternativa a uma Estratégia de Gestão Participativa das Políticas de Saúde. PHYSIS: Rev. Saúde Coletiva, Rio de Janeiro, 14 (1): 67- 83, 2004. 


\title{
PLANEJAMENTO ESTRATÉGICO SITUACIONAL: UM RECURSO PARA A SAÚDE SEXUAL E REPRODUTIVA DE COMUNIDADE QUILOMBOLA
}

\author{
${ }^{1}$ Thamilly Joaquina Picanço da Silva; ${ }^{2}$ Marlucilena Pinheiro da Silva; ${ }^{3}$ Karoline Sampaio \\ da Silva; ${ }^{4}$ Wingred Lobato Gonçalves.
}

${ }^{1}$ Enfermeira. Mestranda do Programa de Pós-Graduação em Ciências da Saúde; Unifap; E-mail: thamillyps@gmail.com;

2 Enfermeira. Doutora; Unifap. Professora efetiva Colegiado do Curso de Bacharelado em Enfermagem;

${ }^{3}$ Enfermeira. Mestranda do Programa de Pós-Graduação em Ciências da Saúde;

${ }^{4}$ Enfermeira. Mestranda do Programa de Pós-Graduação em Ciências da Saúde.

\section{RESUMO}

Introdução: O planejamento estratégico situacional (PES) é um instrumento utilizado na administração em enfermagem, que promove a mudança dos serviços e da assistência, auxiliando tanto no processo de levantamento de situações-problema inerentes à organização quanto no momento da tomada de decisões, promovendo equidade por meio de ações direcionadas, levando em consideração a especificidade de cada população. Objetivo: Analisar os registros das consultas de saúde sexual e reprodutiva com vistas a subsidiar a elaboração de uma proposta de intervenção para a assistência de enfermagem por meio do PES. Método: Estudo qualitativo, por meio de pesquisa aplicada, de caráter exploratório, descritivo, e documental, realizado em uma Unidade Básica de Saúde localizada em comunidade quilombola da capital do Estado do Amapá. A coleta de dados ocorreu no período de setembro e novembro de 2017, a partir de entrevistas semiestruturadas com os profissionais de saúde da unidade e da análise dos registros dos prontuários de mulheres atendidas no Programa de Saúde Sexual e Reprodutiva (PSSR) referentes aos anos de 2010 e 2016. A metodologia de PES utilizou-se da estratégia Strengths, Oportunities, Weaknesses, Threats- Método de análise (SWOT), que permite 0 olhar sobre dois eixos (internos e externos) e compreende também duas variedades de cada um (pontos fortes e pontos fracos da organização; oportunidades e ameaças do meio externo). ${ }^{1}$ Projeto aprovado, parecer $n^{0} 2.410 .534$ - Comitê de Ética em Pesquisa da Universidade Federal do Amapá. Resultados: Nesta pesquisa, os momentos do PES, a saber: explicativo, normativo, estratégico e tático-operacional, foram descritos para uma melhor avaliação da unidade básica estudada, sendo primordial como base para a gestão e estratégia de uma organização. ${ }^{2}$ Iniciou-se então o momento explicativo, em que foram feitas reuniões com o corpo técnico da unidade de saúde, mediante o uso da técnica "brainstorming". Destacaram-se os seguintes pontos fortes do ambiente interno ou forças como também é denominado: equipe organizada; infraestrutura (Espaços físicos, materiais, equipamentos); profissionais qualificados; bom relacionamento entre os integrantes da equipe de saúde; boa relação da equipe de saúde com a comunidade e gestão participativa. No contexto do ambiente externo, os pontos fortes ou oportunidades elencadas foram as seguintes: grande número de profissionais de saúde disponíveis no mercado; relacionamento com as universidades (campos de estágios); educação permanente dos profissionais; padronização de instrumento para as consultas do PSSR e ampliação de 
estratégias de divulgação dos serviços oferecidos. Foi possível ainda identificar as seguintes fraquezas ou pontos fracos do ambiente interno: pouca variedade de medicações contraceptivas; baixa procura das mulheres aos atendimentos; baixa efetividade do PSSR; falta de atendimento especializado; descontinuidade dos métodos contraceptivos; horários de atendimento; tempo de retorno prolongado; precariedade nos registros da equipe de saúde e poucas ações de educação em saúde. Neste estudo situacional, em diálogo com a situação evidenciada, encontram-se os seguintes pontos fracos do ambiente externo, denominados também de ameaças: atual situação conjuntural do país; insatisfação da população quanto aos serviços públicos; insegurança; instabilidade no fornecimento de materiais; dificuldade de acesso; limitações da equipe. Diante das fraquezas expostas e da concepção quanto aos ambientes, ainda no momento explicativo, foi priorizado o problema central: Baixa efetividade do programa de saúde sexual e reprodutiva (grifo nosso) e as principais causas do problema: população vulnerada, dificuldade no acesso, distância dos centros de referência e contrarreferência, atual situação conjuntural das esferas governamentais, pouca variedade de medicação anticoncepcional, falta de atendimento especializado e poucas ações de educação em saúde voltadas para esta temática. Diante desse diagnóstico, o método prescreve a utilização de um Vetor Descritivo do Problema (VDP) ou descritor como também é denominado, este tem como intenção expressar os fatos e a apropriação da situação. No estudo, foram identificados os seguintes VDPs: poucas mulheres que recebem medicação na unidade realizaram consultas; o número de mulheres que buscam atendimento do PSSR na unidade triplicou entre os anos de 2010 a 2016; menos da metade das mulheres possuem registro referente às consultas e às consequências evidentes disso: abandono do uso de métodos contraceptivos; descontinuidade na assistência prestada; desconhecimento ou descaso por parte das mulheres quanto à importância das consultas do PSSR e prevenção de doenças; e a baixa adesão à coleta do exame PCCU. Após conhecer a realidade local e os problemas declarados, buscou-se, ainda no momento explicativo, identificar os nós críticos que representam as causas sobre as quais os atores têm condições de atuar com eficácia e que possuem direta relação no VDP, bem como os recursos necessários para enfrentá-los e desatá-los. A partir da análise dos relatos e as informações colhidas, foi possível sintetizar o momento explicativo, apresentando a Rede de Causalidade ou Árvore do Problema. Na próxima etapa, nomeada de momento normativo, apontaram-se medidas de melhorias a serem adotadas no sentido de dissolução dos nós críticos, projetando o impacto (baixo, médio e alto) no VDP. No momento estratégico, são mapeados os atores que tendem a cooperar e aqueles que se opõem ao projeto, para cada ação específica designada no momento anterior, verificou-se a viabilidade para decidir, executar e manter as ações, de acordo com estratégias específicas e diferenciadas que visam atingir o objetivo principal por meio de articulações de cooperação, participação e negociação para a factibilidade do plano de ação e a concepção da árvore das soluções. Por fim, o momento táticooperacional, houve a construção de um instrumento de avaliação permanente em que cabe aos atores participantes da pesquisa a realização das ações estabelecidas, ressaltando a necessidade da realização de avaliações periódicas para readequação das estratégias do planejamento. Considerações finais: Foi possível enfatizar que o processo de administração em enfermagem deve ser visto como ciência e sua aplicação na rotina profissional do enfermeiro tende a gerar múltiplas possibilidades, vantagens e resolução 
das adversidades existentes no serviço de saúde. Implicações para a enfermagem: Destaca-se o papel do enfermeiro como mediador e administrador das estratégias de atendimento voltadas para a assistência à saúde, em especial como exposto nesta pesquisa, o cuidado com a saúde da mulher quilombola.

Descritores: Planejamento Estratégico; Saúde Sexual e Reprodutiva; Saúde da Mulher.

\section{Referências}

1. Silva PM. Planejamento estratégico situacional: uma proposta metodológica para implantação do Projeto de Internacionalização da Universidade Federal de Lavras. Lavras-MG, 2013.

2. Daychouw M. Ferramentas e Técnicas de Gerenciamento. Rio de Janeiro: Brasport, 3. ed. 2007. 


\title{
A IMPORTÂNCIA DA VISITA DOMICILIAR A IDOSOS HIPERTENSOS MORADORES DE ÁREAS DE RESSACA
}

\author{
${ }^{1}$ Viviane de Souza Bezerra; ${ }^{2}$ Rafael Nascimento da Silva; ${ }^{3}$ Letícia Santos do Monte; \\ ${ }^{4}$ Izabele Grazielle da Silva Pojo; ${ }^{5}$ Aimê Mareco Pinheiro Brandão; ${ }^{6}$ Rosilda Alves da Silva \\ Isla Chamilco.
}

${ }^{1,4}$ Bolsista do Programa de Educação pelo Trabalho para a Saúde/Interprofissional no Curso de Bacharelado em Enfermagem, Universidade Federal do Amapá - Unifap. E-mail: vivibezerra1996@gmail.com;

2,3,5 Bolsistas do Programa de Educação Tutorial-PET/Enfermagem, Unifap;

${ }^{4}$ Enfermeira. Doutora em Enfermagem. Professora efetiva do Colegiado do Curso de Bacharelado em Enfermagem, Unifap.

\section{RESUMO}

Introdução: A hipertensão arterial sistêmica (HAS) é um problema grave de saúde pública no Brasil e no mundo, sendo um fator de risco importante para o desenvolvimento de doenças cardiovasculares, cerebrovasculares e renais. O risco de desenvolver HAS aumenta com a idade, sendo a doença crônica mais comum em idosos ${ }^{1}$. É papel fundamental dos profissionais de saúde da Atenção Primária, em especial do enfermeiro, o desenvolvimento de ações de controle da HAS, como identificação de grupos de risco, diagnóstico precoce, conduta terapêutica, educação em saúde e a busca ativa dos pacientes ${ }^{2}$. Esta última, por sua vez, é cercada de enorme importância no que tange aos pacientes residentes em áreas de ressaca. Ressaca é um termo regional designado para as chamadas bacias de acumulação de águas naturais, sendo muito comuns na região Amazônica. Em geral, são áreas de ocupação irregular que não possuem estrutura mínima de saneamento básico, abastecimento de água e postos de saúde, além de um déficit de acessibilidade e mobilidade urbana ${ }^{3}$. São áreas de espaço "gratuitos" para a construção de moradias, em consequência do grande crescimento demográfico da cidade 4 . Objetivo: Descrever a experiência de acadêmicos de Enfermagem na realização de visitas domiciliares a idosos hipertensos moradores de áreas de ressaca. Método: Trata-se de um relato de experiência, desenvolvido durante as aulas práticas da disciplina Saúde do adulto e do idoso, do Curso de Bacharelado em Enfermagem da Universidade Federal do Amapá (Unifap). O desenvolvimento da experiência transcorreu em três etapas: 1) Elaboração de cartilha educativa sobre hipertensão: a cartilha abordava conceito, prevenção e tratamento da doença. Foi construída com base nas literaturas disponibilizadas pelo Ministério da Saúde e visou transmitir conhecimento de forma mais acessível, com linguagem simples e objetiva; 2) Realização das visitas domiciliares: foram realizadas cinco visitas a idosos hipertensos moradores de área de ressaca de um bairro periférico de Macapá. No decorrer das visitas, foram apresentadas as cartilhas produzidas, bem como a verificação dos sinais vitais, além de orientações sobre alimentação saudável, importância das atividades físicas e de acompanhamento e tratamento da doença. Participaram das visitas seis acadêmicos de Enfermagem, com supervisão de uma enfermeira e Agente Comunitária de Saúde (ACS) da área, tendo sido efetuada uma visita por idoso. 3) Construção do artigo: a partir dessa vivência, foi possível a criação deste artigo, que tem a finalidade de disseminar tal 
experiência e contribuir para a melhoria no atendimento em saúde da população em questão. Resultados: Ao longo das visitas, foram identificadas as fragilidades presentes no dia a dia desses idosos e as peculiaridades de sua condição de hipertensos e moradores de área de ressaca. A partir das questões investigadas, foram elencadas três categorias: 1) Dificuldades de mobilidade e acesso à saúde; 2) Condições socioeconômicas desfavoráveis e aspectos culturais; 3) Ausência de apoio familiar e fragilidade no autocuidado. Na primeira categoria, apurou-se que a maioria dos idosos investigados não realizavam acompanhamento regular em uma Unidade Básica de Saúde (UBS). Os principais motivos relatados foram a distância e a dificuldade de mobilidade, uma vez que a passarelas de madeira para o trajeto não apresentavam boas condições, encontrando-se frágeis, quebradiças e inacabadas, sendo um grave fator de risco para quedas. Do mesmo modo que essa condição dificulta a chegada dos profissionais de saúde à população, a violência predominante no local também é um fator agravante no distanciamento profissional-cliente. Quanto à segunda categoria, apesar de possuírem conhecimento de sua condição de saúde prejudicada e disporem de um entendimento mínimo sobre hipertensão e de como a alimentação influencia em tal condição, houve relatos sobre a dificuldade em manter uma alimentação mais saudável devido, principalmente, ao alto preço de frutas e verduras e dos alimentos com melhor valor nutricional. O perfil socioeconômico dos idosos visitados é predominantemente de renda mensal igual ou inferior a um salário mínimo e o ensino fundamental como nível de escolaridade. Outro fator que compromete sua alimentação é a forte influência indígena na culinária amazônica associada a alimentos industrializados, como o consumo frequente de açaí com embutidos e enlatados, assim relatado nos discursos dos participantes. Segundo Alves, Jaime (2014) as desigualdades econômicas, de gênero e étnicas, bem como o acesso diferenciado aos bens e serviços públicos, são fatores determinantes da situação de insegurança alimentar, sendo papel daqueles que atuam no setor de saúde desenvolver estratégias que promovam o acesso equitativo aos alimentos e diversifiquem o seu uso, dentro das possibilidades da comunidade em que atuam. Na última categoria, ressalta-se que a maior parte dos idosos se encontravam carentes de apoio familiar, tendo que cuidar de si e de todos os deveres provenientes da condição de morar só. Alguns dos obstáculos relatados são a dificuldade de tomar remédio no horário correto e a realização de tarefas mais árduas. Diante de tal realidade, as visitas a esse público tornaram-se instrumento de acolhimento e vínculo entre paciente e profissional, reduzindo o impacto dos determinantes sociais de saúde aos quais estão submetidos. Considerações finais: Através da experiência, foi possível conhecer a realidade demográfica, social e de saúde dos idosos da região em questão, possibilitando um olhar mais particularizado para o desenvolvimento de estratégias eficazes para a garantia de atenção integral a esse público. A equidade, um dos princípios doutrinários do SUS, precisa ser mais efetiva no que diz respeito à identificação das diferenças nas condições de vida e saúde e das necessidades dessas pessoas. Percebeu-se como tais condições interferem no acesso aos serviços de saúde e evidenciam a necessidade de estratégias que diminuam a distanciamento entre o serviço e população. Implicações para a enfermagem: A partir do que foi descrito, a visita domiciliar implica uma nova forma de pensar a prática de Enfermagem no âmbito da atenção básica, com uma valorização maior do social, pois possibilita um melhor conhecimento sobre os aspectos sociais, econômicos, culturais e os agravos presentes na comunidade assistida. Isso facilita o planejamento e o 
direcionamento das ações e possibilita uma assistência mais integral e equitativa aos pacientes.

Descritores: Visita Domiciliar; Hipertensão; Idosos.

\section{Referências}

1. Sociedade Brasileira de Cardiologia. VI Diretrizes Brasileiras de Hipertensão. Arquivos Brasileiros de Cardiologia. 2010; 95 (1): 1-51.

2. Langowiski AR, Trompczynski J. Superintendência de Atenção à Saúde. Linha guia de hipertensão arterial. SESA. 2014. 1-52.

3. Tostes JA, Dias SF. As fragilidades urbanas e ambientais de áreas de ressaca na Amazônia. In: Anais do 4. Encontro da Associação Nacional de Pesquisa e PósGraduação em Arquitetura e Urbanismo; 2016 jun 25-29; Porto Alegre, Brasil. UNIFAP; 2016.

4. Santos Filho H, Almeida MG, Ribeiro MM. Mapeamento e classificação das áreas de ressaca na região metropolitana de Macapá-AP utilizando imagens do satélite CBERS2B. In: Anais do 16. Simpósio Brasileiro de Sensoriamento Remoto; 2013 abr 13-18; Foz do Iguaçu, Brasil. INPE; 2013. 2211-2217.

5. Alves KPS, Jaime PC. A Política Nacional de Alimentação e Nutrição e seu diálogo com a Política Nacional de Segurança Alimentar e Nutricional. Ciência \& Saúde Coletiva. 2014; 19 (11): 4331-4340. 


\section{EIXO IV: ÉTICA E BIOÉTICA NO PRINCÍPIO DA EQUIDADE}




\section{EQUIDADE E ELO EMOCIONAL NA AUTONOMIA DE INDIVÍDUOS PORTADORES DE PARKINSON E ALZHEIMER}

${ }^{1}$ Darci Francisco dos Santos Junior; ${ }^{2}$ Victor Hugo Oliveira Brito; ${ }^{3}$ Jordânia Vieira Silva; ${ }^{4}$ Karoliny Miranda Barata; ${ }^{5}$ Marlucilena Pinheiro da Silva; ${ }^{6}$ Maira Beatrine da Rocha Uchôa.

1 Acadêmico do Curso de Bacharelado em Enfermagem; Unifap; E-mail: darcijunior100799@gmail.com;

${ }^{2}$ Acadêmico do Curso de Bacharelado em Enfermagem; Unifap;

${ }^{3}$ Acadêmica do Curso de Bacharelado em Enfermagem; Unifap;

${ }^{4}$ Acadêmica do Curso de Bacharelado em Enfermagem; Unifap;

${ }^{5}$ Enfermeira. Doutora em Educação; UNIFAP. Professora efetiva do Colegiado do Curso de Bacharelado em Enfermagem;

${ }^{6}$ Enfermeira. Mestranda em Ciências da Saúde; Unifap. Professora efetiva do Colegiado do Curso de Bacharelado em Enfermagem.

\section{RESUMO}

Introdução: O cuidador é um indivíduo de qualidades excepcionais, expressas pelo forte traço de amor ao próximo, de solidariedade e de doação ${ }^{1}$. Essas características podem ser resumidas apenas a uma palavra: cuidar. Esse vocábulo faz parte do cotidiano de qualquer ser humano e é utilizado de diversas maneiras como: alertar, prevenir, através da promoção da cura, preservação da vida e até na ajuda no crescimento e desenvolvimento. O cuidar agrega uma gama de saberes teóricos e práticos, fundamentados em base científica e humana. ${ }^{2}$ Cuidar não é uma tarefa simples, pois o cuidado a ser prestado deve condizer com as necessidades de cada ser humano, portanto, é um processo mutável, e, com o passar dos anos, modifica-se, de acordo com vários fatores que se somam e interagem positiva ou negativamente na qualidade de vida do mesmo, fatores biológicos, genéticos, sociais, culturais ou ambientais. Isso é perceptível quando é realizado o diagnóstico de alguma doença neurodegenerativa, como Parkinson ou Alzheimer, em que não só o portador, mas também o cuidador deste indivíduo necessitam de cuidados e devem ser assistidos de forma holística, humanizada e integral, uma vez que o cuidador familiar pode ficar sobrecarregado por assumir sozinho a responsabilidade pelos cuidados, além de vivenciar o peso emocional da doença que incapacita e traz sofrimento a um ente querido. Ao vivenciar e assumir tais responsabilidades na rotina, sem perceber, o cuidador acaba por suprimir as vontades do doente, ferindo o princípio da autonomia, que define que indivíduos capacitados possam deliberar sobre suas escolhas e devem ser tratados com respeito, priorizando a capacidade ainda existente como direito de decidir sobre as questões relacionadas ao seu corpo e à sua vida. Objetivos: Descrever situações referentes ao princípio da autonomia sustentadas no advento da equidade, relacionado a um grupo de cuidadores de portadores de Alzheimer e Parkinson no município de MacapáAP. Método: Trata-se de um estudo descritivo, caracterizado como relato de experiência, acerca das oficinas semanais do projeto REVIVER, nas quais são realizadas diversas atividades que estimulam o autocuidado, educação em saúde e qualidade de vida, por meio de rodas de conversa, atividades educativas e momentos de lazer, e abordam situações 
que fazem parte do cotidiano dos participantes, como alimentação saudável, questões emocionais, administração de conflitos, aspectos psicológicos, entre outros. O projeto é registrado sob o parecer do comitê de ética 2.301.230, as oficinas ocorreram no período de $1^{\circ}$ de junho de 2018 a $1^{\circ}$ de abril de 2019, no bloco de Fisioterapia, na Universidade Federal do Amapá, no campus Marco zero. Resultados: Os cuidadores, devido a proteção excessiva, acabam tomando decisões pelos indivíduos que estão sob seus cuidados. Essa situação pode ser exemplificada quando o cuidador está próximo do indivíduo portador de Alzheimer e/ou Parkinson, perante um simples questionamento, como "Qual o seu nome?", "O senhor quer água?", ou se o indivíduo deseja participar de uma programação na semana seguinte, o cuidador familiar se posiciona tomando a frente das decisões e escolhas do doente, sem questionar a vontade do mesmo, a quem o profissional fez a pergunta. $O$ cuidado em excesso, sem o discernimento da percepção de si mesmo, acaba prejudicando não somente o cuidador, mas também afeta o paciente, o qual pode se sentir incitado a não realizar as mais simples tarefas, mesmo que consiga realizá-las. Diante desse comportamento extremamente protetor, foi necessário apresentar as funções dos cuidadores. Uma delas consiste em respeitar a capacidade de decisão dos portadores das doenças neurodegenerativas. Ademais foi necessário discutir o motivo para o cuidador não realizar todas as tarefas pelo seu ente querido, que é proporcionar ao indivíduo a manutenção de sua independência, mesmo que mínima, apesar da doença. Essa introdução do incentivo ao doente pelo cuidador para recuperar a sua autonomia é uma das possibilidades que permitem que o indivíduo retorne ao seu plano de vida, principalmente quando o cuidador não pode contar com outra pessoa para dividir o trabalho ou assumi-lo. É um método para o cuidador familiar se integrar ao processo de reabilitação do indivíduo, considerando-o sujeito participativo e ativo de sua recuperação, em que o cuidador estimula o restabelecimento de movimentos, reorienta o doente no tempo, no espaço e oferece outros cuidados que possam possibilitar ajuda nas suas limitações. Considerações finais: O elo emocional entre o familiar cuidador e o indivíduo portador da doença neurodegenerativa, apesar de importante para o enfrentamento da doença, também apresenta aspectos negativos quando ultrapassa a perda do poder de decisão do indivíduo doente. Dessa maneira, é necessário salientar que o olhar da enfermagem a respeito das doenças de Alzheimer e Parkinson não deve ser limitado apenas ao portador da doença, mas também a todos os atores que ela afeta, como os familiares e cuidadores. Evidenciase que relacionamento cuidador-paciente está além da doença, contemplando aspectos emocionais e sociais entre estes indivíduos, e centralizado no respeito mútuo e valorização do portador da doença, em suas escolhas e sentimentos. Diante disso, para que continue ocorrendo processo de sensibilização dos cuidadores, cujo objetivo é alcançar e manter a integridade do princípio da autonomia dos pacientes, a enfermagem deve continuar com as atividades de observação para identificar esses ou novos problemas, ademais, utilizar do bom senso para que essa problemática não se repita também entre os cuidadores e enfermeiros. Implicações para a enfermagem: A utilização dessas simples ações promove o elo entre cuidadores, pessoa cuidada e profissionais pelas relações estabelecidas e possibilita a busca pela autonomia e a emancipação dos envolvidos no processo. Por se tratar de pessoas diferentes, a equipe de enfermagem precisa aprender a estabelecer parâmetros de distribuição heterogênea, ou seja, ambos são distintos, apresentam expectativas de vida e necessidades distintas. Os conceitos abordados sobre 
enfermagem/cuidador e ambiente presentes no cotidiano da enfermagem são trabalhados na proposta apresentada, constituindo ferramentas fundamentais para sua viabilidade, 0 que desafia e promove a elevação da enfermagem na busca da integralidade e autonomia dos indivíduos nos diversos cenários e perspectivas de cuidado de uma forma equilibrada.

Descritores: Bioética; Cuidadores; Doenças Neurodegenerativas.

\section{Referências}

1. Boehs, AE, Patrício, ZM. O que é este "cuidar/cuidado"? - uma abordagem inicial. Rev. Esc. Enf. USP. 1990; 24(1): 111-16.

2. Bocchi SCM. Movendo-se entre a liberdade e a reclusão: Vivendo uma experiência de poucos prazeres ao vir-a-ser um cuidador familiar de uma pessoa com AVC. [Tese]. São Paulo (SP): Escola de Enfermagem/USP; 2001. 


\title{
SIGILO PROFISSIONAL DE ENFERMAGEM COM FOCO NA SAÚDE DO CUIDADOR
}

${ }^{1}$ Grayce Daynara Castro de Andrade; ${ }^{2}$ Letícia Santos do Monte; ${ }^{3}$ Luíny de Souza Lobato; ${ }^{4}$ Kelly Maria Rodrigues da Silva; ${ }^{5}$ Marlucilena Pinheiro da Silva.

\author{
j Acadêmica do Curso de Bacharelado em enfermagem; Unifap; E-mail: \\ grayceandrade7@gmail.com; \\ ${ }^{2}$ Acadêmica do Curso de Bacharelado em enfermagem; Unifap; \\ ${ }^{3}$ Acadêmica do Curso de Bacharelado em enfermagem; Unifap; \\ ${ }^{4}$ Acadêmica do Curso de Bacharelado em enfermagem; Unifap; \\ ${ }^{5}$ Enfermeira. Doutora em Educação; Unifap. Professora efetiva Colegiado do Curso de Bacharelado \\ em Enfermagem.
}

\section{RESUMO}

Introdução: $O$ envelhecimento implica maior prevalência de doenças crônicas e degenerativas, que afetam a independência do idoso nas atividades diárias e, por esse motivo, a necessidade de um cuidador, durante essa fase da vida. Este, geralmente, é um familiar, alguém dedicado a prestar cuidados, quase ou totalmente, integrais. Tal função vivencia uma relação íntima e prolongada com a pessoa que está sendo cuidada. Percebese nos relatos das pessoas que cuidam de outras por longo período, que suas falas são de desabafo, demonstração de angústia e indicativo de dores, demonstrando como a saúde física e mental está comprometida. A condição de saúde do cuidador está associada, muitas vezes, à necessidade de expressar seus sentimentos, suas carências, aspectos que podem parecer simples, mas que não são ${ }^{1}$. Estas questões foram notadas a partir do grupo de extensão REVIVER, um projeto multiprofissional, cabendo aos enfermeiros, docentes e discentes a responsabilidade de cuidar de quem cuida de pessoas com Parkinson e Alzheimer. Por meio desta relação, estabelece-se o contato de confiança entre os envolvidos, em que muitos segredos são colocados pelos cuidadores, cabendo aos docentes e discentes de enfermagem a manutenção de confidências, ou seja, de sigilo. Envolvem questões que implicam, desde o dever daquele que guarda o segredo de se omitir em revelá-lo, até a necessária proteção da intimidade do sujeito, que apresenta o aspecto de sua vida e não quer que seja conhecido por outrem. Esses aspectos se complexificam ainda mais nos termos do sigilo profissional. Pelo exercício de sua profissão, cabe aos professores enfermeiros e, por extensão, aos estudantes, o direito de não revelar a informação obtida do usuário, que o fez na confiança de resguardo da matéria sigilosa, assim, tanto quanto direito como dever do profissional em não divulgar informações colhidas ou obtidas, em decorrência de seu trabalho. A quebra do sigilo configura-se como característica que dificulta o serviço do Grupo REVIVER, a proposta da equipe de enfermagem é garantir a inclusão dos cuidadores nas atividades, viabilizando segurança nos aspectos vivenciados no grupo, seu bem-estar e saúde. Partindo das relações sociais, as quais envolvem fatos e ocorrências, que devem ser mantidas em sigilo, no que diz respeito à questão individual, o sigilo deve ser um dever, uma reponsabilidade, por meio da confidencialidade e do respeito à privacidade da pessoa, diante de troca de informações, conselhos e cuidados. A Resolução do Conselho Federal de Enfermagem no 564/2017, em seu art. 52 traz como dever dos profissionais "manter sigilo sobre fato de que tenha 
conhecimento em razão de sua atividade profissional, exceto casos previstos na legislação ou por determinação judicial, ou com o consentimento escrito da pessoa envolvida ou de seu representante legal"'. O sigilo é um direito da pessoa e um dever dos profissionais, pois informação estabelece relação de confidencialidade, o informado ou discutido durante o atendimento será guardado, esse compromisso se sustenta nas regras de ética dos profissionais de enfermagem. Objetivo: Abordar os aspectos éticos e legais do sigilo profissional de enfermagem no contexto do cuidador, assegurando relação de qualidade e equidade, englobando privacidade e confidencialidade. Método: Estudo descritivo do tipo relato de experiência, desenvolvido por meio de vivências, no projeto de extensão REVIVER, que promove assistência multiprofissional, contínua de pacientes com Parkinson e/ ou Alzheimer, na qual a equipe de enfermagem contribui para a promoção da saúde do cuidador desses pacientes, desenvolvendo roda de conversa e, quando necessário, a conversa individual. $O$ projeto foi aprovado pelo Comitê de Ética em Pesquisa (CEP/UNIFAP) sob o parecer 2.301.230 e todos os participantes do estudo assinaram o consentimento informado. Resultados: A relação de confiança entre os sujeitos envolvidos é sustentada por questões éticas e legais de se exercer tal sigilo, mas, a partir do momento que a convivência passa a ser mais intensa, laços são estreitados entre a equipe e os participantes. Este fator traz um peso maior de confiabilidade, com benefícios para o cuidador, que terá atenção personalizada, de acordo com sua necessidade, quanto à enfermagem que desenvolverá a devida assistência a ser oferecida. O nível de confiança entre os protagonistas desta pesquisa vem aumentando, gradativamente, no grupo REVIVER. Inicialmente, as rodas de conversas eram evidenciadas por momentos de silêncio e timidez, pela maioria dos membros. Ao longo de três meses, estabeleceu-se então um vínculo efetivo, não somente no quesito confiança, mas também de respeito e apreço mútuo. Parte das experiências compartilhadas é de momentos tristes, de extremo estresse, pensamentos intimistas e tentativas, por vezes, frustradas de enfrentar uma situação. Hoje existe diálogo aberto, mesmo diante de novos cuidadores no grupo, os membros mais antigos não se mostram constrangidos, pois existe um ambiente de segurança para a livre expressão destes. O sigilo profissional exercido é fundamental para proporcionar este ambiente seguro, pois, além de manter em segredo o que é mencionado nas reuniões, o respeito e a exclusão do prejulgamento fazem total diferença. Considerações finais: Para se estabelecer vínculo com o cuidador, é necessário que o acolhimento seja um processo do atendimento, em que este se sentirá mais seguro em falar de si, que auxiliará o planejamento das ações pertinentes à sua saúde. A experiência vivida no grupo REVIVER mostra o quão incontestável é a diferença de exercer o que está no Código de Ética dos Profissionais de Enfermagem² sobre o dever de manter o sigilo profissional, este que traz benefícios, não somente para quem está sendo assistido, ele beneficia quem presta os cuidados a fim de manter uma relação harmoniosa e de extremo respeito. Implicações para a enfermagem: A relação de confiança, como a construída no Grupo REVIVER, conduz a importante reflexão à enfermagem, afinal a ética interroga nossas ações, competências e qualificações como profissionais e como estudantes. E, sobretudo, interroga: o que estamos fazendo de nós e das pessoas que são assistidas por nós? Fica indubitável a importância do sigilo, para o aperfeiçoamento dos serviços de enfermagem e domínio dos documentos éticos e legais da profissão, pelos futuros profissionais e profissionais de enfermagem. 
Descritores: Equidade em saúde; Ética profissional; Cuidador.

\section{Referências}

1. Conselho Federal de Enfermagem. Resolução COFEN n. 564, de 06 de dezembro de 2017. Código de ética dos profissionais de enfermagem. Diário oficial da União, Brasília (DF), 2017 Dez 06; Seção 1:157.

2. Instituto Brasileiro de Geografia e Estatística [homepage na internet]. Número de idosos cresce $18 \%$ em 5 anos e ultrapassa 30 milhões em 2017. Rodrigo P, 2018. [acesso em 13 de abril de 2019]. Disponível em: https://agenciadenoticias.ibge.gov.br/agencianoticias/2012-agencia-de-noticias/noticias/20980-numero-de-idosos-cresce-18-em-5anos-e-ultrapassa-30-milhoes-em-2017.

3. Fernandes C S; Agelo M; Martins M M. Dar Voz aos Cuidadores: um jogo para o cuidador familiar de um doente dependente. Revista da Escola de Enfermagem da USP, v. 52, p. e03309-e03309, 2018. 


\title{
DOENÇA DE ALZHEIMER, PERDA DE IDENTIDADE E CONFLITOS NAS ATRIBUIÇÕES DO FAMILIAR CUIDADOR
}

\author{
${ }^{1}$ Jorge Araújo dos Santos Júnior; ${ }^{2}$ Diana Silva de Aguiar; ${ }^{3}$ Joyce Taynara Souza de \\ Miranda; ${ }^{4}$ Lorena Leal de Moraes Simões; ${ }^{5}$ Maria Izabel Tentes Côrtes; ${ }^{6}$ Marlucilena \\ Pinheiro da Silva.
}

\begin{abstract}
${ }^{1}$ Acadêmico do Curso de Bacharelado em Enfermagem; Unifap. E-mail: jorgearauj020162016@gmail.com;

${ }^{2}$ Acadêmica do Curso de Bacharelado em Enfermagem; Unifap;

${ }^{3}$ Acadêmica do Curso de Bacharelado em Enfermagem; Unifap;

${ }^{4}$ Enfermeira. Mestranda; Unifap;

${ }^{5}$ Enfermeira. Doutora em Enfermagem; Unifap. Professora efetiva do Colegiado do Curso de Bacharelado em Enfermagem;

6 Enfermeira. Doutora em Educação; Unifap. Professora efetiva do Colegiado do Curso de Bacharelado em Enfermagem.
\end{abstract}

\section{RESUMO}

Introdução: No Brasil, estima-se, que até 2030, o país alcance a marca de 41 milhões de idosos ${ }^{1}$. E, com o aumento da expectativa de vida, cresce também a prevalência de doenças crônicas, entre elas, as neurodegenerativas como a Doença de Alzheimer (DA). Esta se destaca como a demência mais incidente na população idosa e afeta principalmente o sexo feminino ${ }^{2}$. A DA é definida como uma doença neurodegenerativa, caracterizada pela deterioração definitiva das células nervosas de forma progressiva e contínua, que resulta em uma diminuição de inúmeras funções motoras e cognitivas. Esta doença afeta os mais variáveis aspectos da vida humana, entre eles memória, pensamento, linguagem e conduta, que culminam em sérios prejuízos à vida de seu portador. O declínio motor e cognitivo na DA resulta em redução autonômica, que, por sua vez, torna seus portadores alvos inevitáveis das abordagens bioéticas que circundam o palco da prestação dos cuidados. A autonomia esvai-se gradualmente do portador da doença e, associado a esse fato, aqueles que realizam cuidados formais ou informais acabam por assumir precocemente o protagonismo na construção daquele que um dia exerceu essa função ${ }^{3}$. Objetivo: $O$ estudo tem como objetivo abordar as questões de comportamento vivenciadas por familiares cuidadores de pacientes com Alzheimer, em especial homens familiares cuidadores da pessoa do sexo oposto, o que gera grande conflito no comportamento e atitudes do cuidador, fato este assistido dentro do projeto de extensão e pesquisa Reviver. Método: Trata-se de um trabalho descritivo, do tipo relato de experiência. $O$ projeto de pesquisa e extensão Reviver (edital DEXIPROEAC $N^{O}$ 27\2017) é realizado na Universidade Federal do Amapá (UNIFAP), atende pessoas que possuem DP elou DA e os cuidadores dessas pessoas. Foi observado que, atualmente no grupo, há três cuidadores do sexo masculino que prestam cuidados exclusivos a pacientes com DA, fato este que chama atenção, pois, dentro do projeto e na literatura acerca do tema, observa-se que a maioria dos cuidadores é do sexo feminino. É percebida a dificuldade desses cuidadores ao prestar cuidados e principalmente assumir a identidade da pessoa que um dia cuidou deles, tendo em vista que a DA se encontra muito avançada na pessoa cuidada. A equipe 
de Enfermagem realiza educação em saúde e instruções aos cuidadores dos pacientes, a cada encontro o grupo planeja atividades a fim de proporcionar bem-estar e preparar esses cuidadores a prestar uma assistência de forma mais eficaz, respeitando princípios de autonomia e equidade dos que recebem cuidados. Dentre as atividades realizadas, destaca-se a aferição de sinais vitais, bem como atividades que desenvolvam a automotivação, autocuidado, o controle de estresse e ansiedade, educação em saúde e rodas de conversas para troca de experiências entre cuidadores e equipe profissional de Enfermagem. Resultados: Durante as rodas de conversas e atividades realizadas no grupo, observamos três casos atípicos entre os cuidadores, três pessoas do sexo masculino prestam cuidados às suas mães, que possuem DA. O cuidado prestado pelos mesmos se dá pelo fato de não terem condições financeiras para contratar uma cuidadora formal ou não confiarem neste tipo de atendimento, ou ainda pelo fato de serem filhos únicos e terem que assumir essa responsabilidade. É observado nos relatos feitos pelos cuidadores por meio da roda de conversa que, devido à perda de identidade e fatores incapacitantes ocasionados pela doença, os filhos acabaram assumindo o papel de pai das próprias mães, havendo assim uma troca de identidade não esperada. A decisão de assumir o cuidado da idosa com DA perpassa a autonomia do cuidador. Este, por sua vez, considera que essa decisão tem influência no viver e conviver com o outro, assim como remete a sentimentos de obrigação, retribuição, dependência e amor, não ter outra pessoa para cuidar e por residir com a idosa no mesmo domicílio ${ }^{4}$. Prestar esse cuidado torna-se uma tarefa árdua e, ao mesmo tempo, eles se veem pressionados a passar por cima da privacidade da portadora da DA, tendo em vista que, pela falta de uma pessoa do mesmo sexo, eles acabam fazendo serviços básicos de higiene pessoal como, por exemplo, levar ao banheiro e dar banho, haja vista que a progressão da doença não permite que a paciente realize essas atividades humanas básicas. Realizar esses cuidados foi relatado como a parte mais difícil pelo fato de o cuidador ser do sexo oposto ao da pessoa cuidada, e isso se configura para os cuidadores como uma violação de privacidade. Aqueles que realizam os cuidados aos portadores da doença assumem a responsabilidade de prosseguir na construção do outro e consequentemente encarregam-se de protagonizar sua vida frequentemente, enquanto estes ainda possuem a capacidade autonômica parcialmente preservada. Em consequência desse fato, ocorre o aumento da vulnerabilidade do portador de Alzheimer a um cuidado que favorece o desrespeito a sua dignidade e individualidade ${ }^{3}$. Considerações finais: A falta de preparação desses cuidadores acarreta uma apropriação precoce da identidade da pessoa cuidada e muitos cuidadores não estão preparados para assumir a responsabilidade de trocar a identidade e sentem-se constrangidos em realizar atividades humanas básicas, como dar banho no paciente e levar ao banheiro, e isso se agrava quando o cuidador é do sexo oposto. Implicações para a enfermagem: De grande valia que estudos referentes à relação entre cuidadores e indivíduos cuidados sejam intermediados pela equipe de enfermagem. No projeto Reviver, acadêmicos e professores buscam de forma ética, e com foco na equidade, valorizar e trabalhar as dificuldades dos cuidadores para que os mesmos se fortaleçam no processo do cuidar. As limitações autonômicas comuns à DA tornam cuidadores e profissionais da saúde peças fundamentais na construção de uma atenção adequada. Acrescido a esse fato, surge a necessidade de um suporte emocional e institucional adequado ao prestador dos cuidados, que precisa de conhecimentos acerca dos meios apropriados para sua atuação ${ }^{5}$. 
Descritores: Mal de Alzheimer; Cuidador Familiar; Conflito.

\section{Referências}

1. Instituto Brasileiro de Geografia e Estatística [publicação online]. Brasil: Projeção da população por sexo e idade simples: em $1^{\circ}$ de julho - 2000/2060. [acesso em $25 \mathrm{abr}$ 2019]. Disponível em http:www.ibge.gov.br

2. Da Silva Alves AP et al. O cuidado ao portador do alzheimer fundamentado no princípio bioético da autonomia. Revista Ciência \& Saberes-Facema, 3 (1): 416-421, 2017.

3. Burlá C, Pessini L, Siqueira JE, Nunes R. Envelhecimento e doença de Alzheimer: reflexões sobre autonomia e o desafio do cuidado. Rev bioét [publicação online]: 2014 Jan/Abr [acesso em 25 abr 2019]; 22(1):85-93. Disponível em http://revistabioetica.cfm.org.br/index.php/revista_bio etica/article/view/885/977.

4. Dos Anjos, Karla Ferraz et al. Homem cuidador familiar de idosa com doença de Alzheimer. Saúde e Pesquisa, 10 (2); 317-324, 2017.

5. Ximenes MA, Rico BLD, Pedreira RQ. Doença de Alzheimer: a dependência e o cuidado. Rev kairós [publicação on-line]: 2014 Jun [acesso em 25 abr de 2019];17(2):121-140. Disponível em: http://revistas.pucsp.br/index.php/kairos/article/view/21630/15877. 


\title{
VIOLAÇÃO DA EQUIDADE: UM OBSTÁCULO PARA A PROMOÇÃO DA SAÚDE EM COMUNIDADE QUILOMBOLA
}

\author{
${ }^{1}$ Thamilly Joaquina Picanço da Silva; ${ }^{2}$ Marlucilena Pinheiro da Silva; $;{ }^{3}$ Karoline Sampaio \\ da Silva; ${ }^{4}$ Wingred Lobato Gonçalves.
}

${ }^{1}$ Enfermeira. Mestranda do Programa de Pós-Graduação em Ciências da Saúde; Unifap; E-mail: thamillyps@gmail.com;

2 Enfermeira. Doutora; Unifap. Professora efetiva Colegiado do Curso de Bacharelado em Enfermagem;

${ }^{3}$ Enfermeira. Mestranda do Programa de Pós-Graduação em Ciências da Saúde;

${ }^{4}$ Enfermeira. Mestranda do Programa de Pós-Graduação em Ciências da Saúde.

\section{RESUMO}

Introdução: A Constituição Federal Brasileira de 1988 firmou, por meio do reconhecimento e da constitucionalidade, os princípios e pensamentos defendidos com voracidade pelo Movimento da Reforma Sanitária. Assim, a partir deste marco histórico, os valores sociais como o direito de acesso universal e a integralidade da atenção à saúde refletem a necessidade do Estado de propor o bem-estar da população em contraposição e substituição ao sistema excludente e desigual que existia antes de 1988. Dessa forma, mais que um direito social, é cada vez mais perceptível que o acesso aos cuidados com a vida, de acordo com os determinantes sociais de saúde, incluindo a saúde sexual e reprodutiva, é um direito humano fundamental e um direito inclusivo necessário para a manutenção dos direitos inerentes à condição de cidadania ${ }^{1}$. Em contramão a essa realidade, encontramos a condição dos remanescentes quilombolas, os quais possuem iniquidades e vulnerabilidades persistentes com relação a aspectos sociais e de saúde. As barreiras de acesso se tornam ainda mais expressivas quando falamos sobre essa população, enfatizando a necessidade da real efetivação das políticas públicas, incluindo de forma particular o fortalecimento da atenção básica como a promoção de processos inclusivos de universalidade e equidade para os quilombolas. ${ }^{2}$ A garantia da resolubilidade e integralidade da atenção aos cuidados de saúde tem como intermediários os profissionais de saúde. Estes têm a exigência de focalizar o seu trabalho em benefício da população, pautados nos princípios éticos e bioéticos, prestando assistência com qualidade, responsabilidade, utilizando-se da fundamentação ética para estabelecer verdadeiramente o princípio da equidade. Objetivo: Apresentar dilema ético vivenciado em comunidade quilombola, relacionando-o com o código de ética dos profissionais de enfermagem e medicina. Método: Relato de experiência, estudo de abordagem qualitativa, caráter descritivo e recorte do banco de dados da macro pesquisa intitulada "Planejamento Estratégico Situacional: um recurso para a saúde sexual e reprodutiva de comunidade quilombola". A coleta de dados ocorreu no período compreendido entre setembro e outubro de 2017, em uma comunidade quilombola do Estado do Amapá, a partir de entrevistas semiestruturadas com os profissionais de saúde da unidade e por meio da análise dos registros dos prontuários de mulheres atendidas no programa de saúde sexual e reprodutiva entre os anos de 2010 e 2016. Projeto aprovado, parecer no 2.410 .534 - Comitê de Ética em Pesquisa da Universidade Federal do Amapá. Resultados: Durante a 
construção da macro pesquisa que deu origem este relato, através da observação participante e entrevistas com os profissionais de saúde, foi possível evidenciar que uma determinada profissional de saúde, que prestava assistência na atenção primária da comunidade quilombola por meio do programa Estratégia Saúde da Família, não prescrevia medicamentos anticoncepcionais para as mulheres residentes deste local por conta de suas concepções religiosas. Decorrente dessa situação, outros eventos foram sendo desencadeados na mesma unidade por conta da falta de prescrição dos medicamentos. A enfermeira responsável pela equipe prescrevia fármacos anticoncepcionais estabelecidos pelo programa de saúde pública na primeira consulta e, no entanto, nas consultas subsequentes, as mulheres eram atendidas pelos profissionais técnicos de enfermagem que forneciam o medicamento para as mesmas sem avaliação ou acompanhamentos necessários dos profissionais competentes para esse fim e muitas vezes ainda prescreviam informalmente os anticoncepcionais. Diante desse fato, foi possível destacar a violação da carta dos direitos dos usuários da saúde, a qual, em seu terceiro princípio, assegura ao cidadão o atendimento acolhedor e livre de discriminação, visando à igualdade de tratamento e a uma relação mais pessoal e saudável. Dessa forma, estabelece, no 3o artigo, que, nas consultas, procedimentos diagnósticos, preventivos, cirúrgicos, terapêuticos e internações, devem ser levados em conta: integridade física; privacidade e conforto; individualidade; seus valores éticos, culturais e religiosos. Diante disso, visa garantir que nenhum profissional da saúde permita que seus interesses e pessoalidades, de caráter político, religioso ou de quaisquer outras ordens, interfiram na escolha dos meios de atenção à saúde do paciente, de uma comunidade ou da sociedade em geral ${ }^{3}$. Caracterizando, assim, como omissão profissional em empenhar-se para melhorar os padrões dos serviços de saúde e em assumir sua responsabilidade em relação à saúde pública, à educação sanitária e à legislação referente à saúde. É necessário considerar que atitudes impensadas dos profissionais acabam por violar o Código de Ética dos Profissionais de Enfermagem (Cepe), no que se refere ao art. 91 do capítulo das proibições "Delegar atividades privativas do (a) Enfermeiro (a) a outro membro da equipe de Enfermagem, exceto nos casos de emergência." Contrapondo-se ao art. 24 do capítulo de deveres: "Exercer a profissão com justiça, compromisso, equidade, resolubilidade, dignidade, competência, responsabilidade, honestidade e lealdade". Desta forma, ainda é possível observar a violação do código de ética pelo profissional técnico de enfermagem, pelo art. 62 das proibições: "Executar atividades que não sejam de sua competência técnica, científica, ética e legal ou que não ofereçam segurança ao profissional, à pessoa, à família e à coletividade." Podendo estes profissionais estar expostos a penalidades como: advertência verbal; multa; censura; suspensão do exercício profissional; cassação do direito ao exercício profissional ${ }^{4}$. Considerações finais: Conclui-se que as mulheres quilombolas atendidas por estes profissionais estavam sendo submetidas a imprudência e negligência técnica, as quais ferem os princípios éticos e se tornam mais obstáculos para concretização da equidade na atenção à saúde deste grupo. Implicações para a enfermagem: A ética e a bioética complementam e muitas vezes dirigem as atividades da enfermagem, por isso a importância do conhecimento do código de ética e a aplicação deste no cotidiano da profissão. Sabe-se que toda ação do profissional pode influir de forma positiva ou negativa para a saúde pública, agindo muitas vezes em contramão das lutas dos movimentos da reforma sanitária para a efetivação dos princípios fundamentais, 
destacando neste momento o princípio da equidade, fator que ainda precisa ser mais trabalhado dentro da enfermagem por meio de pesquisas que agreguem e correlacionem à ética e à equidade importantíssimos recursos em vista da transformação social.

Descritores: Ética; Equidade; Saúde Pública.

\section{Referências}

1. Barros FPC; Sousa MF. Equidade: seus conceitos, significações e implicações para o SUS. Saúde Soc. São Paulo, 25(1):9-18. 2016.

2. Prudêncio LS. Itinerários terapêuticos de quilombolas: um olhar bioético sobre a atenção e o cuidado à saúde. Tese (Doutorado), UFSC, Florianopolis, 2017.

3. Brasil. Carta dos direitos dos usuários da saúde: Ministério da Saúde. 2. ed. Brasília: Ministério da Saúde, 2007. 9 p.

4. Conselho Federal de Enfermagem. Código de ética de enfermagem: resolução no 564, de 6 de dezembro de 2017. 2017. 


\title{
FUNDAMENTOS ÉTICOS NO ATENDIMENTO A GRÁVIDAS ADOLESCENTES: RELATO DE UM GRUPO DE APOIO
}

\author{
${ }^{1}$ Victor Hugo Oliveira Brito; ${ }^{2}$ Hiago Rafael Lima da Silva; ${ }^{3}$ Luana Jandira Weber Silva; \\ ${ }^{4}$ Viviane de Souza Bezerra; ${ }^{5}$ Nely Dayse Santos da Mata; ${ }^{6}$ Marlucilena Pinheiro da Silva. \\ ${ }^{1}$ Acadêmico do Curso de Bacharelado em Enfermagem; Unifap. E-mail: victrhug1999@gmail.com; \\ ${ }^{2}$ Acadêmico do Curso de Bacharelado em Enfermagem; Unifap; \\ ${ }^{3}$ Acadêmica do Curso de Bacharelado em Enfermagem; Unifap; \\ ${ }^{4}$ Acadêmica do Curso de Bacharelado em Enfermagem; Unifap; \\ ${ }^{5}$ Enfermeira. Doutora em Ciências; Unifap. Professora efetiva do Colegiado do Curso de \\ Bacharelado em Enfermagem; \\ ${ }^{6}$ Enfermeira. Doutora em Educação; Unifap. Professora efetiva do Colegiado do Curso de \\ Bacharelado em Enfermagem.
}

\section{RESUMO}

Introdução: A ética tem sua origem na palavra grega ethos (caráter) e na latina mores (costumes). Na filosofia, a ética determina o que é bom para o indivíduo e para a sociedade, estabelecendo a natureza dos deveres que as pessoas devem ter consigo e com as outras'. Partindo dessa premissa, entende-se que a Bioética tem por finalidade a aplicação dos conceitos previamente estabelecidos na ética filosófica em um campo específico: o das ciências em saúde ${ }^{2}$. Levando em consideração que, durante as pesquisas das ciências humanas e da saúde, o pesquisador precisa respeitar o livre arbítrio do participante e do seu representante, assim como seus valores morais e crenças, o princípio da autonomia reitera o domínio da pessoa acerca de sua própria vida e enfatiza o respeito à intimidade 3 . Com o propósito de assegurar e respeitar os direitos dos participantes adolescentes de uma pesquisa, utilizam-se os Termos de Consentimento e Assentimento Livre e Esclarecido (TCLE e TALE), assegurados na Resolução № 466, de 12 de dezembro de 2012. Nesse contexto, faz-se necessária a participação dos representantes legais dos convidados da pesquisa durante a etapa de esclarecimento e assinatura do TCLE, a fim de autorizar a participação dos adolescentes e preservar seus direitos. Tendo isso em vista, o Grupo de Pesquisa e Extensão de Apoio a Grávidas Adolescentes (GEAGA), que tem por objetivo desenvolver oficinas de educação para o parto com as adolescentes primigestas, utiliza-se também da bioética para promover assistência a esse público, haja vista que são menores de idade em processo de transformações biológicas e comportamentais. As adolescentes são amparadas, assim como seus responsáveis legais, pela legislação durante o desenvolvimento do estudo. Objetivo: Relatar a experiência de acadêmicos do GEAGA quanto aos aspectos éticos, bioéticos e legais vivenciados no atendimento a grávidas adolescentes. Método: Trata-se de um estudo descritivo, caracterizado como relato de experiência, em que foi utilizada a observação participante no grupo de extensão com adolescentes primigestas como estratégia de coleta de dados. O GEAGA realiza, quinzenalmente, oficinas de educação em saúde direcionadas ao parto e período gravídicopuerperal, em que se trabalham exercícios para o fortalecimento dos músculos do assoalho pélvico e exercícios respiratórios, além da realização de rodas de conversa, dinâmicas e palestras referentes a temas preconizados pelo Ministério da Saúde (MS) acerca do bem- 
estar materno-infantil. Durante o ano, são realizados cerca de dois grupos de grávidas para participar das oficinas, a fim de receber acompanhamento da gestação e possibilitar construção de conhecimento científico. Dessa forma, no início de cada ciclo, há a admissão de novas participantes no grupo, fazendo-se necessário o esclarecimento do objetivo do projeto, dos requisitos éticos para a permanência das grávidas no grupo e para a utilização das informações coletadas pelo GEAGA. Resultados: A partir da vinculação do grupo de extensão com a Unidade Básica de Saúde (UBS) da Universidade Federal do Amapá (UNIFAP), os acadêmicos e demais profissionais fazem o convite às grávidas no momento da realização da palestra para o início do pré-natal ou durante as próprias consultas. Diante da demonstração de interesse das gestantes, os integrantes do grupo de extensão coletam dados necessários para o contato e posterior visita domiciliar. As adolescentes são contatadas e recebem visita domiciliar prévia às oficinas, com o intuito do conhecimento de seus responsáveis legais, além da apresentação e importância do grupo e convite formal da grávida e seu acompanhante para a participação da primeira oficina. Ressalta-se a importância da visita domiciliar no que tange aos aspectos positivos para a adesão das gestantes tanto pela autorização dos responsáveis quanto pela formação de vínculo e incentivo, aumentando também as chances das assinaturas posteriores do TCLE e TALE, os quais serão entregues após sua participação na segunda oficina. Ambos os termos respaldam tanto a adolescente e seu responsável quanto os pesquisadores do grupo, possibilitando a participação da mesma nas oficinas e a utilização de dados, fotografias, vídeos e relatos por parte do grupo para a produção científica. Adicionalmente, referindose à questão bioética, são encontradas algumas situações relacionadas: resultados positivos de Infecções Sexualmente Transmissíveis (ISTs) e desejo equivocado da adolescente para realizar aborto induzido por falta de apoio das pessoas com quem convive ou das transformações sociais que ocorrem durante a gravidez e que afetam, ao seu olhar, negativamente o seu estilo de vida. Assim, a postura e conduta éticas são indispensáveis na tomada de decisões para promover escuta ativa, prestar assistência ou referenciar essa grávida para serviços especializados que auxiliarão na resolução dessas problemáticas. Considerações finais: A promoção da saúde a grávidas adolescentes, por ser um público específico e ter fragilidades sociais emergentes, deve ser promovida de acordo com suas necessidades psicossociais, físicas e ambientais. A permanência das adolescentes no grupo de extensão possibilita o empoderamento do seu corpo, o conhecimento de assuntos relacionados à sua nova condição e à autonomia quanto às suas escolhas durante 0 período gestacional e parto. Dessa forma, a partir do embasamento na legislação atualmente vigente e da visão holística das reais necessidades individuais das grávidas adolescentes, a prática baseada na ética profissional possibilita a concessão do cuidado em saúde subsidiado, de maneira importante, em um dos princípios doutrinários do Sistema Único de Saúde (SUS): a equidade. Implicações para a enfermagem: Entende-se que a pesquisa e a prática de saúde fundamentadas nos aspectos éticos e bioéticos estão estritamente relacionadas com a atenção equânime, de forma que a atenção ao indivíduo seja individualizada e ética. Possibilita uma assistência mais qualificada a partir do modelo holístico de tratamento, visando ao paciente em sua integralidade. Assim, a ética deve sempre ser utilizada como ferramenta capaz de embasar as relações sociais, como forma de humanização para com o indivíduo. Por fim, possibilitará a continuidade de pesquisas em saúde e, principalmente, em enfermagem, que é uma das áreas da saúde que mais 
possuem e mantêm contato direto com o indivíduo, na assistência, no cuidado, na orientação e no exercício da equidade em diversos aspectos.

Descritores: Gravidez na Adolescência; Ética em Enfermagem; Equidade.

\section{Referências}

1. Cornell University Law School [homepage na internet]. Ethics [acesso em 27 Abr 2019]. Disponível em: https://www.law.cornell.edu/wex/Ethics.

2. Neiva-Silva L, Lisboa C, Koller SH. Bioética na pesquisa com crianças e adolescentes em situação de risco: dilemas sobre o consentimento e a confidencialidade. DST j. bras. doenças sex. transm. [Internet]. 2006 [acesso em 27 Abr 2019]; 17(3): 201-206. Disponível em: http://www.dst.uff.br/revista17-3-2005/bioetica-na-pesquisa.pdf.

3.

Filho CM. Uma visão ética e bioética do atendimento ao adolescente. Resid Pediatr [Internet]. 2015 [acesso em 27 Abr 2019]; 5(3 Supl.1):10-12. Disponível em: http://residenciapediatrica.com.br/detalhes/158/uma-visao-etica-e-bioetica-doatendimento-ao-adolescente. 


\section{PRINCÍPIO DA BENEFICÊNCIA: PERCEPÇÃO E INTERVENÇÃO NA RELAÇÃO DO CUIDADOR E SEU FAMILIAR}

${ }^{1}$ Victor Hugo Oliveira Brito; ${ }^{2}$ Darci Francisco dos Santos Junior; ${ }^{3}$ Jordânia Vieira Silva;

${ }^{4}$ Karoliny Miranda Barata; ${ }^{5}$ Marlucilena Pinheiro da Silva; ${ }^{6}$ Maira Beatrine da Rocha Uchôa.

\footnotetext{
${ }_{1}^{1}$ Acadêmico do Curso de Bacharelado em Enfermagem; Unifap. E-mail: victrhug1999@gmail.com;

${ }^{2}$ Acadêmico do Curso de Bacharelado em Enfermagem; Unifap;

${ }^{3}$ Acadêmica do Curso de Bacharelado em Enfermagem; Unifap;

${ }^{4}$ Acadêmica do Curso de Bacharelado em Enfermagem; Unifap;

5 Enfermeira. Doutora em Educação; Unifap. Professora efetiva do Colegiado do Curso de Bacharelado em Enfermagem;

${ }^{6}$ Enfermeira. Mestranda em Ciências da Saúde; Unifap. Professora efetiva do Colegiado do Curso de Bacharelado em Enfermagem.
}

\section{RESUMO}

Introdução: Beauchamp e Childress propuseram, no livro Principles of Biomedical Ethics, a teoria principialista. Essa concepção se baseia em quatro princípios, sendo estes: respeito à autonomia, beneficência, não maleficência e justiça, como fundamentos do agir moral na ética biomédica1. Os princípios da beneficência e não maleficência são inter-relacionados e expressam, respectivamente, o dever do profissional da saúde de não infringir o mal a seu paciente e o dever de fazer o bem a outrem². Portanto, a beneficência tem como objetivo a maximização dos benefícios e a diminuição dos agravos à saúde das pessoas, evidenciadas pela habilidade na hora da avaliação integral do indivíduo, observando suas características biopsicossociais, ambientais, entre outras. Essa característica pode ser atribuída também, principalmente, aos familiares cuidadores, os quais estão próximos diariamente de seu familiar, cuidando e suprindo todas as suas necessidades. Para analisar o princípio da beneficência nesta relação, é necessário conhecer o papel do cuidador e a distinção de suas atividades, sendo a ocupação de cuidador reconhecida pela Classificação Brasileira de Ocupações (CBO) sob o código 5.162, que define o cuidador como alguém que cuida a partir dos objetivos estabelecidos por instituições especializadas ou responsáveis diretos, zelando pelo bem-estar, saúde, alimentação, higiene pessoal, educação, cultura, recreação e lazer da pessoa assistida. Assim, o familiar cuidador é a pessoa que presta cuidados, com ou sem remuneração, a um parente de qualquer idade, que esteja necessitando de cuidados. Essa relação pode ser amplamente baseada no princípio da beneficência, segundo o qual o cuidador se doa totalmente para o cuidado do familiar. Em contrapartida, o cuidado em excesso faz com que os cuidadores acabem negligenciando a si mesmos, pois se esquecem da percepção sobre si, sendo este um importante estímulo de interferência no paciente familiar, o qual pode se sentir incitado a não realizar as mais simples tarefas, mesmo que consiga. Assim sendo, torna-se importante a reflexão sobre os princípios bioéticos inerentes ao cuidar e ao cuidador. Objetivo: Relatar a percepção e intervenção de um grupo de apoio a pessoas com Parkinson e/ou Alzheimer e seus familiares cuidadores no que diz respeito ao princípio da beneficência na relação de ambas as partes. Método: Trata-se de um estudo descritivo, caracterizado como relato de 
experiência. O estudo foi baseado em oficinas do grupo Reviver, registrado no Comitê de Ética em Pesquisa (CEP/UNIFAP) sob o parecer 2.301.230, com enfoque nos cuidadores e portadores de Parkinson e/ou Alzheimer, as quais foram realizadas às segundas-feiras, durante o período matutino dos meses de agosto a dezembro de 2018, nas dependências do bloco de Fisioterapia da Universidade Federal do Amapá. As atividades de educação em saúde realizadas com os cuidadores ocorriam no momento em que seus familiares, portadores de Parkinson e/ou Alzheimer estavam sendo atendidos por outros profissionais e acadêmicos, como fisioterapeutas, farmacêuticos, médicos, psicólogos e educador físico. Os acadêmicos e enfermeiros professores do grupo, por meio da interação com os cuidadores e da percepção da relação desses com seus familiares, conseguiram visualizar algumas características peculiares, intervindo sempre que necessário no ato em questão. Resultados: Percebeu-se, após a realização das oficinas, alguns comportamentos cíclicos entre os cuidadores avaliados, destacando-se alguns: quando se perguntava algo aos pacientes, os cuidadores respondiam, não deixando que aqueles respondessem; os cuidadores acompanhavam os seus familiares com Parkinson e/ou Alzheimer em todas as consultas com profissionais da saúde, porém, ao se tratar de suas próprias consultas, foi possível perceber que estas estavam sendo negligenciadas, notando-se ainda a preocupação excessiva com os familiares. A partir disso, houve o questionamento entre os componentes da organização do grupo: "Até que ponto a beneficência ajuda o indivíduo no processo de cuidar e a partir de quando a relação de dependência que isso pode provocar acaba por se tornar excessiva, prejudicando além do paciente, também ao cuidador?". Para que houvesse uma maior preservação e reconhecimento do real papel de cuidador, foi explanado sobre a importância do exercício correto da beneficência, alertando para que os cuidadores atentassem também para sua própria saúde física, mental e espiritual. Essa intervenção da equipe visava à prevenção de maiores danos à autonomia dos pacientes e cuidadores, assim como a reflexão, pelos cuidadores, da sua própria condição de saúde, levando em consideração que eles precisam gozar de saúde para dar continuidade a suas tarefas como cuidadores e ter qualidade de vida. As orientações foram aceitas e incorporadas, de maneira gradativa, no cotidiano dos cuidadores. Considerações finais: O cuidador vivencia uma intensificação do seu desgaste pessoal que, habitualmente, já cresce à medida que o agravo da saúde do doente que está sendo cuidado se instala. Diante de um contexto de vida complexo, deve-se refletir sobre qual o papel dos princípios da bioética, principalmente da beneficência, para contribuir no apoio ao paciente e ao cuidador. As discussões dessas situações, com o uso das ferramentas da bioética podem nortear a melhor conduta a ser tomada, sendo assim, os cuidadores foram orientados sobre algumas formas de diminuir esse agravo para os pacientes e prevenir seu próprio adoecimento. A concepção moral da beneficência estaria embasada, portanto, no apoio que podemos oferecer ao outro para que ele mantenha sua condição de autonomia, favorecendo sua tomada de escolhas conscientes, e, além disso, buscando sua própria percepção de saúde, ou seja, deve-se por obrigação ética maximizar o benefício e minimizar o prejuízo tanto para si quanto para o outro. Dessa forma, o olhar com equidade, atentando para as reais necessidades do indivíduo, auxilia na mensuração das ações, assim como nas intervenções tomadas, não só em relação aos cuidadores, mas também aos profissionais da área da saúde e nas interações sociais em geral. Implicações para a enfermagem: Reforça a importância da educação em saúde, assim como a aplicação da 
análise bioética na prática, principalmente da intervenção de enfermagem na recuperação ou manutenção da saúde dos indivíduos. Possibilita o olhar holístico às situações encontradas, não só nos atendimentos em instituições de saúde, mas em todas as formas de cuidado.

Descritores: Bioética; Educação em saúde; Cuidadores.

\section{Referências}

1. Beauchamp TL, Childress JF. Princípios de Ética Biomédica. 4.ed. São Paulo: Edições Loyola, 2002.

2. Matte L. Direitos fundamentais e Bioética. Rev Fac Dir UFRGS [Internet]. 2005 [acesso em 24 Abr 2019]; (25): 175-197. Disponível em: http://seer.ufrgs.br/revfacdir/article/download/73923/41626. 